\title{
FLORAE JAPONICAE
}

\section{FAMILIAE NATURALES,}

ADJECTIS GENERUM ET SPECIERUM EXEMPLIS SELECTIS.

\section{SECTIO PRIMA.}

\section{plantae dicotyledoneae polypetadae.}

\section{AÙCTORIBUS}

Dr. Pl. Fr. de Siebold et Dr. J. G. Zuccarini.

$$
\frac{\text { Mo. Bot. Garden, }}{1897}
$$

$x$

From

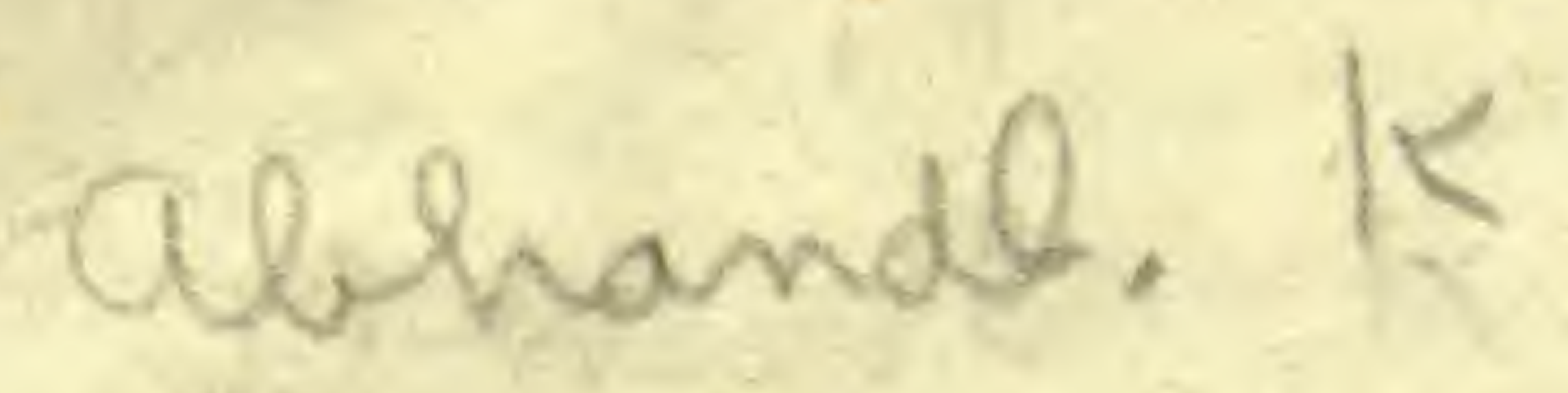

akad.

münchen

math is phayo

$\mathrm{Cl}$.

Sectio. Pruma
altera

4, Abt. 2,

ans

4, Ast 3, pp.

11. -204. pls $1.2 \cdot 1849$ $125-246$, pl. 3. 1846 


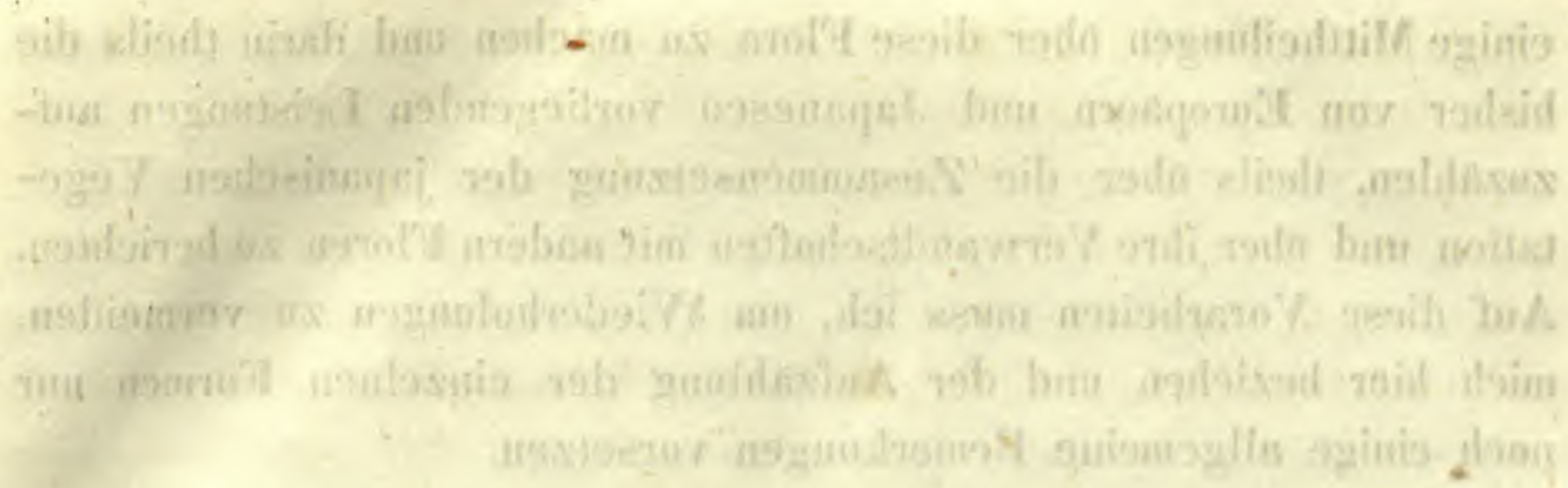

\section{FLORAE JAPONICAE}

FAMILIAE NATURALES.

SECTIO PRIMA.

\section{PLANTAE DICOTYLEDONEAE POLYPETALAE.}

\section{Einleitung.}

Ich habe in gegenwärtiger Arbeit es versucht, dareh möglichst vollständige Zusammenstellung aller Pflanzenfamilien, welche die Flora von Japan constituiren, so wie durch Hervorhebung charakteristischer Gattungen und Arten aus jeder derselben, so weit mir solche gegenwärtig zur Verfugung stehen, ein Bild jener Vegetation zu entwerfen, welche den äussersten Osten von Asien repräsentirend uns zugleich Nachweis zu geben hat aber die Relationen, in welchen die Flora dieses Weltheiles zu der des amerikanischen Continentes steht. Schon früher hatte ich die Ehre, der mathem.-physikalischen Classe in den Sitzungen am 12. Juni 1841 und am 20. Januar 1844 (Gelehrte Anzeigen XIII. Nr. $159-162$ und XVIII. Nr. $53-58$ )

Mo. Bot. Garten 
einige Mittheilungen über diese Flora zu machen und darin theils die bisher von Europäern und Japanesen vorliegenden Leistungen aufzuzählen, theils über die Zusammensetzung der japanischen Vegetation und über ihre Verwandtschaften mit andern Floren zu berichten. Auf diese Vorarbeiten muss ich, um Wiederholungen zu vermeiden, mich hier beziehen und der Aufzählung der einzelnen Formen nur noch einige allgemeine Bemerkungen vorsetzen.

Ein Inselreich, welches so viele Breitengrade fast in directer Richtung von Süden nach Norden (vom Südcap auf Kiusiu unter beiläufig $30^{\circ} 30^{\prime}$ bis Cap Elisabeth auf Krafto unter $54^{\circ}$ ) durchzieht, muss in seinen verschiedenen Proviuzen auch sehr differente Combinationen der Vegetation und ihrer Beziehungen zn andern Floren darbieten, zumal wenn es wie Japan zngleich eine grosse Mannigfaltigkeit in der Beschaffenheit seiner Oberfläche durch Gebirge und Gewässer aufzuweisen hat. Desshalb finden wir zunächst auf den südlichen Inseln des Reiches, anf Kiusin, Sikok und dem mittägigen Theile von Nippon eine grosse Uebereinstimmung der Flora mit der des mittleren und wärmeren China's. Eine grosse Anzahl von Arten, darunter fast sämmtliche Kulturgewächse, gehört beiden Lä́ndern mit Korea gemeinschaftlich an, und die Entdeckungen, welche wir in Folge der neueren Ereignisse uber den südöstlichen Theil von China zu hoffen haben, dürfen grösstentheils wohl auch für den Süden von Japan geltend gemacht werden. In anderen Verhältnissen steht die südjapanische Flora zu der des nördlichen Indieus und der HimalayaAbhänge. Hier finden wir zwar eine grosse Analogie, aber keine Identität mehr, indem sehr viele Genera beiden Floren gemeinschaftlich angehören, aber die Arten, wenn auch oft nahe verwandt, doch fast durchgängig verschieden sind. Aehulich, nor etwas entfernter stellt sich das Verhältniss der sudjapanisehen Vegetation zu der Flora der vereinigten Staaten von Nordamerika. Mebrere Gattúngen, die man früher als ausschliesslich der nenen Welt angehörig 
bezeichnet hatte, wie Negundo, Sassafras, Diervilla, Torreya, Pachysandra, Mitchella, Maclura, Liquidambar u. s. w., sind durch die japanische Flora beiden Hemisphären gemeinsam geworden. Dass jedoch diese Analogie in der Vegetation viel mehr auf die Küsten des atlantischen Oceans (anf die Staaten von Neu-York bis Georgien) sich beziehe, als auf die des stillen Meeres, ist schon anderweitig erwähnt worden. Der nördliche und rauhe Theil von Japan, die Gebirge von Nippon, dann Yesso und Krafto entsprechen höchst wahrscheinlich eben so den ähnlichen Breiten des nördlichen China's, wie wir dieses von dem Süden wissen. Aber Jeider fehlen dafür noch ausreichende Belege, denn aus dem nördlichen China kennen wir nur das Wenige, was die eifrigen Bemühnngen russischer Gelehrter haben erringen können, und die Flora des Nordens von Japan ist bisher nur durch unvollständige Herbarien japanischer Botaniker documentirt. Diese Mangelhaftigkeit der Materialien aus beiden Ländern macht also die Vergleichung noch unsicher. Mit grösserer Bestimmtheit lassen sich die Analogien mit der Flora des russischen Nordasiens verfolgen. Diese seit einem Jahrhundert so vielfach und von so ausgezeichneten Männern untersuchte Vegetation ist hinreichend bekannt, um alle ans dem Norden von Japan uns bisher gewordenen Thatsachen damit vergleichen zu können. Daraus ergibt sich bereits, dass eine nicht unbeträchtliche Anzahl von Arten aus den Familien, welche diese Floren vorzugsweise repräsentiren, theils dem südöstlichen Sibirien, theils Kamtschatka mit Nordjapan wirklich gemeinschaftlich angehören. In den Familien der Ranunculaceen, Papaveraceen, Cruciferen, Leguminosen, Rosaceen, Umbelliferen, Scrophularineen u. s. w. tritt diese Verwandtschaft angenfällig hervor. Sie mindert sich dagegen wieder für die entsprechenden Küsten von Amerika am stillen Ocean, z. B. für die russischen Besitzungen anf Sitcha, wo meistens wieder die Gattungen zwar identisch, die Arten aber nur analog erscheinen. So steht also Japan bis an seine Nordgrenze in den nächsten Beziehungen zu der Flora des asiatischen

Abhandlungen d. II. Cl. d. k. Ak. d. Wiss. IV. Bd. Apth. II. 


\section{4}

Continentes, dessen östlichstes Glied es bildet, und scheidet sich scharf genug von den gegenüberliegenden Küsten von Amerika ab. Eine Verwandtschaft der japanischen mit der europäischen Vegetation ist nur in geringem Grade aus der Identität derjenigen Gattnngen zu ersehen, welche überhaupt fast alle Längengrade der nördlichen gemässigten Zone durchzieben. Sehr selten aber dehnt sich die Identität auf Arten aus, mit Ausnahme der sogenannten Kosmopoliten wie Leontodon Taraxacum, Capsella Bursa, Anagallis phoenicea, Ranunc. sceleratus, Alsine media u.s.w. Die Flora von Australien seheint mit der japanischen völlig ausser Zusammenhang za seyn, und letztere in östlicher Richtung nur bis zu den Bonin Sima Inseln fortzusetzen, auf den Marianen aber schon völlig verschieden zu seyn. Gegen Süden gehen manche japanische Arten zwar noch in die bereits subtropische Vegetation der Liukiu-Inseln ein, aber auf den Philippinen ist keine Spar davon mehr zu finden. Die Standorte japanischer Pflanzen auf Java, wie sie bei mehreren Sehriftstellern vorkommen, bedürfen einer sorgfältigen Prüfung. Vermuthlich beziehen sie sich nur anf eine Anzabl von Arten, welche die Holländer absichtlich oder zum Theil auch zufällig ubergesiedelt haben, nämlich auf Zier- und Nutzpflanzen und auf Unkränter. Mit Südamerika scheinen nur in einzelneu Gattungen, wie z. B. Hisingera, Ternstroemia $u$. a. entfernte Relationen zu bestehen, mit Afrika jede Verbindung zu fehlen.

Charakteristisch scheint für die Flora von Japan die grosse Anzahl von Pflanzenfamilien und Gattungen bei verhältuissmässig wenig Arten. Bisher steigt die Specieszahl noch bei keinem Genus daselbst bis auf 30 und die verhältnissmässig reichsten Genera gehören fast durchgängig, wie Carex, Lilium, Polygonum, Quercus, zu den Typen der gemässigten Zone. Beträchtlich ist dagegen die Zahl der Gattungen, welche bisher überhaupt nur durch eine Art repräsentirt werden, oder in andern Floren als Monotypen aufgestellt, hier ihre 
zweite Art zugetheilt erhalten. Unter solchen ist z. B. die Gattung Humulus interessant. Bezeichnend ist ferner die verhältnissmässig grosse Anzahl von Bambuseen, Coniferen, Cupuliferen, Laurineen, Euphorbiaceen, Rosaceen, welche, nach früheren Ansichten ein räthselhaftes Gemische von Formen der tropischen und der gemässigten Zone, in ihrer Combination nur als Beweis dienen können, dass viele früher als den Tropen eigenthümlich bezeichnete Familien in Wahrheit die Wendekreise überschreiten, und dass demnach die der Aequatorialzone ausschliesslich angehörigen Familien viel weniger zahlreich sind, als man früher glaubte.

Nicht minder bezeichnend fur die japanische Vegetation dürfte die grosse Anzahl von Holzgewächsen im Verhältniss zu den krautartigen Pflanzen seyn, welche überdiess in ihrer Combination sehr an die dendrologische Flora von Nordamerika erinnert. In beiden Floren sind Coniferae, Betulaceae, Cupuliferae, Moreae, Laurineae, Lonicereae, Styraceae, Ericineae, Araliaceae, Hamamelideae, Saxifrageae, Magnoliaceae, Ternstroemiaceae, Acerinae, Celastrineae, Juglandeae u. s. w. durch zablreiche Arten oft zugleich in aberraschender Identität der Gattungen repräsentirt, aber der asiatische Charakter in der japanischen Flora doch auch wieder durch Lardizabaleen, Schizandraceen, Sapindaceen, Pittosporeen, Alangieen u. s. w. aufrecht gehalten. Die Anzahl der Holzgewächse dürfte in Japan anf ein reichliches Drittheil der Gesammtflora anzuschlagen seyn.

Endlich muss noch in der japanischen Flora auffallend erscheinen die grosse Auzahl von Spielarten oder vielmehr die Mannigfaltigkeit von Formen, welche in vielen Gattungen nicht nur an einer Species, sondern an den einzelnen Individuen derselben vorkommen. Mag immer lange und sorgfältige Gartenkultur daran wesentlich Antheil haben, die dadurch gewonnenen Resultate abertreffen jedenfalls Alles, was in gleicher Beziehung in europäischen Gärten bisher ge15年 


\section{6}

leistet worden ist, und setzen zugleich einen Grad von Bildsamkeit oder Variabilität bei den einzelnen Arten voraus, welcher unserer europäischen Vegetation fremd ist. Welcher unserer Bäume hätte z. B. so mannigfaltige und so ansgezeichnet verschiedene Blattformen anfzuweisen, als Acer polymorphum in Japan oft an einem Zweige zeigt. Zngleich ist die Anzahl polymorpher Pflanzen in Japan viel grösser als in unseru Floren, und die Beweglichkeit der Erscheinung dehnt sich bald über den ganzen Habitus, bald nur auf einzelne Organe aus.

Eine vollständige Aufzählung aller bisher in Japan gefundenen Gattungen und Arten zu geben, konnte um so weniger der Zweck der nachfolgenden kleinen Arbeit seyn, als ein grosser Theil des Materials erst der genaueren Bearbeitung entgegen sieht; doch dürfte die getroffene Auswahl ausreichen, um über alle vorkommenden Familien Rechenschaft zu geben, und bei den meisten auch die Formen hervorzuheben, welche den wesentlichen Charakter dieser eigenthümlichen Vegetation ausmachen. Es versteht sich von selbst, dass die aufgezählten Arten alle nach vorliegenden Original-Exemplaren geprüft oder beschrieben worden sind. 


\section{A. Dicotyledonea Polypetalae.}

\section{1. (279 Endl.) MIMOSEAE $\boldsymbol{R}$. Br.}

\section{Acacia Neck.}

1. A. Nemu Willd, - Mimosa arborea Thunbg. Flor. jap. pag. 229. Icon. Kaempferian. tab. 19. $\rightarrow$ Mim. speciosa Thunb. Act. Linn. II. p. 336. - Koquan s. Goquan volgo Nemu no ki Kämpf. Ámoen. exot. p. 840 - Mim. Julibrissin Scopoli delic. insubr. I. tab. 8. Acacia Julibr. (Willd. spece. plant. IV. p. 1065̃. De Cand. Prodr. II. 469 et rel. aut.)

Sorgfältigen Vergleichungen mit Exemplaren von Ac. Julibrissin aus dem Orient und von verschiedenen italienischen Standarten zu Folge ist diese von A. Nemu in Japan und China (Bunge Enum. plant. sin. p. 21) durchaus nicht verschieden. Da nun der letztere schon bei Kämpfer vorkommende Name offenbar der ältere ist, und die Pflanze in Japan wild wächst, so muss der orientalische Name (Gul-ebruschim oder Ghul-ibrischim, flos sericeus bei De Candolle) eingehen. Vermuthlich ist die Pflanze über China als Ziérbaum nach dem Orient und von da nach Italien gelangt.

2. Ac. species inermis foliis bipinnatis multijugis, petiolo uniglanduloso, ramis petiolis foliisque novellis dense ferrugineo-furfuraceis.

\section{2. (277 EndI.) PAPILIONACEAE L.}

\section{Caesalpinia Plum.}

3. Caes. japonica Sieb. et Zuccar. - C. aculeata, pinnis 6-8jugis, foliolis $8-10$-jugis ellipticis obtusis, superne glabris subtus tenuissime pubescentibus pellucide punctatis, petiolo communi aculeis uncinatis armato, racemis terminalibus simplicibus multifloris, floribus horizontaliter patentibus, pedunculis gracilibus ultrapollicaribus, caly- 
cis laciniis ovatis acutiusculis, petalis orbicularibus superiori duplo minore, filamentis barbatis, legumine oblongo recte mucronato dorso carinato glabro coriaceo 6 -8-spermo, seminibus oblongis laevibus. Caes. Crista Thunb. Flor. jap. p. 179?

3. Sophora Linn.

4. S. angustifolia Sieb. et Zuccar. UL S. herbacea? pnbescens, foliis 20 - 30-foliolatis, foliolis lanceolatis vel lineari-lanceolatis acntis pubescentibus breviter pedicellatis, racemis terminalibus laxis, calyce oblique truncato absque dentium rudimento.

- Proxima S. favescenti Ait. recedit a specim. sibiricis habitu graciliori, foliolis multo angustioribus et minus pubescentibus, calyce oblique truncato edentulo. Alae in omnibus Sophorae speciebus herbaceis totae pulcherrime transversim plicatulae.

4. Rhynchosia De Cand.

5. Rh. volubilis $\boldsymbol{D C}$. - Racemi variant foliis longiores et breviores.

5. Lablab Adans.

6. L. vulgaris Savi.

7. I. cultratus DC. - Dolichos ensiformis Thunb. Flor. jap. p. 279. - D. cultratus Id. Act. Linn. II. pag. 340.

Adnot. Dolichos hirsutus Thunb. Act. Linn. 1. e. nec Dolichos nec Mucuna, fortasse peculiaris generis.

6. Phaseolus Linn.

8. Pl. Mungo L.

9. Ph. farinosus $\boldsymbol{L}$.? Specimen nimis mancum.

7. Wisteria Nutt.

10. W. chinensis De Cand. - Sieb. et Zuccar. Flor. jap. p. 90. tab. 44. - Dolichos polystachyus Thunb. l. c. p. 281.

11. W. brachybotrys Sieb. et Zuccur. I. c. p. 92. tab. 45.

12. W. japonica Sieb. et Zuccar. 1. c. p. 88. tab. 43.

8. Canavalia DC.

13. C. incurva DC. Dolichos incurvus Thby. Fl. jap. p. 
280. Legumen in spece. nostris rectum acumine incurvo, crassum, dorso lineis quinque, quarum tres mediae valde approximatae, laterales remotiores. Semina maxima, transversin elliptica utrinque convexo-plana, fusca, hilo longo lineari.

9. Glycine DC.

14. Gl. Soja Sieb. et Zuccar. - Gl. volubilis retrorsum hirsuta, foliis longe petiolatis ovato-lanceolatis acntis vel acuminatis hirtis, intermedio pedicellato bistipellato, stipulis parvis linearibus, stipellis setaceis, racemis axillaribus $8-12$-floris petiolo multo brevioribus, floribus parvis, inferioribus $3-4$ tantum fertilibus, leguminibus linearibus compressis subfalcatis hirsutis $2-3$-spermis, styli basi uncinata terminatis, seminibus transversim ellipticis compressinsculis. - An hic Glyc. javanica Thunb. Act. Linn. II. p. 340 excl. Synon?

10. Soja Mönch.

15. S. hispida Mönch. Dolichos Soja L. Soja japonica Savi. - Duidsu vel Mame Kämpf. Amoen pag. $\$ 37$ c. ic. opt., ubi et condimenti conditio effuse describitur.

11. Dumasia DeCand.

16. D. truncata Sieb. et Zuccar. - D. tota glabra, volubilis, foliis ternato-pinnatis, foliolis e basi truncata deltoideis rarius subrhombeis acutis, intermedio longius pedicellato bistipellato, racemis axillaribus petiolo brevioribns $6-8$-floris, petalorum unguibus calycem dimidio superantibus, leguminibus linearibus $3-5$-spermis basi; longe attenuatis acutis calyce multoties longioribus.

Caulis gracilis, volubilis, uti tota planta glaber. Stipulae parvae, lineares, acutae. Petioli bipollicares; foliola pedicellata, lateralibus uniterminali bistipellatis, pollicaria vel sesquipollicaria, basi truncata vel rarius late cuneata indeque vel deltoidea vel rhombea, Racemi petiolo breviores, floribus breviter pedicellatis, calycibns bibracteolatis. Petala longissime unguiculata. Ovarium basi tubulo obliquo vaginatum. Stylus quam stamina brevior stigmate capitato. Legumen pla- 
num sesquipollicare, glabrum, longe attenuatum et calyce persistente einctum.

\section{Lespedeza L. C. Rich.}

17. L. argyraea Sieb. et Zuccur. L. tota sericeo-nitens, dense foliosa, fruticosa, ramis virgatis, foliis breviter petiolatis, foliolis cuneato-linearibus truncatis mucronatis ntrinque sericeis, intermedio pedicellato, stipulis setaceis, floribus axillaribus solitarïs subsessilibus, calycis laciniis setaceo-acuminatis, legumine calycem superante. - Hedys. sericeum Thunb. Fl. jap. p. 289.

Recedit a L. juncea Pers. foliis multo angustioribus truncatis argenteis, floribns semper solitariis et subsessilibus, calycis laciniis setaceo-acuminatis.

Mit Unrecht zieht demnach De Candolle Thunbergs Hedys. sericeum zu L. juncea. Bisher ist letztere Art, wiewohl sie nach v. Bunge (Enum. plant. monghol. chin. p. 10) auch im nördlichen China vorkommt, in Japan noch nicht gefunden.

18. L. striata Hook. et Arn. - L. caulibus ramisque patentibus gracilibus decumbentibus? foliis brevissime petiolatis, foliolis lineari-oblongis obtusis mucronatis glabriusculis, nervis parallelis dense lineatis, intermedio vix longius pedicellato, stipulis ovato-lanceolatis acuminatis multinerviis, floribus axillaribus solitariis, laciniis calycis abbreviatis ovatis acutis, fructu calycem aequante. - Medys. striatum Thunb. l. c. p. 290. L. striata Hook. et Arn. in Beechey Voyage p. 262.

Caulis (sec. cl. Hooker J. c. annuus vix tripollicaris) in spece. nostris suffruticosus uti rami patentes subflexuosus gracilis, pubescens, Stipulae magnae, membranaceae, multinerviae. Petioli vix 2"' Iongi; foliola omnia subsessilia, lineari-oblonga, obtusa vel nonnunquam retusa, nucronata, 6-10"' longa, $2^{\prime \prime \prime}$ lata, nervis lateralibus parallelis praesertim subtus dense lineata; flores solitarii brevissime pedunculati, calyces campanulati pubescentes, laciniis tubum aequantibus ovatis acutis. 
19. L. virgata DC. - Hedys. virgatum Thunb. l. c. p. 290. Petioli longitudine inter $3-9^{\prime \prime \prime}$ variantes; foliola elliptica vel obovata rotundata mucronulata nervoso-lineata, intermedio longe pedicellato subpollicari, lateralibus minoribus, stipulis lineari-lanceolatis acuminatis, racemis brevibus subcapitatis $6-10$ floris, calycis laciniis lanceolatis acuminatis, legumine calycem superante reticnlato.

20. L. pilosa S. et Z. Hedys. Thbg. Desmodium DC. - Legumen ovatum glabrum, calyce longius.

13. Desmodium DC.

21. D. racemosum DC. - Hedys. racemosum Thbg. Fl. jap. p. 285. - Specimina nostra recedunt foliolis subtus pilis $\mathbf{s}$. setulis adpressis obsitis, floribus in apice ramorum paniculatim raeemosis, calycibus hirtis. An distincta species?

14. Vicia L.

22. V. Faba L.

15. Pisnm Tournef.

23. $\boldsymbol{P}$. sativum $\boldsymbol{L}$.

24. P. maritimum $\boldsymbol{L}$.

16. Astragalus DC.

25. A. lotoides Lam. - A. sinicus Thunb. Fl. jap. p. 290.

17. Car aga na Lam.

26. C. Chamlagu Lam.

A. planta sinensi nullo modo diversa.

18. Crotalaria Linn.

27. Cr. eriantha S. et Z. Cr. annua, caule herbaceo erecto ramoso uti tota planta hirto, foliis brevissime petiolatis linearibus mucronatis, stipulis setaceis, spica terminali densa subcapitata, calycibus fuscescenti-hirsutissimis, intus glabris, corollam glabram subaequantibus.

Adnotatio: Fagara horrida Thunb. Act. Linn. 2. p. 229. Flor. jap. plant, obscur. p. 350 . n. 3. spinis ramosis Gleditschiae species videtur.

Abhandlungen d. II. Cl. d. k. Ak. d. Wiss. IV. Bd. Abth. II. 
3. (275. Endl.) AMYGDALEAE Juss.

19. Ceraseidos Sieb. et Zucear. Act. Mathem. Phys. Monac. III. p. 473. t. 5 .

28. C. apetala S. et Z.

20. Prunus L.

29. Pr. persica $L$.

30. Pr. Mume S. et. Z. Fl. jap. I. p. 29. t. 11. - Variat floribus albis vel roseis et plenis.

31. Pr. japonica Thunb. Fl. jap. p. 201. Sieb. et Zucc. Fl. jap. I. p. 172. tab. 90.

32. Pr. tomentosa Thunb. Fl. jap. p. 203. Sieb. et Zucc. l. c. I. p. 51. tab. 22. - Varietas fructu oblongo est Pr. trichocarpa Bunge Enum. plant. chin. p. 22.

33. Pr. spinulosa S. et $\boldsymbol{Z}$. - Pr. foliis biennibus vel annuis oblongis longe et subfalcato-cuspidatis acumine obtuso, margine undulatis et remote serratis, serraturis superioribus spinuloso-mucronatis spinulis rectis vel incurvis, utrinque glabris superne lucidis coriaceis, racemis axillaribus solitariis folio brevioribns multifloris, floribus polygamis. - An Pr. serrulata Lindl.

Folia biennia vel plerumque annua, petiolata, petiolo $4-6$ "' longo, oblonga, $2 \frac{1}{2}-3^{\prime \prime}$ longa, $10-12^{\prime \prime \prime}$ lata, basi subattenuata, longe et soepe oblique cuspidata acumine integerrimo obtuso mucronulato, margine undulata et remote serrulata serraturis vel muticis vel praesertim superioribus in mucronem s. spinulam rectam vel ineurvam terminatis, glabra, lucida. Racemi dimidio fere quam folia breviores, cylindrici, 20-25-flori. Stamina numerosa.

34. $\boldsymbol{P r}$. macrophylla S. et $\boldsymbol{Z}$. - Pr. foliis biennibus petiolatis oblongis utrinque attenuatis acuminatis argute et uncinato - serratis glabris coriaceis, petiolis biglandulosis, racemis $2-4$ axillaribus folio pluries brevioribus, rachi et alabastris magis minusve lanatis.

Folia biennia, petiolata petiolis semipollicaribus ad laminae basin glandulis duabus oppositis crassis munitis, lamina folii $4-6$ pollices 
et quot excedit longa, $2-2 \frac{1}{2}$ " lata, utrinque attenuata acuminata, serrata serraturis subdistantibus uncinatis, utrinque glabra vel subtus tenuissime pubescente. Racemi terni quaternive e quavis axilla, pollicares vel sesquipollicares. Alabastra dense imbricata aeque ac rachis lana derasili magis minusve vestita.

\section{Pr. Pseudo-Cerasus Lindl.}

Pr. floribus coëtaneis e gemmis distinetis ternis quaternisve, primum umbellatis demum in pedunculo communi longo corymbosis bracteatis, calyce cylindrico lacinijs deltoideis acutis, petalis obovatis emarginato-bifidis, foliis petiolatis basi rotundatis ovato-ellipticis longe acuminatis in toto margine dense et argute serratis serraturis setaceomucronatis apice glandulosis, utrinque glabris, petiolis glandulosis, stipulis elongatis membranaceis simplicibus vel trifidis, glandulosopectinatis, ramis verrucosis. - Pr. floribus plenis, umbellis paniculatis Thrmb. Fl. jap. pl. obsc. p. 370. - Pr. paniculata Edw. Botan. Register tab. 800. non Thunb. et aut. - Cerasus Pseudocerasus Lindl.

a. floribus simplicibus, calycis laciniis vel tubo brevioribus lanceolatis acutis integerrimis vel foliaceis tubum aequantibus vel superantibus subserratis, floribus albis vel roseis.

B. floribus plenis maximis albis, roseis vel virentibus et basi roseis, bracteis magnis spathulatis glanduloso-ciliatis.

Species pulcherrima, per totam Japoniam culta. Rami crassi, lenticellis magnis verrucosi. Gemmae perulis coriaceis nitidis nigrescentibus obductae. Flores e gemmis propriis lateralibus terniquinive, primum umbellati, denique in pedunculo communi excrescente soepius bipollicari corymbosi, pedicellis gracilibus ultrapolli- caribus. Bracteae in var. flor. simplic. parvae, in iis flore pleno magnae, spathulatae, glanduloso - ciliatae. Corolla magna, quam in Pr. Ceraso amplior. Petala figura varia, in flor. simplicibus semper emarginato-bifida, in flor. plenis soepius rotundata. Folia e gemma terminali, raro unum alterumve infra flores, petiolata petiolo pollicari 
glandulis nonnullis obsito; lamina ovata, ovato-oblonga vel oblonga, basi rotundata, longissime acuminata, per totum marginem dense et argute serrata serraturis setaceo-mucronatis mucrone recto apice glandulifero, utrinque glabra, $3-5$ " longa, $1-5$ " lata. Stipulae elongatae fere pollicares membranaceae lineares simplices vel trifidae, glandulis stipitatis glanduloso-ciliatae.

Pr. paniculata Thunb., der bisher nur aus der Beschreibung dieses Autors gekannt ist, kann nicht nit unsrer Art vereiniget werden, denn Thunberg sagt ausdrücklich : differt a $\boldsymbol{P r}$. Mahaleb floribus minoribus et foliis inferne attenuatis. Es ist befremdend, wie Edwards seiner Abbildung unserer Pflanze im Botan. Register diese Thunbergsche Beschreibung beisetzen konnte, ohne auf die Unterschiede aufmerksam zu werden.

\section{4. (274. EndI.) ROSACEAE Endl.}

21. Spirae a Lin.

36. Sp. callosa Thunb. Flor. jap. p. 209. -- Folia lanceolata utrinque attenuata acuminata argute et inaequaliter serrata breviter petiolata superne glabriuscula subtus ad venas villoso-hirta; flores pulchre rosei in paniculam corymbosam terminalem congesti.

Sp. expansa Wall., quae proxima, differt foliis latioribus magis ellipticis, inflorescentiae ramis villoso - hirtis, calycis laciniis argute cuspidatis. Sp. bella Sims. Botan. Magaz. t. 2446 foliis brevioribus subtus tomentosis minusque dentatis satis recedit.

Der callus utrinque ad basin petioli, welchen Thunberg als charakteristisch für diese Art angiebt, umfasst bei unsern Exemplaren die Blattstielbasis halbmondförmig, kömmt aber auch bei Sp. expansa vor, und scheint nur das durch Eintrocknen des Blattstieles vortretende Blattkissen zu seyn.

37. Sp. Thunberyii Sieb. et Zucc. Fl. jap. I. p. 130. tab. 69. tit Sp. crenata Thunb. Fl. jap. p. 210. 
38. Sp. prunifolia S. et Z. Fl. jap. I. p. 131. tab. 70. Sp. crenata var. Niwa Sakura Thunb. Fl. jap. p. 211.

39. Sp. chamaedryfolia $\boldsymbol{L}$. Folia in specc. nostris e basi longe cuneata oblongo-lanceolata obtusa, a medio apicem versus grosse serrata, serraturis acutis nec tamen mucronatis margine calvis. Vix tamen species distineta.

De Hoteia et Astilbe vide Saxifrageas.

22. Rhodotypos S. et Z.

40. Rhod. kerrioides S. et Z. Fl. jap. I. p. 187. tab. 99.

23. Kerria DC.

41. K. japonica DC. S. et Z. Fl. jap. I. p. 183. tab. 98. Corchorus japon. Thunb. Fl. jap. p. 227.

24. Sieversia Willd.

42. S. dryadoides S. et Z. S. suffruticosa, caule basi lignescente ramoso nec tamen stolonifero, foliis pinnatisectis plerumque 7-9foliolatis, foliolis e basi cuneata oblongis argute inciso-serratis utrinque glabris, infimis minimis linearibus, stipulis subulatis, scapis unifloris subnudis, petalis rotundatis quam calycis laciniae acuminatae longioribus, bracteolis linearibus acutis vel nonnunquam apice bidentatis, stylis in fructu longissimis plumosis.

Siev. s. Geo anemonoidi proxima differt eaule suffruticoso, stolonibus nullis, petalis quam calyx vix tertia parte longioribus.

25. Agrimonia Tourn.

43. A. viscidula Bunge Enum. plant. chin. p. 26. (?) Ayrim. Eupatorium Thunb. Flor. jap. p. 195. - Foliola in quovis folio majora 5 , in canlinis summis 3 , lanceolata grosse aequaliter serrata acuta utrinque pilosa sed vix viscidula, Spicae terminales graciles elongatae. Setae calycis erecto-conniventes; tubus urceolatus hispidulus, foveolis ad basin usque productis. Flores parvi, petalis calycem dimidio superantibus.

Antherae in omnibus speciebus utrinque emarginatae loculis connectivo crasso subdilatato disjunctis. 
26. Fragaria Tourn.

44. Fr. chilensis Ehrh. - Specimen unicum, an ex horto?

27. Rubus Linn.

45. R. parvifolius $\boldsymbol{L}$. $\boldsymbol{R}$. canle tereti pubescente, aculeis rectis vel recurvis, foliis ternatis vel pinnato-quinatis, foliolis e basi late cuneata obovatis obtusis argute serratis subtus albo-tomentosis, petiolis villosis aculeatis, stipulis subulatis, floribus corymbosis, laciniis calycis ovato-oblongis aristatis tomentosis aculeatis, fruetibus globosis. - R. triphyllus Thbg. Fl. jap. $p .215$.

Hooker (ap. Beechey p. 184) vereinigt nach Vergleichung japanischer Exemplare mit dem R. parvifolius des Linneischen Herbariums den R. triphyllus mit ersterer Art, bemerkt aber, dass das Citat von R. Moluccus Rumph. Amboin. V. t. 47 irrig bei De Candolle zugezogen sey und wohl eher zu R. Tagellus Schlechtend. et Cham. oder zu unserm R. Thunbergii gehöre. Wir bemerken, dass an unsern Exemplaren wenigstens die Aeste aufrecht zu stehen scheinen.

46. R. Thunbergii S. et Z. - R. suffruticosus, caule parce aculeato aculeis rectis vel recurvis, foliis ternatis vel quinato-pinnatis, foliolis lateralibus breviter, terminali plerumque majore longius pedicellatis, ovato - ellipticis acutis vel acuminatis inaequaliter dense serratis utrinque villosis subtus lineatis, petiolis aculeatis, stipulis lanceolatis acuminatis, floribus solitariis axillaribus, pedunculis longis tenuibus, calycis laciniis anguste lanceolatis longissime acuminatis villosis, petala ovata obtusa superantibns. - R. idaeus Thbg. Fl. jap. $p .216$.

Variat raro foliis tantum trilobis. Flores magni ultra pollicares. Calycis foliola in acumen longissimum subulatum terminata. Torus dense lanatus. Carpella numerosissima.

47. R. palmatus Thunb. R. fruticosus, aculeis sparsis rectis (nec recurvis), ramis flexuosis, foliis e ramulis lateralibus (abbreviatis) pluribus petiolatis e basi cordata $3-5$-lobis, lobo intermedio duplo lon- 
giore oblongo-lanceolato acuminato, lateralibus acutis, omnibus et ad basin usque argute inaequaliter serratis utrinque ad venas pilosis ceterum nudis, floribus axillaribus solitariis, pedunculis petiolo multo brevioribus, laciniis calycinis ovatis cuspidatis hirtis quam petala oblongo-elliptica brevioribus. - R. microphyllus L. fil. suppl. 263 et De Cand Prodr. II. p. 566 ?

Caulis pars inferior firma erecta, digiti minoris crassitie. Folia inferne in nervo medio soepius aculeis nonnullis parvis recurvis armata. Pedunculi $3-6^{\prime \prime \prime}$ longi, tenues, hirti; petioli plusquam pollicares. Petala oblonga, obtusa, laciniis calycinis duplo longiora. $\boldsymbol{R}$. crataegifolio Bunge affinis videtur.

48. R. corchorifolius Linn. fil. - R. fruticosus caule villoso vel glabriusculo, aculeis rectis, in ramulis et petiolis recurvis armato, foliis e basi cordata vel rotundata ovato-oblongis acuminatis vel raro trilobis lobis lateralibus abbreviatis, dense et argute serrulatis utrinque hirtis et canescentibus, nervo medio subtus aculeolato, pedunculis solitariis unifloris villosis petiolo brevioribus, laciniis calycinis lanceolatis acutis quam petala spathulata dimidio brevioribus vel nonnunquam apice foliaceis serratis petala superantibus. $-\boldsymbol{R}$. villosus Thunb. Fl. jap. p. 218.

Variat caule villoso vel glabro, foliis integris vel trilobis lobis lateralibus abbreviatis acutis, basi cordatis vel rotundatis, laciniis calycinis lanceolatis acutis vel apice in laminam foliaceam spathulatam vel linearem serratam extensis. Rami stricti, virgati. Petioli semipollicares. Folia $1-2^{\prime \prime}$ longa, $8-12^{\prime \prime \prime}$ lata nervo medio subtus (nunquam superne) aculeato. Calyces dense villoso-hirti.

49. R. ribifolius S. et $\boldsymbol{Z}$. R. fruticosus, caule glabro aculeis sparsis rectis armato, ramulis petiolis pedunculisque pubescentibus, foliis e basi cordata suborbicularibus quinquelobis lobo terminali majori, infimis soepe obsoletis, omnibus ovatis acutis ad basin usque inaequaliter serratis, ad nervos pilosis ceterum glabris, stipulis lineari-lanceolatis, pedunculis axillaribus solitariis unifloris quam 
petioli brevioribus, lobis calycinis lanceolatis acuminatis utrinque (intus magis) villosis, quam petala ovata obtúsa brevioribus. R. incisus Thunb. Fl. jap. p. 217?

A Thunbergii descriptione $\boldsymbol{R}$. incisi differt foliis multo majoribus et petiolum longe superantibus, nec non pedunculis quam petioli brevioribus. Petioli pollicares vel parum longiores aculeolati; lamina folii $2-3$ " longa et lata, praeter nervos utrinque glabra, lobi infimi soepe obsoleti. Pedunculi 6- $8^{\prime \prime \prime}$ longi, graciles hirti, aculeolis minutis soepius intermixtis. Flores magni, diametro pollicem et quot excedit metientes. Petala ovata, obtusa.

Reliquae species Thunbergianae aeque ac $\boldsymbol{R}$. heterophyllus Willd. nobis nondum notae.

28. Rosa Tournef.

50. R. sempervirens $\boldsymbol{L}$.

51. R. multiflora Thbg. et var. $\beta$ platyphylla Rad.

52. R. Hystrix Lindl. ? - Specimen nimis mancum.

53. R. Banksiae $\boldsymbol{R B r}$.

54. R. microphylla Roxb. - Spinae geminae ad basin foliorum patentes longe decurrentes. tab. 28.

55. R. rugosa Thby. - Sieb. et Zucc. Flor. jap. I. p. 66.

56. R. polyantha S. et Z. - R. aculeis sparsis solitariis falcatis, foliolis $\tilde{0}-7$ nis obovatis cuspidatis sursum argate serratis, petiolis aculeolatis glanduloso-pubescentibus, stipulis adnatis superne falcato-patentibus glanduloso-fimbriatis, floribus numerosis corymbosis, pedunculis longis filiformibus parce glandulosis, sepalis integris lanceolatis reflexis glanduloso-hirtis, disco calycino conico supra stamina elevato, stylis longe exsertis in columnam glabram congestis nec tamen connatis.

R. multiflorae Thbg. affinis, diversa tamen pedunculis fere filiformibus sesquipollicaribus parce tantum glandulosis et praesertim 
calycis disco circa styli basin in conum ultra stamina elevato. Flores parvi, albi, simplices.

57. 58. R. canina et gallica Thunb., a specc. Limeanis diversae sed ulterius examinandae.

Genera Potentilla, Geum, Sanguisorba etc. ulteriori examini remanent.

\section{5. (273. Endl.) CALYCANTHEAE Lindl.}

29. Chimonanthus Lindl.

59. Chim. fragrans Lindl. - Oboi s. Roboi Kämpfer Amoen. V. p. 879. c. icone (mala), qui plantam e China allatam in hortis tantum cultam dicit.

\section{6. (272. Endl.) POMACEAE Juss.}

30. Stranvaisia Lindl.

60. Str. digyna S. et Z. - Str. foliis breviter petiolatis ellipticis utrinque attenuatis acuminatis dense at argute serrulatis pubescentibus vel subtus molliter villosis subcoriaceis, corymbis terminalibus multifloris, pedunculis filiformibus villosis, calycibus brevissime urceolatis lanatis, petalis unguiculatis late ovatis obtusis, ovario superto lanato biloculari loculis biovulatis, stylis 2, stigmatibus peltatoincrassatis concavis. - Crataegus villosa Thunb. Flor. japon. p. 204.

Fructus non observati, at toto habitu planta magis cum Stranvaisia quam cum Photinia convenit. Ramuli villosi. Folia 2-3pollicaria, dense et argute serrulata acuminata acumine subfalcato, subtus plerumque molliter villosa. Corymbi terminales 15-20-flori; pedunculi tenues fere filiformes subpollicares; calyces brevissime urceolati extus lanati intus glabri laciniis deltoideis acutis. Petala late ovata obtusa. Ovarium superum, globosum, dense lanatum. Styli stamina aequantes.

Abhandlungen d. II. Cl. d. k, Ak, d. Wiss. IV. Bd. Abthl.II. 
31. Crataegus Linn.

61. Cr. cuneata S. et Z. - Cr. spinosa, ramis divaricatis villosis, foliis e basi longe cuneata integerrima obovatis subretnsis apice subtrilobis inaequaliter inciso-serratis hirtis vel rameis infimis minoribus ellipticis serratis, stipulis in ramis vegetis foliaceis dimidiatocordatis inciso-serratis, corymbis pancifloris, calycis villosi laciniis deltoideis acutis eglandulosis, stylis 5, stigmatibus peltato-concavis subinaequilateris.

Flores magnitudine eorum $\boldsymbol{C r}$. oxyacanthae. Rami laterales horizontaliter patentes, divaricati. Folia ad duas tertias longitudinis usque cuneata integerrima, apice tantum inciso-serrata et soepe subtriloba, pollicaria vel sesquipollicaria. Spinae axillares subulatae. Fructus globosi, quinqueloculares, calycis laciniis foliaceis serratis coronati.

62. Cr. alnifolia S. et Z. - Cr. inermis, foliis e basi rotundata ovatis acuminatis vel cuspidatis basi simpliciter ceterum in toto margine duplicato-serratis, nervis parallelis superne impressis subtus prominentibus costatis, glabris annuis subcoriaceis, corymbis terminalibus multifloris, laciniis calycis deciduis, fructibus ellipticis disco calycino concavo coronatis bilocularibus, loculis dispermis, seminibas oblongis subtrigonis.

Inermis, tota glabra. Folia petiolata petiolo $8-10^{\prime \prime \prime}$ longo; lamina $2 \frac{1}{2}-3$-pollicaris, $1 \frac{1}{2}-2$ " lata, basi rotundata crenulata ceterum in apicem usque argnte duplicato-serrata. Flores non observati. Fructus magnitudine pisi, elliptici, apice disco calycino parvo concavo coronati.

32. Rh aphiole pis Lindl.

63. Rh. juponica Sieb. et Zucc. Fl. jap. I. p. 162. tab. 85 .

64. Rh. Mertensii S. et Z. I. c. p. 164. An Rhaphiolepis? integerrima Hooker ap. Beechey p. 260? In insulis Liu-kiu legit beatus Merteus. 
33. Photinia Lindl.

65. Ph. serrulata Lindl. - Crataegus glabra Thunb. Fl. jap. p. 205.

34. Eriobotrya Lindl.

66. E. japonica Lind. S. et Z. Fl. jap. I. p. 182. tab. 97. Mesp. japonica Thunb. H'. jap. p. 206.

35. Aronia Pers.

67. A. asiatica S. et Z. Fl. jap. I. p. 87, tab. 42.

36. Osteomeles Lindl.

68. O. anthyllidifolia Lindl. Vidi specc. a beato Mertens in insulis Liukiu lecta et ab Academia Imp. Petropolitana benevole commonicata. 37. Pyrus Lindl.

69. P. Malus. - Culta.

70. P. spectabilis Ait. P. baccata Thbg. Fl. jap. p. 207.

71. P. communis L. - Culta.

72. P. (Sorbus) gracilis S. et $Z \mathbf{Z}$ - P. ramis gracilibus, foliis pinnatis 4-6jugis, foliolis subsessilibus ellipticis acutis, argute serratis subtus pubescentibus, stipulis summorum foliorum foliaceis inciso-serratis, corymbis paucifloris, calycibus glabris, laciniis deltoideis acutis quam petala ovata unguiculata brevioribus.

Corymbi 20-30-flori. Flores parvi. Folia circiter 4-pollicaria petiolo hirto. Foliola lateralia brevissime pedicellata basi rotundata integra, sursum serrata, pollicaria, infima minora.

38. Cydonia Tourn.

73. C. sinensis Thouin.

74. C. japonica Pers. - Pyrus japon. Thunb. Flor. japon. p. 207. Folia in ramis floriferis soepe obtusa crenata, in ramis vegetis annuis utrinque longe attenuata et acuminata dense et mucronato-serrata, spinam subulatam fere pollicarem soepius ex axillis emittentia. In his praesertim et stipulae foliaceae, breviter petiolatae reniformes mucronatae serratae. Fructus maturus nullo modo, ut Thunhergius voluit, in valvulas dehiseit. 


\section{2}

75. C. vulgaris Pers.

Fide clar. Kaempferi (Umbatz vulgo Marmaer Amoen. p. 800) a Lasitanis introducta.

\section{7. (271. Endl.) MYRTACEAE $\boldsymbol{R}$. Br.}

39. Punica Tourn.

\section{P. Granatum Linn.}

Var. frutescens ramis lateralibus spinosis, foliis anguste et sublineari-lanceolatis, fructibus nuce Juglandis vix majoribus exacte globosis.

Vermuthlich die wilde oder verwilderte Pflanze, die auch im Orient dornig vorkommt. Wahrscheinlich meint anch Thunberg diese Form, indem er- sagt: crescit vulgaris in Kosido, während Kämpfer die kultivirte Pflanze raram hoc coelo et fructu ingrato nennt. 40. Myrtus Tournef.

77. M. tomentosa Ait.

Anmerkung. Myrtus laevis Thunb. Fl. jap. 198 und der spätern Autoren gehört offenbar gar nicht zu den Myrtaceen, sondern ist vielleicht eine Pomacea, weil Thunberg sagt: Rami et ramuli alterni und folia e gemmis alternis solitaria, bina vel terna.

41. Metrosideros R. Br.

78. Species nondum determinata.

8. (270. Endl.) MELASTOMACEAE $\boldsymbol{R}$. $\boldsymbol{B} r$.

42. O sbeckia L.

79-82. O. chinensis $L$. cum 3 aliis e familia nondum determinatis.

9. (269. Endl.) LYTHRARIEAE Juss.

43. Ammannia Houst.

83. 84. Species duae nondum determinatae. 
44. Lythrum L.

85. L. Salicaria $L$. - A planta europaea non diversa.

45. Lagerstro e mia $L$.

86. L. indica $\boldsymbol{L}$.

10. (268. Endl.) HALORAGEAE $\boldsymbol{R} . \boldsymbol{B}$.

46. Myriophyllum Vaill.

87. Species nondum determinata. - Flores desunt.

47. Haloragis Forst.

88. H. micrantha P. Br. Gonocarpus micranthus Thunb. Fl. jap. p. 69. t. 15.

Herba debilis, uti videtur perennis, stolonifera, canle adscendente ramoso tetragono. Folia opposita brevissime petiolata ovata vel suborbicularia, acuta vel obtusa, serrata serraturis uncinatis margine calloso cinctis, glabra, firma, 2-4"' longa, $1 \frac{1}{2}-2^{\prime \prime \prime}$ lata. Flores in spicas soepe paniculatim congestas terminales longas laxas filiformes dispositi, subsessiles, secundi, nutantes, bractea minuta lanceolata suffulti. Calycis tubus globosus octangularis, glabra; limbus quadrifidus laciniis ovato-deltoideis acutis extus basi callosis. Petala 4 oblonga cucullata erecto-conniventia. Stamina 8, antheris linearibus longis.

48. Trapa Linn.

89. Tr. bispinosa Roxb. Tr. petiolis medio/ elliptice inflatis utrinque attenuatis teretibus, foliis e basi truncata integerrima abbreviato-deltoideis cuspidatis dentatis superne glabris subtus tomentosis, fructibus bicornibus cornubus oppositis divaricatis subulatotrigonis acuminatis spinescentibus, styli rudimento conico apice spinescente. - Roxb. corom. tab. 234. p. 29. De Cand. Prodr. III. p. 64. - Tr. natans Thunb. Fl. jap. p. 65.

Specimina nostra ab indicis recedunt foliis minoribus e basi truncata deltoideis nec late cuneatis subquadratis, margine dentatis non serratis; an species distincta? Fructus cornua recta acuminata 
apicem versus decorticata et spinulis dense distichis rectis retrorsis pectinata.

90. Tr. incisa $\boldsymbol{S}$. et $\boldsymbol{Z}$. - Tr. petiolis medio elliptice inflatis, lamina folii rhombea acuta argute et inaequaliter incisa superne glabra subtus subtomentosa. - An Tr. cochinchinensis Lour. coch. I. p. 108 ?

Folia subtus inter pilos maculis parvis numerosis brunneis notata.

\section{1. (267. Endl.) OENOTHEREAE Endl.}

49. Epilobium L.

91. 92. Specimina manea.

50. Circaea Tournef.

93. C. mollis S. et ZZ. - C. erecta ramosa, caule foliisque oblongis acuminatis denticulatis brevissime molliter pubescentibus, racemis paniculatis, pedicellis fructiferis deflexis fructum aequantibus.

A. C. Lutetiana, cui proxima, differre videtur caule magis ramoso, pubescentia in canle et in foliorum venis e pilis brevissimis, decumbentibus in illa e pilis longis rectis patentissimis composita, racemis brevioribus in paniculam foliosam congestis, pedicellis fructum aequantibus in illa duplo longioribus.

\section{2. (266. Endl.) PHILAdElPHEAE Don.}

51. Philadelphus L.

94. Pl. coronarius $\boldsymbol{L}$.

\section{3. (264. Endl.) ALANGIEAE De Cand.}

52. Marlea Roxb.

95. M. platanifolia $\boldsymbol{S}$. et $\mathbf{Z}$. M. foliis e basi cordata palmato-tri - quinquelobis, Jobis ovatis ellipticis vel oblongis cuspidatis integerrimis, sinubus rotudatis, pagina folii superiore glabra, inferiore 
pubescente et in axillis venarum soepe barbulata, pedunculis panci(2-4) floris.

M. barbatae R. Br. proxima, sed hujus folia acuminata integra vel irregulariter bi-triloba lobis brevibus, pedunculi multiflori, dichotome divaricati, flores duplo minores.

96. M. macrophylla S. et $\mathbf{Z}$. M. foliis e basi cordata vel rarius rotmndata integris ovatis acuminatis vel retusis trilobis, lobis late deltoideis longe cuspidatis, intermedio parum longiore, lateralibus divergentibus, sinubus rotundatis, lamina folii superne glabra subtus pubescente, pedunculis 1 -3-floris.

Petioli teretes superne canaliculati bipollicares; lamina soepe 6 " longa et inter lobos lata, tenera, membranacea. Drupa elliptica, disco epigyno coronata, utrinque planiuscula, ossea, abortu unilocnlaris monosperma.

\section{4. (263. Endl.) COMBRETACEAE $\boldsymbol{R}$. Br.}

\section{Quisqualis Rumph.}

97. Qu. sinensis Lindl. Bot. Reg. Mant. 1844. Qu. ramis petiolisque molliter pubescentibus, foliis oblongo-ellipticis vel ovatis, acuminato-cuspidatis superne glabris subtus pubescentibus, floribus terminalibus spicatis primum corymboso-fastigiatis, bracteis linearibus fugacibus, calycis tubo filiformi glabro, limbi 10-nervati laciniis abbreviatis late deltoideis, petalis oblongis vel ellipticis.

E China allata. Folia basi rotundata, oblongo-elliptica vel ovata, $3 \rightarrow 4$ " longa, $1 \frac{1}{2}-2^{\prime \prime}$ latà, penninervia. Flores spicati sed primum fastigiati, bracteis linearibus ovarii longitudine suffulti, oppositi, sessiles, congenerum longissimi, tripollicares; tabas calycis filiformis, quinquenervius, glaber; limbus dilatatıs, 10-nervius, lacinïs late deltoideis brevibus. Petala oblonga vel elliptica, obtusa, rosea vel purpurea. Drupa elliptica. 
15. (259. Endl.) BALSAMINEAE A. Rich.

54. Impatiens Linn.

98. I. Balsamina Thunb. Fl. jap. p. 327.

99. 100. Species nondum determinatae.

16. (258. Endl.) OXALIDEAE De Cand.

55. Oxalis Linn.

101. O. corniculata L. Thunb. Fl. jap. p. 187.

102. Species nondum determinata. O. Acetosella Thunb. l. c., sed a planta europaea diversa.

\section{7. (257. Endl.) LINEAE De Cand.}

56. Linum L.

103. 104. Lini species 2.

18. (256. Endl.) GERANIACEAE De Cand..

57. Geranium L'Herit.

105. G. Thunbergii S. et Z. - G. palustre Thunb. Fl. jap. p. 268.

106. 107. Species nondum determinatae.

19. (255. Endl.) ZYGOPHYLLEAE $\boldsymbol{R}$. Br.

58. Zygophyllum L.

108. Zyg. species.

20. (254. Endl.) RUTACEAE Bartl.

59. Boenninghausenia Rehbch.

109. B. albiflora Rchb.

60. Ruta Tourn.

110. Rutae species. 
21. (253. Endl.) DIOSMEAE Adr. Juss.

61. Dictamnus L.

111. D. vix a D. Fraxinella diversus.

\section{2. (252. Endl.) ZANTHOXYLEAE Adr. Juss.}

62. Zanthoxylon Kunth.

112. Z. piperitum $D C$. $-\mathbf{Z}$. aculeatum aculeis conicis geminis infrapetiolaribus, foliis alternis oppositisve imparipinnatis 5-9-jugis, petiolis (novellis superne pubescentibus) subtus soepe spinulosis, foliolis breviter petiolatis lanceolatis vel ovato-lanceolatis basi subinaequalibus glanduloso-serratis vel crenatis, apice plerumque bidentatis glandula inter dentes apicales, primum pubescentibus demum glabris, cymis terminalibus, carpellis solitariis geminisve. - Fagara piperita Linn. Thunb. Flor. jap. p. 64. - Seo et Sansjo Kämpfer Amoen. p. 892. c. ic. Non vero Fay. piperita Loureiro Coch. p. 101, quae Zanth. nitidum DC. Arbuscula 10-12 pedalis. Rami cinereo-fuscescentes, teretes, glabri. Folia plerumque alterna, petiolo communi inter spinas solidas conicas rectas inserto passim spinuloso, cum rachi $3-5^{\prime \prime}$ longo. Foliola $8-12^{\prime \prime \prime}$ longa, 3-4" lata. Glandulae pellucidae in serraturarum axillis et inter summas apicales. Flores parvi, albi. Carpella piso minora, coriacea, fusca, transversim rugosa. Semina globosa, nigra, nitida.

F. piperita Hook. et Arn. ap. Beechey l. c. p. 261 aus den Liu-kiu-Inseln gehört ebenfalls nicht hieher. Sie unterscheidet sich durch (schmal) gerandete Blattstiele und sehr kleine nur $3 \longrightarrow 4^{\prime \prime \prime}$ lange Blättchen.

113. Z. schinifolium S. et Z. - Z. aculeatum aculeis conicis rectis sparsis, totum glabrum, foliis alternis imparipiunatis $7-9$ jugis, petiolis spinulosis, foliolis basi inaequalibus lanceolatis utrinque attenuatis obtuse acuminatis glanduloso-crenatis apice bidentatis, glandulis in axilla crenarum, corymbo terminali convexo multifloro, carpellis geminis ternisve.

Abhandlungen d. II. Cl. d. k. Ak. d. Wiss. IV. Bd. Abth. II. 
Foliola $6-10^{\prime \prime \prime}$ longa, 3-4"' lata, longe attenuata sed glandula terminali inter summas dentes posita obtusa, dense crenata, glandulis pellucidis in crenarum axillis. Flores parvi. Carpella vix magnitudine grani Piperis, gemina vel terna. Seminum epidermis lucida, testa foveolata.

114. Z. ailanthoides $\boldsymbol{S}$. et $\mathbf{Z}$. - Z. aculeatam aculeis numerosis sparsis conicis, foliis alternis impari-pinnatis $9-11$-jugis, foliolis breviter petiolatis e basi rotundata lanceolatis longe attenuatis et acuminatis crenulatis, crenis eglandulosis, glandulis per totam laminam sparsis, petiolis inermibus, corymbis terminalibus plerumque geminis multifloris, carpellis geminis ternisve rugulosis, seminibuns laevibus.

Rami crassitie fere digiti minoris, aculeis crebris conicis rectis armati. Folia pedalia et longiora, 9-11-juga, foliola breviter petiolata, basi rotundata longe attenuata, $3-4^{\prime \prime}$ longa, $6-8^{\prime \prime \prime}$ lata, glabra, per totam. paginam glandulis sparsis pellucide punctata. Corymbi terminales, gemini, nudi, foliis breviores. Semina nitida, nigra.

115. Z. planispinum S. et Z. Z. aculeatum aculeis stipularíbus basi dilatatis a lateribus compressis sursum subulatis rectis aliisque minoribus ad foliolorum basin et in nervis mediis, foliis ternatis vel quinato-pinnatis jugo inferiore distante, foliolo terminali sessili, omnibus lanceolatis utrinque attenuatis acutis glabris obsolete crenatis et inter crenas glanduloso-punctatis, petiolis alatis, corymbis axillaribus pancifloris, carpellis solitariis verruculosis.

Spinae basi valde dilatatae ab utroque latere compressae, subulatae, nitidae, fuscae. Folia plerumque ternata, foliolis lanceolatis acutis sessilibus obsolete crenatis margine inter crenas nec in reliqua lamina glanduloso-punctatis $1-1 \frac{1}{2}$ " longis; rarius folia pinuata bijnga jugo inferiore remotiusculo; petioli alati, pollicares; ispinae minores ad basin foliolorum et in nervo medio praesertim folioli ter- 
minalis. Corymbi in axillis foliorum inferiorum panciflori. Semina grano piperis minora, lucide nigra.

Adnotatio. De Fagara horrida Thunb. Act. Linn. II. p. 329. et Flor, jap. p. 350 vide inter Leguminosas Gleditschiam.

63. Boymia Adr. Juss.

116. B. rutaecarpa A. Juss. Sieb. et Zuccar. Flor jap. I. p. $80 . t a b .21$.

\section{3. (347. Fidl.) ANACARDIACEAE $\boldsymbol{R}$. Br.}

\section{Rhus Linn.}

117. Rh. semialata Murr. B. Osbeckii De Cand. - Rh. in ramis junioribus, petiolis, pedunculis et foliorum pagina inferiori tenuiter tomentosa, foliis $3-5$-jugis, foliolis sessilibus ellipticis acutis dentatis superne glabris, summo longe decurrente, petiolo basi tereti inter juga foliaceo-alato plano, panicula terminali pyramidata valde ramosa, fructibus furfuraceo-tomentosis. - Rh. javanicum Linn. speci. plant. 380. Thunb. Fl. jap. p. 121.

Folia pedalia et quot excedit. Foliola inferiora minora vix pollicaria soepius subfaleata, superiora $2-2 \frac{1}{2}$ " longa, $1-1 \frac{1}{2}$ ", lata, terminali in petiolum longe decurrente; juga distantia petiolo inter superiora $2-3$ foliaceo-alato, basin versus nudo tereti. Panienla terminalis, pyramidata, pedalis, valde ramosa, fructibus furfuraceotomentosis. In petiolis soepe gallae occurrunt difformes, vel sessiles tomentosae, vel pedicellatae ramosae, apicem versus clavatae, glabrae.

118. Rh. succedanea $L$. Rh. tota glabra, foliis 4-6-jugis, foliolis e basi subinaequilatera lanceolatis acuminatis integerrimis subtus concoloribus vel glancescentibus, petiolis nudis basi teretibus inter juga canaliculatis, paniculis lateralibus infrafoliaceis ex axillis perularum fugacium, floribus pedunculatis, drupis snbrhombeis, epidermide laevi, sarcocarpio crustaceo fibroso-cereo, pyreno osseo laevi. - Rh. succedanea Thunb. Fl. jap. p. 122 et auct. Fari no ki Kämpfer Amoen. p. 794. c. icone bona. 
Rami teretes, nti tota planta glabri. Folia 8-12" longa, 5-7juga; foliola brevissime petiolata basi subinaequilatera, lanceolata acuminata acumine subfalcato, utrinque glabra subtus vel concolora vel glanca, $1 \frac{1}{2}-2$ " longa, $6-8^{\prime \prime \prime}$ lata. Paniculae plures infra folia ex axillis perularum delapsarum, patentes vel deflexae, ramosae ramis patentibus. Flores pedicellati, parvi, e viridi flavescentes. Drupae subrhombeae, utrinque convexo-planae, glabrae, rugosae, sordide stramineae. Sarcocarpium fibrosum, magna cerae vegetabilis copia fibris intermixta, quae ad fabricandas candelas inservit, tritum camphoram redolens. Pyrenum compressum, osseum, laeve.

119. Rh. sylvestris $\boldsymbol{S}$. et $\boldsymbol{Z}$. Rh. villosa vel pubescens, foliis 4-7-jugis, foliolis e basi subinaequilatera rotundata oblongo-lanceolatis acuminatis integerrimis, supra pubescentibus subtus villosis vel novellis sericeis costato-venosis, petiolis teretibus inter foliola canaliculatis, paniculis lateralibns infrafoliaceis vel axillaribus, pyramidatis villosis, floribus pedunculatis, drupis subrhombeis laevibus sarcocarpio crustaceo fibroso-cereo, pyreno osseo Taevi.

Rh. succedaneae valde affinis recedit indumento villoso omnium partium et foliis subtus venis numerosis parallelis sed ante marginem anastomosantibus costatis. Fructus minores, sicci magis rugosi et sarcocarpium minus cera faretum, tritum eamphoram redolens. Folia soepius pedalia et quot excedit, 5-7-juga, rarins in ramis vegetis virgatis bijuga vel ternata; foliola $1 \frac{1}{2}-2$ " longa, $8-12^{\prime \prime}$ lata. Panicnlae erectae vel fructiferae divaricatae. An prioris varietas sylvestris?

120. Rhus vernicifera $D C$. - Rh. foliis $5-6$-jugis, foliolis brevissime pedicellatis e basi rotundata ovatis acutis integerrimis superne glabris subtus tenuiter pubescentibus, petiolis basi semiteretibus, inter folia carinato - convexis, paniculis infrafoliaceis vel axillaribus erectis laxis rachi peduneulisque molliter pubescentibus. Rhus Vernix Linn. Syst. nut. II. p. 242. Thunb. Fl. jap. p. 121. Sitz vel Sitz dsju Kämpfer Amoen. p. 791 cum icone. 
Folia adulta soepius fere bipedalia, omnia 4-6-juga; foliola breviter pedicellata basi rotundata subinaequilatera, ovata acuta vel acuminata, subtus molliter pubescentia, inter $2-6$ " longa, $1 \frac{1}{2}-2 \frac{1}{2}{ }^{\prime \prime}$ lata. Petioli basi semiteretes superne plani, inter foliola convexocarinati. Paniculae rami distantes uti pedunculi villosi. Flores virides, calyces glabri. Stigmata crassa subsessilia.

Adnotatio: Quid Rhus hirsuta spinosa et Rh. foliis subtus glaucis spinosa Thunb. Flor. jap. p. 351? — Vix Rhois species!

\section{4. (246. Endl.) JUGLANDEAE De Cand.}

65. Platycarya Sieb. et Zuccar.

121. Pl. strobilacea S. et Z. Act. Mathem. Plysic. Monac. III. p. 743. tab. 5. Flor. jap. II. tab. 159 ined.

66. Pterocarya Kunth.

122. Pt. sorbifolia S. et Z. Fl. jap. Ir. tab. ined. 161. P. foliis alternis imparipinnatis $4-8$-jugis, foliolis suboppositis subsessilibus lanceolatis longe acuminatis dense ac argute serrulatis aeque ac petioli et pedunculi molliter pubescentibus, amentis masculis simplicibus laxis infrafoliaceis vel in axillis foliorum inferiorum, foemineo elongato foliis breviore laxo subterminali (infra gemmam terminalem extrafoliaceo), bracteis dense hirtis.

123. Pt. rhoifolia S. et Z. l. c. $t$. 160 . Pt. foliis alternis imparipinnatis 8-9-jugis, foliolis sessilibus e basi rotundata inaequali oblongo-lanceolatis acuminatis argute et dense serrulatis superne glabris subtus ad venas aeque ac petioli molliter pubescentibus, amentis foemineis solitariis subterminalibus laxifloris folia aequantibus vel superantibus, bracteis glabris.

Amenta foeminea pedalia et sesquipedalia, singuli flores $3-4^{\prime \prime \prime}$ a se invicem distantes.

67. Juglans L.

124-26. Species nondum determinatae. 


\section{5. (245. Endl.) EUPHORBIACEAE Juss.}

68. Pachysandra Mich.

127. P. terminalis S. et $\mathbf{Z}$. - P. caule adscendente basi nudo, foliis in petiolum longe decurrentibus et e basi cuneata obovatis obtusis vel truncatis raro acutis, a medio sursum grosse et remote serratis serraturis deltoideis acutis, glabris, racemo solitario ex apice canlis.

Caulis semipedalis vel pedalis adscendens herbaceus uti tota planta glaber. Folia versus apicem caulis alterna, in petiolum longe attenuata obovata, obtusa vel subtruncata et serraturis grossis quasi praemorsa, $2-2 \frac{1}{2}$ " longa, 1" lata, glabra subcoriacea. Racemi terminales, erecti, simplices, multiflori. Flores foeminei inferiores panci multibracteati, bracteis ovatis acutis coriacéis; masculi tribracteati.

\section{Bux us Tournef.}

128. B. microphylla S. et $\mathbb{Z}$. - B. foliis lineari-oblongis yel subspathulatis obtusis subemarginatis coriaceis nitidis glabris, floribus glomeratis, rudimento ovarii in floribus masculis stipitato calycem aequante.

Frutex ramosissimus; folia vix semipollicaria, $3^{\prime \prime \prime}$ lata, coriacea, glaberrima. Flores axillares, 5 vel plures capitati. Ovarii rudimentum in flor. masculis columnare trisulcatum, stigmatibus 3 sessilibus carnosis emarginatis coronatum, calycem aequans. Flores foeminei in medio capituli solitarii soepius deficientes. Calyx 4-phyllus. Ovarium superum, 3 -loculare loculis biovulatis. Styli 3 breves crassi planiusculi, stigmatibus carnosis emarginato-bilobis, patentes et alternantes cum squamulis tribus super ovarii verticem inflexis et ei adnatis.

Thunberg Fl. jap. p. 77 führt B. sempervirens L. als in Japan häufig vorkommend anf und meint damit gewiss zum Theil unsre Art, welche er nicht unterscheidet. Es soll aber anch mit letzterer die europäische Art vorkommen. Nur kann das Citat aus Kämpfer Amoen. $p$. 781 Ojo vulgo Tsuge nicht dazu gezogen werden, da 
die Beschreibung angiebt: folia raris aculeis serrata und baccae atropurpureae succo purpureo sylvestri turgidae, di-tetra-spermae, was offenbar auf einen Ilex hindeutet.

70. Glochidion Forst.

129. Gl. obovatum S. et Z. - M. foliis alternis brevissime petiolatis e basi longe attenuata cuneata obovatis obtusis vel breviter cuspidatis integerrimis glabris subtus glancescentibus, floribus monoicis fasciculatis, masculis plerumque ex axillis foliorum inferiorum 5-6 longe pedunculatis, peduneulis laxis filiformibus, foemineis superioribus eodem modo fasciculatis pedunculis stricte erectis quam in masculis dupio brevioribus, stigmatibns simplicibus erecto-conniventibus.

Frutex valde ramosus. Folia sesquipollicaria subsessilia vel in petiolo decurrentia, obovata obtusa vel mucronato-cuspidata, integerrima, margine plana, glabra, subtus glancescentia sicca nigricantia. Capsula depresso-globosa, 5-6-cocca coccis medio dorso sulco exaratis dispermis.

A Gl. (Bradleia) sinaico diversa videtur foliis obovatis non lanceolatis, flor. masculis fasciculatis nee solitariis, seminibus in quovis loculo juxta - non super-positis.

71. Cieca Linn. (?)

130. C. (?) flexuosa S. et $\mathbf{Z}$.

Frutescens, rami subflexuosi. Folia parva, ovato-elliptica acntiuscula, integerrima, glabra. Stipulae membranaceae fimbriatae. Flores masculi fasciculati, pedunculis filiformibus. Calyx 4-partitus, stamina 2. Flores foeminei desunt.

72. Phyllanthus Swartz.

131. Ph. lepidocarpus $\mathbf{S}$. et $\mathbf{Z}$.

Ph. annuus caule erecto, foliis pinnatis floriferis, foliolis oblongis obtusis mucronatis glabris subtus glaucis, floribus omnibus sessilibus, fructibus squamulis deltoideis echinulatis, seminibus trigonis transverse sulcato-plicatis. 
Ph. Niruri Thunb. Fl. jap. p. $\check{6}$ ? sed flores pedicellati dicuntur. Caulis pedalis subsimplex, stricte erectus. Foliola $7-11$ in quovis ramulo subsessilia oblonga et apicem versus soepe parum latiora, obtusa, mucronata, subtus glanca, unguicularia. Fructus sessiles, parvi, globosi, sexsulcati, squamulis primum patentibus demum adpressis echinulati.

Den Untersuchungen Hooker's (ap. Beechey p. 210) zufolge wäre unsere Pflanze zunächst verwandt mit Ph. urinaria $L$., welche ebenfalls schuppige Kapseln und nach der Definition in Specc. pl. 1393 flores sessiles haben soll. Aber zugleich wird der Stengel procumbens genannt und Willdenow sagt noch weiter, die weiblichen Blüthen seyen gestielt. Beides passt nicht auf unsre Pflanze. Ebenso ist Ph. cantoniensis Hornem. nahe mit unsrer Pflanze verwandt, weicht aber durch die starke Verästelung und breite fast geflügelte Blattstiele ab. Wir haben desshalb die japanische Pflanze als eigne Art gesondert halten wollen, bis eine genaue Revision sämmtlicher in diese Gruppe gehöriger Species erfolgt. Dazu dürften vorzüglich die Samen gute Anhaltspunkte liefern. Sie sind bei einigen durch zahlreiche in Reihen gestellte Wärzchen weichstachlig, bei andern der Länge nach gefurcht, bei cantoniensis und lepidocarpa mit Querrunzeln besetzt, hei einer Art aus Nubien grubig, bei Niruri nach Sprengel glatt. Rechnet man zu diesen Merkmalen noch, dass die Kapselu glatt oder beschuppt, die Blüthen gestielt oder ungestielt seyn können, so fellt es nicht an brauchbaren Charakteren, sobald nur einmal die Linneischen Ph. Niruri und urinaria wieder mit Sicherheit ausgemittelt sind.

132. Ph. species nondum determinata.

73. Croton Linn.

133. Croton Siraki S. et Z.

74. Rottlera Roxb.

134. R. japonica Spreng. Sieb. et Zuccar. Fl. jap. p. 147. t. 79. - Croton japon. Thunb. Fl. jap. p. 270. 
75. Ricinus Tournef.

135. R. communis $\boldsymbol{L}$.

76. Elaeococea Commers.

136. El. verrucosa .Juss. - Dryandra cordata Thunb. Flor. jap. p. 267.

Rami crassi, lenticellis oblongis dense verrucosi. Folia petiolata, petiolo 2--3-pollicari tereti, e basi cordata ovata acuta vel triloba lobis late deltoideis acuminatis, glandula vel stipitata vel sessili in fundo sinuum, aliis duabus longe stipitatis peltatis utrinque ad basin folii. Stipulae lanceolatae, foliaceae, persistentes. Panicula terminalis corymbosa.

77. A calypha Linn.

137. Species.

78. Mercurialis $\mathbf{L}$.

138. M. lejocarpa $\boldsymbol{S}$. et $\mathbf{Z}$. M. annua, monoica, caule erecto ramoso glabro, foliis oppositis e basi rotundata ovato-oblongis acutis crenato-serratis, crenis apice glandula notatis, parce ciliatis superne glabris subtus ad venas passim setosis, spicis masculis inferioribus filiformibus interruptis folia superantibus, foemineis ex axillis foliorum superiorum, floribus singulis pedicellatis, carpellis glabris.

Recedit a $\boldsymbol{M}$. annuc cui affinis, foliis glanduloso-serratis, floribus masculis duplo fere majoribus, spicis foemineis longe racemosis, carpellis glabris.

79. Stillingia Gard.

139. St. sebifera Michx.

140. St. japonica $\boldsymbol{S}$. et $\mathbf{Z}$. St. frutescens, foliis petiolatis e basi rotundata biglandulosa ovato-oblongis acuminatis integerrimis utrinque glabris, racemis masculis terminalibus cylindricis, florum fasciculis bi- vel trifloris ex axilla brateae subulatae basi biglandnlosae, floribus foemineis ...

Abhandlungen d.II. Cl. d. h. Ak. d. Wiss. IV. Bd. Abth. II. 
Variat aeque ac St. sebifera floribus masculis di- vel triandris. Folia 2-4" longa, 2" lata, longe acuminata, glabra. Racemi masculi terminales, pollicares vel bipollicares, erecti, graciles.

80. Euphorbia L.

Species 10 nondum determinatae.

\section{6. (243. Endl.) EMPETREAE Nutt.}

81. Empetrum Tournef.

140. $\boldsymbol{E}$. nigrum $\boldsymbol{L}$.

A planta europaea nullo modo recedit nisi foliis parum angustioribus et magis patentibus.

\section{7. (241. Endl.) RHAMNEAE $\boldsymbol{R}$. Br.}

82. Rhamnus Juss.

141. Rh. globosus Bunge Enum. plant. chin. p. 14.

142. Rh. crenatus $\mathbf{S}$. et $\boldsymbol{Z}$. - Rh. inermis, foliis alternis e basi rotundata ovatis longe cuspidatis crenato-serrulatis erenis calloso-mucronulatis, glabris vel novellis fuscescenti-hirtis, costato-venosis, floribus axillaribus subumbellatis, $5-8$ e peduneulo communi, pedicellatis hermaphroditis, calycibus aeque ac pedunculi pubescentibus, laciniis deltoideis acutis intus carinatis, petalis stamina aequantibus cucullatis emarginatis, stylo brevi apice breviter trilobo.

Rh. alpino et caroliniano affimis. Folia $2-3^{\prime \prime}$ longa, $1-1 \frac{1}{2}^{\prime \prime}$ lata, novella fuscescenti-hirta demum glabra, longe cuspidata, minutim crenato-serrulata, nervis parallelis utrinque 6-10-costata; stipulae deciduae. Flores in pedunculo brevi subumbellati, petiolo breviores pedicellis et calycibus pubescentibus.

83. Hovenia Thunb.

143. H. dulcis Thunb. Fl. jap. p. 101. Sieb. et Zuce. Fl. jap. I. p. 135. tab. 73.74 .

Folia novella subtomentosa, adultiora calva. 
84. Berchemia Nick.

144. B. racemosa $\boldsymbol{S}$. et $\boldsymbol{Z}$. B. inermis, foliis petiolatis e basi rotundata ovatis acutis integerrimis costato-lineatis glabris, stipulis intrapetiolaribus connatis apice tantum liberis persistentibus, floribus axillaribus fasciculatis vel interrupte racemosis, racemis nudis, calycis segmentis ovato-lanceolatis acutis, drupis obovatis, pyreno osseo dispermo.

B. lineata De Cand. et Hooker ap. Beechey pag. 177. t. 37. recedit foliis subsessilibus obtusis et praesertim calycis segmentis elongatis linearibus. In planta nostra petioli $2-3^{\prime \prime \prime}$ longi, folia subpollicaria. Racemi vel axillares breves et fasciculati, vel versus apicem ramorum nudi pollicares interrupti. Flores parvi. Alabastra globosa, argute cuspidata.

85. Zizyphus Tournef.

\section{Z. sinensis Lam.}

Specimina nostra omnia subinermia, raro spina uнa alterave subulata ad basin ramulorum. Ramuli glabri. Folia breviter petiolata e basi rotundata ovata vel ovato-lanceolata acuta repandoserrata, glabra, $1-1 \frac{1}{2}$ " longa, $8-10^{\prime \prime \prime}$ lata. Flores axillares, gemini - quaterni subumbellati, pednnculo communi brevi, pedicellis nudis pubescentibus. Calycis laciniae ovatae acutae in facie interiore ab apice carinatae; petala breviter unguiculata, spathulata, concava, calyce breviora, virentia. Discus 10-crenatus. Stigmata 3 recurva. Drupa ovato-elliptica, rotundata, carnosa, pollicaris. Colitur in horto botanico in insula Dezima.

86. Paliurus 'Tournef.

146. P. Aubletia R. S. vel nova species? Folia suborbicularia dense crenato-serrata, sed flores desunt.

\section{8. (240. Endl.) ILICINEAE Brogn.}

87. Hex Linn.

147. Il. crenata Thunb. - I. foliis breviter petiolatis ellipticis 19 * 
obtusis mucronatis crenatis crenis mucronulatis, glabris coriaceis, ramis tenuissime pubescentibus, pedunculis axillaribus folio brevioribus strictis erectis dichotome $3-7$-floris, pedicellis filiformibus florem aequantibus vel superantibus. - I. crenata Thb. l. c. p. 78 et Aut.

Rami tenuissime pubescentes. Folia alterna elliptica vel obovato-elliptica indeque spathulata, obtusa, mucronata, crenata crenis mucronulatis, basi breviter attenuata, glabra, superne nitida subtus opaca pallidiora, coriacea, $8-12^{\prime \prime \prime}$ longa, 4-5"' lata; petioli brevissimi lineam longi. Pedunculi axillares stricte erecti tenues, ad lentem pubescentes, dichotome 3-7-flori, folio breviores; flores pedicellati pedicellis filiformibus strictis glabris, $1-2^{\prime \prime \prime}$ longis; calycis laciniae obtusae, petala semiorbicularia. Drupa globosa, magnitudine pisi minoris, plerumque dipyrena.

148. Il. integra Thbg. I. foliis petiolatis ovato-oblongis utrinque attenuatis acutis acumine obtuso glandula terminato, integerrimis margine subreflexis glabris coriaceis, florum fasciculis axillaribus multifloris e gemmis propriis perulatis, perulis ciliatis, pedunculis strictis unifloris, calycis laciniis ovatis obtusis, petalis oblongis obtusis calycem superantibus, drupis globosis tetrapyrenis. - I. integra Thbg. Fl. jap. p. 77. - Prinos integra Hook. et Arn. ap. Beechey p. 261.

Folia alterna; petioli $4-6^{\prime \prime \prime}$ longi, superne plani; lamina ovatooblouga vel elliptica utrinque attennata, apice excurrens in acumen breve glandula terminatum indeque obtusum, integerrima, utrinque glabra, coriacea, $1 \frac{1}{2}-2$ "' longa, $9-12^{\prime \prime \prime}$ lata. Flores e gemmis propriis perulatis, perulis coriaceis ciliatis, umbellato-faseiculati $5-10$; pedunculi uniflori, erecti, firmi, $3^{\prime \prime \prime}$ longi. Drupa magnitudine fructus Pruni spinosae minoris, globosa, tetrapyrena.

149. II. latifolia Thbg. I. ramis angulatis, foliis alternis petiolatis, in eodem ramo figura variis, oblongis ovatis vel ellipticis, acuminatis vel obtusis, argute serratis vel leviter crenatis utrinque glabris superne lucidis, petiolis trigonis, floribus axillaribus e gemmis 
propriis umbellato-fasciculatis numerosis, pedunculis unifloris. I. latifolia Thbg. Fl. jap. p. 79. - I. macrophylla Blume Bijdr. 17. p. 1150.

Rami angulati, crassi. Folia figura et magnitudine varia, petiolata, petiolo semipollicari crasso superne plano canaliculato subtus carinato; lamina $3-8$ " longa, $1 \frac{1}{2}-3$ " lata, oblonga, elliptica vel ovata, acuninata vel obtusa, vario modo serrata, coriacea, lucida. Flores ultra 20 in quovis fasciculo, e viridi flavescentes. Drupa parva, glabosa, coccinea, plerumque tetrapyrena, pyrenis trigonis.

150. Il. rotunda Thunb. I. tota glabra, foliis petiolatis e basi rotundata ovato-ellipticis acutis integerrimis vel rarius suberenatis utrinque glabris, pedunculis axillaribus nudis dichotome subumbellatis multifloris filiformibus strictis, pedicellis longitudine florum, calycis laciniis acutis, petalis obovatis rotundatis, drupis longe pedunculatis globosis 4-5-pyrenis. I. rotunda Thunb. Fl. jap. p. 77.

Rami angulati. Folia petiolata petiolo semipollicari, e basi late rotundata ovato- elliptica acuta integerrima vel rarius suberenata, glabra, $1 \frac{1}{2}-2^{\prime \prime}$ longa, 6-10"' lata. Pedunculi axillares, basi nudi nec perulati, petiolo parnm longiores, stricti, glabri, multiflori. Hlores parvi. Drupae magnitudine pisi minoris, globosae, stigmate 4-5-lobo coronatae.

151. Ilex serrata Thunb. Fl. jap. p. 28.

Flores in spece. nostris desunt.

Accedunt praeterea Ilicis species $5-6$ nondum determinatae.

Adnotatio. Il. japonica Thby. est Mahonia japonica De Cand. -Il. Aquifolium Thby. et Blume Bijdr. 17. p. 1150 pertinet fortasse ad Oléam Aquifolium Sieb. et Zuccar.

\section{9. (238. Endl.) CELASTRINEAE $\boldsymbol{R}$. Br.}

88. Elaeodendron Jacq.

152. Species nondum determinata.

89. Celastrus Kunth.

153. C. articulata Thbg. Fl. jap. p. 97. 
Rami (sicei) angulati, lenticellis albidis soepe adspersi; ramuli laterales vel divaricato-horizontaliter patentes rigidi, vel vegetiores adscendentes subflexuosi. Folia petiolata, petiolo $6-8$ "' longo, ovata vel ovato-elliptica raro suborbienlaria, enspidata basi rotundata vel attenuata, in toto margine crenato-serrulata, glabra, membranacea, $1 \frac{1}{2}-3^{\prime \prime}$ longa, $8-20^{\prime \prime \prime}$ lata. Pedunculi axillares petiolo breviores, solitarii gemini ternive, dichotome $3-5$-flori. Calycis laciniae ovatae, obtusae; petala plusquam duplo Iongiora, obtusa, Capsula pisi magnitudine globosa, trivalvis, loculis plerumque monospermis.

\section{C. punctulata Thbg. l. c. p. 97.}

155. C. Orixa S. et Z. C. dioica tetrandra, foliis in ramis lateralibus abbreviatis alternis subfasciculatis obovato-oblongis vel oblongis utrinque attenuatis acutis integerrimis vel obsolete crenulatis, novellis praesertim in nervis villosis, adultis glabris vel tenuissime pubescentibus aeque ac bracteae et calyces pellucide glanduloso-punctatis, racemis axillaribus solitariis multifloris, pedunculis villosis, bracteis membranaceis late ovatis ciliatis longitudine pedicellorum, calycis laciniis acutis, petalis ellipticis trinerviis obtusis, disco in floribus masculis eruciato. - Orixa japonica Thenb. Fl. jap. $p .3$ et 61.

Folia alterna, breviter petiolata petiolo vix $2^{\prime \prime \prime}$ longo, lamina ' $1 \frac{1}{2}-2$ " longa, 8-12"' lata. Racemi coëtanei circiter pollicares, laxi, 6-10-flori, rachi pedicellisque villosis; bracteae magnae, membranaceae, ovato-orbiculares utrinque atteuiatae, apice ciliatae. Discus in fundo calycis carnosus quadrilobo-cruciatus, lobis truncatis cum staminibus alternantibus. Flores foeminei ignoti.

Die Thunbergsche Gattung Orixa wurde von Sprengel mit Unrecht zu Ilex gezogen, von Endlicher u. A. unter die plantas incerte sedis gestellt, wozn weniger die Unkenntniss der Frucht als die irrige Deutung der männlichen Bluthe Anlass gab, dẹen vierlappige Honigscheihe man für ein stigma urceolatum, quadrilohu- 
latum in angulis stamina recipiens erklärte, obgleich man darunter kein ovarium fand und Thunberg ausdrücklich sagt: Germen superum, stylus unicus èrectus stigmate capitato obtuso. Wir haben nur männliche Blüthen gesehen, zweifeln aber dennoch nicht, dass die Pflanze ein Celastrus sey, wenn auch die durchsichtigen Drüserpunkte auf Blättern und Deckblättern sonst in der Gattung ungewöhnlich sind.

90. Evonymus Tournef.

156. E. japonicus Thunb. Fl. jap. p. 100. Blume Bijdr. 17. p. 1147. Hook. et Arnott ap. Beechey p. 261. tab. 54.

157. E. Sieboldianus Blume l. c. - Ev. europaeus Thunb. l. c. p. 101.

158. T. Thumbergianus Blume $l$. c. - Celastrus alatus Thb. Fl. jup. p. 98.

Die Zweige stark korkig geflügelt.

159. E. subtriflorus Bl. l. c. ?

Die beiden letztern Arten scheinen durch vier oder in Folge der Verkümmerung weniger völlig von einander freie Karpellen wesentlich von Evonymus verschieden.

\section{0. (237. Endl.) STAPHYLEACEAE Bartl.}

91. Euscaphis Sieb. et Zucc.

160. E. staphyleoides S. et Z. Flor. jap. I. p. 124. t. 67. Sambucus japonica Thunb. Fl. jap. p. 125 et Aut.

161. ? Husc. simplicifolia $\mathbf{S}$. et Z. E. foliis simplicibns e basi subcordata vel truncata late ovato-deltoideis acuminatis serratis. Banks. Icones Kämpfer. tab. 57.

Ipsa planta nobis non visa, sed ex icone vix alio generi adscribenda et certe non Volkameria fragrans ut voluit beatus Willdenow in Enum. plant. hort. Berol. 
$91 \frac{1}{2}$. Staphylea $\dot{L}$.

162. St. Bumalda. Sieb. et Zucc. F7. jup. I. p. 108. t: 95 .

Bumalda trifolia Thunb. Fl. jap. p. 8 et 114.

\section{1. (236. Endl.) PITTOSPOREAE $\boldsymbol{R}$. $\boldsymbol{B}$.}

92. Stachyurus S. et Z.

163. St. praecox S. et Z. Fl. jap. I. p. 43. t. 18.

93. Pittosporum Soland.

164. P. Tobira Ait. - Evon. Tobira Thunb. Fl. jap. p. 99.

32. (234. Endl.) POLYGaleaE Juss.

94. Salomonia Lour.

165. S. stricta S. et ZZ. - S. annua, glabra, caule erecto ramoso sulcato, ramis strictis subvirgatis, foliis sessilibus lanceolatis vel linerari-lanceolatis acutis, spicis elongatis, bracteis flores subaequantibus vel brevioribus, capsulis margine setoso-cristatis, setis biseriatis.

Planta annua 6-8-pollicaris, caule erecto ramoso. Rami stricti, sulcati; folia alterna sessilia, inferiora ovato-lanceolata utrinque attenuata, superiora sensim angustiora lineari-lancelata vel linearia, omnia acuta integerrima, 3--4"' longa. Spicae elongatae $2-3$ " longae; flores sessiles bractea lineari suffulti, vix 2"' longi. Capsulae obcordato-bilobae, margine cristatae, crista e setis s. laciniis subulatis rectis biseriatis composita.

95. Polygala L.

166. P. japonica Houtt. - P. vulgaris Thunb. Flor. jap. p. 277.

33. (232. Endl.) SAPINDACEAE Juss.

96. Sapindus Linn.

167. S. Mukorossi Gaertn. Sieb. et Zuccar. Fl. jap. II. tab. 164. ined. S. rachi aptera inter foliola carinata pubescente, foliolis 
vel oppositis $3-6$-jugis vel alternis, pedicellatis, e basi rotundata oblongis acutis vel acuminatis integerrimis glabris, panicula terminali pyramidata ramis divaricatis pubescentibus, floribus subsessilibus, petalis cilialis, staminibus basi barbatis, carpellis globosis, duobus semper abortivis. - S. Mukorossi Gaertn. I. tab. 70. Thunb. Fl. jap. p. 356. n. 37 .

Arbor ramis teretibus erassis. Folia alterna, pedalia et bipedalia; petiolus basi articulatus, inter foliola superne carinatus villosus, apterus; foliola pedicellata, pedicellis $3-4^{\prime \prime \prime}$ longis, opposita $3-6$-juga vel alterna, acuta, soepius subfalcata, subtus ad nervos pubescentia, $4-7$ " longa, $1-2$ " lata. Calycis foliola obtusa, petala orbicularia, ciliata. Carpella tria, duobns abortivis brevibus acutis, tertio fertili obovato-globoso carnoso, endospermio tomentoso lapideo.

97. Koelreuteria Laxm.

\section{8. $\boldsymbol{K}$. paniculata Laxm.}

98. Meliosma Blume (Millingtonia Roxb.)

169. M. rigida S. et $\mathbf{Z}$. - M. foliis alternis isimplieibus oblongis vel obovato - oblongis utrinque longe attenuatis acnminatis remote spinoso-serratis superie glabris subtus aeque ac petioli et panicula ferrugineo-tomentosis costatis reticulatis coriaceis firmis, panicula terminali ramosissima pyramidali, floribus subsessilibus.

Rami juniores ferrugineo-tomentosi; folia petiolata petiolo fere pollicari, lamina longe attenuata oblonga vel obovato-oblonga acnminata, a medio apicem versus serraturis remotis spinescentibus munita, superue glabra subevenia, subtus nervis parallelis costata et inter eos reticulata, ferrugineo-tomentosa, $4-6$ " longa, $1-2$ " lata. Panicula semipedalis valde ramosa, dense ferrugineo-tomentosa. M. pungenti Wall. affinis jam foliis subtus costatis distinguitur.

170. M. myriantha S. et Z. $\mathbf{Z}$ - M. foliis alternis simplieibus ellipticis oblongis vel obovato-oblongis cuspidatis serratis serraturis argutis mucronatis, superne adpresse pilosis, subtus nervis paralleAbhandlungen d. II. Cl. d. k. Ak. d. Wiss. IV. Bd. Abth. II. 
lis numerosis costatis et in eis ferrugineo-hiris, panicula terminali pyramidata, ramis aeque ac rachis ferrugineo-tomentosis patentissimis, floribus numerosissimis pediceliatis.

Petioli 6-10"' longi tomentosi; lamina folii basi attenuata vel subrotandata, elliptica, oblonga vel obovato-oblonga, argute cuspidata, in toto margine argute serrata serraturis (siccis uncinato-) mncronatis, superne ad lentem adpresse pilosa, subtus nervis tenuibus parallelis utrinque $24+30$ dense costata et in costis ferrugineo-hirta, membranacea, $2 \frac{1}{2}-6$ " longa, $1+2 \frac{1}{2}$ " lata. Panicula erecta $3-4-$ pollicaris, pyramidata, ramis horizontaliter patentibus tomentosis. Flores numerosissimi, in ramulis ultimis racemosi. Calyx et corolla glabra. 99. A esculus L.

171. Aesc. chinensis Bunge Enum. plant. chin. p. 10.

\section{4. (229. Endl.) ACERINEAE De Cand.}

100. Acer Linn.

a) foliis indivisis.

172. A. distylum S. et $\boldsymbol{Z}$. A. foliis e basi cordata ovatis acuminatis inaequaliter serrulatis penninerviis utrinque pubescentibus, racemis terminalibus subsimplicibus multifloris nutantibus, pedicellis calyce ovariisque villosis, stylis ad basin usque discretis papillosis, alis adscendentibus.

Folia in spece. nostris $2-3 \frac{1^{\prime \prime}}{2}$ longa, $1+2$ " lata; racemi sesquipollicares cylindrici; flores minuti.

173. A. carpinifolium S. et Z. Flor. jap. II. tab. 152. ined.A. foliis e basi rotundata ovato-oblongis acuminatis argute duplicatoserratis costato-penninerviis et praesertim subtus ad nervos pilosis, racemis paucifloris subcymosis, fructiferis erectis, calycis lobis ovatis obtusis dense ciliato-barbatis, stylo profunde bifido, pedicellis fructiferis elongatis filiformibus, alis divergentibus cultratis rotundatis glabris. 
Folia $2 \frac{1}{2}-5$ " longa, $1-2$ " lata, in apicem nsque serrata, membranacea, dense costata. Racemi terminales graciles $3-16$-flori; pedicelli praesertim fructiferi elongati filiformes glabri. Calycis lobi late elliptici longe ciliati. Stigmata subulata, papilloso-hirta.

174. A. crataegifolium S. et Z. Fl. jap. I. tab. 157 ined.

A. floribus coëtaneis, foliis e basi cordata vel ovatis acuminatis inaequaliter duplicato-serratis vel trilobis, lobis lateralibus abbreviatis intermedio producto, omnibus deltoideis inaequaliter serratis, novellis pubescentibus adultis glabris et subtus glancis, racemis simplieibus paucifloris erectis, petalis spathulatis calycem glabrum superantibus, carpellis et alis divaricatis.

Folia $1 \frac{1}{2}-2 \frac{1}{2}$ " longa, integra $10-15^{\prime \prime \prime}$, lobata inter lobos 20 rt $25^{\prime \prime \prime}$ lata, glabra subtus glauca. Racemi e ramulis lateralibns plerumque diphyllis terminales filiformes erecti sesquipollicares, 5 - -8 flori; pedicelli floriferi et fructiferi erecto-adpressi, filiformes; calycis laciniae oblongae obtusae glabrae, petalis spathulatis multo breviores. Ovarium glabrum. Carpella et alae glabra divaricata.

b) foliis lobatis.

175. A. rufinerve S. et Z. Flor. jap. II. tab. 158 ined. A. foliis e basi cordata palmato-tri-vel rarius quinquelobis argnte duplicato-serratis superne glabris subtus ad nervos lana rufa adspersis, Iobis lateralibus brevioribus, omnibns deltoideis acuminatis, racenis simplicibus erectis multifloris, floribus breviter pedicellatis, calycis laciniis oblongis quam petala obovata parum brevioribus ovarioque glabris, alis late cultratis rotundatis adscendentibus.

Flores subcoëtanei. Folia adulta longe petiolata petiolo fere bipollicari, lamina $5^{\prime \prime}$ longa et inter lobos lata, firma, subcoriacea. Racemi pollicares vel sesquipollicares, fructiferi 5 " longi, ereeti; pedicelli breves, firmi. Carpella subglobosa uti alae glabra.

176. A. micranthum S. et Z. Flor. jap. II. tab. 151 ined. A. foliis e basi cordata palmato-quinquelobis argute duplicato-serratis subiucisis utrinque glabris vel subtus in axillis venarum bar$20 *$ 
bulatis, lobis lanceolatis longe acuminatis, petiolis canalicnlatis laminam folii superantibus, racemis erectis simplicibus multifloris eylindricis, lobis calycinis rotundatis quam petala obovato-elliptica triplo brevioribus glabris.

Petioli 2-3" longi, graciles, canaliculati; lamina folii eircumscriptione suborbicularis, $2^{\prime \prime}$ circiter longa et inter lobos lata, 5-7nervia; lobi longissime acuminati et in apicem usque serrati, basin versus subincisi duplicato-serrati serraturis setaceo-acuminatis. Racemi terminales graciles multiflori, bi- et tripollicares, in specc. nostris tantum masculi. Flores praeter eos A. distyli congenerum minimi, serotini; pedicelli horizontaliter patentes, $2^{\prime \prime \prime}$ longi. Calyeis laciniae minimae rotundatae, petala obovato-spathulata.

177. A. japonicum Thunb. - A foliis e basi cordata orbicularibus palmato - $9-13$-lobis superne glabris vel novellis aeque ac perulae et pedunculi sericeis subtus pubescentibus, Iobis anterioribus omnibus aequilongis, posticis abbreviatis oblongis acutis inaequaliter duplicato-serratis, floribus coëtaneis in cymam erectam pancifloram congestis, calycis laciniis coloratis ovatis quam petala orbicularia triplo majoribus, ovariis hirsutissimis, carpellis glohosis, alis adscendentibus. - A. japonicum Thunb. Fl. jap. p. 162.- S. et Z. Fl. jap. II. tab. 154 ined.

Petioli pollicares. Lamina folii orbicularis cordaturae lobis conniventibus vel uno altero impositis, adulta 4 " longa et lata, novella aeque ac perulae sericea. Pedunculi erecti cymosi, cyma 5-10-flora. Calycis laciniae petaloideae rubrae ovato-ellipticae, quam petala orhicularia triplo longiores, glabrae. Ovarium sericeo-hirsutissimum. Stigmata erecta, arete sibi apposita. Carpella globosa, hirta, alae oblongae rotundatae adscendentes, glabrae.

178. A. pictum Thunb. - A. foliis e basi rectilinea (truncata) vel cordata orbicularibus glabris palmato- 5-7-lobis oblongodeltoideis acuminatis integerrimis intermedio parum productiore, infimis abbreviatis, cymis coëtaneis erectis multifloris, calycibus glabris 
quam petala unguiculata spathulata parum brevioribus, ovariis glabris, carpellis oblongis, alis cultratis oblongis erectis. - A. pictum Thby. Fl. jap. 162.

Variat $\alpha$. petiolis quam lamina folii duplo longioribus vel ea brevioribus.

$\beta$. lobis anguste deltoideis acuminatis vel fere ovatis longe cuspidatis dimidio laminae brevioribus.

$\gamma$. lobis lineari-lanceolatis longe acuminatis ultra dimidium laminae incisis.

A. laetum C: A. Meyer Enum. plant. Caucas. 206 et A. truncatum Bunge Enum. plant. clinens. p. 10. fide specc. orig. vix nisi floribus majoribus et fructuum aliis divaricatis diversa videntur.

179. A. trifidum Thunb. - A. foliis glabris subtus glancescentibus e basi truncata rotundata vel longissime cuneata integris oblongis acutis vel diverso modo tri-aut subquinquelobis, lobis integerrimis acutis vel serratis ant angulato-dentatis, aequilongis vel medio productiore, petiolis laminam aequantibus vel superantibus, floribus praccocibus vel coëtaneis cymosis, stylis ad basin usque discretis, alis cultratis erectis marginibus sibi invicem impositis. - A. trifidum T'hunb. Fl. jap. p. 163. Hooker ap. Beechey p. 174. Sieb. et Zucc. Fl. jap. II. tab. 153 ined.

\section{Variant folia:}

c. basi truncata, rotundata vel longissime cuneata, petioli simul in var. ulteriore laminam superantes, in reliquis aequantes.

$\beta$. circumscriptione integra oblonga acuta integerrima vel vario modo triloba, rarius sub-5-loba.

$\gamma$. lobis inaequalibus, intermedio longiore lateralibus divergentibus ad dimidium laminae usque incisis vel ex apice folii longe cuneati aequilongis deltoideis abbreviatis.

$\delta$. lobis integerrimis, serratis vel angulato-dentatis.

Sepala lanceolata, petala spathulata aequantia. Ovarium glabrum. Styli ad basin usque disjuncti, divaricati, papillosi. Carpella 
elliptico-subrhombea, alae cultratae erectae et marginibus se invicem obtegentes.

180. A. polymorpleum S. et Z. Flor. jap. II. tab. 155. 156. ined. - A. foliis e basi cordata vel rotundata ad vel ultra dimidiom vel in basin laminae usque palmatifidis 5-9-raro 3-lobis, lobis vel basi confluentibus yel discretis, sessilibus ant pedicellatis, lanceolatis brevioribus vel linearibus elongatis, argute simpliciter vel angulatoet duplicato-serratis vel pinnatifidis, laciniis ant integerrimis ant inciso-serratis, floribus coëtaneis cymosis, calycis lacinïs ciliatis petala rhombea superantibus, carpellis globosis alis brevibus rotundatis divergentibus.

Ad diversas varietates pertinent A. dissectum, palmatum et septemlobum Thunb. Fl. jap. p. 160-162.

Variant folia:

- c. basi rotundata vel cordata,

$\beta$. palmatifida vel ad basin usque palmata,

$\gamma$. palmatifida $5-9$ (rarius $3-$ ) loba,

d. palmata divisionibus $5-9$ basi vel confluentibus vel distinctis sessilibus vel pedicellatis,

£. lobis oblongis, lanceolatis vel linearibus elongatis,

ร. integerrimis, aequaliter vel inaequaliter et duplicato-serratis, incisis pinnatifidisve, laciniis lanceolatis vel linearibus adscendentibus vel scalatim patentibus, integerrimis vel serratis,

$\eta$. in eodem ramulo conformia vel circumscriptione et divisione diversissima.

9. viridia vel rubro-picta.

Folia novella pilosa. Cymae graciles subracemosae. Flores parvi calycis laciniis oblongis obtusis ciliatis quam petala obovatorhombea longioribus, ovariis glabris, stylis altra dimidium connatis, alis brevibus rotundatis divergentibus.

181. A. sessilifolium $\boldsymbol{S}$. et $\mathbf{Z}$. - A. foliis subsessilibus ternatis vel quinatis, foliolis pedicellatis e basi longe attennata cuneata 
vel rotundata oblongis vel lanceolatis incisis vel pinnatifidis, lobis argute simpliciter vel doplicato-serratis, floribus ... . . ...

Flores desunt sed species distinetissima foliis subsessilibus, petiolis vix $2^{\prime \prime \prime}$ longis, foliolis pedicellatis pedicellis $3^{\prime \prime \prime}$ longis vario modo incisis vel pinnatifidis.

182. 183. Species nondum determinatae.

Die Ahornarten sind seit den ältesten Zeiten Lieblingsbänme der japanischen Gartenkultur und eben desshalb mehrere derselben auch in Form, Färbung, Grösse u. s. w. der Blätter zu einer unendlichen Menge von Varietäten vervielfacht. Ein uns vorliegendes japanisches Herbarium zeigt über 30 verschiedene allmälig in einander übergehende Blattformen allein von A. polymorphum, unter welchen anch die scheinbar differentesten oft auf demselben $\mathbf{Z}$ weige vorkommen.

101. Negundo Mönch.

184. N. cissifolium S. et $\mathbf{Z}$. - N. foliis trifoliolatis, foliolis pedicellatis ovato-oblongis acuminatis grosse inciso-serratis vel rarius lanceolatis integerrimis glabris, racemis simplicibus erectis, floribus in pedicellis calyce brevioribus villosis, stylis ad basin usque discretis, alis (immaturis) lineari-ablongis apicem versus non dilatatis.

Recedit a specie americana foliolis multo minoribus grosse inciso-serratis serraturis mucronatis, racemis et fructiferis erectis, pedicellis primum vix lineam longis, alis aequilongis in dorso rectilineis anguste cultratis. - Folia, 1-1 $\frac{1}{2}{ }^{\prime \prime}$ longa, $6-12^{\prime \prime \prime}$ lata, ea Cissi referentia, intermedium plerumque longius pedicellatum. Racemi tripollicares.

\section{5. (227. Endl.) MELIACEAE Juss.}

\section{Melia Linn.}

185. M. Azedarach L.

186. M. Toosendan S. et Z. - M. foliis bipinnatis, 3-4jugis cum impari, pinnis $2-4$-jugis, foliolis pedicellatis e basi rotun- 
data lanceolatis acuminatis integerrimis utrinque glabris, paniculis axillaribus folio multo brevioribus divaricatis, fructibus globosis, pyreno osseo 6 - 8 -sulcato totidem loculari.

Ex imperio chinensi introducta dicitur. Folia sesquipedalia bipinnata, 3-4-juga cum impari; petiolus communis teres articulatus; pinnae $2-5$-jugae cum impari, $3-4$ " longae; foliola pedicellata pedicello $2-3^{\prime \prime \prime}$, lamina $12-15^{\prime \prime \prime}$ longa et $4-6^{\prime \prime \prime}$ lata. Flores albi tubo stamineo violaceo. Fructus globosi quam in M. Azedarach duplo triplove majores, carnosi, sordide flavescentes. Nucleus globosus, longitudinaliter $6-8$-sulcatus, $6-8$-locularis, seminibus oblongis compressiusculis.

\section{6. (226. Endl.) AURANTIACEAE Juss.}

\section{Aegle Corr.}

186. Aegl. sepiaria $L$. - Aegl. ramis flexuosis angulato-compressis spinosis, spinis basi compressis sursum subulatis validis axillaribus, foliis trifoliolatis, petiolo alato, foliolis omnibus sessilibus cuneatis, truncatis vel acutiusculis crenulatis coriaceis, floribus ex axillis spinarum sessilibus solitariis vel geminis, staminibus 20-30 liberis, antheris brevibus ovatis, ovario et stylo brevi cylindrico tomentosis, stigmate crasso clavato glabro. - Citrus trifolia Thunb. Flor. jap. p. 294. - Ssi vulgo Karatats banna, aliis Gees. Kämpfer Amoen. V. p. 801. c. ic.

Rami flexuosi, compressi et subangulati glabri. Folia alterna, petiolata petiolo semipollicari foliaceo-alato, trifoliolata; folia omnia sessilia e basi cuneata spathulata vel elliptica, truncata vel acutiuscula, crenata, glanduloso-punctata, pollicaria, 6"' lata. Spinae axillares, solitariae, persistentes divaricatae, basi compressae sursum teretes, acutissimae, validae, pollicares. Flores solitarii vel gemini, sessiles. Fructus globosus, magnitndine pomi, $6-8$-locularis, septis 
membranaceis, seminibus in quovis loculo pluribus biseriatis, in pulpam ut in Citris*) compositam immersis.

Vix cum Aegle Marmelos ejusdem generis.

104. Citrus L.

157. C. japonica Thunb. Flor. jap. p. 192. Sieb. et Zuccar. Fl. jap. I. p. 35. tab. 15 .

188. C. Aurantium $\boldsymbol{L}$.

189. C. Decumana $\boldsymbol{L}$. Petioli foliaceo-alati, ultra pollicem lati. Rami valde angulati tenuissime tomentosi. Semina figura varia, compressiuscula, marginata.

105. Skimmia Thunb.

190. S\%. japonica Thunb. Flor. jap. p. 4 et 62. Sieb. etZucc. Flor. jap. I. p. 127. tab. 68.

37. (225. Endl.) OLACINEAE Mirb.

106. Tripetaleia $\mathbf{S}$. et $\mathbf{Z}$.

191. Tr. paniculata S. et Z. in Act. Acad. Monac. Mathem. Phys. III. p. 731, tab. 3.

An revera hujus Familiae?

39. (223. Endl.) TAMARISCINEAE Desv.

107. Tamarix L.

192. T. chinensis Lour. Sieb, et Zucc. Flor. jap. I. p. 132. tab. 71. Tam. gallica Thunb. l. c. p. 126.

39. (220. Endl.) HYPERICINEAE Desv.

108. Hypericum $\mathbf{L}$.

193. H. patuhum Thunb. Fl. jap. p. 295. - H. glabrum, ramis strictis divaricatis, foliis subsessilibus lanceolatis utrinque attenuatis acutis margine revölutis subtus glaucis vel ferrugineis, floribus terminalibus plerumque ternis breviter pedunculatis bibracteatis, caAbhandlungen d. II. Cl. d. k. Ak. d. Wiss. IV. Bd. Abth. II. 
lycis foliis rotundatis, staminibus pentadelphis, stylis 5 patentibus obtusis.

Rami teretes, purpurascentes, glabri. Folia vix pollicaria, $3-5^{\prime \prime \prime}$ lata utrinque attenuata acuta, subtus glauca vel ferruginea, glabra. Capsula sicca, chartacea, 5-locularis, a vertice ad medium usque 5 -valvis.

194. H. sulicifolium S. et Z. - H. glabrum, ramis teretibus, foliis subsessilihus lanceolatis vel lineari-lanceolatis utrinque longe attenuatis acutis integerrimis subtus glaucescentibus, corymbo terminali dichotomo multifloro, pedunculis longis medio bibracteolatis, calycis foliolis lineari-lanceolatis acutis integerrimis eglandulosis, petalis dimidiato-obliquis, stylo filiformi, stigmatibus 5. - Hyp. monogynum Thunb. Fl. jap. p. 297.

Rami graciles. Folia $1 \frac{1}{2}-3^{\prime \prime}$ longa, $4-8^{\prime \prime \prime}$ lata, lanceolata vel lineari-lanceolata, utrinque attenuata. Corymbi multiflori flore solitario e dichotomiae angulo praecociori longissime pedunculato. Bracteae lineares; pedunculi laterales pollicares, graciles, stricti, medio bibracteolati bracteolis minutis. Calycis foliola aequalia. Corolla ultra pollicem diametro metiens, petalis inaequilateris et quasi dimidiatis. Stamina ima basi pentadelpha. Stylus longus, filiformis, stigmatibus brevibus subulatis. Cum $\boldsymbol{H}$. monogyno $\boldsymbol{L}$. praeter generis characterem nulla affinitas.

195. H. erectum Thunb. Flor. jap. p. 296. - H. herbaceum, glabrum, caule stricte erecto tereti, foliis sessilibus subamplexicaulibus lanceolatis acutiusculis margine subreflexis glabris subtus nigro-punctatis, floribus terminalibus corymbosis, calycis laciniis lanceolatis acutis integerrimis aeque ac petala nigro-lineatis, staminibus ima basi triadelphis, stylis 3 , stigmatibus capitatis.

Canlis herbaceus purpurascens superne tantum ramosus, ramis stricte erectis. Folia sessilia, amplexicanlia, lanceolata, acutiuscula, $\frac{1}{2}-1 \frac{1}{2}$ " longa, $3-6$ "' lata, ntrinque glabra, subtus nervata et praesertim in margine glandulis nigris punetata. Flores magnitudine 
circiter eorum $\boldsymbol{H}$. hirsuti, ex apice canlis ramorumque dichotomi et in corymbum planum congesti; calycis foliola ovato-lanceolata acuta vel obtusa integerrima glabra, aeque ac petala lineolis inaequalibus nigris notata.

196. H. japonicum Thunb. Flor. jap. p. 295. - H. caule herbaceo debili adscendente tetragono ramoso, foliis sessilibus amplexicaulibus ovatis vel suborbicularibus obtusis $3-5$-nerviis glabris glaucescentibus, minutim pellucide punctatis, quam internodia brevioribus, floribus in apice caulis ramorumque dichotomis breviter pedicellatis, calycis foliolis lanceolatis acutis integerrimis glabris eglandulosis, stylis 3 brevibus, stigmatibus capitato-truncatis.

Caulis herbaceus circiter pedalis adscendens, basi simplex superne ramosus. Folia amplexicaulia ovata vel suborbicularia obtusa glabra glaucescentia, ad lentem pellucide punctata, 3-4"' longa, $2^{\prime \prime \prime}$ lata, 3-5-nervia. Flores dichotomi, ramis dichotomiae (abortn) racemosis, singuli breviter pedunculati, bractea lineari pedicello breviore suffulti, magnitudine circiter ut in $\boldsymbol{H}$. humifuso.

\section{0. (217. Endl.) TERNSTROEMIACEAE De Cand.}

109. Ternströmia Nutt.

197. T. japonica S. et Z. Fl. jap. p. 148. tab.80. - Cleyera japonica Thunb. Flor. jap. p. 224 et Aut.

110. Eurya Thunb.

198. E. japonica Thunb. Flor. jap. p. 191.

199. E. littoralis Sieb.

200. E. microphylla Sieb.

201. E. uniflora Sieb.

202. E. hortensis Sieb.

203. E. montana Sieb. 
111. Cleyera Thunb.

204. Cl. japonica Thunb. Fl. jap. p. 12. (non p. 224 et Act. Linn.) Sieb. et Zuccar. Flor. jap. I. p. 153. tab. 81.

205. Cl. Mertensiana Sieb. et Zucc. l. c.p. 154.

112. Stuartia Catesb.

206. St. monadelpha S. et Z. I. c. p. 181. t. 96.

113. Camellia Linn.

207. C. japonica L. Sieb. et Zuccar. l. c. p. 155. t. 82.

208. C. Sasanqua Thunb. Sieb. et Zuccar. l. c. p. 158. t. 83.

114. The a Linn.

209. Th. chinensis $\mathbf{L}$.

115. Trochostigma $\mathbf{S}$. et $\mathbf{Z}$.

210. Tr. rufa S. et Z. Act. Acad. Monac. Phys. Mathem. III. p. 727.

211. Tr. arguta S. et Z. I. C.

212. $\boldsymbol{T}$ r. repanda $\mathbf{S}$. et $\boldsymbol{Z}$. $t$. $\boldsymbol{c}$.

213. Tr. polygama S. et Z. l. c. p. 724. tab. II. 2.

214. Tr. volubilis S. et Z. l. c. p. 728.

An potius Dilleniaceis adscribendum genus?

\section{1. (214. Eindl.) TILIACEAE Juss.}

116. Corchoropsis $\mathbf{S}$. et $\mathbf{Z}$.

215. C. crenata S. et Z. Act. Acad. Monac. Mathem. Phys. III. p. 738, tab. IV. 1.

117. Tilia Linn.

216.217. Species ab europaeis certe diversae, sed specimina manca.

118. Elaeocarpus Linn.

218. El. photiniaefolius Hooker in Beechey Bot. p. 259. t. 53.

Antherae totae setulis parvis echinulatae, sed in specc. nostris apice non expresse barbulatis. 
219. El. japonica S. et Z. $\quad$ E. polygama, folis longe petiolatis ellipticis vel oblongis cuspidatis vel acuminatis acumine obtuso, serrato - crenatis glabris subtus minutim glanduloso-pilosis et in axillis venarum inferiorum glandula pertusa munitis, racemis axillaribus secundis multifloris simplicibus, calycis foliolis lineari-lanceolatis petala oblonga apice bi - trifida aequantibus et cum his hirtis, antheris apice bivalvibus echinulatis, ovario styloque hirtis, stigmate 2-3-crenato, drupa elliptica glabra abortu monosperma.

Petioli pollicares vel sesquipollicares, eglandulosi; lamina elliptica vel oblonga, $1 \frac{1}{2}-4^{\prime \prime}$ longa, $10-15^{\prime \prime}$ lata, subtus glandulis minutis nigris piliferis ohsita et in axillis venarum inferiorum glandulas sacculiformes apice pervias ferens. Racemi axillares, petiolo longiores; pedicelli pubescentes. Flores masculi nintantes; petala utrinque hirsuta, apice truncata, bi- rarius trifida; stamina $10-15$; discus carnosus, 10-crenatus hirtus; ovarii rudimentum brevissimum; in floribus hermaphroditis ovarium globosum 2-3-loculare, hirtum; stylus hirtus stigmate 2-3-dentato. Drupa glabra, elliptica, magn. ejus Vib. Opuli, carnosa, abortu monopyrena; pyrenum osseum, uniloculare, monospermum.

Adnotatio. In Elaeocarpeis pubescentia simplex, in veris $\mathbf{T i -}$ liaceis stellata.

\section{2. (213. Endl.) BUETTNERIACEAE $\boldsymbol{R}$. Br.}

119. Pentapetes L.

220. P. phoenicea $\boldsymbol{L}$.

43. (212. Endl.) STERCULIACEAE Vent.

120. Sterculia L.

221. Sterculiae species.

44. (221. Endl.) MALVACEAE Juss.

121. Malval.

222. M. mauritiana $\boldsymbol{L}$. ? 
223. M. ruderalis Blume Bijdr. II. p. 64.

122. Urena L.

224. U. morifolia DC. ?

123. Hibiscus $\mathbf{L}$.

225. H. Hamabo S. et Z. Flor. jap. I. p. 176. t. 93.

226. H. mutabilis L.?

227. H. syriacus $\mathbf{L}$.

124. Gossypium L.

228. G. herbaceum Thunb. An G. siamense Fisch.

\section{5. (210. Endl.) PHYTOLACCEAE De Cand.}

125. Phytolacea Tournef.

229. Ph. octandra $\boldsymbol{L}$.

46. (209. Endl.) CARYOPHYLIEAE De Cand.

126. Stellaria L.

230. St. undulata Thunb. Flor. jap. p. 185. - Pedunculi filiformes, folio longiores. Calycis foliola lineari-lanceolata acuminata uninervia; petala dimidio breviora, bifida. - Specimen mancum.

127. Dianthus L.

231. D. japonicus Thunb. Flor. jap. $p .183$.

232. D. chinensis $\boldsymbol{L}$.

233. D. caryophyllus L.?

234. Species nondum determinata.

128. Silene L.

235. S. firma S. et Z. - S. caule simplici erecto stricto glabro folioso, foliis e basi attenuata oblongis vel lanceolatis acutis margine crenulato-scabriusculis subtrinerviis coriaceis firmis, summis linearibus, floribus racemosis subverticillatis stricte erectis, laciniis calyeinis deltoideis acutis margine late membranaceis, tubo glabro tenuiter 
15-nervio sed non striato, petalis bifidis calycem aequantibus, semiuibus parvis reniformibus echinulatis.

Caules strictissimi, obtuse quadrangulares. Folia internodiis semipollicaribus duplo triplove longiora, basi longe attenuata, oblonga vel lanceolata, acuta coriacea, rigida, erecta. Racemi semipedales, stricti; flores oppositi vel e quavis axilla terni indeque subverticillati, stricte erecti. Flores parvi, albi vel rosei (?); petala calycem aequantia bifida; stamina et pistillum inclusa.

129. Lychnis De Cand.

236. L. grandiflora Jacq. Sieb. et Zuccar. Flor. jap. I. p. 97. tab. 48. - L. coronata Thunb. Fl. jap. p. 187.

237. L. Senno S. et Z. l. c. p. 98. tab. 49, - L, chalcedonica Thby. l. c. p. 188.

47. (208. Endl.) POR'TULACACEAE Juss.

130. Portulaca Tournef.

238. P. oleracea $\boldsymbol{L}$.

131. Tetragonia $\mathbf{L}$.

239. T. expansa Ait. - T. japonica Thunb. jap. p. 208.

48. (260. Endl.) CACTEAE De Cand.

132. Opuntia Tournef.

240. O. species non satis nota. Cactus Ficus. Thunb. Flor. jap. p. 198.

49. (205. Endl.) BEGONIACEAE $\boldsymbol{R} . \boldsymbol{B}$. 133. Begonia $\mathbf{L}$.

241. B. grandis Dryand. - B. obliqua p. 231.

50. (204. Endl.) CUCURBITACEAE Juss.

134. Bryonia L.

242. Br. japonica Thunb. Fl. jap. 325. 


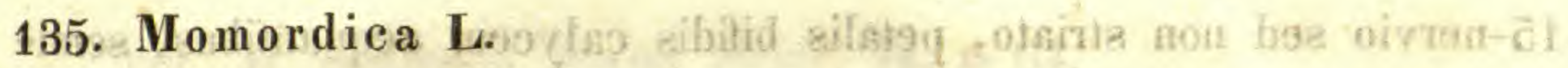

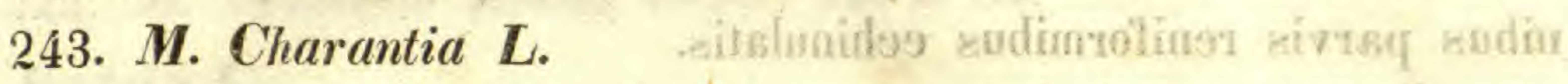
136. Luffa Tourn. 244. L. foetida Cav.

137. Lagenaria Ser.

245. L. vulgaris Ser.

138. Cucumis L.

246. C. Melo $\boldsymbol{L}$.

247. C. sativus $\boldsymbol{L}$.

248. C. Conomon Thbg.

249. C. flexuosus $\boldsymbol{L}$.

250. C. Colocynthis L.

139. Cucurbita Linn.

251. C. Pepo L.

252. C. Citrullus $\boldsymbol{L}$.

253. C. hispida Thbg.

140. Trichosanthes $L$. bas? od efudozy test

254. Tr. anguina $\boldsymbol{L}$.

255. Tr. cucumerina L. Thatrong (Jhist .09s)

141. Sicyos L.

256. S. angulata $\boldsymbol{L}$.

51. (199. Endl.) PASSIFLOREAE Juss.

142. Passiflora L.

257. P. coerulea $\boldsymbol{L}$.

52. (197. Endl.) BIXACEAE Lindl.

143. Hisinger a Hellen.

258. H. japonica Sieb. et Zucc. Hl. jap. I. p. 169. t. 88. 100. 


\section{3. (192. Endl.) ViOLARIEAE De Cand.}

\section{Viola L.}

259. $\boldsymbol{V}$. canina $\boldsymbol{L}$.

Clár. De Candolle folia in specc. japonicis ex herb. Lambert, vidit basi vix cordata, in nostris vero folia sunt profunde cordata et utrinque lineolis daedaleis minutissimis badiis densissime obsita, quae in specc. europaeis pallidiores et minus distinctae observantur.

Praeterea 11 species nondum accuratius examinatae.

\section{4. (191. Endl.) DROSERACEAE De Cand.}

145. Drosera L.

Species duae.

146. Parnassia Tournef.

260. P. mucronata S. et Z. - P. appendicibus $9-13$-fidis e basi late cuneata ovario longioribus, calycis foliolis acutis, folio caulino sessili e basi cordata suborbiculari mucronato, radicalibus late cordatis acutis, omnibus dense ferrugineo - punctatis.

Proxima P. palustri differt foliolis calycinis acutis, nectarii squamis longioribus et setis ovarium superantibus, foliis omnibus mucronato - acutis.

Adnotatio. Omnes fere Parnassiae species in foliis et in calyee punctis lineolisque ferrugineis (in P. mucronata et palustri optime conspicuis] densissime adspersae sunt.

\section{5. (189. Endl.) NELUMBONEAE Bartl.}

147. Nelumbium Juss.

261. N. speciosum Willd. - Nymph. Nelumb. Thunb, Flor. jap. $p .223$.

\section{6. (187. Endl.) NYMPHAEACEAE Salisb.}

148. Euryale Salisb.

262. E. ferox Salisb.

Abhandlungen d, II. Cl. d. k, Ak, d. Wiss. IV. Bd. Abth. II. 
149. Nymphaea Neck.

Species 2 nondum determinatae.

150. Nuphar Smith.

263. N. japonica DC. - Nymph. lutea Thbg. Fl. jap. p. 223. Folia ovato-oblonga obtusa, basi sagittata lobis recte descendentibus acutis vel obtusis, cordaturae angulo acnto. Flores quan in N. Intea nostrate minores. Stigmata erecta $12-15$.

Species altera nondum determinata.

57. (184. Endl.) CAPPARIDEAE Juss.

151. Gynandropsis DC.

264. G. viscida Bunge Enum. plant. chin. p. 7. (?)

\section{8. (183. Endl.) CRUCIFERAE Juss.}

152. Nasturtium DC.

265. N. amphibium DC. - Sis. amphibium Thby. Flor. jap. p. 260 fide cl. De Cand.

266. N. officinale R. Br. - Sisymbr. Nasturtium Thbg. Flor. jap. p. 260.

153. Cardamine DC.

267. C. scutata Thbg. Act, Linn. Card. trifolia Thbg. Fl. jap. p. 260.

\section{Draba DC.}

268. Dr. nemoralis Ehrh. - Dr. muralis Thbg. Flor. jap. p. 259 (fide cl. De Cand.)

155. Capsella Mönch.

269. C. Bursu Pastoris Mönch.

156. Brassica DC.

270. Br. chinensis $\boldsymbol{L}$ - Br. orientalis Thby. Flor. jap. p. 261. 
157. Sinapis Tourn.

271. S. cernue Thbog. Fl. jap. 1. c.

272. S. japonica Thby. Fl. jap. p. 261.

158. Raphanus $\mathbf{L}$.

273. R. sativus. $\boldsymbol{L}$.

Die japanischen Cruciferen, im v. Sieboldschen Herbarium beilänfig 30 an der Zahl, unterliegen noch genauerer Bearbeitung.

\section{9. (182. Endl.) PAPAVERACEAE Juss.}

\section{a. Papavereae.}

159. Papaver Linn.

274. P. somniferum L.

Specimina prostant tam floribus simplicibus quam plenis.

275. P. Rhoens L. - Fide clar. Thunberg.

160. Chelidonium L.

276. Ch. majus $\boldsymbol{L}$.

A planta europaea nullo modo diversum.

277. Ch. uniflorum S. et $\boldsymbol{Z}$. - Ch. foliis inferioribus pinnatisectis bijugis cum impari, summis ternatisectis, segmentis subsessilibus ovato-oblongis acutis inaequaliter argute serratis vel rarius incisis glabris, floribus axillaribus subsolitariis pedunculatis, calycis foliolis aristatis, siliqua polysperma cylindrica, stigmatibus divergentibus. Chel. japonicum Thunb. Fr. jap. p. 221 et Aut.

Descriptio Thunbergiana in plantam nostram bene quadrat, at serraturae foliorum nunquam ciliatae et segmenta terminalia lateralibus non majora. Folia radicalia non visa. Canlina petiolata imparipinnata bijuga, segmentis lateralibus subsessilibus vel breviter petiolatis, infunis soepius abbreviatis: summa ternati-secta, omnia vel in aequaliter argute serrata vel rarins simul pinnatifida. Flores axillares pedunculati, pedunculo nudo tenui quam folium breviore. Sepala caduca, ovata, aristata, virentia. Corolla pollicaris patens, petalis e 
basi cuneata late obovatis rotundatis. Stamina numerosa petalis quadruplo breviora, pistillum aequantia. Siliqua longe pedunculata cylindrica tenuis, sursum attenuata, pollicaris, stigmatibus dnobus linearibus divergentibus.

\section{b. Fumarieae. (Fumariaceae DC.)}

161. Pteridophyllum S. et Z. Act. Mathem. Physic. Monac. III. p. 719. tab. 1.

278. Pt. racemosum S. et Z. 1. c.

162. Eucapnos S. et Z. l. c. p. 271. tab. 1.

279. E. spectabilis S. et Z. - Fumaria spect. Limn. Amoen.

7. p. 457 et Aut. - Corydalis spectabilis Persoon Enchir. II. p. 269. - Dielytra spectab. De Cand. Syst. II. p. 110. Prodr. I. p. 126.

Recedit a Dielytra filamentis cujusvis phalangis exterioribus in basi libera late alatis, intermedio angusto ecalcarato. Caulis foliosus.

163. Dicentra Borhh. - Dielytra De Cand.

280. D. pusilla S. et Z. - D. scapo nudo bi-trifloro, calcaribus brevibus rotundatis, pedicellis calyce deltoideo acuto longioribus, foliis pluries ternati-sectis, laciniis ultimis anguste linearibus acutis glancis.

Proxima D. lachenaliaeflorae Ledeb. recedit statura minori, floribus multe majoribus, calcaribus magis prominentibus, foliorum segmentis ultimis angustioribus et dimidio hrevioribus.

164. Corydalis De Cand.

281. C. ambigua Cham: et Schlchtdl.

Specimina japonica, cum kamtschaticis, quae ab Eschscholzio lecta vidi in herb. clar. Ledebour, optime conveniunt. Squama in basi eanlis folium vel soepius ramum unum duosve floriferos profert. 282. C. decumbens Pers. - C. radice tuberosa, foliis radicali- 
bus pluribus biternatis, segmentis ovatis incisis lobis ovato-oblongis vel oblongis obtusis mucronulatis, canlibus soepius pluribus ex eadem radice decumbentibus vel erectis, simplicibns basi nudis absque squama, superne diphyllo foliis alternis quam radicalia minoribus, lobis angustioribus soepe acutis, racemo laxo panci- $(3-6-)$ floro, bracteis ovato-rhombeis acutis pedicello duplo brevioribus, calcare recto obtuso tubi partem superiorem aequante. - Fumaria bulbosa Thby. Fl. jap. p. 277. - Fum. decumbens Thbg. Nov. Act. Petrop. 12. p. 102, tab. A. * Willd. Spec. plant. III. p. 862. Corydalis decumbens Pers. Enchir. II. p. 269 et rel. Aut.

Caulis soepe erectus, spithameus. Flores in spece. siccis non lutei sed rubri videntur.

283. C. incisa Pers. - C. caule erecto simplici vel ramoso, foliis inferioribus triternato-sectis vel subdecompositis, segmentis ultimis ovatis vel oblongis inaequaliter inciso-dentatis lobis acutis, racemo multifloro, primum denso fructifero elongato, bracteis inferioribus ovatis incisis, superioribus lineari-oblongis serratis omnibus quam pedicelli brevioribus, calcare recto obtuso, tubi partem superiorem aequante, siliquis linearibus planis, stigmatis lobis orbicularibus, seminibus laevibus. - Fum. incisa Thunb. Act. petrop. l. c. p. 104. t. U. - Willd. Specc. II. p. 859. - Coryd. incisa Pers. Enchir. II. p. 269. De Cand. Syst. Veget. II. p. 121. Prodr. I. p. 127.

Caulis soepe ramosus ultra pedalis. Folia is Petroselini sativi similia. Racemi floriferi pollicares vel bipollicares inferne laxi superne densi, bracteis infimis multifidis; pedicelli filiformes, floriferi $6-9^{\prime \prime \prime}$ longi, fructiferi soepe ultra pollicares.

\section{C. heterocarpa S. et $\mathbf{Z}$.}

Caule erecto ramoso, foliis bipinnato-sectis, segmentis cuneatooblongis incisis lobis lineari-oblongis mucronatis, racemis laxifloris, bracteis integris lineari-subulatis quam pedicelli longioribus, calcare quan tubi pars superior multo breviore, siliquis vel late linearibus rectis planis brevioribus vel subarcuatis inter senina lomentaceo- 
constrictis, stigmatis lobis oblongis apice callosis, seminibus dense muricatis. - Fum. racemosa Thbg. Act. Petrop. l. c. p. 103. tab. B. * (?) - Coryd racemosa Pers. et Aut. - Hooker ap. Beechey l. c. $p .258$.

Brevis Thunbergi descriptio cum planta nostra bene convenit, sed bracteae quamvis pedicellis sub anthesi $3-4^{\prime \prime \prime}$ metientibus longiores eos vix dimidio nec triplo superant. Siliquae difformes in eodem racemo, aliae lineares rectae breviores, aliae inter semina fomenit in modum constrietae curvatae longiores. Semina dense et tenuiter muricata.

ner 285. C. pallida Pers. - Caule ereeto vel decumbente ramoso, foliis bipinnati-sectis segmentis oblongis pinnatisectis, Iobis linearioblongis obtusis mucronulatis glancescentibus, racemis laxis $10-12-$ floris, bracteis inferioribus cuneatis incisis, superioribus linearibus dentatis, omnibus quam pedicelli longioribus, siliquis linearibns arcuatis subtornlosis, stigmatis lobis divaricatis linearibus, seminibus dorso tenuiter muricatis ceterum elevato-punctatis. Hum. lutea Thbg. Flor. jap. p. 277. Fum pallida Thbg. Act Petrop. l. c. p. 103. t. C. * Coryd. pallida Pers. Enchir. II. p. 270 et Aut.

Caulis in specc. robustis pedalis erectus strictus, in debilioribus flaceidus vel decumbens, ramosus. Tota planta glancescens; foliorum lobi parvi lineari-oblongi obtusi cun mucrone, rarius acuti. Flores pallide flavi, calcar rectum vel subcurvatum rotundatum, tabo coroltae brevius.

286. C. lineariloba $\mathbf{S}$. et $\mathbf{Z}$. - C. radice tuberosa, caule diphyllo absque squama, foliis alternis petiolatis triternato-sectis, lobis ultimis linearibus acuminatis integerrimis, racemo panci- (2-3-) floro, bracteis late ovatis incisis, quam pedicelli filiformes brevioribus, calcare recto obtuso tubum superante.

9roxima C. angustifoliae $\boldsymbol{D} e$ Cund. recedit ab hac squama in caule nulla, foliis triternato-sectis lobis angustioribus soepe subfalcatis, floribus minoribus. 
287. C. orthoceras S. et $\mathbf{Z}$. - C. radice tuberosa, canle basi squama munito ef ex ejusdem axilla soepe ramoso ceterum simplici diphyllo, foliis alternis biternati-sectis, lobis ultimis linearibus (rarius bifidis) sessilibus utrinque attenuatis acutis, bracteis cuneato-obovatis incisis pedicello filiformi parum brevioribus, calcare recto obtuso quam tubus longiore, rudimento secundi calcaris opposito.

Caulis vix spithamaeus, ex axilla squamae plerumque ramo auctus; folia caulina duo, lobis linearibus soepe 1" longis.

Flores e minoribus, calcare stricte retrorsum spectante recto obtuso, rudimento secundi calcaris brevi e basi petali oppositi.

\section{0. (181. Endl.) BERBERIDEAE Vent.}

165. Berberis Linn.

288. B. Thunbergii De Cand. - B. cretica Thunb. Fl. jap. p. 146.

Pedunculi uni - sexflori. Flores parvi. Folia obovato-spa- thulata integerrima.

289. B. sinensis Desfr.? - B. vulgaris Thbg. Flor. jap. l. c.

290. B. japonica S. et Z. - Mahonia japonica De Cand. Ilex japonica Thunb. Fl. jap. p. 79 et Icones tab. 12.

Folia trijuga; foliola valde spinoso-dentata lanceolata praeter terminale sessilia utrinque glabra. Racemi terminales, simplices. 166. Nandina Thunb.

291. N. domestica Thunb. Fl. jap. p. 9 et 147.

167. Epimedium L.

292. E. Muschianum De Caisne.

293. E. macranthum De.Caisne.

294. E. violaceum De Caisne.

168. Aceranthus De Caisne.

295. A. diphyllus De Caisne. L Epim. diphyllum Lodd.

296. A. sagittatus $\mathbf{S}$. et $\mathbf{Z}$. A. canle stricte erecto, foliis 
caulinis duobus suboppositis longe petiolatis ternatis, foliolis pedicellatis e basi acute sagittata deltoideis acuminatis in toto margine setoso - ciliatis, racemo inter folia terminali cylindrico composito multifloro.

Caulis pedalis stricte erectus glaber. Folia duo subopposita, inferioris petiolo superiorum amplectente, longe petiolata erecta, ternata. Foliola pedicellata pedicellis pollicaribus, basi sagittata lobis acutis, deltoidea acuminata setoso-ciliata glabra. Racemus terminalis erectus tripollicaris compositus, pedunculis horizontaliter patentibus trifloris, floribus pedicellatis.

\section{1. (180.) RANUNCULACEAE De Cand.}

\section{Clematis DC.}

297. Cl. paniculata Thbg. Act. Linn. II. p. 337. - Cl. crispa Thbg. Flor. jap. p. 239.

Carpella glabra, caudae plumosae duplo longiores.

298. Cl. apiifolia DC:- Hooker ap. Beechey l. c. p. 258. -Flores paniculati, parvi, hermaphroditi. Sepala extus sericea intus glabra. Proxima Cl. brevicaudatae DC., sed in hac flores minores, in panicula foliosa numerosiores et folia firmiora.

299. Cl. triternata DC. Cl. virginica Thby. Fl. jap. p. 240. - Pedunculi folio breviores longioresve, corymboso-paniculati. Foliola trinervia acuta vel obtusa. Folia summa inter flores breviter petiolata integra elliptica, oblonga vel sublinearia.

300. Cl. japonica Thby. Flor. jap. p. 240. - Caulis adultus lignescens tenuis sordide stramineus. Petioli soepe cirrhosi. Folia e ramulis lateralibus abbreviatis subfasciculata, pubescentia. Flores solitarii vel gemini, nutantes, pedunculo quam folia breviori, habitu Atrag. alpinae sed dimidio minores. Filamenta dense hirsuta.

301. Cl. florida Thunb. Fl. jap, p. 240. - Variat quam maxime circumscriptione foliolorum, quae basi rotundata vel subcordata, ovata, lanceolata, obtusa, acuta, vel acuminata, simplicia vel trifida. Aequo 
modo flores variant simplices vel vario modo pleni; numerus sepalorum in floribus simplicibus variat inter 5 et 8 . Carpella plurima, sericeo-hirta, caudae longissimae sesquipollicares plumosae. - An Cl. patens De Caisne Bullet. de l'Acad. de Bruxelles 1836. n. 5. hujns varietas?

302. Cl. stans $\mathbf{S}$. et Z. - Cl. fruticosa erecta dioica; ramis novellis angulatis, foliis oppositis longe petiolatis ternatis, foliolis lateralibus subsessilibus, terminali longe pedicellato, omnibus e basi rotundata vel late cuneata obovatis repente acuminatis grosse et inaequaliter inciso-serratis, subtrilobis, molliter pubescentibus, floribus terminalibus dichotome racemoso-paniculatis, rachi sepalisque linearibus albido-tomentosis, floribus masculis $12-15$-andris, pistillorum rudimento minimo.

Rami adultiores stricte erecti, cortice papyraceo solubili, novelli uti foliola molliter pubescentes; petioli subsemipedales; folia ternata, foliola pro ratione congenerum maxima, $2 \frac{1}{2}-3$ " longa et lata, lateralia subsessilia basi subinaequalia, terminalia in pedicello $1 \frac{1}{2}-2$-pollicari, magnitudine inter se subaequalia, grosse et inaequaliter incisoserrata, soepins subtriloba lobis et serraturis breviter acuminatis; flores terminales remote et dichotome racemoso-paniculati, extus albido-tomentosi, in specc. nostris nondum aperti.

303. Species nondum determinata.

170. Thalictrum L.

304. T\%. rubellum S. et Z. - Th. foliis tripinnatisectis, segmentis e basi rotundata late ovatis inciso-dentatis lohis acutis, stipellis binis rotundatis ad ramificationum basin, panicula corymbosa multiflora, filamentis apice dilatatis anthera latioribus, carpellis $8-10$ stipitatis triquetris, stigmatibus sessilibus.

Proximum Th.aquilegifolio, sed tota planta glaucescenti-rubens; lobi foliorum acuti, segmenta superiorum anguste lanceolata utrinque attenuata.

Abhandlungen d. II. Cl. d. k. Ak. d. Wiss. IV. Bd. Abth. II. 
305. Th. acteaefolium S. et Z. - Cl. stipellis nullis, foliis triternatis, foliolis pedicellatis e basi rotundata vel cordata ovatosuborbicularibus, grosse inciso-dentatis dentibus latis obtusis vel acutiusculis mucronatis, subtus glancescentibus nervosis, panicula divaricata subcorymbosa nuda, floribus hermaphroditis longe pedunculatis, filamentis filiformibus, antheris muticis, carpellis binis ternisve sessilibus sulcatis stylo recto apice uncinato aristatis.

Planta gracilis; foliola pro ratione magna, subtus glancescentia et nervosa; rami paniculae corymbosae divaricato-patulae tenues nudi.

306. Th. hypoleucum S. et Z. - Th. stipellis nullis, foliis inferioribus bi- vel triternatis, foliolis subsessilibus ellipticis basi attenuatis obtusis mucronatis vel rarius dentato-trilobis, subtus alboglaucescentibus, glabris, panicula pyramidata patula subfoliosa, staminibus $15-20$, antheris mucronatis, carpellis sessilibus, plerumque 5 sulcatis, stigmate sessili crasso coronatis.

Folia iis Bönninghauseniae hand dissimilia, subtus rore albido obducta. Rami panículae tenues, patentes subfoliosi, flores e minoribus.

307. Th. affine Ledeb. Flor. ross. I. p. 10.

308. 309. Species nondum determinatae. Ex his Th. flavum Thunb.

\section{Anemone DC.}

310. A. cernua Thbg. Fl. jap. p. 238. - Sieb. et Zucc, Flor. jap. I. pag. 14. tab. 4.

311. A. japonica S. et Z, Flor. jap. I. pag. 15. tab. 5. Atragene japonica Thunb. Fl. jap. p. 239. - Clematis? polypetala De Cand. Prodr. I. p. 10.

312. A. umbrosa Ledel.

313. A. altaica Fisch.

Planta japonica differt foliorum dentibus obtusis. 


\section{A. baikalensis Turcz.}

Recedit involucri foliis magis incisis, lobis angustioribus, linearibus. Flores et in specc. sibiricis magnitudine variant.

315. A. narcissiflora $\boldsymbol{L}$.

316. A. dichotoma $\boldsymbol{L}$.

317. A. Hepatica Gort.

172. Adonis L.

318. A. sibirica Patrin. - A. apennina $\beta$. sibirica Aut.

173. Ranunculus L.

319. R. japonicus Thbg. Act. Linn. II. p. 337. - R. asiaticus Thbg. Flor. jap. p. 241.

Nulla cum R. asiatico affinitas. Radix fibrosa. Carpella compressa glabra brevissime mucronulata.

320. R. ternatus Thbg. Fl. jap. p. 241.

Flores flavi. Carpellorum rostrum uncinatum. Cum R. aconitifolio nulla affinitas.

321. R. auricomus Thbg. Fl. jap. p.?

Specimina nostra manca, sed vix species Linneana.

322. R. sceleratus $\boldsymbol{L}$.

A planta europaea nullo modo diversus, nam carpella in specc. nostris japonicis non in spicam oblongam sed in capitulum disposita eodem modo in planta germanica variant.

323. 324 . Species nondum determinatae.

174. Caltha L.

325. C. palustris $\boldsymbol{L}$.

Var. floribus minoribus.

175. Trollius L.

326. Species ob specimen mancum nondum definita.

176. Copt is Salisb.

327. C. trifolia Salisb. 
328. C. brachypetala S. et Z . C Coliis biternatim sectis, segmentis pinnatifidis, lobis pinnatifidis vel inciso-serratis, inferioribus saepius pedicellatis, serraturis acutissimis, scapo tri - quadrifloro, floribus longe pedunculatis, sepalis linearibus acutis demum reflexis quam stamina vix dimidio longioribus, petalis unguiculatis breviter cucullatis ellipticis acutis subcanaliculatis exappendieulatis, antheris oblongis vel ellipticis utrinque obtusis.

Habitus omnino ut in C. asplenifolia DC., sed segmenta foliorum profundius incisa lobis plerumque angustioribus et minoribus. Scapus 3-4-florus floribus longe pedicellatis erectis vel patentibus. Calycis foliola linearia acuta patentia vel reflexa, staminibus vix dimidio longiora; petala unguiculata, lamina breviter cucullata subcarnosa elliptica mucronata parum canaliculata exappendiculata; staminibus breviora vel ea subaequantia; antherae oblongae vel ellipticae obtusae. In C. asplenifolia contra, sepala sunt angustissime linearia stamina plus quam triplo superantia, petala unguiculata in áppendicem elongatam filiformem reflexam extensa indeque staminibus plus quam duplo longiora, antherae suborbiculares, emarginatodidymae.

De Candolle zieht Thalictrum japonicum Thbg. Act. Linn. II. p. 337. (Didynamista Salviae similis Flor. jap. p. 364. nach Thunberg's eigner Angabe) auf Smith's Antorität zu C. asplenifolia. Es gehört aber unzweifelhaft zu obenstehender Art.

329. C. anemonaefolia $\mathbf{S}$. et $\mathbf{Z}$. - C. foliis ternati-sectis, segmentis pedicellatis circumscriptione ovatis vel oblongis pinnatifidis, lobis basi confluentibus vel subdecurrentibus oblongis inaequaliter inciso-serratis, serraturis argute-mueronatis, scapo tri - quadrifloro, floribus breviter pedunculatis, sepalis lineari-lanceolatis acutis demum reflexis quam stamina dimidio longioribus, petalis unguiculatis lamina breviter cucullata lanceolata acutiuscula canaliculata crassa, quam stamina brevioribus, antheris ellipticis obtusis.

Differt a praecedente foliis simpliciter ternati-sectis, segmentis 
multo majoribus minus incisis, floribus breviter pedunculatis, petalis angustioribus profunde canaliculatis et fere complicatis. Variat foliolorum lobis angustioribus vel latioribus basi vel ad rachin usque distinctis et decurrentibus vel latioribus jam $\frac{1}{3}$ a rachi confluentibus. 330. Species nondum determinata.

\section{Isopyrum Linn.}

331. Is. japonicum S. et $\boldsymbol{Z}$. - I. caule herbaceo gracili erecto ramoso folioso, foliis radicalibus petiolatis subbiternatis, segmentis primariis pedicellatis e basi cuneata obovatis profunde tripartitis, lobis cuneato-oblongis vel obovatis inciso-dentatis dentibus obtusis, foliis canlinis sessilibus ceterum conformibus, floribus longe pedunculatis, petalis quam sepala lanceolata dimidio brevioribus cucullatis, labio majore rotundato, brevissime calcaratis, staminibus $12-15$, carpellis quatuor erecto-conniventibus, seminibus pluribus biseriatis oblongis granulatis.

Ipsorum adoxoides DC. Prodr. I. p. 48. (Isop. capnoides, Fisch.) gehorrt vermuthlich zu unserer Pflanze, ist aber so unvollständig beschrieben, dass wir dennoch glaubten, einen andern Namen wählen zu müssén.

178. Anemonopsis Sieb. et Zuce. Tab. I. A.

Calyx polyphyllas, foliolis sessilibus exterioribus tribus subfoliaceis, reliquis petaloideis ovatis obtusis; petala duodecim, late sessilia, basi foveola nectarifera incrassata notata sepalis breviora. Stamina hypogyna, indefinita, numerosa (ultra 50), libera; filamenta linearia, compresso-plana, uninervia; antherae continuae, linearioblongae, antice quadriloculares, mucronatae. Ovaria in specc. nostris $3-4$, sessilia, inter se libera erecta unilocularia, pluri- $(8-10)$ ovulata ovulis biseriatis. Styli terminales subulati glabri, hinc sulco a stigmate truncato decurrente notati, ovario longiores. Fructus capsularis. 
332. An. macrophylla $\mathbf{S}$. et Z. - An. foliis alternis radicalibus et caulinis tri-quadri-ternatosectis, segmentis primariis et secundariis pedicellatis, tertiariis (soepius sessilibus) oblongis acuminatis grosse et inaequaliter inciso-serratis serraturis mucronatis, utrinque glabris; petiolo communi basi vaginante, caule tereti gracili sursum subnudo plurifloro, floribus subracemosis distantibus pedunculatis, pedunculo bractea trifida vel simplici suffulto.

Folia radicalia maxima plus quam bipedalia, longe petiolata, tri- vel in segmentis terminalibus quadri-ternata; segmenta oblonga acuminata, 4" longa, $1 \frac{1}{2}-2$ " lata, membranacea, glabra; folia caulina circiter pedalia triternata, segmentis pollicaribus vel sesquipollicaribus, petiolo communi basi vaginante. Canlis gracilis, sursum denudatus subaphyllus. Flores inferiores ex axillis foliorum solitarii longissime pedunculati; superiores in apice caulis subracemosi, distantes, ante anthesin nutantes, pedunculati, pedunculo bractea sessili tripartita vel simplici lineari suffulto, bracteolis $2-3$ alternis linearibus munito. Calyx patens, diametro ultra pollicem metiens, in spece. nostris enneaphyllus, foliolis tribus extimis coriaceis subfoliaceis latioribus. Corolla dodecapetala; petala basi late sessilia et foveola nectarifera incrassata munita, spathulata, rotundata, radiatoquinquenervia; quam calyx dimidio fere breviora. Stamina petalis breviora numerosissima. Ovaria glabra, stylis stamina superantibus.

Diese Gattung, welche uns nur in wenigen von einheimischen Botanikeru ohne. Zweifel im Norden von Japan gesammelten Exemplaren vorliegt, hat in den Blättern grosse Aehnlichkeit mit Actaea und Cimicifuga, in der Blüthe dagegen für den ersten Anblick mit einer gefülten Anemone, ohne dass jedoch eine theilweise Füllung statt gefunden zu haben scheint. Der Bau der Fruchtknoten weist ihr ihre Stellung unter den Helleboreen an, von welchen sie aber wieder durch die grossen flachen durchaus nicht tutenförmigen und nur an der Basis mit einer fleischigen Honiggrube versehenen Blumenblätter abweicht. Am nächsten dürfte sie gegen- 
wärtig dem Blüthenbau nach zu Aquilegia gestellt werden, so sehr übrigens anch der Habitus widerspricht.

\section{Aquilegia Tournef.}

333. A. Bürgeriana S. et $\boldsymbol{Z}$. - A. foliis radicalibus biternatis, segmentis pedicellatis e basi rotundata obovatis rotundatis incisodentatis dentibus obtusis glabris subtus parum glancescentibns, summis canlinis simpliciter ternatis sessilibus integris linearibus, calcaribus rectis petala truncata aéquantibus, sepalis lanceolatis acutis petalis longioribus, staminibus inclusis, ovariis hirtis.

Proxima A. canadensi recedit foliis radicalibus multo majoribus, segmentis pedicellatis, petalis quam sepala brevioribus, genitalibus inclusis. Calcara soepius apice parum eurvata. Flores rubri, petala pallidiora.

\section{A. fabellata S. et Z.}

A. foliis radicalibus ternatis, foliolis longe pedicellatis iterum ternatis vel quaternatis circumscriptione orbiculari-flabellatis, segmentis brevibus sessilibus e basi cuneata obovatis inaequaliter inciso-dentatis dentibus rotundatis subtus intense glancis, foliis summis caulinis sessilibus ternatis, sepalis unguiculatis ovato-ellipticis obtusis quam petala rotundata breviter cucullata majoribus, calcaribus in annulum involutis, carpellis elongatis (ultra pollicaribus) stricte erectis arcte sibi adpressis. - A. vulgaris Thunb. Flor. japonic. p. 132.

Tota planta glancescens. Folia pollicaria, orbiculari-flabellata, subtus intense glauca. Flores magni, sepala coerulea, petala apice flavescentia, carpella oblongata, stricte erecta vel apice tantum parum recurva, ultra pollicem longa.

180. Aconitum Tournef.

335. A. chinense Sieb. - A. japonicum Hortul. non Thunberg. - A. Napellus Thbg. Fl. jap. p. 231. 
336. A. japonicum Thunb. Fl. jap. p. 231.

A. Lycoctono affine sed diversum. Variat foliorum lohis obtusis vel acutis. Flores sulphurei.

181. Cimicifuga DC.

Species nondum determinata.

182. Trautvetteria Fisch. et Mey.

337. Tr. japonica S. et $\boldsymbol{Z}$.

Specimen mancum, sed folia quam in $\boldsymbol{T} r$. palmata profundius incisa, lobis latioribus et brevioribus inaequaliter inciso-serratis, serraturis argutis.

153. Pityrosperma S. et Z. in Act. Mathem. Physic. Monac. III. p. 731. tab. 3.

338. P. acerinum S. et Z. I. c.

339. P. obtusilobum S. et Z. 1. c.

340. P. biternatum S. et Z. I. c.

184. Paeonia L.

341. P. Moutan Sims.

342. P. albiflora Pall.

Variat carpellis glabris et sericeo-hirtis.

185. Glaucidium S. et,Z. Tab. I. B.

Calyx caducus? Corolla hypogyna tetrapetala regularis; petala obovata rotundata vel acuta. Stamina hypogyna, numerosa, multiseriata, libera; antherae erectae, ellipticae, loculis adnatis lateralibus, longitudinaliter quadrivalvibus. Ovarium superum, sessile, cylindricum, uniloculare, ovulis plurimis in placenta unica parietali multiseriatis horizontalibus. Stigma crassum recurvato-adnatum hinc subdecurrens snlco longitudinali exaratum, papillosum. Capsula?

343. Gl. palmutum S. et $\mathbf{Z}:^{*}$ - Gl. canle herbaceo unifloro triphyllo, foliis alternis, inferioribus duobus petiolatis, summo infra florem sessili, omnibus circumscriptione orbicularibus e basi profunde 
cordata palmato-quinquelobis quinquenerviis, lobis obovato-oblongis bi- vel trifidis segmentis acuminatis aeque ac cordatura argute serratis serraturis mucronatis, utrinque tenuiter pubescentibus, flore terminali, petalis ovatis acutis vel obtusis teneris glabris horizontaliter patentibus.

Caulis herbaceus simplicissimus erectus circiter pedalis, basi squamis fuscis membranaceis e collo rhizomatis provenientibus cinctus. Folia 3, inferiora 2 petiolata, petiolo $1-2$ " longo, lanina $3-4$ " diametro metiente. Calycis in flore aperto vestiginm nullum. Corolla ampla, tripollicaris, petalis tenuiter radiatim venosis venis anastomosantibus.

Die wenigen uns vorliegenden und von japanischen Botanikern auf Jesso gesammelten Exemplare sind leider unvollständig. Alle Blüthen sind geöffnet und an keiner eine Spur des abgefallenen Kelches zu sehen. Doch könnte nur die Ansicht der Knospe entscheiden, ob derselbe wirklich fehlt oder vielmehr ob der jetzt als Blnmenkrone angesprochene Kreis nicht ein gefärbter Kelch ist und die Corolla fehlt. Der Fruchtknoten verhält sich ganz wie die Karpellen von Paeonia. Die fleischige, angewachsene, kammförmige Narbe ist auf dem Scheitel der ganzen Länge nach mit einer Furche durchzogen, welche an der Innenseite des Fruchtknotens herabläuft und die Anheftung der Placenten im Inneren des Faches bezeichnet. Die Gattung gehört demzufolge gewiss auch nicht zu den Papaveraceen, sondern reilit sich unter den Paeonieen an Paeonia selbst an.

\section{2. (178. Endl.) MAGNOLIACEAE De Cand.}

\section{Illici um Linn.}

344. I. religiosum S. et Z. Flor. japon. I. p. 5. t. 1. - IIl. anisatum Thumb. et Aut.

187. Trochodendron $S$. et $\mathbf{Z}$.

345. Tr. arrilioides S. et Z. Flor. japon. I. p. 83. t. 39. 40. 
188. Bürgeria S. et Z, Tab. II. A.

Spatha calycina diphylla, decidua. Calyx triphyllus plerumque lanatus. Corolla $9-18$-petala, petalis pluriseriatis patentibus lineari-oblongis. Stamina numerosa multiseriata, antheris linearibus mucronatis marginalibus. Ovaria numerosa, in tori columna imbricatospicata, sessilia, inter se libera, unilocularia, plerumque biovulata. Styli subulati patentes, stigmate decurrente papilloso. Capsulae in axi carnosa cum hac et inter se confluentes, abortu magnae ovariorum partis irregulariter dispositae, corticatae, denique in angulo centrali ab axi pro recipiendis seminibus excavata solutae, plerumque dispermae. Semina ex angulo centrali capsulae pendula.

Diximus hoc genus in honorem Doctoris Bürger, Sieboldii in Japonia successoris, de flora hujus terrae optime meriti.

Differt a reliquis generibus capsulis corticatis ne apice quidem bivalvibus sed in angulo centrali toto ambitu ab axi carnosa secedentibus.

346. B. stellata S. et Z. - B. foliis obovato-oblongis basi attenuatis obtusis vel breviter cuspidatis, junioribus subtus pubescentibus, lyssterantheis, deciduis, gemmis et alabastris lanatis, calycibus quam petala duplo brevioribus ellipticis obtusis hirsutis, petalis numerosis $(9-18)$ lineari-spathulatis glabris, extimis nonnyllis soepe abbreviatis.

Rami floriferi laterales soepe abbreviati divaricati, foliiferi steriles virgati. Pedunculi brevissimi, erecti, tomentosi. Sepala ovatoelliptica, obtusa, sericeo-hirta, $8-10^{\prime \prime \prime}$ longa. Petala alba, numerosa, late linearia, sursum parum dilatata indeque subspathulata obtusa, glabra, stellatim patentia, sesquipollicaria, 3-4"' lata, alba. Antherae appendiculatae. Ovaria circiter 50 , glabra, viridia, stylis śbulatis patentibus. Syncarpium cylindricum, pollicare vel sesquipollicare. Capsulae corticatae, cum axi carnosa primum confluentes, demum ab angulo centrali solutae, dispermae. Folia in specc. nostris 
obovato-oblonga, 3 rarius 4 "' longa, $1 \frac{1}{2}-2 \frac{1}{2} "$ lata, nunquam acuminata sed obtusa vel breviter cuspidata.

347. B. obovata S. ei Z. - B. foliis deciduis obovatis repente cuspidatis glabris, gemmis pubescentibus, alabastris terminalibus solitariis.

Fructus ut in priore. Flores expansos non vidi. Planta e China in Japoniam introducta dicitur.

348. B. salicifolia $\mathbf{S}$. et Z. - B. foliis deciduis oblongo-lanceolatis vel lanceolatis utrinque attenuatis acutis glabris subtus glaucescentibus, gemmis glabris, alabastris hirsutis.

Flores et fructus non visi sed toto habitu planta optime cum praecedentibus convenit. 189. Magnolia Linn.

349. M. hypoleuca S. et Z. - M. foliis biennibus petiolatis alternis vel ad innovationes subverticillatis, e basi rotundata obovatoellipticis obtusis vel breviter cuspidatis superne glabris subtus dense albido-pruinosis tenuiter pilosis, gemmis albo-sericeis, petalis 6-9 crassis obovato-spathulatis subcuspidatis, antheris anticis obtusis, strobilo maturo elliptico, capsulis parallelopipedis truncatis coriaceis.

Folia pedalia obovato-elliptica petiolis sesquipollicaribus. Flores diametro $4-5$ " metientes, flavescenti-albi. Filamenta, antherae in dorso et ovaria purpurea. Carpella numerosissima ultra 100.

$\beta$. concolor. $\boldsymbol{S}$. et $\boldsymbol{Z}$. foliis subtus concoloribus vel pallidius tantum virentibus.

350. M. Kobus De Cand. - M. glauca var. a. Thunb. Flor. jap. p. 236.

Variat petalis numerosioribus. Filamenta basi incrassata, dilatata; antherae marginales appendiculatae appendice subcaruosa.

351. M. parviflora S. et $\mathbf{Z}$. - M. foliis deciduis obovatis breviter cuspidatis superne glabris subtus pubescenti-lirtis, pedanculis longis gracilibus ebracteatis, ealyce triphyllo glabro foliolis 
elipticis obtusis, petalis $6-9$ late ellipticis obtusis, antheris anticis truncato-obtusis, stylis recurvis.

Rami juniores pubescentes. Folia petiolata, petiolis pollicaribus vel longioribus uti folii pagina inferior pubescenti-hirtis. Folia obovata breviter cuspidata annua, superne glabra. Gemmae hirtae. Flores sesqui-bipollicares, numero petalorum variantes, toti glabri. Pedunculi pollicares vel bipollicares, graciles, pubescentes. Ex fructu immaturo manco fortasse Bürgeriae species.

190. Michelia L.

352. Species nondum determinata.

So grosse Verdienste sich auch De Candolle, Blume, Wallich, Wight u. A. um die Kenntniss der asiatischen Magnoliaceen erworben haben, so sind doch sowohl Gattungen als Arten noch viel zu wenig gekannt. Die Schwierigkeit die meisten derselben zu trocknen und noch mehr die zur Charakteristik so wichtigen Früchte zu erhalten, die Spielarten, welche durch langwierige Kultur entstanden sind und die Seltenheit der meisten in unsern Gärten legen dem europäischen Botaniker bei Bearbeitung dieser Familie Hindernisse in den Weg, welche nur dereinst durch gründliches Studium dieser schönen Pflanzen in ihrer Heimath beseitiget werden können.

\section{3. (177. Endl.) SCHIZANDRACEAE Blume.}

191. Kadsura Juss.

353. K. japonica S. et Z. Flor. japon. I. p. 40. tab. 17. Uvaria japonica Thun. Fl. jap. p. 237. - Fute kadsura s. Sane Kadsura Kämpfer Amoen. p. 476. c. ic. et 785.

192. Sphaerostemma Blume.

354. Sph. japonica S. et $\mathbf{Z}$. 
64. (174. Endl.) LARDIZABALEAE De Caisne.

193. Akebia De Caisne.

355. A. quinata De Caisn. - S. et Z. Fl. jap. p. 143. t. 77.

- Rajania quinata Thbg. Fl. jap. 148.

356. A. lobata De Caisne. - S. et Z. l. c. p. 145.t. 78.

357. A. clematifolia S. et Z. l. c. p. 146.

355. A. quercifolia S. et Z. l. c. p. 146.

194. Stauntonia De Cand.

359. St. hexuphylla De Caisne. Sieb. et Zucc. l. c. p: 140. Rajania hexaphylla Thbg. Fl. jap. p. 149.

\section{5. (173. Endl.) MENISPERMACEAE $D C$.}

195. Coceulus DC.

360. C. japonicus DC. - Menisp. japonicum Thunb. Fl. jap. p. 193.

361. C. Thunbergii DC. - Menisp. orbiculatum Thbg. l.c. p. 194 .

$\beta$. foliis e basi cordata hastato-trilobis lobis acuminatis. $-M$. trilobum Thbg. Fl. jap. l. c. - Cocc. trilobus De Cand. Syst. Veget. I. p. 522. Prodr. I. p. 98.

\section{6. (172. Endl.) RIBESIACEAE.}

196. Ribes L.

362. R. fasciculatum S. et Z. - R. inerme foliis e basi cordata trilobis lobis ovatis inciso-dentatis dentibus ovatis mucronulatis, subtus aeque ac petioli pubescentibus eglandulosis, floribus fasciculatis quaternis quimisve breviter pedunculatis erectis, calycibus eglandulosis glabris, petalis orbicularibus quam calycis laciniae duplo brevioribus, stipulis glabris apice fimbriatis, fimbriis setaceis longe ciliatis.

Rami subflexuosi cortice albido glabro solubili tecti. Folia e basi cordata orbicularia tri- vel obsolete 5 -loba, lobis obtusis grosse 
serratis serraturis obtusis mucronatis, subtus praesertim ad venas pubescentia, in specc. nostris floriferis pollicem longa et lata; petioli basi cum stipulis connati $6-12^{\prime \prime \prime}$ longi, pubescentes; stipulae membranaceae, pubescentes apice fimbriato-lacinulatae fimbriis setaceis ciliatis. Flores $4-5$ fasciculati breviter pedunculati erecti; pedunculi articulati glabri; calyx glaber eglandulosus limbi laciniis ovatis obtusis petala suborbicularia duplo superantibus.

Species duae nondum determinatae.

\section{7. (171. Endl.) SAXIFRAGEAE Vent.}

\section{Saxifraga L.}

363. S. sarmentosa $\boldsymbol{L}$.

364. S. cortusaefolia $\mathbf{S}$. et $\mathbf{Z}$. - S. subglabra, foliis e basi cordata suborbicularibus $5-7$-lobis ovatis obtusis grosse et inaequaliter dentatis, ciliatis, ceterum adultis glabris, novellis pilosis, petiolis scapisque basi rufescenti-hirtis, floribus in apice scapi in racemum basi compositum multiflorum dispositis, irregularibus, petalis ñnguiculatis, duobus quam reliqua tria ovato-spathulata pluries longioribus linearibus acuminatis adscendentibus.

Stolones in specc. nostris nulli. Folia radicalia, petiolata petiolis 6 " longis basi ut scapi hirtis pilis longis articulatis rufis; lamina reniformis, 1 $\frac{1}{2}-2^{\prime \prime}$ longa et lata, 5-7-loba, lobis ovato-oblongis obtusis grosse et inaequaliter dentatis ciliatis. Scapi pedales et ultra, erecti; racemus bi - tripollicaris, multiflorus, basi compositus; pedicelli filiformes, longi, glanduloso-pilosi; petala longiora $5-6^{\prime \prime \prime}$ longa anguste linearia utrinque attenuata acuminata, breviora uiguiculata spathulata calyeis lacimiis acutis longiora. Stamina subulata et ovarium glahra.

198. Mitellop sis Meisn.

365. M. japonica $\boldsymbol{S}$. et $\boldsymbol{Z}$. Cum tribus speciebus nondum determinatis. 
199, Hoteia Morr et De Caisne,

366. H. japonica Morr, et De Caisne. Annal. des sciences nat, 1834. c. tab: (excl. synon. Thunberg).

367. H. Thunbergii $\boldsymbol{S}$. et $\boldsymbol{Z}$. + H. foliis tripinnati-sectis, foliolis e basi rotundata vel subcordata rarius attenuata ovato-lanceolatis acuminatis argute duplicato-serratis, foliola terminali plerumque longe pedicellato, caule infra inflorescentiam longe aphyllo, racemo composito, racemis secundariis cylindricis, rachi hirta. Spiraea Aruncus Thunb. Flor. jap. p. 211.

Herba perennis habitum Sp. Arunci multo magis referens quam H. japonica De Caisne et cum Thunbergï descriptione optime conveniens. Recedit a specie praecedente foliis molto majoribus inferioribus fere bipedalibus, foliolis longioribus et latioribus soepe 3 "' longis 1" latis teneris membranaceis nec firmis, basi plerumque rotundatis, serraturis secundariis in setam longam subulatam terminatis, folio summo 5-6" ab inflorescentiae basi distante. Florum alabastra tantum obvia, sed certe decandra distyla, stylis brevibus crassis.

Adnotatio. Reliquae generis species praeter Astilben rivularem Don nobis notae sunt Spiraea indica Reinvardt in litt. et altera a clar. Bar. de Hïgel in India superiori prope Massuri lecta, quam H. bipinnatam dicimus.

200. Stephanandra S. et $\mathbf{Z}$.

368. St. flexuosa S. et Z. in Act. Acad, Monac. Math. Phys. III. p. 740. tab. IV. 2.

201. Hydrangea L:

369. H. Hortensia DC.

370. H. acuminata S. et Z. Fl. jap. I. p. 110. tab. 56. 57.

371. H. Asisai Sieb. - S. et Z. l. c. I. p. 104. tab. 51.

372. H. Belzonii S. et Z. l. c. p. 109, tab. 55. 
373. H. bructeata S. et Z. l. c. p. 176. tab. 92. - Vix ab H. cordifolia diversa.

374. H. cordifolia S. et Z. l. c. p. 113. tab. 59. 2.

375. H. hirta S. et Z. l. p. 117. tab. 62.

376. H. involucrata S. et Z. l. c. p. 118. tab. 63. 64 .

377. H. japonica S. et Z. l. c. 106. tab. 53.

378. H. Otaksa S. et Z. l. c. p. 105. tab. 52.

379. H. paniculata S. et Z. I. c. p. 115. tab. 61.

350. H. petiolaris S. et Z. l. c. p. 108. tab. 54 .

381. H. stellata S. et Z. l. c. p. 112. tab. 59. 1.

382. H. Thunberyii Sieb. - S. et Z. l. c. p. 111. tab. 58.

383. H. virens Sieb. - S. et Z. l. p. 114. tab. 60.

202. Cardiandra $\mathbf{S}$. et $\mathbf{Z}$.

384. C. alternifolia S. et Z. l. c. p. 121. tab. 65. 66.

203. Schizophragma S. et $\mathbf{Z}$.

385. Sch. hydranyeoides S. et Z. T. c. p. 60. tab. 26.

204. Platycrater $S$. et $Z$.

386. Pl. arguta S. et Z. l. c. p. 64. tab. 27.

205. Deutzia Thunb.

387. D. crenata S. et Z. l. c. p. 19. tab. 6.

388. D. scabra S. et Z. l. c. p. 20. tab. 7.

389. D. gracilis S. et Z. t. c. p. 22. tab. 8.

68. (170. Endl.) CRASSULACEAE DC.

206. Sedum L.

390. S. Sieboldi Sweet.

Praeterea Sedi species $10-12$ nondum determinatae et Sempervivum. 
69. (169 *. Endl.) HELWINGIACEAE De Caisne.

207. Helwingia Willd.

391. H. rusciflora Willd. - Sieb. et Zucc. Flor. jap. p. 164. tab. 86 .

\section{0. (168. Endl.) HAMAMEIJDEAE $\boldsymbol{R}$. $\boldsymbol{b} r$.}

208. Hamamelis L.

392. H. japonica S. et Z. - H. foliis ovatis vel ovato-suborbicularibus breviter cuspidatis vel ohtusis repando-crenatis basi inaequalibus costato- venosis, costis utrinque $7-8$, calycibus capsulae imae basi tantum adnatis.

Differt ab H. virginica L. foliis densins costatis (costae in illius foliis utrinque tantum 3-4), floribus majoribus, petalis longioribus et capsulis a calyce fere liberis, in illa ultra dimidium calyci adnatis. 209. Corylopsis $\mathbf{S}$. et $\mathbf{Z}$.

393. C. spicata S. et Z, Fl. jap. I. p. 47. tab. 19.

394. C. panciflora S. et Z. l. c. p. 48. tab. 20.

210. Distylium $\mathbf{S}$. et $\mathbf{Z}$.

395. D. racemosum S. et Z. l. c. p. 179. tab. 94.

\section{1. (167. Endl.) LORANTHACEAE Lindl.}

211. Viscum Tourn.

396. V. japonicum Thunb. ex Steud. - V. Opuntia T'lunb. Fl. jap. $p$. 64 .

397. I: Kämpferi DC. - V. album Thunb. l. c. p. 63.

\section{Loranthus L.}

398. L. Jodoniki Sieb.

\section{2. (166. Endl.) CORNEAE DC:}

\section{Benthamia Lindl.}

399. B. japonica S. et Z. l. c. p. 38. tab. 16.

Abhandlungen d. II. Cl. d. k. Ak. d. Wiss. IV. Bd. Abth. IJ. 


\section{Cornus Tournef.}

400. C. officinalis S. et Z. Fl. jap. I. p. 100. tab. 50.

401. C. sanguinea Thbg. Fl. jap. p. 62.

A planta europaea differt foliis densius (utrinque 7-9-) costatis acuminatis nec breviter cuspidatis subtus glancis, cymis majoribus ramis secundis pedicellis brevissimis.

402. C. alba Thbg. l. c. p. 63.

A planta sibirica recedit petiolis longioribns, foliolis multo densius (7-9-) costatis superne glabris, pedicellis longioribus filiformibus, petalis linearibus nec lanceolatis.

In utraque fructus expectandi.

C. japonica Thunb. certe non hujus generis, sed vix Viburnum. 215. Aucuba Thnob.

403. A. japonica T'hbg. Fl. jap. p. 64.

Flores masculi in paniculam pyramidatam dispositi. Stigma in foemineis crassum oblique truncatum et subdecurrens basin versus sulco exaratum.

\section{Quadriala S. et Z. Tab. II. B.}

Flores dicici. Calyx ovario adnatus; tubus cylindricus octostriatus; limbi laciniae quatuor aequales vel inaequales, basi attenuatae et articulatae, lanceolatae acutae foliaceae reticulatin venosonervosae, demum in fructu persistentes et alarum in modum elongatae. Corolla supera, tetrapetala; petala cum calyce alternantia deltoidea brevia firma, primum patentia, demum in fructu persistentia inflexa. Staminum in flor. foem. rudimentum nullum. Discus ovarii verticem tegens carnosus breviter quadrilobus, lobis calycis foliolis oppositis. Ovarium uniloculare ovulo unico e vertice pendulo. Stylus primum brevissimus, stigmate carnoso oblique peltato umbonato, in fructu excrescens stigmate irregulariter quadrilobo lobis reflexis. Bacca infera, calyce, corolla et stylo persistentibus coronata, sicca, globosa, monosperma. Semen pendulum, subglobosum. Testa cum 
pericarpio connata. Albumen crassum aequabile, carnosum. Embryo orthotropns, rectus longitudine fere seminis, radicula brevi conica, cotyledonibus linearibus plane sibi incumbentibus.

Nomen generis a fruetu quadrialato et simula dispositione quaternaria omnium floris partium.

404. Qu. lanceolata $\mathbf{S}$. et $\mathbf{Z}$. - Qu. foliis oppositis subsessilibus ląnceolatis acuminato-falcatis integerrimis glabris.

Frutex vel arbor: Ramuli oppositi, tenues, novelli tetragoni. Gemmae decussatim perulatae. Folia opposita, exstipulata, subsessilia utrinque attenuata lanceolata, longe acuminata acumine falcato, integerrima utrinque glabra, penninervia tenera membranacea, $1 \frac{1}{2}-2$ " longa, 6-8" lata. Flores masculi non observati. Foemineis post foecundationem tubus calycis cylindricus $3-4^{\prime \prime \prime}$ longus, glaber, cum ovario connatus; laciniae lineari-lanceolatae utrinque attenuatae semipollicares $1 \frac{1}{2}-2^{\prime \prime \prime}$ latae, foliaceae, in fructu demum pollicares et longiores, 3 "' latae, nervoso-venosae, basi constrictae et articulatae, glabrae. Corolla tetrapetala petalis deltoideis acutis brevibus persistentibus. Discus carnosus primum coucavus, obtuse quadrilobus. Stylus primum brevissimus, demum 1"' longus stigmate irregulariter quadrilobo. Bacca sicca magnitudine pisi, globosa, obtuse octangalaris. Embryonis radicula brevis appendice filiformi ancta, cotyledones elongatae, semiteretes, plane sibi incumbentes.

\section{3. (165. Endl.) AMPELIDEAE Kunth.}

217. Cissus L.

405. C: Thunbergii S. et Z. C. tota glabra, foliis vel e basi subcordata late ovatis acutis grosse inciso-serratis serraturis deltoideis ovatis mucronatis eiliatis, vel trifoliolatis, foliolis e basi cuneata oblongis serrato-angulatis, lateralibus basi inaequalibus.

Rami debiles angulati. Folia difformia; aliis petioli $6-12$ "' longi tennes, lamina basi truncata vel subeordata, late ovata acuta, grosse et inaequaliter-inciso serrata serraturis deltoideis acutis in 
setam terminatis ciliatis, ceterum glabra, pollicem circiter longa et lata, Urticae folium referens; aliis petioli multo longiores et foliola tria sessilia lateralibus basi inaequalibus intermedio attenuato, omnibus oblongis acuminatis grosse angulato-serratis, $1-1 \frac{1}{2}$ " longis.

406. C. viticifolia S. et Z . - C. tota glabra, caule tetragono, foliis ternatis, foliolis difformibus integris grosse serratis acuminatis vel pinnatifidis, basi auriculatis, laciniis lanceolatis integerrimis vel serratis, decurrentibus vel sessilibus, pedicellis inter lacinias alatis ; lateralibus plerumque sessilibus intermedio semper pedicellato et in petiolo decurrente, racemis oppositifoliis cymosis, peduneulis rectis vel cirrhosis folio brevioribus.

Folia semper trifoliolata; foliola variant:

$\alpha$. integra, lateralia sessilia basi inaequilatera et soepe deorsum auricula foliacea aucta, ovato-oblonga vel lanceolata, acuta vel acuminata, grosse serrata; intermedium longe in pedicellum decurrens, lanceolato-rhombeum acuminatum, serratum vel subincisum.

ß. pinnatifida, omnia pedicellata; laciniae inferiores oppositae sessiles petiolo inter juga alato, vel decurrentes, lanceolatae, acutae subserratae, superiores confluentes in laciniam terminalem subrhombeo-lanceolatam acuminatam serratam. An Ampelopsis serianaefolia Bunge Enum. pl. chin. p. 12.?

218. Ampelop sis Michx.

407. A. tricuspidata S. et Z. - A. hermaphrodita, foliis e basi cordata circumscriptione suborbicularibus grosse aristato-serratis trinerviis et apicem versus breviter trilobis, lobis inter se aequalibus vel medio parum longiore, cuspidatis, glabris vel subtus ad venas parce pubescentibus, petiolis longissimis laminam duplo superantibus, cymis bifidis divisionibus racemoso-dichotomis divaricatis.

Petioli tri - quadripollicares, tenues; lamina folii $2-2 \frac{1}{2}$ " longa et inter lobos lata, e basi cordata orbicularis grosse serrata, serra- 
turis in setam terminatis, breviter triloba lobis sursum spectantibus late deltoideis argute cuspidatis serratis. Cymae divaricato-bifidae, divisionibus dichotome racemosis; flores breviter pedicellati; petala lineari-oblonga, libera, demum reflexa; discus basin ovarii eingens quinquecrenatus, stylus brevis stigmate capitato.

408. A. heterophylla S. et $\mathbf{Z}$ - A. hermaphrodita, foliis e basi cordata vel suborbicularibus acntis grosse serratis ant sublobatis serraturis obtusis mucronatis, vel profunde tri - quinquelobis lobis integris ovatis vel eroso-subpinnatifidis acuminatis, sinubus acutis vel rotundatis, glabris vel subtus pubescentibus, cymis bifidis fastigiatis, petalis liberis, disco membranaceo truncato. - Vitis heterophylla Thunb. Fl. jap. p. 103.

Variant folia :

$\alpha$. integra, e basi cordata ovata, acuta, obtusa, serrata vel subtriloba. Amp. humulifolia Bunge Enum. pl. chin. p. 12. (!)

6. profunde tri - quinqueloba, lobis vel integris basi constrictis ovato-rhombeis acuminatis serratis, vel eroso-pinnatifidis, sinubus rotundatis vel acutis.

Petioli pollicares vel/sesquipollicares. Folia in ramulis vel inferiora vel superiora magis divisa; lamina $1 \frac{1}{2}-3^{\prime \prime}$ longa et lata; lobi ad vel ultra dimidium incisi medio productiori. Cymae fastigiatae, flores pedicellati; calyx brevissime quinquedentatis vel truncatus; petala libera, oblonga; discus membranacens truncatus.

219. Vitis Linn.

409. V. vinifera $\boldsymbol{L}$.

Colitur.

410. V. Alexuosa Thunb. Act. Linn. II. p. 332. - V. indica Thbg. Fl. jap. p. 103.

411. V. japonica S. et Z. Thunb. Fl. jap. p. 104. Cissus japon. De Cand. Prodr. I. p. 632. Hooker in Beechey Botany p. p. 175. - V. glabra, foliis pedato-quinquefoliolatis, foliolo intermedio majori et longius pedicellato, omnibus oblongis acutis grosse serratis 
serraturis obtusis mucronatis, cymis trifidis fastigiatis, totis furfuraceo-lepidotis, floribus tetrameris, petalis calyptratis disco quadrilobo, lobis emarginatis.

Cissi habitus, sed petala calyptrata.

412. V. Thunbergii S. et $\mathbf{Z}$. $-\mathbf{V}$. polygama, foliis e basi cordata tri - vel quinquelobis superne pubescentibus glabrisve subtus fuscescenti-tomentosis, lobis vel indivisis oblongis acutiusculis vel eroso-panduraeformibus vel pinnatifidis, semper remote serratis, sinubus acutis vel rotundatis, paniculis divaricatis tomentosis multifloris, floribus tandem umbellatis, masculis minimis absque ovarii rndimento, diseo quinquangulari.

Flores congenerum fortasse minimi. Baccae globosae, nigrae, magnitudine pisi minoris.

Vitis ficifolia Bunge l. c. p. 12. secundum spece. ab amicissimo auctore communicata forma hujus speciei videtur foliis minus incisis.

Adsunt praeterea Ampelidearum species sex nondam determinatae.

\section{3. (164, Endl.) ARALIACEAE Juss.}

\section{Panax L.}

413. $\boldsymbol{P}$. innovans $\boldsymbol{S}$. et $\boldsymbol{Z}$. P. fruticosum inerme, ramis striete ereetis ad innovationes incrassatas foliatis ceterum nudis, foliis annuis $3 \multimap 5$ verticillatis rarius binatis lvel simplicibus, foliolis ovatorhombeis acuminatis serrulatis serraturis setaceo-mucronatis, umbellis in pedunculo terminali elongato nudo solitariis vel $3-4$ racemosis hemisphaericis 5-15-floris, floribus tetrameris calyce truncato.

Fratex; rami stricte erecti, crassitie pennae anserinae, teretes, inter innovationes $4-8^{\prime \prime}$ a se invicem distantes nudi. Folia annua ex innovationibus, in verticillum terminalem disposita, $3-5$, petiolata petiolis teretibus superne canaliculatis 2 " longis, plerumque tri-rarius bifoliolata vel simplicia; foliola ovato-rhombea acuminata, adpresse serrulata, glabra, tenera, membranacea, $1 \frac{1}{2}+2$ " longa, 1-1 $\frac{1}{2}$ " lata. 
Pedunculi terminales stricte erecti nudi, $3-6$ " longi, glabri; umbellae simplices solitariae vel $3+4$ in racemum dispositae, convexae, $1-$ 15-florae; flores parvi, glabri, tetrameri, styli duo.

Die Blätter kommen an Stamm und Seitenzweigen oft $12-18$ Jahre nach eimander alljährlich nur in einem Wirtel dicht über dem vorjährigen zum Vorschein, so dass jeder Jahrestrieb kaum $\frac{1}{2}$ Linie lang wird. Dann entwickelt sich in einem günstigen Jahrgang einmal ein rascher meistens völlig schuppen- und blattloser Trieb aus der Spitze des vorjährigen Wirtels zu einer Länge von $4-8^{\prime \prime}$, der erst an seinem Ende einen einfachen Blattwirtel trägt, dessen Internodium gegen das Vorjahr der Trieb selbst bildet. Darauf folgt wieder mehrere Jahre lang die frühere Verkürzung des Wachsthums, so dass die Verlängerung des Stammes im Ganzen sehr langsam und nur in vieljährigen Intervallen rasch erfolgt und ein Zweig kaum von der Dicke einer Schreibfeder nnd von $1 \frac{1}{2}$ Fuss Länge 20 Jahre alt seyı kann. Die Verkürzungsstellen sind immer beträchtlich verdickt und dicht mit den Stielnarben der abgefallenen Blattwirtel besetzt.

414. P. ricinifolium S. et $\boldsymbol{Z}$. - P. fruticosum, ramis inter innovationes nodosas aculeatis, foliis alternis longe petiolatis e basi subcordata vel truncata orbicularibus profunde palmato-quinquefidis, lobis oblongis acuminatis argute serratis glabris coriaceis, pedunculis terminalibus numerosis umbellas $5-9$ globosas multifloras divaricatopatentes ferentibus, floribus polygamis, stylo unico.

Rami crassitie digiti minoris innovationibus numerosis, nodosi, aculeati aculeis rectis conicis. Folia annua, alterna; petioli $4-6$ " longi, teretes; lamina basi subcordata, rotundata vel truncata, orbicularis, ad medium circiter usque palmato-quinqueloba lobis oblongis acuminatis lateralibus parum brevioribus, utrinque glabra subtus dense reticulato-venosa, coriacea, $4-6$ " longa et lata. Pedunculi terminales fasciculatim congesti, $10-20$; singuli $3-6$ "l longi umbellas ferunt $5-9$, quarum inferiores alternae, superiores $3-7$ umbellatim approximatae, terminali plerumque abortiva; umbellae ipsae in pe- 
'dunculi ramis $1-1 \frac{1}{2}$ " longis divaricatis globosae multiflorae; calyx brevissime 5-dentatus; styli in unum connati stigmate truncato.

415. P. divaricatum S. et $\mathbf{Z}$. - P. fruticosum aculeatum aculeis plerumque geminis substipularibus basi compressis recurvis, foliis quinato-digitatis, foliolis subsessilibus e basi cuneata obovatooblongis acutis duplicato-serratis pubescentibus, umbellis nudis vel infimis axillaribus, $5-7$ vel pluribus in racemum simplicem vel compositum dispositis terminali multo praecociori, omnibus globosis multifloris in pedunculis longis divaricatis lanatis, stylis in nnum connatis stigmatibus duobus.

Rami glabri, cinerei, aculeis armati plerumque geminis et infrafoliaceis basi dilatatis sursum subulatis et acutis deorsum spectantibus; petioli $1 \frac{1}{2}$ " longi, pilosi; foliola breviter pedicellata, medium $2 \frac{1}{2}$ " longum, 12-15"' latum, lateralia parum minora. Pedunculi sesquibipollicares, aeque ac rachis fuscescenti-lanati, rectangule divaricati; umbellae globosae, $40-60$-florae, terminali jam fructifera dum laterales florent; calycis limbus lanatus, tubus glaber, petala glabra; stylus unicus, stigmatibus duobus brevibus patentibus.

\section{Aralia Linu.}

416. Ar. japonica Thunb. A. fruticosa, inermis ramis crassis, petiolis basi late vaginantibus, foliis e basi cordata suborbicularibus palmato-septemlobis vel rarins quinquelobis, 7 -9-nerviis, lobis oblongis acutis sursum serratis sinubus rotundatis, coriaceis firmis glabris vel novellis tomentosis, panicula terminali composita, umbellis pedunculatis globosis multifloris, ovariis tnrbinatis, stylis 5 discretis - stignatibus subemarginatis. - A. japonica Thbg. Fl. jap. p. 128.

Rami crassitie digiti. Folia approximata; petioli basi late vaginantes teretes, $3-\delta^{\prime \prime}$ longi, crassi; lamina e basi leviter cordata suborbicularis, plerumque ad medium usque septemloba, novemnervia, lobis oblongis acutis basi integerrimis sursum serratis penuinerviis, utrinque glabra, novella tomentosa, coriacea, $6-8^{\prime \prime}$ longa, inter 
lobos laterales $7-10^{\prime \prime}$ lata. Panicula terminalis erecta, glabra, sesqui - bipedalis, ramosa, primum bracteis deciduis obterta demum nuda, glabra; umbellae in pedunculis $1-1 \frac{1}{2}$ " longis patentibus globosae, 40 50-florae, pedicellis pubescentibus, terminales praecociores; calyeis limbus truneatus, petala oblonga reflexa, discus earnosus.

Thumberg nennt die Frucht eine Beere; die añ unsern Exemplaren befindlichen sind noch nicht reif, scheinen aber Beeren zu werden. Dann müsste die Pflanze, zu Hedera gezogen werden, wofür anch der Habitus spricht.

417. Ar pentaphylla Thunb. - A. fruticosa, aculeis solitariis infrafoliaceis rectis, foliis longe petiolatis quinatis, foliolis e basi longe cuneata obovato-oblongis acutis sursum serratis glabris, umbellis terminalibus simplicibus longe pedunculatis hemisphaerieis $20-$ 30-floris, stylis $5-6$ basi coalitis, drupa in vertice calyce et disco coronata profunde quinquesulcata, sieca, pyrenis osseis monospermis. - A. pentaphylla Thunb. Fl. jap. p. 128. - Panax, spinosa Linn.

\section{fide Lamarkii.}

Rami cinereo-albidi; acnlei solitarii infrafoliacei recti; folia e gemmis hornotinis plura subfasciculata longe petiolata, petiolis tandem $3^{\prime 0}$ longis laminam superantibus; foliola subsessilia e basi longe cuneata integerrima obovato-oblonga sursum serrata serraturis mucronatis, glabra, membranacea subtus glancescentia (?), $1-1 \frac{1}{2}$ " longa, $4-6^{\prime \prime \prime}$ lata, lateralia minora. Umbellae solitariae subterminales longe pedunculatae pedunculo stricto nudo petiolos superante, 2030-florae, glabrae. Drupae acute 5-6-sulcatae, siccae, magnitudine grani Piperis. Calyx et discus in vertice drupae infra stylos persistentes; pyrena $5-6$ compressa, ossea, monosperma. An distineti generis?

418. A. edulis Sieb. et Zuccar. Ft. jap. I. p. 57. tab. 25. A. cordata Thunb. Flor. jap. 127. A ri A. nudicaulis Blume Bijdr. p. 870 ?

Abhandlungen d. I1. CI. d. k. Ak, d. Wiss. 1V. Bd. Abth. II. 
419. A. canescens S. et $\boldsymbol{Z}$. - A. frutescens, inermis? foliis 5 -6-jugis, jugis distantibus, foliolis lateralibus brevissime, terminali subtrilobo longe pedicellatis, e basi rotundata ovatis acuminatis serrulatis superne glabris subtus canescenti-glancis ad venas pilosis, panicula terminali elongata, ramis divaricatis, nmbellis $9-12$ in quovis ramo racemosis, pedicellatis involueratis hemisphaericis uti rachis tomentoso-hirtis, floribus glabris, calyce quinquedentato, stylis 5 patentibus.

Folia pinnata, sesqui - bipedalia, $3-6$-juga; juga $1 \frac{1}{2}-2$ " a se invicem distantia; foliola lateralia breviter, terminale soepe subtrilobum longe pedicellata, e basi rotundata ovata acuminata serrulata serraturis uncinato-mucronatis, utrinque ad venas pilosa subtus canescenti- glauca, $3-3 \frac{1}{2}$ longa, $1 \frac{1}{2}-2$ " lata. Paniculae terminales, bipedales tomentoso-hirtae; rami rectangule divaricati, racemosi, umbellis $9-11$ in quovis ramo, terminali praecociori, pedicellatis squamis lanceolatis involucratis, semiorbicularibus multifloris, floribus glabris parvis, fructibus globosis quinquesulcatis.

\section{Hedera Linn.}

420. H. Helix L. Thunb. l. c. p. 102.

Folia in ramis floriferis longius petiolata quam in specc. europaeis, elliptica utrinque attenuata cuspidata; umbellae terminales solitariae vel $2-3$ subracemosae, globosae, multiflorae, furfuraceotomentosae.

421. H. rhombea $\mathbf{S}$. et $\mathbf{Z}$.

An prioris varietas?

\section{5. (16 . Endl.) UMBELLIFERAE Juss.}

Inter Umbelliferas hucusque examinatas occurrunt genera: 223. Hydrocotyle-Tourn., 224. Sanicula Tourn., 225. Apium Hoffm., 226. Cryptotaenia DC., 227. Sium L., 228. Buplenrum Tourn., 229. Foeniculum Adans., 230. Ligusticum L., 
231. Angelica Hoffm., 232. Pencedanum L., 233. Archemora DC., 234. Heracleum L., 235. Daucus Tourn., 236. 'Torilis Adans., 237. Osmorhiza Rafin.

E speciebus enumerari possunt:

422. Hydrocotyle interrupta Mühlbg. - H. vulgaris Thunb. Fl. jap. p. 116, et H. verticillata Ejusd. Dissert. Acad. 2. p. 415, tab. 3 .

423. Sanicula elata Hamilt. - S. canadensis Thbg. Fl. jap. p. 116. An hic et S. chinensis Bunge Enum. pl. chin. p. 32.

424. Cryptotaenia canadensis DC. - Sison canadensis Thbg. l. c. p. 118.

425. Apium graveolens $\boldsymbol{L}$.

426. Foeniculum vulgare Gärtn.

427. Ligusticum scoticum $L$.

428. Lig. acutilobum S. et Z $\mathbf{Z}$ - L. glabrum, foliis biternatis. segmentis pedicellatis basi cuneatis profunde tripartitis, laciniis lanceolatis argute inciso-serratis, vaginis longe attenuatis, involucro nullo, involucelli foliolis setaceis, floribus polygamis.

429. Peucedanum japonicum Thbg. l. c. p. 117. - Fructus in specc. nostris immaturi. An hujus generis?

330. Torilis japonica DC. Hooker ap. Beechey p. 189. Chaeroph. scabrum Thunb. l. c. p. 119.

431. Osmorhiza japonica S. et Z. - 0. hirta, folioloram lobis inciso-serratis, serraturis mucronatis, pedicellis fructum superantibus, stylis erectis subulatis latitudinem fructus aequantibus. - Chaeroph. aristatum Thunb. l. c. p. 119.

o. longistyli affinis, sed foliorum lobis obtusis, in illa acutis et pedicellis fructu longioribus distincta. 


\section{Explicatio Tabularum.}

Tab. I. A. Fig. 1. Flos Anemonops. macrophyllae a facie et magn. nat. - Fig. 2. Idem a dorso. - Fig. 3. Foliolum calycis, anctum. - Fig. 4. Petalum m. n. - Fig. 5. Idem anctum. - Fig. 6. Stamen a facie, a. - Fig. 7. Anthera loculis effoetis, a. - Fig. 8. Pistillum, a. - Fig. 9. Idem dissectum ovula monstrans, m. a.

T'ab. 1. B. Fig. 1. Flos Glaucid. palmati a facie, m. n. Fig. 2. Idem a dorso. - Fig. 3. Petalum, m. n. - Fig. 4. Stamen a facie et a dorso, a. Fig. 5. Pistillum, m. a. - Fig. 6. Idem, transversim dissectum, ovula monstrans, a.

Tab. 2. A. Fig. 1. Flos Bürgeriae stellatae, a facie et $\mathrm{m}$. nat. Fig. 2. Idem a dorso. Fig. 3. Stamen a facie et a dorso, a. - Fig. 4. Colnmna pistillaris, m. n. - Fig. 5. Pistillum singulum, m. a. - Fig. 6. Syncarpium, capsnlas in axi carnoso ex parte jam apertas monstrans, m. n. - Fig. 7. Syncarpii pars, a.

Tah. 2. B. Fig. 1. Quadrialae lanceolatae flos foem. magn. nat. Fig. 2. Idem anctus, - Fig. 3. Idem a vertice, m. n. Fig. 4. Ovarium longitudinaliter dissectum, a. - Fig. 5. Fruetns maturus m. n. Fig. 6. Idem anctus, resectis alis majoribus. - Fig. 7. Alae pars, a. - Fig. S. Fruetus longitudinaliter dissectus, albumen et embryonem monstrans, a. id Fig. 9. Embryo, m. a. 


\title{
FLORAE JAPONICAE
}

\section{FAMILIAE NATURALES,}

\section{ADJECTIS GENERUM ET SPECIERUM EXEMPLIS SELECTIS.}

\author{
SÉCTIO ALTERA.
}

PLANTAE DICOTYLEDONEAE (GAMOPETALAE, MONOCHLAMYDEAE) ET MONOCOTYLEDONEAE.

\section{AUCTORIBUS}

Dr. Ph. Fr. de Siebold et Dr. J. G. Zuccarini.

$$
\begin{aligned}
& \text { From abhande. IR. Ol<ad } \\
& \text { mach - plmp Ce. 4. } 4^{3}: 125-240 \cdot \mathrm{jel} \cdot 3.1846 \\
& 16 \text { * }
\end{aligned}
$$




\section{FLORAE JAPONICAE}

\section{FAMILIAE NATURALES.}

SECTIO ALTERA.

PLANTAE DICOTYLEDONEAE (GAMOPETALAE, MONOCHLAMYDEAE) ET MONOCOT'YLEDONEAE.

\section{6. (126 Endl.) ERICACEAE $\boldsymbol{h}$. Br.}

238. Andromeda $\boldsymbol{L}$.

432. Andr. japonica Thunb. - A foliis obovato-oblongis vel lanceolatis utrinque attenuatis acutis sursum serrulatis coriaceis glabris, racemis terminalibus solitariis simplicibus vel paniculatis multifloris secundis, corollis apice constrictis laciniis brevibus rotundatis, filamentis linearibus ciliatis muticis, antheris dorso biaristatis, ovario squamulis 10 cincto, seminibus linearibus trigonis pendulis. - Andr. japonica Thunb. Fl. jap. p. 181. tab. 22. et Auct. Gaertn. Carpol. II. p. 481. tab. 187. 2. - Pieris? japonica De Cand. Prodr. VII. p. 599.

A Pieride recedit antherarum loculis nec filamentis eristatis.

Rami innovando-subverticillati, angulati. Folia in apice ramorum fasciculato-approximata, breviter petiolata, coriacea, glabra $1-2^{\prime \prime}$ longa, 8-12"' lata. Racemi terminales solitarii simplices vel compositi, laxi, saepe nutantes et subsecundi; bracteae lineares pedicellos $2^{\prime \prime \prime}$ longos aequantes, bracteolae infra florem 2 lineares. Calycis lobi lanceolati acuti coriacei; corolla ovato-elliptica apice 
constricta lobis brevibus rotundatis. Stamina corolla dimidio breviora; filamenta linearia, ciliato-barbata; antherae dorso affixae, ellipticae, apice bifidae, dorso biaristatae, aristis subulatis scabris sqnarrosis. Squamulae decem, carhosae parvae, ovarii basin cingentes. Stylus corollae longitudine, stigmate truncato. Capsula depressoglobosa, calycem superans; placentae subglobosae ex apice columnae; semina pendula, lineari-trigona subarcuata, utrinque attenuata, laevia, $8-10$ in quovis loculo.

Warum geschieht der corona hypogyna, welche bei sehr vielen Andromeden, selbst bei A. polifolia und calyculata vorkommt, nirgends Erwälunng? Ihr Daseyn oder Mangel und ihre Beschaffenheit könnten gate Merkmale liefern. In der Gattung Pieris bildet sie bei $\mathbf{P}$. formosa einen deutlichen 10 zähnigen urceolus, scheint dagegen bei P. ovalifolia ganz zu fehlen.

433. Andr. (Pieris) elliptica S. \&. Z. - A tota glabra, foliis e basi rotundata ovato-ellipticis acutis integerrimis annuis, racemis lateralibus basi foliosis simplicibus, bracteis deciduis, calycis laciniis lanceolatis acutis, corolla cylindrica lobis abbreviatis obtusis, filamentis e basi lineari subulatis longe ciliatis infra antheram biaristatis, corona nulla, stylo cylindrico truncato corollam aequante.

Rami alterni, teretes, glabri. Folia annua, alterna, petiolata petiolis $3-6$ "' longis; lamina e basi rotundata ovata vel elliptica acuta, integerrima vel margine subundulata et obsolete crenulata, utrinque glabra, penninervia, membranacea, $3-4^{\prime \prime}$ longa, $1 \frac{1}{2}-2^{\prime \prime}$ lata. Racemi e gemmis lateralibus in ranulo brevi terminales, subcoëtanei, simplices, bipollicares, hasi foliosi, foliis parvis ovatis vel lanceolatis. Bracteae deciduae; pedunculi $2^{\prime \prime}$ longi, nudi. Calycis laciniae membranaceae, acutae, corolla cylindrica glabra, fauce vix constricta, 3-4"' longa, stamina duplo superans. Filamenta basi lineari-compressa sursum subulata, pilis albis raris longe ciliata, apice biaristata; antherae breves, ovatae, apice bifidae, dorso 
affixae. Coroua nulla. Ovarium globoso-subpentagonum, glabrum. Stylus longitudine corollae, truncatus, strictus, glaber.

P. ovalifoliae Don proxima, sed in hac folia basi plerumque cordata, coriacea, racemi longiores, corolla major extus pubescens et styli exserti.

239. Meisteria Sieb. et Zuccar. Tab. I.

Calyx 5-partitus, persistens, lobis acutis. Corolla campanulata vel urceolata ore ampliato quinquefido, lobis laciniatis plerumque trifidis, laciniis subulatis. Stamina 10 inclusa; filamenta supra basin dilatato-incrassata sursum subulata, mutica, barbata; antherae breves incumbentes, (primum posticae), apice dehiscentes ibique biaristatae, totae pubescentes. Corona nulla. Ovarium pentagonum loculis multiovnlatis, stylo pentagono truncato. Capsula elliptica, 5-locularis, 5-valvis valvulis loculicidis. Semina in quovis loculo panca, pendula, lineari-oblonga compressa vel trigona, foveolata et in angulis squamuloso-cristata.

Diximus hoc genus in honorem Georgii Meisteri, per decennium Cleyeri in Java hortulani, qui bis (1682-84 et 1685-87) Japoniam adiit indeque plantas vivas, semina et icones plantarum in Javam turelit. *)

434. M. cernua S. et. Z. - M. folïs e basi cuneata obovatis vel obovato-spathulatis obtusis vel acutiusculis, totis uncinato-serrulatis serraturis setaceo-mucronatis, subtus basi ad nervum medium barbatis, racemis terminalibus solitarïs simplicibus cernuis, pedanculis ebracteatis hirtis, capsulis maturis reflexis.

Rami teretes iunovando-subverticillati, novelli pubescentes. Folia in apice ramorum fasciculato-approximata et subrosulata, annua, breviter petiolata et basi cuneata in petiolum decurrentia, obovatospathulata, obtusa vel acutiuscula, toto margine dense serrulata, ser-

*) Confer. Gel.-Anz. 1844. n. 55. (Bullet. N. 19.) 
raturis in setam uncinatam terminatis, superne glabra vel ad venas impressas setulis adspersa, subtus basi ad nervum medium (praesertim juniora) fuscescenti-barbata, 1-1 $\frac{1}{2}{ }^{\prime \prime}$ longa, 4-6 $6^{\prime \prime \prime}$ lata. Racemi terminales, solitarii, simplices, cernui, multi-(10-15-) flori, $1-2$ " longi; pedunculi ebracteati, tenues, uti rachis ferrugineo-hirti, $3-4$ " longi. Calyx brevis 5 -fidus laciniis lanceolatis acutis. Corolla campanulata fance subampliata, 5-fida; lobi iterum trifidi laciniis linearibus acuminatis. Stamina 10, corolla dimidio breviora; filamenta parum supra basin dilatata et incrassata, sursum subulata, pilis brevibus dense barbata; antherae primum posticae (basi dehiscentes et aristatae), demum introrsum inclinatae indeque apice oblique hiporosae et aristatae, totae aeque ac aristae breviter hirtae. Corona nulla. Ovarii locula multiovulata. Capsula calyce triplo longior, obovatoelliptica, matura in pedunculo reflexa. Semina (abortu) in quovis loculo pauca, ex apice columnae pendula, oblonga, compressa vel trigona, dense foveolata et in angulis cristata, crista irregulariter incisa rigida.

240. Clethra L.

435. $\boldsymbol{C l}$. barbinervis $\boldsymbol{S}$. et $\mathbf{Z}$. $-\mathbf{C l}$. foliis deciduis petiolatis $e$ basi cuneata obovatis vel obovato-ellipticis acutis argute serratis superne glabris subtus in nervo medio venisque primariis setoso-pubescentibus et in axillis venarum barbatis, racemis terminalibus paniculatis elongatis, rachi pedunculis calycibusque ferrugineo-prubescentibus, bracteis caducis, genitalibus exsertis, capsulis nutantibus hirsutis. Cl. japonica Thunb. apud Steudel Nonencl. I. p. 383?

Rami alterni vel innovando-subverticillati, novelli hirti. Folia annua alterna, petiolata, petiolo semipollicari; lamina in basi cuneata integerrima ceterum argute serrata, subtus inter venas tenuissime reticulato-venosa, $2-3^{\prime \prime}$ longa, $1-1 \frac{1}{2}$ " lata. Racemi terminales, 5-9 in paniculam congesti, 3-6" longi, stricte erecti; bracteae jam ab alabastris caducae; pedunculi $2^{\prime \prime \prime}$ longi, horizontalites patentes una cum rachi et calycibus fuscescenti-hirti. Calycis laciniae 
ovatae obtusae. Corolla pentapetala, petalis obovato-oblongis obtusis glabris calycem duplo superantibus. Stamina exserta, filamentis glabris, antheris sagittato-cordatis basi biporosis. Ovarium globosum dense hirtum. Stylus persistens stricte erectus hasi hirtus, $2^{\prime \prime \prime}$ longus, 'stigmate trifido. Capsula globosa, deflexo-nutans.

\section{Gantiera Kalm.}

436. G. triquetra S. et Z. - G. ramis glabris subalato-triquetris, foliis ellipticis utrinque attenuatis acutis glandula terminatis crenato-serrulatis glabris coriaceis subtus punctatis, racemis compositis vel paniculatis axillaribus et terminalibus erectis multifloris, rachi argute angulata, bracteis lanceolatis acutis quam pedicelli apice bihracteolati brevioribus, calyce post foecundationem excrescente capsulam depresso-globosam pubescentem obtegente carnoso-sicco.

Fruticosa, erecta. Rami acute triquetri et subalati. Folia peremnia, coriacea, breviter petiolata, elliptica utrinque attenuata, in glaudulam callosam terminata, utrinque glabra, subtus glandulis nigricantibus punctata, $3^{\prime \prime}$ longa, 12-15"' lata. Racemi compositi basi soepe foliosi foliis sessilibus lineari-lanceolatis, stricti, $3-h^{\prime \prime}$ longi; rachis acute triangularis glabra. Bracteae lanceolatae coriaceae quam pedicelli pubescentes breviores; bracteolae 2 ad basin calycis oppositae ovatae acutae carinatae. Calyx 5- partitus, laciniis ovatis acutis coriaceis glabris. Corolla subglobosa apice constricta breviter 5- fida. Stamina 10 corolla breviora; filamenta basi dilatata pubescentia; antherae breves apice quadriaristatae. Cupula e squamis 10 late ovatis acutis ovarii basin cingens. Stylus cylindricus longitudine corollae. stigmate obtuso. Semina numerosa, minuta, difformia, testa subfoveolata.

242. Vaccinium L.

437. Vaccinium bracteatum Thunl. Flor. jaj) p. 156. - V. ramis junioribus angulatis glabris, foliis annuis petiolatis ovatis acutis serrulatis, racemis axillaribus simplicibus secundis, bracteis vel foliaceis lanceolatis acutis persistentibus florem fructumque superan-

Abhandlungen d. II. Cl. d. k. Ak. d. Wiss. IV. B. Abthl. III. 
tibus vel minutis linearibus caducis, rachi pedicellis basi bibracteolatis calycibusque cano-pubescentibus, corollis cylindricis pubescentibus, filamentis inclusis barbatis, antheris muticis apice longe rostratis, stylo corollam aequante, bacca 10-loculari. De Cand. Prodr. VII. p. 573. et reliq. auctorum.

Frutex ramis adultioribus teretibus, novellis angulatis glabris. Folia alterna, petiolata, petiolo $2-3^{\prime \prime \prime}$ longo, ovata vel ovato-elliptica acuta, serrulata, adultiora coriacea et (sicca) soepius margine revoluta, glabra, $1-2^{\prime \prime}$ longa, $8-10^{\prime \prime \prime}$ lata. Racemi axillares $1-2^{\prime \prime}$ longi, erecti, simplices secundi; rachis pedunculi et calycęs canopubescentes. Bracteae ad florum basin vel foliaceae, lanceolatae acutae argute serratae glabrae, florem fructumque superantes et persistentes, vel lineares canescentes pedicello basi bibracteolato breviores, caducae. Corolla cylindrica, extus pubescens, $3^{i m}$ longa. Antherae longe rostratae, rostris locula superantibus. Bacca magnitudine pisi minoris, 10 - locularis.

243. Rhododendron L.

438. Rhod. Metternichii S. et Z. Flor. japon. I. p. 23. tab. 9. Rhod. maximum Thunb. Fl. japon. p. 181. - Hymenanthes japonica Blume Bijdragen p. 862.

Capsula matura cylindrico-subpenta - heptagona, extus lana ferruginea derasili adspersa, styli basi coronata, lignescens, $8-10^{\prime \prime \prime}$ longa, 6-8-locularis et valvis totidem saepius per paria longitudinaliter cohaerentibus dehiscens. Columna centralis crassa per totam longitudinem placentifera placentis 6-8. Semina numerosa pluriseriata, erecta, oblonga, compressa, anguste marginata et apice membranaceo- appendiculata appendice lacera albida, testa tenuissima tenuiter striolata brunnea.

439. Rhod. indicum Sweet. - Azalea indica Linn. Thunb. Flor. jap. p. 84. - Tecki Tsjocku vulgo Tsutsusi Krempf. Amoen. p. 845. c. icone. Cum varietatt. 
140. Rleod. Burmani G. Don et De Cand. Prodr. VII. p. 727. Azalea rosmarinifolia Burm. fl. ind. 43. t. 3. Blune Bijdr. 853. 441. Rhod. ledifolium De Cand. Prodr. VII. p. 727. - Azalea mucronata Blume Bijglr. p. 853.

442. Rhod. molle. Azalea mollis Blume l. c. p. 853.

443. Rhod. linearifoliun $\boldsymbol{S}$. et $\mathbf{Z}$. Rh. foliis linearibus utrinque attenuatis longe acnminatis ferrugineo-hirsutissimis, floribus terminalibus $1-3$, laciniis calycis lineari-setaceis elongatis acuminatis uti tubus glanduloso-hispidis, corollae laciniis linearibus acuminatis glabris, staminibus $\tilde{5}$.

Rami innovando-subverticillati. Folia anuna fasciculata, linearia, utrinque longe attenuata acuminata margine revolnta pilis rigidis patentibus fuscis praesertim basin versus hirsntissima, $1-1 \frac{1}{2}$ " longa, 1- $2^{\prime \prime \prime}$ lata. Flores terminales solitarii-terni. Calycis laciniae subulatae longe acuminatae glanduloso-hispidae, semipollicares. Corollae laciniae lineares acuminatae $8-9^{\prime \prime \prime}$ longae, glabrae. Stamina glabra corollam superantia stylo breviora.

Nach Endlichers Vorgang finden wir keinen Grund, die fünfmännigen Arten der Gattung Rhododendron von den zehn- oder mehrmännigen als eigenes genus getrennt zu halten. Im übrigen unterliegen noch mehrere japanische Arten genanerer Bestimmung, welche durch die bei der grossen Menge von Spielarten obwaltende Unsicherheit der Merkmale sehr erschwert wird.

244. Pyrola Tournef.

444. P. media $\mathbf{S w}$.

\section{7. (160 Endl.) STYRACEAE Endl.}

245. Styrax Tournef.

445. St. japonicum S. et. Z. Fl. jap. I. p. 53. tab. 23.

446. St. Obassia S. et Z. Fl. jap. I. p. 92. tab. 46.

246. Pterostyrax S. et $\mathbf{Z}$. 
447. Pt. corymbosim S. et Z. Fl. jap. I. pag. 92. tab. 47.

448. Pt. anicranthun S. et Z. - Pt. foliis e basi rotundata ovato-ellipticis acutis repando-glanduloso-serrulatis utrinque pilis stellatis pubescentibus viridibus, paniculis terminalibus pyramidatis, ramis brevibus densifloris, floribus subsessilibus secundis distichis, calyce ovario adnato quinquangulari petalisque albido-tomentosis, staminibus liberis, antheris imberbihus, stylo basi tantum barbato sursum nudo.

Folia bipollicaria. Pankeulae bi - tripolicares, erectae, pyramidatae nec corymbosae, ramis horizontaliter patentibus abbreviatis densifloris. Flores quam in praecedente triplo minores. Calyx ovario adnatus, 5- dentatus dentibus ovatis acutiusculis, pilis brevissimis stellatis aeque ac petala oblonga albido-tomentosus, quinquesulcatus. Stamina 10 libera; filamenta filiformia tenuiter barbata; antherae erectae lineari-oblongae, imberbes. Stylus stamina parum superans eylindricus, basi barbatus sursum glaber, stigmate $3-5$ dentato.

449. Pr. lispidum $\mathbf{S}$. et $\mathbf{Z}$. - Pt. foliis e basi rotundata ovatis acutis repando-glanduloso-serrulatis superne pubescentibus subtus pilis stellatis minutissimis canescentibus, paniculis terminalibus pyramidatis, floribus sessilibus, calycis dentibus lanceolatis acuminatis, drupis cylindricis utrinque attenuatis decemnerviis apteris densissime albido-hispidis, stylo basi tomentoso superne nudo.

Die Exemplare der beiden vorstehenden Arten sind leider sehr unvollständig und von der erstern nur Bruchstücke mit Blüthen, von der zweiten ähnliche mit unreifen Früchten vorhanden. Es wäre möglich, dass beide zusammenfielen, doch glanbte ich sie vor der Hand trennen zu müssen, weil bei Pt. micranthum der mit dem Fruchtknoten verwachsene Kelch stark 5kantig und von sehr kurzen Sternhaaren filzig, bei Pt. hispidum dagegen fast stielrund, zehnnervig und von lang abstehenden Steifhaaren zottig ist. Auch die Gestalt der Kelchzähne und die Pubescenz der Blätter ist verschieden, obgleich letztere bei Pt. hispidum zu wechseln scheint. 
247. Symplocos L.

450. S. japonica De Cand. Prodr. VIII. p. 255. - S. lucida. S. et Z. Flor. jap. I. p. 55. tab. 21.

Myrtus laevis Thunb., welchen wir in der Flora japonica als Synonym hieher gezogen haben, gehört nicht zu Symplocos und ist vielleicht eher eine Pomacea.

451. S. prunifolia $\boldsymbol{S}$. et $\boldsymbol{Z}$. - S. foliis petiolatis oblongo-ellipticis subfalcato-cuspidatis acumine obtuso, remote crenulatis utrinque glabris biennibus coriaceis, racemis axillaribus simplicibus erectis multifloris eylindricis petiolo plusquam duplo longioribus, rachi pedicellisque calycem aequantibus vel parum superantibus bibracteolatis pilosis, calycis laciniis ovatis rotundatis glabris.

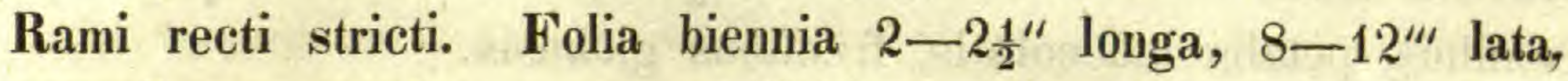
coriacea, firma, margine parum revoluta, novella ad serraturas glandulis capitatis munita; petioli semipollicares. Flores coëtanei. Raceni erecti stricti, pollicares vel sesquipollicares. Stamina numerosa.

452. S. myrtacea S. et Z. - S. tota glabra, foliis petiolatis oblongo-lanceolatis vel lanceolatis longe falcato-acuminatis acumine integerrimo glanduloso-mucronato, ceterum a basi crenato-serrulatis, racemis axillaribus laxe erectis panci- $(3-5)$ floris subcorymbosis petiolum duplo triplove superantibus, pedicellis calyce multoties longioribus filiformibus, bracteolis deciduis, calycis laciniis ovatis obtusis.

Rami tenues virgati. Folia bipollicaria longe acuminata acumine $6-8^{\prime \prime \prime}$ longo, basi rotundata vel parum attenuata, $6-8^{\prime \prime \prime}$ lata; petioli $5-6^{\prime \prime}$ longi. Racemi dimidium folii circiter aequantes, panciflori, floribus inferioribus longius pedicellatis indeque subcorymbosi, laxi; pedicelli filiformes, $4-5^{\prime \prime \prime}$ longi. Fructus elliptici.

453. S. lancifolia S. et Z. - S. foliis breviter petiolatis lanceolatis utrinque attenuatis acuminatis acumine obtuso, serrulatis glabris vel subtus ad nervos parce pilosis, racemis, axillaribus solitariis cylindricis multifloris tertiam vel dimidiam folii partem aequan- 
tibus, floribus subsessilibus tribracteatis, rachi bracteis et calycis laciniis ellipticis obtusis ferrugineo-pubescentibus. Rami juniores ferrugineo-pubescentes. Folia basi attenuata, lanceolata, longe acuminata acumine falcato obtuso, $2-2 \frac{1}{2}^{\prime \prime}$ louga, $6-9^{\prime \prime \prime}$ lata. Racemi semipollicares - pollicares, a basi floriferi, cylindrici. Bracteae ovatae acutae, uti calycis laciniae ellipticae obtusae dorso ferrugineo-pube scentes.

454. S. leptostachys $\boldsymbol{S}$. et $\boldsymbol{Z}$. - S. foliis breviter petiolatis e basi rotundata ovatis vel ovato-lanceolatis acuminatis acumine acuto, serrulatis utrinque glabris, racemis basi nudis gracilibus sparsifloris folium saepius aequantibus, floribus sessilibus tribracteatis, bracteis suborbicularibus obtusis calycisque laciniis ellipticis pubescentibus, petalis lanceolatis, fructibus globosis.

Praecedenti affinis, diversa tamen foliis latioribus basi rotnndatis acute acuminatis, racemis basi nudis gracilioribus et laxioribus petalisque lanceolatis. Fructus magnit. grani piperis globosi.

455. S. theophrastaefolia S. et Z. - S. foliis petiolatis oblongis vel oblongo-ellipticis utrinque attenuatis acuminatis serratis utrinque glabris coriaceis, racemis axillaribus solitariis vel saepius ternis quaternisve basi connatis, erectis strictis fliformibus elongatis, floribus remotiusculis sessilibus tribracteatis, rachi bracteis calycisque laciniis ovatis rotundatis pubescentibns.

Folia $6-8$ " longa, $1-2 \frac{1}{2}$ " lata, firma, coriacea, basi in petiolum semipollicarem teretem attenuata, argute serrata, facie fere eorum Theophrastae. Racemi plerumque basi compositi, tripollicares, stricti, floribus parvis a se invicem distantibus sessilibus.

456. S. neriifolia $\mathbf{S}$. et $\mathbf{Z}$. - $\mathbf{S}$. foliis petiolatis oblongo-sublinearibus ntrinque attenuatis obtusis vel obtuse acutis integerrimis vel apicem versus remote serratis margine subrevolutis coriaceis glabris subtus glaucescentibus, racemis abbreviatis axillaribus solitariis ternisve glomeratis densis, floribus subessilibus tribracteatis, 
hirac bracteis et calycis laciniis ovatis obtusis dense ferrugineotomentosis.

Folia 5-6" longa petiolo pollicari, 10-15" Jata, lineari-oblonga, obtusa vel in acumen obtusum terminata, integerrima vel apicem versus remote serrata. Racemi petiolis breviores glomerati, dense ferrugineo-tomentosi. Flores in specc. nostris plerique abortivi. Drupa elliptico-oblonga, calyce coronata, obtusa, glabra.

248. Schöp fia Schreb.

457. Sch. jasminodora S. et Z. - Sch. foliis e basi rotundata ovatis acuminatis acumine subfalcato, integerrimis, racemis simplicibus axillaribus paucifloris, calycis margine quadridentato, corollae lobis deltoideis acutiusculis.

Rami teretes subflexuosi. Folia alterna, petiolata petiolo $3^{m}$ longo, e basi rotnndata ovata vel rarius ovato-lanceolata, oblique acuminata, integerrima, penninervia, glabra, $1 \frac{1}{2}-2 \frac{1}{2}^{\prime \prime}$ longa, $10-15^{\prime \prime \prime}$ lata. Racemi axillares solitarii simplices, tri- quinqueflori pedunculo fi liformi glabro pollicari. Flores sessiles, basi bractea minuta suffulti. Calyx cum ovario connatus tubo subcylindrico, limbo brevissime quadridentato. Corolla gamopetala tubulosa tobo cylindrico glabro, limbo quadripartito laciniis deltoideis acutiusculis. Stamina 4 corollae fauci ad locum insertionis barbulatae affixa et ejusdem laciniis opposita; filamenta brevissima, subulata, in corolla decurrentia; antherae parun supra basin affixae ovatae antice quadriloculares. Ovarium calyci innatum triloculare loculis uniovulatis. Discus carnosus ovarii verticem obtegens stylumque rectum trisulcatum inclusum basi ambiens. Stigma trilobum labis divergentibus carnosis obtusis. Drupa elliptica obtusa sicca crustacea, calycis rudimento coronata, abortu mono-, raro trisperma. Variat floribus pentameris. Odor florum gratus, fortis, Jasminum referens.

De Candolle und anch Endlicher im Enchiridion stellen die Gattun Schöpfiag zn den Loranthaceen; wir möchten sie lieber mit Bentam znh den Olacinen rechnen; da dieselbe uns aber bei Bearbei- 
tung jener Familie noch nicht vorlag, so führen wir sie einstweilen hier an der Stelle auf, welche ihr Eudlicher in den generibus anwies.

\section{Diospyros $L$.}

\section{9. (159.-Endl.) EBENACEAE $\boldsymbol{R}$. $\boldsymbol{B}$.}

458. D. Kaki Lin. fil. Thunb. Flor. jap. p. 158. D. Kaki. De Cand. Prodr. VIII. p. 229. - Si vulgo Kalki. Kämpfer Amoen. p. 805. cum icone.

459. D. japonica S. et Z. D. ramis glabris, foliis ovato-ellipticis obtusis vel acutiusculis utrinque glabris subtus glancis, floribus masculis in pedunculo brevissimo ferrugineo-hirto plerumque ternis subsessilibns, calyce cupulari quadrifido laciniis deltoideis acutis, calvo vel ferrugineo-pubescente, corolla quam calyx triplo longiore cylindrica apice constricta breviter 4loba, staminibus 16 inter se liberis, antheris cristato-acuminatis utrinque inter locula et ad margines valvularum barbatis, fructibus globosis. $\boldsymbol{D}$. microcarpa Siebold in Annuaire de la société hortic. des Pays-bas 1844. p. 28.

Diosp. Kaki ß. Sina no Kaki Thumb. Fl. jap. p. 158. - D. Kaki $\gamma$. glabra. DeCand. Prodr. VIII. p. 299.

Differt a $D . K u k i$ praeter folia glabra subtus glanca praesertim floribus subsessilibus, calyce cupulari uon ampliato nec profunde quadripartito sed potius quadridentato dentibus sen lobis abbreviatis deltoideis acutis, corolla quam calyx triplo longiore apice constricta breviter quadriloba.

79. (158. Endl.) SAPOTACEAE Inss.

250. Achras L. 182. 460. A. Sapota $L$.

251. Sideroxylon $L$. 461. Species. 


\section{0. (157 Endl.) MYRSINEAE $\boldsymbol{R}$. $\boldsymbol{B}$.}

252. M y r sine $\boldsymbol{L}$.

462. M. neriifolia S. et Z. - M. glabra, foliis lineari-oblongis utrinque attenuatis integerrimis glabris coriaceis, umbellis e gemmis propriis infra et inter folia sessilibus subquinquefloris, perulis numerosis imbricatis cinctis, calycis laciniis lanceolatis acutis aeque ac corollae lobi ovato-oblongi acutiusculi margine dense papillosis ceterum glabris, staminibus corolla parum brevioribus, drupis subglobosis pedicellos superantibus.

Folia versus apicem ramorum approximata, petiolata petiolis semiteretibus $3^{\prime \prime \prime}$ longis, lineari-oblonga utrinque attenuata obtusa vel acutiuscula integerrima utrinque glabra et adultiora subtus (sicca) fuscescentia, $3-4$ poll. longa, $9-12^{\prime \prime \prime}$ lata. Flores in ramis hornis et anni praecedentis e gemmis propriis dense pernlatis, $4-\overline{0}$ in umbellas simplices sessiles dispositi; pedicelli $1-2^{\prime \prime \prime}$ longi. Calycis laciniae lineari-lanceolatae acutae coriaceae-margine aeque ac corollae lobi oblongi papillis brevibus dense cincti, ceterum glabri. Filamenta brevia, antherae ovato-oblongae acutinsculae antice quadriloculares. Drupa magnitudine pisi minoris ovato-globosa, styli basi coronata.

253. Ardisia $\boldsymbol{L}$.

463. Ard. crispa Alph. De Cand. Linn. Transact. XVII. p. 124. et Prodr. VIII. p. 134. - Bladhia crispa Thunb. Flor. jap. p. 97. et fide Banks Icon. Kaempfer tab. 7. Ard. crenulata Lodd. bot. cab. t. 2. - A. crenata Bot. Magaz. tab. 1950. - A. lentiginosa. Bot. Feg. tab. 553. - A. glandulosa Blume Bijdr. p. 690.

Folia margine crenato-crispa, superne punctis elevatis verruculosa. Corollae laciniae et praesertim antherae dorso glandulis nigris adspersae.

464. Ard. glabra Alph. De Cand. Prodr. VIII. p. 135. - Bladhia glabra Thunb. Linn. Transact. II. pqg. 331. Flor. jap. p. 350. n. 5.

Abhandlungen d. II. Cl. d. k. Ak. d. Wiss. IV. B. Abthl. III. 
465̃. Ard. japonica Blume Bijdr. p. 690. De Cand. Prodr. VIII. p. 135. - Bladhia japonica Thunb. Hlor. jap. p. 95. tab. 18. et Hornst. Dissert. pars 1. pag. 6. 7. c. ic. Caules semipedales vel pedales tenues simplices adscendentes inferne radicantes. Folia venis utrinque prominulis reticulata, pellucide punctata. Calycis laciniae tenuiter glanduloso-ciliatae. Corolla et antherae dorso glandulis nigris adspersae.

466. Ard. pusilla. Alph. De Cand. Linn. Transact. XVII. $p$. 137. et Prodr. VIII. pag. 137. - Bladhia villosa Thunb. Flor. jap. pag. 56.

254. Maesa Forsk.

467. M. Doraena $\boldsymbol{B l}$. - M. foliis plerumque oblongis vel obovato-oblongis utrinque attenuatis acuminatis, basi cuneata integerrimis ceterum remote et argute serratis, utrinque glabris, rarius lineari-oblongis vel quoque ovatis, acutis vel obtusis, margine subintegerrimis, racemis axillaribus solitariis geminisve petiolo longioribus secundis multifloris, pedicellis flore longioribus apice bibracteolatis, calycis laciniis ovatis obtusis, corollae tubo cylindrico quam caly $\mathbf{x}$ triplo longiore, drupis globosis calyce coronatis multinervio-lineatis, polyspermis. - Doraena japonica Thunb. Fl. jap. p. 6 et 84 et Auct.

Rami virgati teretes glabri. Folia figura varia, petiolata petiolis $3-6^{\prime \prime \prime}$ longis ; lamina folii $1 \frac{1}{2}-6$ - pollicaris, plerumque oblonga vel obovato-oblonga utrinque attenuata acuminata, a medio sursum argute et remote serrata serraturis mucronatis, penninervia, rarius late ovata vel quoque lineari-oblonga. Racemi solitarii gemini ternive plerumque supraaxillares, 6-18"' longi, erecti secundi multiflori. Bracteae pedicellis triplo breviores ovatae obtusae; bracteolae duae alternae calycis basin amplectentes. Calyx semïnferus, tubo ovario adnato turbinato; limbi laciniae ovatae rotundatae lineolis glandulosis notatae. Corolla cylindrica, limbi laciniis brevibus rotundatis punctis lineolisve glandulosis anrantiacis notata. Stamina in- 
clusa, filamentis filiformibus. Ovarii pars libera conica. Stylns subulatus stigmate tridentato. Drupa grano Coriandri parum major globosa, calyce coronata, sicca, membranacea, lineolis numerosis resinosis nigricantibus longitudinaliter striata. Semina numerosa angulata, nigra.

\section{1. (156. Endl.) PRIMUlaceae Vent.}

25̃. Primula L.

468. R. cortusoides L. Thunb. Flor, jap. p. 82.

256. Lysim a chia L.

469. L. japonica Thunb. L. caule decumbente debili ramoso sursum adscendente villoso, foliis inferioribus oppositis superioribus alternis petiolatis e basi rotundata vel subcordata orbiculari-spathulatis acutiusculis, integerrimis, pubescentibus, floribus axillaribus solitarïs geminisve breviter pedunculatis, pedunculis quam petioli brevioribus, et fructiferis ereetis, calycis laciniis lanceolatis acnminatis hirtis capsulam dimidio superantibus. L. jap. Thunb. FT. jap. p. 83. De Cand. Prodr. VIII. p. 67.

Specineu nostrum mancam. Corolla subrotata et longitudine ca-

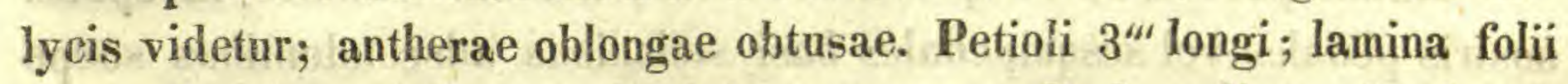
semipollicaris, ad lentem glanduloso-punctata. Pednncnli 1-2'“ longi, erecti, hirti.

470. L. clethroides Duby ap. De Cand. Prodr. VIII. p. 61. L. Ephemerum Thunb. Fl. jap. p. 83.

Folia breviter petiolata utrinque longe attenuata acuminata ovatolanceolata, ad lucem nigro-punctata, tripollicaria, alterna. Racemns terminalis cylindricus densus primum nutans, demum elongatus erectus; pedicelli $2-3^{\text {un }}$ longi, bractea subulato-filiformi breviores. Calycis laciniae ovato-lanceolatae acutiusculae, margine breviter ciliatofimbriatae, dorso nigro-punctatae. Corollae tubus brevissimus; laciniae oblongae obtusae, calyce duplo longiores. Stamina basi vix 
monadelpha, dimidium corollae aequantia. Antherae lineari-oblongae acutae. Stylus brevis eylindricus stigmate truncato.

471. L. lubinioides S. et Z. L. caule stricte erecto, foliis alternis sessilibus subamplexicaulibus oblongis vel oblongo-lanceolatis acutiusculis uti tota planta glabris nigro-punctatis, racemo laxo folioso foliis floralibus sensim minoribus, pedunculis strictis fructiferis folium subaequantibus, calycis laciniis lineari-oblongis obtusis nigropunctatis, corolla profunde quinquefida, laciniis oblongo-lanceolatis obtusis, staminibus basi monadelphis corolla dimidio brevioribus, stylo brevi cylindrico, stigmate truncato.

Habitu Lubiniam spathulatam referens, sed omnibus partibus minor. Folia in petiolum brevissimum late decurrentia indeque subamplexicanlia, 2-2.1" longa, 6-10" lata, superiora floralia seusim minora. Calycis laciniae anguste albo-marginatae. Tubus corollinus limbo plus quam quadruplo brevior. Stamina basi monadelpha, compresso-plana; antherae lineari-oblongae.

472. L. lineariloba Hook. ap. Beechey Bot. p. 268. De Cand. Prodr. l. c. p. 61.

Radix perennis, oblique descendens, fibrosa. Caules in specc. nostris pedales vel sesquipedales basi stolonibus adscendentibns soepe floriferis, sursum parce ramosi vel simplices. Folia inferiora distincte petiolata et in petiolum decurrentia, spathulata obtusa, superiora oblonga sessilia; omnia glabra, crassiuscula glaucescentia, punctis minutis nigricantibus densissime adspersa, inferiora cum petiolo $6^{\prime \prime \prime}$ longo bipollicaria. Racemi terminales stricti erect icylindrici densi, bipollicares; bracteae foliaceae calycem aequantes; pedunculi vix $2^{\prime \prime \prime}$ longi. Calycis laciniae lanceolatae acutae, albo-marginatae, ceterum densissime nigro-punctulatae. Corollae tubus cylindricus, laciniis lineari-oblongis obtusis plus quam duplo brevior. Stamina fanci affixa filamentis brevibus inter se liberis, antheris ovatis obtusis. Stylus cylindricus stigmate truncato. 
Crescit in insulis Peel et Bonin-Sima (unde specc. a beato Mertens lecta vidi in herb. Acad. Imper. Petropol.), nec non in insulis Liu-Kiu (Hooker l. c.)

Die Drüsen auf den Blättern sind dicht gestellt, von unregelmässiger Gestalt und so klein, dass sie sehr leicht ubersehen werden. 257. Anagallis Tournef.

473. A. urvensis $L$.

a) floribus phoeniceis Thunb. Flor. jap. p. 83.

B) floribus coeruleis Herb. Siebold.

\section{2. (155 Endl.) UTRICULARIEAE Link.}

258. Utricularia $\mathbf{L}$.

474. Species absque floribus.

83. (154 Endl.) OROBANCHEAE L. C. Rich.

259. Boschniakia C. A. M.

475. Species. Plantam ipsam non vidimus, sed ex icone ad vivum delineatam genus recognovimns.

260. Aeginetia Linn.

476. Aeg. japonica S. et Z. Aeg. indicae Roxb. proxima diversa videtur flore majore et magis inflato, calycem duplo fere superante nec non stigmate peltato duplo latiore.

261. Phacellanthus $\mathbf{S}$. et $\mathbf{Z}$.

Calyx diphyllus foliolis distinctis, exteriori spathaceo florem amplectente, interiori multo minori lanceolato acuminato. Corolla longe tubulosa cylindrica limbo breviter quinquefido (subregulari?). Stamina 4 antheris suberectis oblongis bilocularibus muticis. Ovarium uniloculare placentis parietalibus quatuor aequidistantibus multiovulatis. Stylus simplex stigmate dilatato carnoso oblique decurrente medio canaliculato. Capsula .... 


\section{Ph. tubiflorus S. et Z.}

Scapus simplex vix tripollicaris carnosus squamis multis oblongis obtusis laxe imbricatis munitus. Flores terminales fasciculati $2-6$, brevissime pedicellati. Corolla tubulosa anguste cylindrica basi circa. ovarium parum ampliata, pollicaris.

\section{4. (152 Endl.) GESNERACEAE Cyrtandraceae $\boldsymbol{R}$. Br} 262. Conandron S. et Z.

478. C. ramondioides Zuccar in Act. Mathem. Phys. Acad. Monac. III. p. 729. tab. III. f. 1. De Cand. Prodr. IX. p. 273.

\section{5. (15̃ Endl.) BIGNONIACEAE $\boldsymbol{R}$. $\boldsymbol{B}$.}

263. Sesamum L.

479. S. orientale $L$.

264. Catalpa Scop.

480. C. Kaempferi \$. etZ. - Catalpa bignonioides $\beta$. Kämpferi De Cand. Prodr. IX. p. 226. Bignonia Catalpa Thunb. Fl. jap. p. 251. Kakusju, vulgo Kawara fisági Kümpfer Amoen. anot. p. 841 c. icone.

Es unterliegt keinem Zweifel, dass die japanische Catalpa von der amerikanischen als Art verschieden sey, obgleich leider die im Augenblick uns vorliegenden Exemplare nicht genügen, um die Unterschiede festzustellen.

Indessen sind bei der japanischen Art die Blüthen überhaupt, vorzüglich aber die Kelche mehr als dreimal kleiner als bei der amerikanischen, die Blätter meístens kurz dreilappig, die Schoten nach Kämpfer spithama longiores et culmum avenaceum crassae, bei der amerikanischen dagegen $1 \frac{1}{2}^{\prime}$ lang und fingerdick. Bei Vergleichung vollständiger Exemplare werden sich zuverlässig noch andre genauere Merkmale herausstellen.

265. Tecom a Juss.

481. T. grandiflora De Cand. Prodr. IX. p. 223. Bignonia grandiftora Thunb. Fl. jap. p. 253. Banks Jcones Kaempfer, tab. 21. 
Bign. chinensis Lam. dict. I. p. 423. - Campsis adrepens Lour. Flor. cochinch. $p$. 458. - Incarvillea grandiflora Poir. dict. sc. nat. 23. p. 53. Spreng. Syst. 2. p. 836. - Rjotsjo Kämpf. Amoen. p. 856 .

86. (150 Endl.) ACANTHACEAE $\boldsymbol{R}$. $\boldsymbol{B}$.

266. Justicia L.

482. J. japonica Thunb. Flor. jap. p. 20.

267. Paullownia S. et $\mathbf{Z}$.

483. P. imperialis S. et Z. Flor. jap. I. p. 25. tab. 10. Bignonia tomentosa Thunb. Fl. jap. p. 252. et Auct. - Jncarv. tomentosa Spreng. Syst. Veget. II. p. 836.

\section{7. (149 Endl.) SCROPHULARINEAE $R$. $B$ r.}

\section{Vandellia L.}

484. V. angustifolia Benth. Scroph. indicae p. 37! Tittmannia angustifolia Benth. in Wallich Catal. $n .3951$.

269. Gratiola L.

485. Species.

270. Veronica L.

486. V. Anagallis L. Thunb. Fl. jap. p. 20.

487. I. paniculata $L$.

488. V. longifolia $L$.

499. V. japonica Steud. V. foliis quinis senisve verticillatis subsessilibus ovato-ellipticis acuminatis argute serratis pubescentibus, spica terminali simplicissima cylindrica elongata, corollae tubulosae laciniis conniventibus lanceolatis, staminibus inclusis, antheris sagittatis. - Veronica virginica Thunb. Fl. jap. p. 20. V. japonica Steudel et ejusdem fide Eustachya japonica Rafin.

Perennis, canle bi-tripedali tereti herbaceo. Folia $4-6$ verticillata verticillis $2-3$ "a se invicem distantibus, subsessilia, utrinque attenuata ovato-elliptica, acuminata, argute et dense serrulata, pubescentia, $1 \frac{1}{2}-2 \frac{1}{2}{ }^{\prime \prime}$ 
longa, $10-15^{\prime \prime \prime}$ lata. Spica terminalis solitaria erecta $3-8$ "longa, cylindrica continua. Flores valde approximati sessiles bractea linearisubulata suffulti. Calyx 5partitns laciniis lanceolatis acuminatis, duabus superioribus parum majoribus. Corolla tubulosa tubo cylindrico calycem plus quam triplo superante parum incurvo intus basin versus pubescente, laciniis quatuor conniventibus lanceolatis. Stamina inclusa tubum aequantia; filamenta filiformia, antherae a basi ultra medium bifidae loculis divergentibus indeque sagittatae acutae glabrae. Ovarium ovatum, biloculare placentis mul tiovulatis. Stylus filiformis superne primum subclavatus, inclusus, demum excrescens, $3^{\text {in }}$ longus, persistens.

Habitus omnino Veronicae virginicae $\boldsymbol{L}$.

Quid. V. Chamaedrys et arvensis Thunb.?

271. Paederota Linn.

490. P. axillaris $\mathfrak{S}$. et $\boldsymbol{Z}$. P. canle erecto, foliis alternis brevissime petiolatis e basi rotundata ovatis acuminatis argute serratis glabris, spicis axillaribus solitarïs sessilibus cylindricis multifloris densis.

Canlis herbacens erectus subvirgatus parum ramosns teres glaber. Folia alterna petiolo vix $2-3^{\prime \prime \prime}$ longo affixa, hasi rotundata ovata oblique acuminata, argute serrata, $2-5^{\prime \prime}$ longa, $1 \frac{1}{2}-2 \frac{1}{2}$ "lata. Spicae in axillis foliorum solitariae, sessiles, vix pollicares, cylindricae, obtusae, multiflorae. Flores subsessiles, bractea minuta lineari suffulti. Calyx ad basin usque quinquepartitus, laciniis linearibns acuminatis glabris aequalibus persistentibus. Corolla rosea, calycem vix dimidio superans, tubo cylindrico limbo quadrifido laciniis lanceolatis argute acutis, superiori parum latiori. Stamina exserta, antheris suborbicnlaribus utrinque emarginatis loculis parallelis. Ovarium ovatum, biloculare, placentis utrinque in septo multiovulatis. Stylus exsertus, filiformis, emarginato-truncatus, persistens. Capsula calyce brevior, ovata compressiuscula, glabra, bivalvis valvis coriaceis demum bipartitis. 
491. P. bracteata S. et Z. P. caule erecto ramoso, foliis alternis breviter petiolatis ovatis vel lanceolatis utrinque attenuatis acutis serratis glabris, spicis terminalibus bracteis nonnullis foliaceis suffultis breviter cylindricis obtusis multilloris densis.

Caulis herbaceus erectus ramosus; folia alterna breviter petiolata petiolo vix $2^{\prime \prime \prime}$ longo, utrinque attenuata ovata vel superiora lanceolata acuta serrata glabra, pollicaria vel sesquipollicaria $6-12^{\prime \prime \prime}$ lata. Spicae in apice caulis et ramorum sessiles bracteis foliaceis $2-3$ inaequalibus lanceolatis acutis integerrimis suffultae, breves cylindricae, obtusae. Flores bractea lineari acuminata calycem parum superante suffulti. Calyx ad basin usque 5-partitus, laciniis linearibus acuminatis, una parum breviori. Corolla tubulosa calycem aequans; tubus cylindricus rectus, limbus quadrifidus laciniis lanceolatis acutis summa parum majori. Stamina duo, utrinque ad basin laciniae superioris, exserta. Filanenta subulata glabra, antherae suborbiculares utrinque emarginatae loculis parallelis. Ovarium ovatum biloculare, placentis utrinque septo affixis multiovulatis. Stylus filiformis exsertus, stamina superans, stigma teemarginatotruncato.

Dem Habitus nach weichen die vorstehenden Arten schon durch die folia alterna völlig von den europäischen ab, indessen konnten wir keine ausreichenden Merkmale auffinden am sie als Gattung zu trennen.

272. Siphonostegia Benth.

492. S. chinensis Benth. Scrophul. indicae p. 51. Hooker Botany of Capt. Beechey p. 203 tab. 44. -

Sprengel (Syst. II. p. S03) zieht Lindernia japonica Thunb. (F1. p. 253) zu Mazus rugosas Lour. oder Hornemannia bicolor Willd. Mit Recht?

Abhandlungen d. II. Cl. d, k. Ak. d. Wiss. IV. B. Abthl. III. 


\section{8. (148 Endl.) SOLANACE AE Bartl.}

273. Nicotiana Tourn.

493. N. chinensis Fisch. N. Tabacum Thunb. Fl. jap. p. 91. 274. Datura L.

494. D. Stramonium $\boldsymbol{L}$.

Nach Bunge wächst um Peking D. ferox. Sollte diess auch die japanische Pflanze seyn?

495. D. alba Nees. Linn. Transact. XVII. p. 73. Corolla semipedalis; folia basi valde inaequalia.

275. Physalis L.

496. Ph. Alkekengi L. Siebold Synops. in Act. Batav. XII. p. 34. Kömmt nach Bunge anch um Peking vor.

497. Ph. ciliata $\boldsymbol{S}$. et $\mathbf{Z}$. - Ph. herbacea erecta caule simplici angulato glabro, foliis longe petiolatis ovatis acutis grosse sinuato-dentatis dense ciliatis ad venas pilosiusculis ceterum glabris, floribus breviter pedunculatis nutantibus, calycis lacinïs tubo brevioribus lanceolatis acutis margine dense barbato-ciliatis, tubo parce pubescente, pedunculis fructiferis elongatis stricte deflexis et cauli adpressis. - Ph. angulata Thunb. Fl. jap. p. 91.

Caules in specc. nostris simplices erecti angulati glabri $1 \frac{1}{2}-2$ pedales. Folia alterna soepeque gemina, remota, longe petiolata, petioli 1-1 $\frac{1}{2} "$ longi; lamina e basi rotundata vel subattenuata ovata acuta grosse sinuato-dentata dentibus utrinque $2-3$, margine dense ciliata ceterum praeter pilos sparsos ad venas glabra, 3-4" longa, $2-2 \frac{1}{2}$ " lata. Flores solitarii extraaxillares, breviter pedunculati pedunculo nutante $3-4^{\prime \prime \prime}$ longo. Calyx campanulatus glabriusculus limbo quinquefido, laciniis tubo brevioribus lanceolatis margine dense barbatis ciliatis. Corolla immaculata? Pedunculi fructiferi pollicares stricte deflexi et canli adpressi glabri; calyces inflati apice ad lacinias conniventes barbati, ceterum glabriusculi.

Da Ph. Alkekengi nach v. Siebold in Japan vorkömmt, so gehört das Kämpfersche von Thunberg zu seiner Ph. angulata gezo- 
gene Citat Sansjo, Solanum vesicarium vulgo Alkekengi Amoen. p. 785. zu jener Pflanze.

276. Capsicum Tournef.

498. C. longum Dc. cum variett.

499. $\boldsymbol{C}$. annuum. $\boldsymbol{L}$, cum variett.

277. Solanum L.

500. S. nigrum $\boldsymbol{I}$.

501. S. tuberosum L. Rarius cultum.

502. S. Melongena L.

503. S. Dulcamara L. var. lyrata. S. lyratum Thunb. F'l. jap. p. 92.

Wir haben bisher die Pflanze zwar nicht selbst gesehen; aber theils weist Thunbergs Beschreibung die nahe Verwandtschaft derselben mit S. Dulcamara nach, theils berichtet Blume Bijdr. p. 698 , dass er diese Art als S. lyratum Thbg, ans Japan erhalten habe. 278. Lycium L.

504. L. chinense Blume Bijdr. p. 707. non Miller. L. barbarum Siebold Synops. l. c. p. 34 .

Accuratius examinandum an simul L. Trewianum R. S. Syst. IV. p. 693 et Duhamel.

\section{9. (145 Endl.) POLEMONIACEAE Vent.}

279. Schizocodon S. et $\boldsymbol{Z}$.

505. Sch. soldanelloides Zuccar. in Act. Mathem. Phys. Acad. Monac. III. p. 725. tab. II. fig. 1.

280. Polemonium L.

506. P. coeruleum L. Thunb. Fl. jap. p. 87.

90. (144 Endl.) CONVOLVULACEAE $\boldsymbol{R}$. Br.

281. Calystegia R. Br.

507. C. Soldanella R. Br. De Cand. Prodr. IX. p. 433. Conv. Soldanella Thunb. Fl. jap. p. 86. 
282. Batatas Chois.

508. B. edulis Chois. Conv. p. 53. De Cund. Prodr. IX. $p$. 338. - Conv. edulis Thunb. Fl. jap. p. 84. J. batatas Siebold Synops. l. c. p. 35. Aus den Liu-Kin-Inseln eingefüht. 283. Pharbitis Chois.

509. Ph. Nil. Chois. Conv. p. 57. De Cand. Prodr. IX, p. 343.? Jpomoea triloba Thunb. l.c.p. 86. Convolvulus Nil Thunb. Linn. transact. II. p. 330.

Wir geben eine Definition der Pflanze, welche wir vorlänfig zwar nicht von $\mathbf{P h}$. Nil trennen wollen, die aber durch Wurzel und Kelchbildung verschieden scheint.

Ph. radice tuberosa, canle retrorsum piloso, foliis cordatis trilobis lobo intermedio productiore omnibus cuspidatis, pedunculis quam petioli brevioribus, sepalis linearibus hispidis pollicaribus, corolla speciosa violacea.

Tubera radicum nigra vel alba; nigra laxantia (Thunb.). Petioli 4-6" longi; lamina folii basi profunde cordata triloba, lobis lateralibus brevioribus divergentibus, medio productiori basi latiori. Pedunculi $1-3$-flori, $2-4$ " longi. Flores breviter pedicellati. Sepala basi oblonga sursum longe linearia acuminata hispida. Corolla speciosa, fere tripollicaris, violacea.

$\mathrm{Ph}$. Nil hat eine einjährige Faserwurzel und eiförmige oder breitlanzettliche Kelchlappen. Dabei sagt Thunberg ausdrücklich, dass unsre Pflanze um Nangasaki und weiter einwärts sowohl wild wachse als kultivirt werde. $\mathbf{Z} n$ derselben scheint anch $\mathbf{J p}$. Nil Bunge Chin. p. 46 zu gehören, welche in Hecken bei Peking und nördlich bis an die Gebirge wild wachsen soll, während die eigentliche Nil ein Tropengewächs ist.

Conv. trinervius Thunb. Fl. p. 85 scheint, wie De Candolle mit Recht bemerkt, der folia opposita wegen nicht zu der Familie zu gehören. 284. Jpoma ea L.

510. J. filicaulis Blume Bijdr.p. 721. - Conv. japonicus Thunb. l. c. p. 85 ? ex auct. De Cand. Prodr. IX. p. 353. 
285. Cuscuta L.

511. C. major C. Bauh. - C. europaea Thunb. l. c. p. 76. ex auct. De Cand. Prodr. IX. p. 452.

\section{1. (143 Endl.) ASPERIFOLIAE $L$.}

\section{Lithospermum L.}

512. L. erythrorhizon S. et Z. - L. annuum, radice simpliei perpendiculari, caule erecto folioso uti omnes plantae partes hispido scabro, foliis brevissime petiolatis utrinque attenuatis, lanceolatis vel oblongo-lanceolatis acutis subtus nervosis, calycis laciniis corollae tubum aequantibus demum excrescentibus fructu triplo longioribus, nuculis dorso laevissimis acutis, ventre foveolatis. - Lithosp. arvense Thunb. l. c. p. 81. L. murasaki Sieb. Synops. in Act. Batav. XII. $p .32$.

Radix annua, simplex vel parce ramosa perpendicularis crassitie pennae anserinae, intense rubra. Caulis erectns pedalis vel bipedalis teres ramosus ramis erectis. Folia subsessilia utrinque attenuata lanceolata vel oblongo-lanceolata acuta papilloso-scabra et ad venas hispida, $1 \frac{1}{2}-4^{\prime \prime}$ longa, 6-18 $18^{\prime \prime}$ lata, subtus nervis prominentibus pinnatis notata. Bracteae lanceolatae foliaceae. Flores brevissime pedunculati. Calycis laciniae lineares obtusae hispidae tubum corollae aequantes. Corolla breviter tubulosa, fance ut in Lith. officinali squamulis 5 barbatis et in tubi hasi fornicibus 5 in annulum positis aucta, ochrolenca. Calycis fructiferi laciniae elongatae lineares fructu triplo longiores. Nuculae ovatae sursum attenuatae acutiusculae, dorso laevissimae ventre lineolis punetisve irregulariter exsculptae.

Differt a L. árvensi fructibus laevibus, canle basi simplici sursum ramoso foliis multo majoribus acutis nervosis, a. L. officinali radice annua, foliis nervosis latioribus, nueulis majoribus sursum attenuatis dorso laevibus ventre irregulariter sulcato-foveolatis, a $\mathbf{L}$. lineato, cui fortasse proxinum, radice annua, tubo corollae calycem non superante, nuculis duplo majoribus. 
Die Wurzel wird hänfig zum Rothfärben verwendet und die Pflanze deshalb auch angebaut.

287. Bothriospermum Bunge.

513. B. asperugoides $\mathbf{S}$. et Z $\mathbf{Z}$ - B. canlibus ramosis decumbentibus, foliis obovato-spathulatis obtusis vel acutiusculis scabris, pedunculis fructiferis extraaxillaribus erectis, calyce patente, nuculis tuberculato-scabris, caruncula in fundo umbilici longitndinaliter elliptica.

Habitis Asperuginis. Canles debiles ramosi decumbentes. Folia petiolata et in petiolum attenuata obovato-spathulata acutiuscula pollicaria vel sesquipollicaria. Flores solitarii extraaxillares breviter pedinculati. Corolla parva calycem aequans. Calyces fructiferi excrescentes laciniis lanceolatis acutis patentibus.

288. Cynoglossum L.

514. Cynoylossum japonicum Thunb. Flor. jap. p. 81. Decades plant. jap. HI. tab. 2. Lehmann Asperifol. p. 139.

Clariss. Hasskarl in Catal. hort. Bogoriensis altero p. 137. Ehretiam ovalifoliam enumerat quam e Japonia allatam suspicatur.

\section{2. (142 Endl.) CORDIACEAE $\boldsymbol{R}$. $\boldsymbol{B}$.}

\section{Cordia R. Br.}

515. C. thyrsiftora S. et Z. - C. glabra, foliis petiolatis e basi rotundata vel subcuneata ovatis vel ovato-ellipticis acutis serratis, panicula terminali pyramidata densa, floribus breviter pedicellatis, calycibus quinquefidis laciniis ovatis rotundatis ciliolatis, corollae lobis 5 ovato-oblongis acutiusculis, staminibus glabris, stylo bifido, stigmatibus brevissime emarginatis, drupa globosa dipyrena, pyrenis bilocularibus dispermis.

Rami novelli angulati, adultiores teretes. Petioli pollicares vel breviores superne canaliculati; lamina folii basi rotundata vel breviter cuneato-attenuata ovata vel ovato-elliptica acuta serrata, utrinque glabra penninervia, $3-5^{\prime \prime}$ longa, 1 $\frac{1}{2}-2 \frac{1}{2}$ "lata. Panicula ter- 
minalis soepe basi foliosa pyramidata densa (fere it in Ligustro); rachis et rami angulati puberuli; pedicelli bractea lineari-oblonga obtusa suffulti lineam longi. Calyx cupularis persistens laciniis ovatis rotundatis brevissime ciliatis. Corolla magnitudine circiter ut in Olea europaea, quinquefida, laciniis ovato-oblongis obtusis glabris. Stamina glabra. Ovarium quadriloculare. Stylus basi simplex superne bifidus stigmatibus divergentibus brevissime emarginatis, glaber. Drupa calyce persistente cincta magnitudine grani Piperis, globosa, dipyrena pyrenis osseis bilocularibus dorso convexis irregulariter exsculptis ventre planis, loculis monospermis altero plerumque abortivo.

\section{3. (141 Endl.) MYOPORINEAE $\boldsymbol{R} . \boldsymbol{B r}$.}

\section{Pentacoelium S. et $\boldsymbol{Z}$. Tab. III. 2.}

Calyx hypogynus regularis quinquepartitus persistens, fructifer haud mutatus. Corolla hypogyna, infundibuliformis vel subcampanulata tubo sensim ampliato in limbum aequaliter quinquelobum subbilabiatum. Stamina corollae tubo affixa, exserta, didynama absque quinti postici rudimento; antherae dorso affixae reniformes, anticae.. Ovarium superum, quinquangulare, ovulo solitario pendulo in quovis loculo. Stylus cylindricus stigmate obtuso subemarginato. Drupa calyce persistente basi cincta, pentagono-conica, carnosa; pyrenum osseum, pentagonum, quiuqueloculare, semine unico pendulo in quovis loculo.

\section{P. bontioides $\mathbf{S}$. et Z. -}

Frutex totus glaber ramis alternis teretibus. Folia alterna breviter petiolata utrinque longe attenuata, oblongo-lanceolata acuta integerrima coriacea, praeter nervum medium evenia, $2 \frac{1}{2}-4^{\prime \prime}$ longa, 10-15" lata. Flores ex axillis foliorum, pedunculis unifloris solitariis vel 2-3 sibi superpositis florem aequantibus ebracteatis. Calyx regularis quinquepartitus laciniis subdeltoideo-lanceolatis acutis coriaceis. Corolla infundibuliformi-campanulata pollicaris, tubo sursum sensim ampliato, limbi subbilabiati laciniis ovatis rotundatis in- 
ter se aequalibus. Stamina 4 didynama absque quinti rudimento, tubo corollae affixa, exserta; filamenta glabra; antherae dorso affixae, reniformi-bilobae loenlis basi divaricatis. Ovarium superum ovatum quadrilocalare. Stylus terminalis staminibus brevior cylindricus persistens, stigmate obtuso vix emarginato. Drupa pentagonoconica, subcarnosa. Pyrenum osseam, pentagonum, quinqueloculare. semine unico pendulo in quovis loculo.

\section{4. (137 Endl.) VERBENACEAE Juss.}

291. Verbena L.

517. V. officinalis L. Thunb, Fl, jap. p. 22.

292. Priva Adans.

518. Pr. species.

293. Vitex L.

519. V. ovata Thunb. Flor. jap. p. 257. et Awct.-Hooker Botany of Capt. Beechey p. 206. tab. 47.

520. V. cannabifolia S. et Z. V. foliis quinatis, foliolis lan- ceolatis acuminatis argute serratis superne glabris subtus ad nervos pubescentibus, extimis duobus quam tria intermedia brevius pedicellatis vel subsessilibus, paniculae terminalis ramis elongatis strictis calycis laciniis subulatis, corollis extus lanatis intus glabris.

Rami juniores tetragoni pubescentes, adultiores teretes glabri. Folia opposita distantia; petioli sesquipollicares pubescentes. Folio!a quinata, basi vel rotundata vel parum attenuata lanceolata acuminata argute serrata superue glabra subtus ad venas pubescentia, tria intermedia majora $2 \frac{1}{2}-3$ pollicaria, longins pedicellata pedicellis $3-4^{\text {it }}$ longis, extima subsessilia pollicaria vel sesquipollicaria soepius integerrima. Panicula terminalis ampla, e ramis eomposita strictis subvirgatis $3-6^{\prime \prime}$ longis; cymulae laterales verticillastra constituentes remotiusculae multiflorae; bracteae foliaceae inferiores ternatae longiores, superiores simplices lineares acuminatae integerrimae cymas aequantes. Flores subsessiles bibracteolati, parvi; calyx campanulatus 
pubescens lacinis brevibus e basi lanceolata subulatis. Corolla extus lanata, intus glabra; stamina exserta, filamentis glabris; antherae loculis a basi ad apicem usque fere divergentibus reniformi-bicrures. Stylus filiformis stigmate bifido laciniis longis subulatis divergentibus. 294. Clerodendron R. Br.

521. Cl. trichotomum Thunb. Flor. jap. p. 256. Banks Icones Kaempfer. tab. 22. non vero Seokuritz Amoen. exot. p. 827, cui folia alterna tribunutur.

522. Cl. squamatum Vahl Symbol. II. p. 74. - Volkameria japonica Thumb. Fl. jap. p. 255. - Volk. Kämpferi Jacq. icones rar. III. tab. 500. Go Too vulgo Go too Giri Kampf. Amoen. exot. p. 861. Banks Icones Kampfer. tab. 58. Volk. japonica et Kämpferi Willd. Specc. III. p. 358. Non vero Volk. fragrans Vent. et reliq. Auct.

Schon Willdenow bemerkt, (Specc. plant. III. p. 385) mit Recht, dass die Thunbergsche Volk. japonica nicht mit der in Gärten unter diesem Namen kultivirten Pflanze zusammengezogen werden könne, und nennt in der Eumeratio hort. berol. p. 659 letztere Cler. fragrans. Persoon führt ebenfalls V. japonica und fragrans gesondert auf. Erst die neueren Schriftsteller ziehen beide wieder zusanimen, Jassen dagegen aber $\mathbf{C l}$. squamatum oder Kämpferi als eigne Art bestehen. Allerdings scheinen zwar zwischen dieser und Volk. japonica Thunb. nach des Letzteren Beschreibung seiner Pflanze einige Verschiedenheiten obzuwalten, aber da Thunberg, Kämpfer a. a. O. zu seiner Pflanze citirt, dessen Beschreibung offenbar auf Volk. Kämpferi hinweist (Fi kiri, i. e. ignea kiri, a colore igneo stylos floridos, perianthia ac flosculos tingente), so dürfte dieses die Abweichungen in der Beschreibung ausgleichen nnd demnach $\mathrm{Cl}$. squamatum Vahl als identisch mit Volk japonica Thunb. zu betrachten seyn, Cler. fragrans dagegen als eigne Art bestehen, deren Stammform mit einfachen Blüthen jetzt auch schon in Gärten vorkommt. Cl. squamatum ist nach Thunberg aus Korea nach Japan Abhandlungen d. II. Cl. d. k. Ak. d. Wiss. IV. Bd. Abth. III. 


\section{4}

verpflanzt, ob Cl. fragrans auch in Japan sich finde, scheint noch zweifelhaft. Im Sieboldtschen Herbarium wenigstens fehlt sie.

523. Cl. divaricatum S. et $\mathbf{Z}$. Cl. ramis tetragonis glabris, foliis inferioribus petiolatis e basi rotundata ovatis superioribus subsessilibus basi attenuatis lanceolatis, omnibus acutis grosse serratodentatis glabris, cymis axillaribus divaricatis dichotomis paucifloris paniculam laxissimam efficientibus, calycis cupularis laciniis brevissimis late deltoideis acutis, corollae tubo anguste cylindrico, staminibus longe exsertis, antherarum loculis divaricatis.

Folia pollicaria vel sesquipollicaria, et inferiorna petioli $6-10^{\prime \prime \prime}$ longi. Cymae axillares divaricatae bis trifidae $3-7$-florae; pedicelli filiformes $3-4^{\prime \prime \prime}$ longi. Corollae tubus semipollicaris. Antherae locula horizontaliter divergentia.

295. Callicarpa L.

524. C. japonica Thunb. Fl. jap. $p$. 60 et Anct. (excl. Synon. C. longifoliae Lain.)

Folia petiolata petiolo $4-9^{\prime \prime \prime}$ longo, lamina utrinque longe attenuata acuminata, basi et apice integerrima utrinque serrata, ceterum lanceolata, ovata vel ovato-rhombea, glabra, subtus glandulis minutis globosis citrinis dense adspersa, $3-5^{\prime \prime}$ longa, $1-2^{\prime \prime}$ lata. Cymae axillares dichotomo-ramosissimae multiflorae, petiolum duplo superantes. Calyx urceolatus truncatus obsolete quadridentatus, uti pedunculi pilis stellatis adspersus. Corolla extus papilloso-pubescens, quadrifida. Stamina exserta; antherae obovato-oblongae, basi emarginatae vertice truncatae, loculis apice poro obliquo dehiscentibus, connectivo glandulis seriatis citrinis dense obsito.

525. C. gracilis $\mathbf{S}$. et $\boldsymbol{Z}$. C. ramis pilis stellatis puberulis, foliis brevissime petiolatis, utrinque attenuatis oblongo-lanceolatis vel oblongis, acuminato-cuspidatis, basi et apice integerrimis a medio sursum serratis, subtus pellucide glanduloso-punctatis, eymis supraaxillaribus petiolo quadruplo longioribus dichotomo-bifidis $12-20$-floris, calyce cupulari brevissime 4-dentato, corolla glabra, staminibus ex- 
sertis, antheris ovatis tuncatis basi emarginatis, loculis rima longitudirali dehiscentibus, connectivo dense glanduloso.

Rami teretes, graciles pilis stellatis scabriusculi. Folia oblonga vel raro obovato-oblonga utrinque attenuata acuminato-cuspidata, a medio sursum serrata basi et apice integerrima, glabra, subtus glandulis minutis pellucide punctata, $1 \frac{1}{2}-2 \frac{1}{2}$ " longa, $6-12^{\prime \prime}$ lata; petioli $1-2^{\text {in }}$ longi. Cymae supraaxillares, tertiam folii partem aequantes; pednuculus et pedicelli pilis stellatis canescentes. Calyx glaber cupularis. Corolla quam in praecedente multo minor, glabra. Stamina exserta. Antherae per totam longitudinem dehiscentes. Bacca minuta, globosa, disperma.

526. C. mollis $\mathbf{S}$. et Z. C. ramis teretibus novellis canescentibus, foliis petiolatis e basi rotundata vel rarius attenuata ovatooblongis vel oblongo-lanceolatis longe acuminatis, basi et in acumine integerrimis ceterum inaequaliter serratis, superne pilis simplicibus molliter villosis subtus pilis stellatis villosis, glanduloso-punctatis, cymis petiolum triplo superantibus cano-villosis $7+11$-floris, calycibus cylindricis profunde quadrifidis laciniis lanceolatis acutis, corollis extus villosis, staminibus exsertis, antheris oblongis obtusis rima dehiscentibus in comnectivo glandulosis, stigmate capitato-incrassato.

Rami juniores pilis stellatis furfuraceo-canescentes. Folia petiolata, petiolis circiter $3^{\text {m }}$ longis, e basi rotundata raro attenuata ovato-oblonga, vel superiora noununquam oblongo-lanceolata longe acuminata, $1 \frac{1}{2}-4^{\prime \prime}$ longa, $6-18^{\prime \prime \prime}$ lata, inaequaliter serrata, superne pilis simplicibus subtus stellatis villoso-canescentia, utrinque glandulis pellucidis punctata. Cymae axillares vel supraaxillares strictae vix quartam folii partem aeqnantes, pilis stellatis dense villosae. Calyx cylindricus laciniis tubnm fere superantibus linearilanceolatis acutis. Antherae pro ratione magnae basi bifidae, dorso glandulosae. Stylus cylindricus stamina parum superans, stigmate incrassato truncato. Variat floribus pentameris pentandris. 
$\beta$ ? microphylla foliis lanceolatis vel ovato-lanceolatis acuminatis basi rotundatis dense et aequaliter serrulatis pollicaribus vel-bipollicaribus.

Die Behaarung und allgemeine F'orm der Blätter stimmt mit der mollis überein, nur sind dieselben viel kleiner und am Rande mit Ausnahme der Basis und Spitze gleichmässig feinsägezähnig. Die Blüthen sind an unsern Exemplaren nicht vollständig entwickelt.

527. C. Murasaki Sieb. Annuaire de la Soc. hortic. l. c. I. 25. - C. mimurasaki Hasskarl hort. Bogor. p. 136.

Ausser dieser und C. japonica erwälint Hasskarl a. a. O. noch der C. acuminata H. B. K. und C. cuspidata Roxb. als aus Japan nach Java eingeführt.

Nicht allein die japanischen, sondern alle Arten von Callicarpa, deren wir uber 20 untersuchten, haben das Connectiv der Antheren dicht mit goldgelben Drüsen besetzt. Aehnliche Drüsen stehen auch immer auf der Rückseite der Blätter und werden nur häufig durch den filzigen Ueberzug (von Sternhaaren) verdeckt. 296. Mastacanthus Endl.

528. M. sinensis Endl. - Nepeta incana Thunb. Fl. jup. p. 244. Barbula sinensis Lour cochinch. p. 445. Nepeta japonica Willd. Specc. plant. III. p. 52. et Auct.

Suffruticosa, tota pilis simplicibus villoso-canescens. Folia opposita vel abortu alterna breviter petiolata, petiolo $2-4^{\prime \prime \prime}$ longo, ovatoelliptica vel angustiora oblonga, basi rotundata, obtusa, grosse inciso-serrata, utrinque sed praesertim subtus venis lateralibus prominentibus lineata, $1-2^{\prime \prime}$ longa, $6-12^{\prime \prime \prime}$ lata. Cymae axillares pedunculo petiolum aequante, densae, multiflorae. Flores breviter pedunculati. Calyx tubulosus profunde quinquepartitus, laciniis linearioblongis aequalibus. Corollae extus pubescentis tubus calycem superans sursum ampliatus; limbus quinquefidus, laciniis quatuor superioribus aequalibus ovatis obtusis, infima quinta duplo longiori orbicnlari venosa inciso-laciniata, laciniis plerumque septem basi del- 
toideis sursum subulatis laminam subaequantibus. Stamiua 4, summo quinto deficiente, exserta; filamenta filiformia, subaequalia, ima basi ad insertionem barbata; antherae ovatae, cordatae loculis sursum parallelis. Stylus filiformis, staminibus brevior, glaber, stigmate bifido laciniis subulatis.

\section{5. (136 Endl.) LABIATAE Inss.}

\section{Plectranthus Herit.}

529. 530. Species ex sententia elar. Bentham novae.

298. Perilla L.

531. P. arguta Benth.! - Ocymum crispum Thby. Flor. jap. p. 248. Flores albi.

299. Salvia L.

532. S. japonicu Thunb. Flor. jap. p. 22. Benth.!

533. S. plebeia R. Br. Benth.!

300. Melissa Benth.

534. M. Clinopodium Benth! - Clinopodium vulgare L. Thunb. Fl. jap. p. 247. et aut.

301. Prunella L.

535. Pr. vulgaris $\boldsymbol{L}$. Benth.!

302. Scutellaria L.

536. Sc. indica L. Benth.!

Sc. japonica De Caisne Annales des Sc. Nat. Nov. 1843 scheint sehr verwandt und vielleicht nur durch Grösse und mindere Behaarung verschieden. Die Antheren sind auch in unsern Exemplaren, welche Bentham selbst für Sc. indica bestimmte, alle 4 gleich stark bebartet.

537. Sc. species nova $S c$. minori affinis. 303. Nepeta Benth.

535. N. Glechoma Benth! ß3. hirsuta W. K.

Von der europäischen Pflanze in nichts verschieden. 


\section{Lamium L.}

539. L. amplexicaule L. Benth.

540. L. barbatum $\boldsymbol{S}$. et $\boldsymbol{Z}$. - L. foliis ovatis vel deltoideis basi cordatis vel superioribus truncatis acuminatis grosse et subinciso-dentatis, dentibus inaequalibus acutis subgeminatis, parce pilosis, dentibus calycinis longe subulatis ciliato-hispidis, corollae tubo amplo intus piloso-annulato, fauce ampliata, galea oblonga emarginata margine villoso-barbata, lobis lateralibus dente longo subulato appendiculatis, antheris hirsutis.

Folia inferiora longe petiolata petiolo bipollicari, floralium semipollicari; lamina $1 \frac{1}{2}-2 \frac{1}{2}^{\prime \prime}$ longa, $1-2^{\prime \prime}$ lata parce pilosa, grosse et profunde dentata, dentibus inaequalibus plerumque bifidis. Verticillastri 6-12-flori. Flores magnitudine fere ut in L. Orvala. 305. Ajuga L.

541. A. remota Benth! Labiatae p. 694.

542. A. decumbens Thbg. Fl. jap. p. 243. Bentham Labiat. p. 697 .

\section{6. (135 Endl.) GEN'TIANEAE. Iuss.}

306. Gentiana Tournef.

543. G. Thunbergii Griseb. - G. radice anuua, caule simplici vel parce ramoso, foliis radicalibus majoribus rosulatis, caulinis ovatooblongis vel ovatis basi connatis aristatis margine subcallosis papilloso-scabris, floribus $1-5$ fastigiatis, calycis laciniis lanceolatis acuminatis carinatis tubo corollae dimidio brevioribus, corolla infundibuliformi, plicis quam lobi brevioribus ovatis acutis, staminibus liberis, stylo cylindrico, stigmatibus oblongo-spathulatis, capsula longe stipitata obovato-oblonga. - G. Thumbergii Don gen. syst. gard. $4 p$. 192. Griseb. in De Cand. Prodr. IX. p. 108. G. aquatica Thby. Fl. jap. p. 115.

Radix annua filiformis simplicissima vel parce ramosa. Caulis erectus 3-6-pollicaris tetragonus simplex vel parce ramosus. Folia 
radicalia rosulata in specc. nostris delapsa vel soepe nulla; caulina sessilia, basi in tubum brevem connata, ovato-oblonga vel ovata acuta setaceo-aristata margine albo papilloso-scabro cincta, semipollicaria, 3-4"' lata. Flores solitarii vel $2--5$ fasciculato-corymbosi sessiles. Calyx ope epidermidis in tubum cylindricum pentagonum connexus, limbi laciniis lanceolatis acuminatis carinatis albo-cinctis. Corolla infundibuliformis $6-9^{\prime \prime \prime}$ longa; limbi laciniae ovatae acntae plicis simplicibus acntis longiores. Antherae inter se liberae lineares. Ovarium stipite crasso longius, obovato-cylindricum. Stylus cylindricus stigmatibus duobus oblongo-spathulatis obtusis papillosis. Semina minuta, numerosissima, aptera?

307. Pleurogýne Eschscholz.

544. Pl. rotata Griseb. Gent. 309. De Cand. Prodr. IX. p. 122. Suertia rotata Thunb. Fl. jap. p. 115. Siebold Synops. l. c. p. 37. Specimina magna fere pedalia, ramosissima. Folia linearia vel lanceolata argute acuminata. Flores in ramis racemosi.

308. Op helia Don.

545. Oph. bimaculata $\mathbf{S}$. et Z. - O. caule tereti elato, ramis patentibus strictis pyramidatis, foliis subsessilibus ad vaginam interfoliaceam undulato-ciliatis ovato-lanceolatis acuminatis trinerviis glabris, calycis segmentis aequalibus lineari-lanceolatis acutis corolla duplo brevioribus, corollae 5-partitae albae segmentis ellipticis acutiusculis supra medium maculis seu glandulis duabus virentibus et inde apicem versus punctis nigricantibus notatis, fovea inconspicua. Radix biennis? Caulis sesqui-bipedalis teres, stricte erectus. Rami teretes, brachiato-pyramidati. Folia $1 \frac{1}{2}-2 \frac{1}{2}$ " Jonga, 6-10" lata, in petiolum brevissimum attenuata ibique et ad vaginulam interfoliaceam undulato-ciliata. Flores in apice ramorum cymosi $3-5$, pedunculati pedunculis fructiferis pollicaribus snleatis. Calycis laciniae breves aequales lineari-lanceolatae acutae, apice reflexae et subcallosae. Corollae rotatae tubus brevissimus, albido-virens, glandulis in specc. siccis inconspicuis; laciniae ellipticae acutinscnlae albae, 
facie supra mediun glandulis seu maculis duabus ellipticis notatae et inde apicem versus punctis nigricantibus adspersae. Filamenta inter se libera imae corollae affixae ibique parum latiora, sursum subulata. Ovarium sessile oblongo-cylindricum, stigmate subsessili bilobo lobis rotundatis. Capsula oblonga corolla persistente duplo longior, nnilocularis bivalvis, placentis ad valvularum marginem decurrentibus. Semina numerosa angulato-difformia, reticulata, aptera.

309. Craw furdia Wall.

546. $\boldsymbol{C r}$. japonica S. et $\mathbf{Z}$. - Cr. foliis e basi rotundata vel subcordata ovato-oblongis oblongisve acuminatis $3-5$-nerviis, floribus axillaribus plerumque ternis subsessilibus, calycis laciniis linearibus longe acuminatis tubum superantibus, corollae infundibuliformis lobis brevibus ovato-deltoideis acutis plicis brevibus emarginatis, ovario oblongo stipitem aequante.

Caulis tenuis volubilis teres. Folia petiolata petiolo $3-6^{\prime \prime \prime}$ longo canaliculato; lamina basi leviter cordata vel rotundata, ovato-oblonga, oblonga vel lanceolata, acuminata tri-vel quinquenervia nervis in apice confluentibus, margine tenuissime papillosa et sicca subundulata, $1-3 \frac{1}{2}{ }^{\prime \prime}$ longa, $1-18^{\prime \prime \prime}$ lata. Flores axillares solitarii gemini ternive subsessiles. Calycis tubus cylindrico-pentagonos inter lacinias truncatus; laciniae lineares longe acuminatae subaequales tubum superantes. Corolla pollicaris infundibuliformis, limbi laciuiis brevibus ovatodeltoideis acutis, plicis brevibus in dentes adscendentibus emarginatis. Filamenta tubo inserta linearia; antherae basi emarginatae oblongae. Discus ovarii stipitem cingens urceolaris breviter quinquelobus. Stipes ovarium oblongum aequans. Stylus cylindrieus, stigmatibus duobus linearibus revolutis. Capsula ovato-elliptica stipitem aequans unilocularis, polysperma.

310. Limnanthemum Gmel.

547. L. peltatum Griseb. De Cand. Prodr. IX. p. 141. Memyanthes nymphoides Thbg. Fl. jap. p. 82. M. peltata Ejusd. 
Act. Upsul. 7. p. 142. tab. 4. f. 2. - Villarsia peltata Roem. et Schult. Syst. Veget. IV. p. 178. Siebold Synops. l. c. p. 37.

\section{7. (134 Endl.) ASCLEPIADEAE Iuss.}

\section{Metaplexis R. Br.}

548. M. chinensis D. C. Prodr. VIII. p. 511. M. Stauntoni Roesn. et Schult. VI. p. 111. Urostelna sinense Bunge Enum. pl. chin. p. 44. Siebold Annuaire de la Soc. hort. l. c. p. 38. Pergularia japonica Thunb. Fl. jap. 111.

Caulis volubilis glaber. Folia petiolata basi cordata lobis rotundatis, ovata vel superiora subdeltoidea, acuta vel cuspidata margine plana utrinque glabra subtus glaucescentia, $3-5^{\prime \prime}$ longa, $1 \frac{1}{2}-3 \frac{1}{2}$ lata; petioli sesqui - bipollicares. Inflorescentia interpetiolaris; pedunculi $1 \frac{1}{2}-3$ pollicares folio hreviores. Flores cymoso-subracemosi 5-10, pedicelli breviter villosi bractea lineari acuminata suffulti. Calycis laciniae lanceolatae longe acuminatae pubescentes ciliatae. Corolla subrotata, limbi laciniis lanceolatis acutis apice reflexis extus glabris intus pilis albis crispis dense barbatis. Corona brevissima. Antherae membrana ovato-lanceolata cordata acuta alba terminatae. Stigma elongatum, filiforme, simplex.

Chinesische von Fortune (plant. exsicc. chin. n. A. 87) gesammelte Exemplare weichen durch länger gestielte und deutlicher in Trauben gestellte Bluthen etwas von den japanischen ab.

312. Vincetoxicum Moench.

549. V. purpurascens Morr. et De Caisne Bull. Acad. Brux. 1836. p. 17. De Cand. Prodr. VIII. p. 524.

Canles herbacei, erecti, apice tantum volubiles. Folia breviter petiolata e basi rotundata elliptica, ovata vel rarius obovata, breviter acuta vel cuspidata, ad venas tenuiter pubescentia ciliolata; petioli

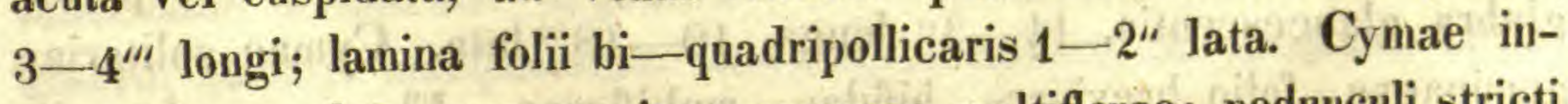
terpetiolares plerumque geminae ramosae multiflorae; pedunculi stricti pubescentes folio breviores 1-3-pollicares, pedicelli filiformes flore

Abhandlungen d. II. Cl. d. k. Ak. d. Wiss. IV. B. Abthl. III. 
longiores. Flores inter congeneres magni. Calycis laciniae lanceolatae acuminatae pubescentes. Corollae laciniae lanceolatae acutae glabrae. Corona staminea stigmate parum brevior.

550. V. macrophyllum S. et Z. - V. caule herbaceo erecto vel apice volubili, tenuiter bifariam pubescente, foliis petiolatis, inferioribus e basi rotundata late ovatis, summis utrinque attenuatis lanceolatis, omnibus acuminatis ad venas pubescentibus, cymis ramosis laxifloris folio brevioribus, corollae laciuiis ovato-lanceolatis acutis intus albido-barbatis, corona staminea pentapliylla, foliolis gynostegium aequantibus, stigmate depresso.

V. acuminato De Caisne affine videtur, sed corollis intus albidobarbatis differt. Folia inferiora maxima petiolis soepe duos, lamina $6--8$ pollices longa et $4-5$ " lata; summa lanceolata vel lineari-lanceolata utrinque attenuata acuminata sesqui-bipollicaria. Cymae graciles ramosae, solitariae vel geminae; pedicelli filiformes flores plusquam duplo superantes pubescentes. Flores parvi, albidi? Calycis laciniae lanceolatae acuminatae glabrae. Corollae laciniae ovato-lanceolatae acutae extus glabrae intns pilis albis hirsutae. Folliculi duo bipollicares tenues longe attenuati divaricati.

551. V. amplexicaule $\mathbf{S}$. et Z. V. herbaceum glancescens caule erecto glabro, foliis sessilibus e basi cordata subamplexicaulibus obovato-ellipticis vel ellipticis brevissime cuspidatis ntrinque glabris, cymis interpetiolaribus bifidis folio brevioribus, pedicellis glabris flores aequantibus, corollae laciniis ovato-lanceolatis acutis introrsum puberulis, corona stam. 5-phylla, foliolis obovato-spathulatis crenatis gynostegium aequantibus.

Caulis erectus simplex vel superne ramosus. Folia sessilia basi cordata et amplexicaulia, elliptica, mucronata vel brevissime cuspidata glabra glaucescentia, $1 \frac{1}{2}-3^{\prime \prime}$ longa, $10-18^{\prime \prime \prime}$ lata. Cymae solitariae geminaeve, folio breviores, bifidae, multiflorae. Flores parvi pedicellos aeqnantes. Calycis laciniae ovato-lanceolatae acutae glabrae. 
Folliculi in specc. nostris abortu solitarii, basi cylindrici sursum longe attenuati, subbipollicares, nutantes.

552. V. japonicum Morr. et De Caisne Bullet. Acod. Brux. 1836. p. 17. De Cand. Prodr. VIII. p. 524.

553. I. acuminatum De C. Prodr. $l$. c.

554. V. atratum Bunge Enum. plant. chin. p. 45. De C. l. c. p. 523.

555. V.? micranthum S. et $\mathbf{Z}$.

Die vorliegenden Exemplare sind zu unvollständig zu genauer Untersuchung.

313. Marsdenia R. Br.

556. M. tomentosa Morr. et De Caisne l. c. p. 17. De Cand. Prodr. VIII. p. 617. Folia subtus ad venas pubescentia, $3-4^{\prime \prime}$ longa et lata. Petioli, pedunculi et calyces tomentosi. Cymae ramosae laxae. Laciniae calycis rotundatae.

98. (133 Endl.) APOCYNACEAE. R. Brown.

314. Vinca L.

557. V. rosea $L$.

Culta et spontanea facta.

315. Nerium L.

558. N. odorum Soland.

Cultum.

316. Malouetia Alph. De Cand.

559. M. asiatica S. et Z. M. ramulis villosis, ceterum glabra, foliis oblongo- vel ovato-ellipticis utrinque attenuatis apice obtuse acutis, cymis axillaribus folia aequantibus vel superantibus corymbosis subdichotomis, bracteis parvis lanceolatis acutis, lobis calycinis ovatolanceolatis acuminatis aequalibus, tubo corollae cylindrico utrinque glabro, laciniis inaequilateris basi angustatis sursum latioribus et oblique truncatis tubum aequantibus, antheris apice exsertis, nectario cupuliformi lobis truncato-emarginatis. 
Nerium divaricatum Thunb. Fl. jap. p. 110. non Linn.

Uno Fanna Kämpf. Amoen. exot. p. 909.

Frutex ramis teretibus e Thunbergio prostratis vel scandentibus, in specc. nostris subvolubilibus, novellis ferrugineo-villosis. Folia opposita breviter petiolata petiolis vix $3^{m i}$ longis novellis hirtis; lamina folii oblongo-vel ovato-elliptica, rarius lanceolata utrinque attenuata acuta acumine obtuso, utrinque glabra, penninervia venis ante marginem anastomosantibus, eglandulosa, $2-3 \frac{1}{2}^{\prime \prime}$ longa, $10-18^{\prime \prime \prime}$ lata. Cymae axillares longe pedunculatae folia aequantes vel superantes pedunculo sursum compresso, trifidae et subdichotomo-multiflorae, corymbosae, divisionibus plerumque trifloris, bracteae minntae squamaeformes lanceolatae acutae; pedicelli $3-4^{\prime \prime \prime}$ longi. Calyx profunde $\mathbf{5}$-fidus laciniis lanceolatis acuminatis glabris. Glandulae 10 , intus ad basin laciniarum duae ante quandam laciniam affixae, minutae, truncatae, plerumque tridentatae carnosae. Corollae tubus cylindricns vix dilatatus calyce triplo longior, utrinque glaber fauce nudus. Limbus 5-fidus, hypocrateriformis; laciniae inaequilateres obliquae, basi angustatae sursum dilatatae et oblique truncatae, venosae, albidae. Corona nulla. Stamina tubo faicem versus affixa; filamenta adnata decurrentia; antherae inde sessiles dorso affixae basi sagitiatae lobis subaristatis conniventibus, superne acuminatae et semiexsertae, medio stigmati affixae. Nectarium hypogynum cupuliforme subquinquelobum lobis truncato-emarginatis. Ovaria 2 supera ovatocompressa, glabra, multiovulata ovulis imbricatis multiseriatis. Stylus cylindricns vel subangulatus glaber, stamina subaequans, apice subpeltato-dilatatus. Stigma cylindrico-subclavatum, simplex, antheris adhaerens.

Occurrit quoque in insulis Peel et Bonin-sima, unde spece, vidi in herb. Mertensiano.

317. Amsonia Walt.

560. A. elliptica $\boldsymbol{R}$. et $\mathbf{S}$. - A herbacea, caule tereti simplici glabro, foliis alteruis vel binis ternisve subverticillatis, lanceolatis 
utrinque attenuatis acuminatis brevissime petiolatis glabris, racemo terminali, calycis laciniis lanceolatis setaceo-acuminatis, corolla extus glabra. - Tabernaemontana elliptica Thby. Fl. jap. p. 385. excl. synon. - Ansonia? elliptica Roem. et Schult. Syst. Veget. IV. p. 432. De Cand. Prodr. VIII. $p$. 385.

Ams. latifoliae Mich. valde affinis et praeter lácinias calycis acuminatas corollasque glabras vix distinguenda.

\section{9. (132 Endl.) LOGANIACEAE $\boldsymbol{R}$. $\boldsymbol{B}$ r.}

318. Gardneria Wall.

561. G. nutans $\boldsymbol{S}$. et $\mathbf{Z}$. - G. foliis ellipticis utrinque attenuatis acuminatis, pedunculis axillaribus uni-, rarius bi-vel trifloris nutantibus, floribus pentameris pentandris, antheris liberis in connectivo furfuraceo-tomentosis.

Rami novelli tetragoni, serius teretes, glabri. Folia opposita, petiolata, petiolis $3^{\prime \prime \prime}$ longis; lamina elliptica utrinque attenuata acuta vel acuminata utrinque glabra penninervia, $2-2 \frac{1}{2}$ " longa, unum cireiter lata. Pedunculi axillares solitarii vel nonnumquam gemini sibi superpositi nutantes longitudine petiolum subaequantes apice bibracteati bracteis parvis subulatis, nni-bi-, rarins triflori. Flores pedicellati; pedicelli pedunculum communem aequantes, intermedii et (abortu florum lateralium) solitarii ebracteolati, laterales bracteolis duabus alternis muniti. Calyx minutus quinquepartitus laciniis orbicularibns rotundatis ciliolatis ceterum glabris coriaceis. Corolla rotata ad basin usque quinquepartita; laciniae lanceolatae longe attenuatae, intus marginibus inflexis bicarinatae papillosae, coriaceae. Stamina 5, libera, cum corollae lobis alternantia et eorum basi affixa. Filamenta brevissima compresso-plana; antherae erectae oblongo-attenuatae acutae anticae quadriloculares, ab apice non ultra $\frac{1}{3}$ longitudinis rima dehiscentes; connectivum basi dilatatum papilloso-tenuiter tomentosum. Ovarium superum globosum biloculare ovulo in quovis loculo solitario 
pendulo medio septo affixo. Stylus subnlatus longitndine staminum stigmate obsolete emarginato. Bacca.

\section{0. (131 Endl.) OLEACEAE.}

319. Olea Tourn.

562. O. Aquifolium S. et ZZ. 0 sempervirens, foliis oppositis breviter petiolatis coriaceis totis glabris difformibus, aliis (plerumque inferioribus) ovato-ellipticis vel ellipticis inciso-dentatis dentibus deltoideis in spinam rigidam terminatis, aliis (superioribus) minoribus oblongo-ellipticis lanceolatisve acutis vel obtusiusculis integerrimis inermibus, floribus in axillis foliorum fasciculatis, pedunculis unifloris ehracteatis.

Ilex Aquifolium Thunb. Hlor. jap. p. 79. Il. Aquif. var. heterophylla Ait? Blume Bijdr. p. 1150. - Koo Kotz vulgo Firaggi Kämpf. Amoen. p. 781. - Olea ilicifolia Hasskarl in Catal. hort. Bogor. p. 118. Osmanthus Aquifolium Sieb. in litt.

Rami teretes vel novelli obsolete tetragoni. Folia opposita, per triennium virentia, petiolata petiolis $3-4^{\text {un }}$ longis, difformia; alia et plerumque inferiora e basi cuneata vel rotundata elliptica vel ovatoelliptica, profunde inciso-dentata sinubus rotundatis, dentibus et apice deltoideis in spinam validam pungentem terminatis, 1 $\frac{1}{2}-2 \frac{1}{2}{ }^{\prime \prime}$ longa,

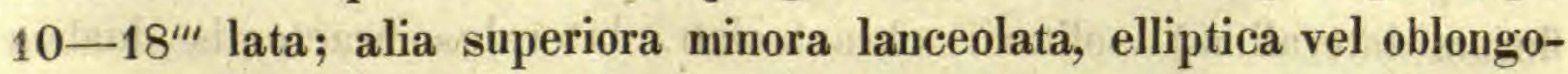
elliptica integerrima, breviter acuta vel obtusiuscula inermia, $12-15^{\prime \prime \prime}$ eirciter longa, 4-8" lata, omnia coriacea utrinque glabra superne lucida. Flores ex axillis foliorum anni praecedentis e gemmis propriis perulatis, fasciculati; pedunculi uniflori petiolos aequantes vel parum superantes ebracteati glabri. Calycis laciniae parvae, ovatae acutiusculae, coriaceae. Corolla profunde quadripartita, laciniis ovatoellipticis obtusis. Stamina 2, corollam aequantia; antherae basi cordatae ovatae obtusae. Ovarium ovato-globosum, stylo cylindrico stamina aequante, stigmate capitato. 
563. O. japonica Sieb. Hasskarl in Catal. hort. Bogor.p. 118. Osmanthus japon. Siebold Annuaire l. c. p. 34 .

320. Osmanthus Lour.

564. O. fragrans Lour. - Olea frayrans Thunb. Fl. jap. $p$. 18. tab. 2. et Auct. - Mokksei Kämpf. Amoen. exot. p. 844. 321. Ligustrum Tourn.

565. L. Ibota Sieb. L. ramis, petiolis et foliis in margine et utrinque in nervo medio pubescentibus, foliis ellipticis lanceolatisve utrinque attenuatis acutis vel basi rotundatis, racemis terminalibus subsimplicibus pancifloris, rarius paniculatis. - L. Ibota Sieb. in Act. Batav, vol. 12. p. 36. Hasskarl hort. Bogor. p. 118. - Ibutta Kämpf. Amoen. exot. p. 896.

Rami stricti graciles, laterales subrectangulo-divaricati, (annui) pilis patentibus aeque ac petioli pubescentes. Folia breviter petiolata petiolo $1-2^{\prime \prime \prime}$ longo; lamina elliptica vel lanceolata utrinque attenuata acuta vel basi rotundata, utrinque ad nervum medium et in margine pubescens. Flores in ramis primariis paniculati, in lateralibus simpliciter racemosi, racemis brevibus pauci-(5-9-)floris. Flores breviter pedicellati, pedicelli lineam longi bibracteolati glabri. Calyx cupularis truncatus vel obsolete 4-5-dentatus. Corollae tubus cylindricus ntrinque glaber, limbus $4-5$-fidus laciniis ovatis obtusis . patentibus. Stamina subinclusa; filamenta brevia, corollae tubo affixa, subulata. Antherae lineares, medio dorso affixae anticae, dimidium corollae tubum aequantes, apice subexsertae. Ovarium globosum stylo filiformi stamina subaequante, stigmate bilobo.

Variat floris 4-5-meris.

566. L. ovalifolium Hasskarl Catul. hort. Bogor. p. 119. L. ramis teretibus glaberrimis, foliis brevipetiolatis ovalibus ant oblongis utrinque acutis coriaceis glaberrimis, supra atroviridibus subnitidis subtus pallidioribus, panicula terminali contracta subracemosa, floribus bracteatis subsessilibus fragrantibus. L. vulgare Thunb. Fl. jap. p. 17.? 
567. L. obtusifolium S. et Z. L. ramis pedunculis calycibusque hirtis, foliis brevissime petiolatis e basi rotundata ellipticis obtusis vel rotundatis, novellis utrinque, adultis subtas in nervo medio tantum hirtis, ceternm glabris, paniculae terminalis ramis abbreviatis coarctatis strictis, calycibus distincte quadridentatis, corollae laciniis oblongo-lanceolatis obtusiusculis.

Rami teretes hirti, laterales numerosi breves, (in specc. nostris) omnes floriferi. Folia brevissime petiolata petiolo vix lineam longo, lamina elliptica basi rotundata vel rarius subattenuata, apice obtusa vel rotundata, subtus tantum in nervo medio lirta ceterum glabra, 1-2" longa, 6-9"' lata. Paniculae terminales pedunculo pedicellisque hirtis, pollicares vel sesquipollicares; rami abbreviati coarctati stricti cymoso-3-5-flori. Flores brevissime pedicellati. Calyx urceolatus hirtus pedicellum superans, quadridentatus dentibus brevivibus late deltoideis mucronulatis. Corollae tnbus infundibuliformis lacinias oblongo-lanceolatas obtusiusculas dimidio superans.

L. Stauntoni D. C. affine videtur, differt vero panicula contracta ramis simpliciter cymosis nec divaricata ramosissima.

568. L. japonicum Thbg. Flor. jap. p. 17 et Aut. Nysimi motsji, aliis Tanna wattasj Kämıfer Amoen. p. 776.

Folia in spece. nostris acuminata, acuta vel obtusa. Flores in panicula pyramidata subsessiles. Calyx cupularis truncatus vix quadridentatus. Corollae tubus cylindricus, laciniae oblongo-lanceolatae acutae. Stamina exserta.

569. L. micranthum Zuccar. L. totum glabrum, foliis petiolatis e basi attenuata ellipticis vel oblongo-ellipticis obtuse acutis, paniçula terminali composita ramis patentibus, calycibus cupularibus obsolete quadridentatis quam pedunculi brevioribus, corollae profunde quadrifidae laciniis oblongo-lanceolatis acutis tubum superantibus.

Rami dichotomi divaricati glabri. Folia petiolata petiolo $3-4^{\prime \prime \prime}$ longo; lamina magnitudine varia plerumque utrinque attenuata et apice obtuse acuta, utrinque glabra, coriacea, $1 \frac{1}{2}-3^{\prime \prime}$ longa, $9-18^{\prime \prime}$ lata. 
Panicula terminalis 2-3-pollicaris valde ramosa ramis patentibus; bracteae minutae ovato-oblongae acutae. Pednnculi calycem parvum cupularem obsolete dentatum plus quam dnplo superantes. Corolla infundibuliformis tubo brevi, limbo profunde 4-partito, laciniis oblongolanceolatis acutis patentibus tubum superantibus.

- In insulis Bonin-sima legit beatus Mertens.

322. Fraxinus Tournef.

570. F. longicuspis S. et Z. - Fr. (Ornus) foliolis bi- vel trijugis petiolatis lanceolatis longe et subfalcato-acuminatis serratis utrinque glabris, ramis petiolisque tetragonis, paniculis lateralibus et terminalibus, samaris in alam linearem, apicem versus parum latiorem acutam vel obtusam glabram terminatis, gemmis ferrugineotomentosis.

Foliola petiolata, longe et subfalcato-acuminata, basi rotundata vel attennata, serrata, otrinque glabra, 2-3" longa, 6-10"“ lata. Paniculae terminales et Jaterales, erectae. Pedicelli filiformes. Calyx persistens, quadridentatns, dentibus sinubus rotundatis. Corolla? Samarae $12-15^{\prime \prime \prime}$ longae, ala lineari sursum parum latiori obtusa vel acuta terminatae.

Quid Fr, excelsior Thunb. Fl. jap. p. 23.? 323. Forsythia Vahl.

571. F. suspensa Vuhl. Sieb. et. Zuccar. Flor. jap. I. p. 11. tab. 3. Syringa suspensa T'hunb. Fl. jap. p. 19. Rengjo Kämpf. Amoen. p. 907.

\section{1. (129 Endl.) JASMINEAE $\boldsymbol{R}$. $B r$,}

324. Jasminum Tourn.

572. J. Sambac. Act.

Com tribus aliis cultum. Ex his J. humile Hassk. Catal. hort. Bogor. idem videtur ac J. floridum Bunge Enum. plant. Chin. p. 42. et Siebold Annuaire 1. e. p. 31.

Abhandlungen d. II. Cl. d. k. Ak. d. Wiss. IV. B. Abthl. III. 2 24t 22 


\section{2. (128 Endl.) LONICEREAE Endl.}

325. Abelia R. Br.

573. A, serrata S. et Z. Flor. jap. I. p. 76. tab. 34.

574. A. spathulata S. et Z. l. c. p. 77. tab. 34. fig. 2.

326. Diervilla Tourn. (Weigela Thunb., Weigelia Pers., Calysphyrum Bunge.)

575. D. hortensis S. et Z. Flor. jap. I. p. 70. tab. 29. 30 et 33 . II.

576. D. grandiflora S. et Z. l. c. p. 71. tab. 31. - D. coraeensis De Cand. Prodr. IV. p. 330. Weigela coraeensis Thunb. in Act. Linn. II. p. 331. Weigelia coraensis Pers. Enchir. I. p. 176. et Aut. Korei Utsugi Käapf. Amoen. p. 855. Icones tab. 45.

577. D. versicolor. S. et Z. l. c. p. 76. tub. 33. Dierv. japonica De Cand. Prodr. IV.p. 330. Weigela japonica Thunb. Fl. jap. p. 90. tab. 16. Linn. transact. II. p. 331. Act. holm. 1780. p. 137. tab. 5. et Auct. TT

578. D. Roribunda S. et Z. l. c. p. 73. tab. 32.

- Nippon Utsugi Kämpf. Amoen. p. $85 \bar{\jmath}$.

327. Lonicera Desf.

579. I. japonica Thunb. Flor. jap. p. 89. Loud. Arbor. britt. p. 534. fiy. 985. - L. chinensis Wats. dendr. britt. t. 117. De Cand. Prodr. IV. p. 333, $\rightarrow$ L. Alexuosa Bot. Reg. t. 912. Bot. Cabin. t. 1037. L. repens hort. Bogor. Nintoon japonica Sweet hort. britt. edit. 2. - Nintoo it. Sintoo vulgo Sui Kadsura Kümpt. Amoen. p. 785.

580. L. affinis Honk. ap. Beechey l. c. p. 264.

L. Leschenaultii proxima, sed glaberrima, glancescens. Folia omnia petiolata, inferiora late ovata basi truncata vel subcordata breviter acuta vel obtusa, $2 \frac{1}{2}$ " longa. $18-20^{\prime \prime \prime}$ lata, superiora vel ramo-

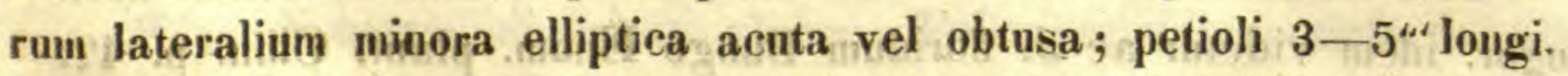
Flores axillares vel terminales subcorymbosi; pedunculi petiolis breviores biflori. Bracteael minutae, ovatae, acutae. Calycis laciniae 
breves, ovato-deltoideae, acutae. Corollae tubus réctus, tenuis, cylindricus, $10-12^{\prime \prime}$ longus; limbus $8-10^{\prime \prime}$ longus bilabiatus, labio superiore truncato, quadridentato dentibus obtusis, inferiore lineari deflexo.

581. L. brachypoda D. C. Prodr. IV, p. 335. L. nigra Thunb. Fl. jap. p. 89. L. Alexuosa Id. in Act. Linn. II. p. 330.

328. Viburnum L.

582. V. plicatumn Thunb. Act. Linn. II. p. 332. Sieb. et Zuccar. Fl. jup. I. p. 81. tab. 37. P. dentatum Thbg. Fl. jup. p. 122.

583. V. tomentosum Thunb. Sieb. et Zuccar. l. c. p. 81. t. 38. Verosimiliter praecedentis forma spontanea fertilis.

584. V. cuspidutum Thbg. Fl. jap. p. 120. Foliis e basi rotundata vel cuneato-attenuata obovatis rotundatis et repente cuspidatis vel acutis, argute serratis subtus dense costatis et inter nervos pilis stellatis adspersos tenuissime reticulatis, cymis terminalibus radiantibus, petiolis pedunculisque pilis stellatis pubescentibus.

Rami laterales numerosi abbreviati subdivaricati, novelli angulati. Folia in spece. nostris dnos pollices, longitudine et $12-15^{\prime \prime}$ latitudine non excedentia, figura varia, e basi cuneata vel rotundata plerumque obovata rarius elliptica, apice vel rotundata et repente cuspidata vel simpliciter acuta, dense et argute serrata, serraturis a medio apicem versus multo majoribus ovatis cuspidatis; venis ntrinque 9-11 parallelis dense costata et inter eas tenuissime reticulata, superne pilis simplicibus subtus stellatis adspersa; petioli $4-8^{\prime \prime \prime}$ longi pubescentes. Cymae terminales foliis longiores, planae, multiflorae, radiantes; pedunculus strietus angulatos pubescens ; radii $5 \pi 6$ absque involucro. Flores radiantes magnitudine et figura ut in $V$. Opulo. Fertilium laciniae calycis parvae ovatae acutae, corollae tubus brevissimus, laciniae ovatae obtusae. Stylus brevissimus crassus stigmate capitato-tridentato.

585. V. erosum Thunb. Fl. jap. p. 124. De Cand. Prodr. IV. p. 327. V. foliis e basi rotundata late oyatis acuminatis inaequali- 
ter sinuato-et inde quasi eroso-dentatis utrinque subvillosis, breviter petiolatis, ramis petiolis pedunculis et calycibus pilis stellatis tomentosis, stipulis setaceis hirtis, cymis terminalibus non radiantibus subinvolucratis plerumque quinquefidis, stylo brevi stigmate tridentato.

Rami laterales soepe numerosi abbreviati, novelli tomentosi.

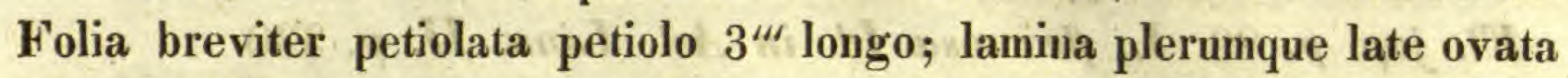
rarius oblonga, acuminata, dentata dentibus inaequalibus cuspidatis sinubus rotundatis, $2-3^{\prime \prime \prime}$. longa, $12-18^{\prime \prime \prime}$ lata. Stipulae subulatae hirtae, petiolum subaequantes. Cymae strictae pedunculo quam folium breviore. Involucri foliola 4 linearia.

586. V. dilatatum Thunb. Fl. jap. p. $124 .+$ V. foliis petiolatis e basi cuneata vel rotundata obovatis acutis acuminatisve inaequaliter sinuato-dentatis utrinque pilis simplicibus pubescentibus, ramis petiolis pedunculis calycibusque hirtis, stipulis nullis, cymis terminalibus non radiantibus nudis.

Rami novelli tetragoni aeque ac petioli et pedunculi pilis stellatis tomentoso-hirti; petioli $4-6^{\text {"' }}$ longi; lamina folii e basi rotundata vel cuneata obovata acuta vel acuminata, inaequaliter dentata, dentibus brevibus mucronatis sinubus rotundatis, utrinque pilis simplicibus decunbentibus pubescens, $2 \frac{1}{2}-4 \frac{1}{2} "$ longa, $1 \frac{1}{2}-2 \frac{1}{2}$ " lata. Cymae terminales foliis breviores, plerumque 5̃-radiatae. Corolla extus pubescens. Stylus brevissimus stigmate tridentato.

587. V. urceolatum S. et $\mathbf{Z}$ : - V. foliis petiolatis e basi rotundata ovato-oblongis acuminatis acumine obtuso, crenatis superne glabris subtus ad nervos pilis stellatis parce adspersis rugosis, stipulis nullis, eymis terninalibus nudis, corollis urceolatis apice subconstrictis, staminibus exsertis.

Rami novelli aeque ac petioli et pedunculi pilis minutis stellatis adspersi; lanina folii ovato-oblonga vel oblonga, basi rotundata, obtuse acuminata, irregulariter crenata, $1 \frac{1}{2}-3^{\prime \prime}$ longa, 10-18". lata. Cymae terminales foliis breviores, plerumque 5-radiata non involucrata. Flores subsessiles. Calycis laciniae glabrae ova- 
tae obtusae. Corolla parva urceolata apice subconstricta laciniis brevibus erectis. Antherae exsertae.

588. V. phlebotrichum S. et Z. - V. foliis annuis breviter petiolatis e basi rotundata ovatis acuminatis argute et mucronato-dentatis costatis superne glabris subtus ad costas pilis simplicibus decumbentibus hirsutis ceterum glabris, cymis terminalibus folio longioribus rarifloris non radiantibus, pedunculis strictis tenerrimis pilosis, radiis plerumque quadrifloris, pedicellis longis strictis filiformibus, corolla rotata, staminibus brevissimis, stylo cylindrico stigmate trilobo.

Rami novelli tetragoni, glabri. Petioli brevissimi, 1-2 $2^{\prime \prime}$ longi, pilosi; lamina folii $2-2 \frac{1}{2}^{\prime \prime}$ longa, $12-15^{\prime \prime \prime}$ lata, argute dentata dentibus deltoideis mucronatis, superne praeter nervum medium parce pilosum glabra, subtus venis parallelis utrinque $6-7-$ costata et in costis pilis Jongis albis decumbentibus hirta, ceterum glabra. Cymae quam in reliquis speciebus multo graciliores, rariflorae, plerumque 5 radiatae; radii plerumque quadriflori, floribus 3 exterioribas longe pedicellatis, centrali subsessili. Pedicelli stricti, filiformes. Calycis tubus subcylindricus, laciniae parvae oblongae obtusiusculae. Corolla subrotata lobis ovatis obtusis. Filamenta brevissima, corolla multo breviora, antherae ovato-cordatae. Stylus cylindricus brevis stigmate distincte trilobo.

Die langen weissen Haare auf den Rippen der Rückseite der Blätter, die sehr dünnen schlanken Dolden- und Blumenstiele so wie die radförmigen Blumenkronen geben der Art ein vorr den äbrigen abweichendes Ansehen.

589. V. odoratissimum Ker Botan. Reg. tab. 456. De Cand. Prodr. IV. p. 326. V. sinense Zeyh. in Colla hort. rip. $p .145$. appl. 2.

329. Sambucus Tourn.

590. S. species. Specimina haud suppetuit. Folia bijuga. Umbellae trifidae, planae. Medulla ut in $\mathbf{S}$. racemosa fascescens. An hic S. pubescens Pers. ap. Siebold Annuaire l. c. p. 37. 
591. S. ebuloides Desv. De Cand. Prodr. IV. p. 323. Siebold Annuaire l. c. p. 37.

S. japonica Thunb. est. Euscuphis staphyleoides S. et Z.

\section{3. (127 EudI.) RUBIACEAE Iuss.}

330. Galium L.

592. G. strignsum Thunb. Nox. Act. Upsal 7. p. 141. tab. 4. f. 1-9. - G. (Euaparines) totum scabrum caule decumbente tetragono retrorsum aculeato-aspero, foliis infinis $8-10$, superioribus senis lineari-subspatlulatis obtusis aristatis, superne, margine et subtus in carina retrorsum aculeato-scabris, pedunculis trifidis glabris, fructibus globoso-didymis setis apice uncinatis hispidis. G. strigosum De Cand. Prodi. IV. p. 611. G. uliginosum Thunb. Flor. jap. p. 58.

Caules debiles ramosi. Folia infima octona - dena, superiora sena, basi longe attenuata indeque subpetiolata linearia, apicem versus parum latiora et subspathulata, obtusa sed mucrone setaceo aristata, 15-18"' longa, 2"' lata. Pedunculi breves, solitarii, gemini ternive; pedicelli divaricato-patentes nee reflexi, glabri. Fructus parvi, globoso-didymi setis glochidiatis hispidi.

Quid G. verum et rotundifolium Thumb.?

331. Rubia Tournef.

593. R. Munjista Roxb. De Cand. Prodr. IV. p. 588. R. cordata Thunb. Fl. jap. p. 60.

332. Serissa Commers.

594. S. foetida Comm. De Cand. Prodr. IV. p. 575. Blnme Bijdr. p. 969. - Lycium japonicum Thunb. Flor. jup. p. 93. tab. 17.

333. Paederia Linn.

595. P. foetida L. De Cand. Prodr. IV. p. 471. Thunb. Fl. jap. p. 106. Kämpfer Icones tab. 9. 
Recedit a specc. indicis foliis subtus ad venas pubeseentibus et pedunculis quam petioli brevioribns.

\section{Mitchella L.}

596. M. undulata $\boldsymbol{S}$. et $\boldsymbol{Z}$. M. caulibus filiformibus repentibus, foliis e hasi rotundata acutis margine undulatis glabris, floribus terminalibus geminis subsessilibus ovario coneretis, ealycis laciuiis irregulariter trifidis.

Caules filiformes radicantes radiculis filiformibus, ramosi. Folia opposita petiolata, petiolis $1-2^{\prime \prime \prime}$ longis uti tota planta glabris; lamina e basi rotundata vel subtruncata ovata acuta margine undulata et inde quasi crenata, subtus pallida, $4-5^{\prime \prime \prime}$ longa, $2-3^{\prime \prime \prime}$ lata. Stipulae connatae minutae lanceolatae acutae. Flores inter summa folia terminales gemini sessiles ovario conereti. Calycis quadrifidi laciniae deltoideae, hine vel utrinque lacinulis subulatis brevioribus auctae indeque trifidae. Corellae tubus cylindricus, limbus quadrifidus laciniis ovato-oblongis ad fancem intus barbatis superne glabris. Omnibus partibus quam $\boldsymbol{M}$. repens minor et gracilior.

335. Damna canthus Gaertn. (et De Cand. Prodr. - Baumannia De Cand. Act. Genev.)

Calycis tubus urceolatus limbo quadrifido. Corolla infundibuliformis tubo cylindrico limbo quadrifido, fauce vel et in laciniis lirto, Stamina 4, corollae tubo adnata, apice tantum libera; antherae oblongae inclusae vel subexsertae. Ovarium inferum quadriloculare loculis uniovulatis, vertice nectario urceolato coronatum. Stylus filiformis inclusus vel exsertus. Stigma quadrifidum lobis linearibus vel oblongis. Bacca globosa carnosa, calyce coronata, tetra-vel abortu di-tricocca; cocci cartilaginei, monospermi. Semen convexoplauum testa tenuiter membranacea albumini carnoso adnata. Embryo minutus, basilaris, radicula infera, cotyledonibus brevibus.

Frutices humiles ramis dichotomis divaricatis flexnosis. Folia sempervirentia, opposita, subsessilia, ovata, mucronata, coriacea. S $t i-$ 
pulae breves connatae interpetiolares, spinam subulatam in axilla gerentes. Flores axillares, gemini, subsessiles.

Genus inter Nertermn et Mitchellam ponendum. Conf. Zuccarini in Gelehrte Anzeigen der k. Akad. 1846 n. 39. p. 313.

597. D. indicus Guertn. D. ramis divaricato-flexuosis, folits - brevissime petiolatis ovato-suborbicularibus cuspidatis glabris coriaceis rigidis, calycis laciuis lineari-lanceolatis acnminatis, stigmatis laciniis linearibus. Gaertn. Fil. Carpol. III. p. 18. tab. 182 et ejusdem fide Carissa spinarum Thunb. Flor, jap. p. 108. So no ki aliis Sirà et Firasi Kämpfer Amoen. p. 784. De Cand. Prodr. IV. p. 473. - Baumannia geminiflora De Cand: in Mém. de Pleys. et dHist. nat. à Genève Vol. VI. c. icone.

Frutex humilis ramosissima ramis tenuibus dichotome divaricatis flexuosis, novellis setis seu squamulis adpressis furfuraceis. Folia opposita brevissime petiolata petiolis vix lineam longis; lamina e basi rotundata vel subcordata ovato-suborbicularis breviter cuspidata integerrima, subtus in nervo medio pubescens ceterum glabra evenia coriacea, 5-6" longa, 3-4" lata. Stipulae interpetiolares connatae brevissimae late deltoideae. Spina ex axilla cujusvis stipulae simplex subulata recta strictissima, $4-8^{\text {mi }}$ longa. Flores in axillis foliorum gemini rarius solitarii, subsessiles. Calyx superus cupularis pubescens; limbus quadrifidus laciniis lineari-lanceolatis acuminatis tubum superantibus sinnbus rotundatis. Corollae albae tubus cylindricus tenuis glaber superne parum ampliatus, fance barbatus, 3-4" longus; limbus quadrifidus laciniis oblongis acutinsculis patentibus basi villosis. Staminum filamenta fundo corollae inserta agglutinata apicem versus libera, filiformia; antherae supra basin affixae, oblongae, semiexsertae. Ovarium globosum, quadriloculare loculis uniovulatis. Stylus simplex filiformis, staninibus subbrevior; stigma quadripartitum, Jaciniis linearibus papillosis. Bacca globosa magnitudine pisi minoris, carnosa, calyce persistente coronata tetravel abortu tri-dicocca coccis cartilagineis monospermis. 
598. D. major S. et $\mathbf{Z}$. D. ramis divaricato-flexuosis, foliis brevissime petiolatis ovatis vel ellipticis acutis glabris coriaceis rigidis, calycis lacinïs ovato-lanceolatis acutis, stigmatis lacinïs oblongis obtusis.

Praecedenti valde aftinis sed omnibus partibus major ac robustior notis supra indicatis certe diversa.

336. Hedy otis Gaertu.

599. H. corduta Zuccar. H. foliis sessilibus e basi cordata late ovatis cuspidatis integerrimis coriaceis utrinque glabris, praeter nervum medium eveniis, stipulis vaginantibus late ovatis mucronatis persistentibus; corymbo terminali folia superante denso, calycis quadridentati dentibus ovatis acutis, fauce nuda, corolla breviter tubulosa fauce barbata profunde quadripartita laciniis linearibus, staminibus exsertis.

Tota glabra. Rami tetragoni. Folia sessilia decussata basi cordata lobis rotundatis, late ovata acuta vel cuspidata integerrima glabra $1 \frac{1}{2}-2$ " longa, $10-15^{\prime \prime \prime}$ lata. Corymbi terminales fastigiati multiflori densi plerumque basi foliis duobus suffulti; rami dichotomi tetragoni pubescentes. Calyx campanulatus, 4 dentatus, glaber. Corolla brevissime tubulosa tubo calycem aequante, limbo quadripartito aciniis longis linearibus. Stamina imo tubo inserta filiformia, longitudine corollae. Discus ovarium obtegens concavus glaber. Stylus filiformis stigmate bifido, laciniis linearibus.

Crescit in insulis Bonin-sima, unde specc. a beato Mertens lecta vidi in herb. Acad. Imper. Petropolitanae.

337. Ophiorrhiza L.

600. Oph. japonica Blume Bijdr. p. 978. De Cand. Prodr. IV. p. 416.

Caulis herbaceus radicans, ramosus, ramis novellis petiolis et pedunculis ferrugineo-hirtis. Folia opposita petiolata petiolis $4-6^{\prime \prime \prime}$ longis; lanina ovata vel ovato-oblonga utrinque attenuata vel basi rotundata, acuta, superne setulis parvis adspersa subtus pallidior vel

Abhandlungen d. Il. Cl. d. k. Ak. d. Wiss. IV. Bd. III. Abth. 
soepe rubens, $1-2^{\prime \prime}$ longa, $6-12^{\prime \prime \prime}$ lata. Stipulae minimae. Corymbi terminales dichotomi multiflori. Bracteae lineares pedicellos aequantes vel superantes. Calycis tubus subvillosus, laciniae lancenlatae acutae soepius subinaequales. Corolla coccinea, longe tubulosa tubo cylindrico sursum parum dilatato pubescente, limbo quinquefido, Jaciniis ovato-oblongis obtusis intus hirsutis.

338. Nanclea L.

601. $\mathbf{N}$. racemosa $\mathbf{S}$. et $\mathbf{Z}$. - N. foliis longe petiolatis e basi rotundata vel subcordata ovatis acuminatis praeter venas subtus puberulas glabris, stipulis cadncis, pedunculis $5-9$ in racemos terminales decussatos congestis tenuiter tomentosis capitulo duplo longioribus, calycis tomentosi laciniis abbreviatis ovatis acutinsculis.

Rami obtuse tetragoni, novelli subtomentosi. Folia opposita longe petiolata, petiolis 1-3" longis; lamina folii e basi late rotundata vel subcordata ovato-acuminata, superne glabra lucida, subtus ad venas parce pubeseens. Stipulae ovato-oblongae fugaces. Pedunculi $5-9$ abortu foliornm in racemos terminales dispositi et inferiores soepius axillares, subtetragoni, stricti, tenuiter tomentosi, circiter pollicares, ad basin capitulorum bibracteolati. Calyces ferrugineo-tomentosi, laciniis brevibus ovatis acutinsculis vel obtnsis. Corollae tubus gracillimus, limbus urceolatus laciniis ovatis obtusis pubescentibus. Styli pars exserta corollae tubum aequans.

339. Gardenia Ellis.

602. G. florida L. Thunb. Fl. jap.p. 108 et Auct.

603. G. Maruba Sieb. in Blume Bijdr. p. 1015. G. inermis ramulis novellis pubescentibus, foliis oppositis ternisve subsessilibus utrinque attenuatis, oblongis vel obovato-oblongis, acutis vel acuminatis utrinque glabris subtus pallidis, stipulis connatis ovatis acutis, floribus terminalibus solitariis subsessilibus hexameris, calycis laciniis linearibus mucronatis patentibus, tubo corollae cylindrico brevioribus, limbi laciniis inaequilateris subcultratis obtusis. 
Folia $2-3 \frac{1}{2}^{\prime \prime}$ longa, $8-15^{\prime \prime \prime}$ lata, oblonga, obovato-oblonga vel rarius lanceolata. Calycis laciniae $8^{\prime \prime \prime}$ longae; corollae tubus soepius pollicaris. Antherae exsertae lineares. Stigma crassissimum clavatum bilobum.

fi04. G. grandiflora Lour. A. cochin. p. 182. Siebold Annuaire l. c. p. 29.

605. G. radicans Thunb. A. jap. p. 109.

\section{4. (125 Eudl.) CAMPANULACEAE De Cand.}

340. Campanumoea Blume.

606. C. lanceolata S. et Z. Flor. jap. I. p. 174. tab. 91. Thunb. Flor. jap. plant. obscur. n. 21. p. 350.

341. Platycodon A. De Cand.

607. Pl. grandiflorum Alph. De Cand. Prodr. VII. p. 422. Wahlenbergia grandiflora Schrad. - Campanula grandiflora Iac\%. hort. Vindob. III. p. 4. tab. 2.

. glaucum, foliis caulinis numerosioribus magis approximatis subtus intensins glaucis vel albicantibus. Camp. glauca Thunb. Flor. jıp. p. 88. - Kekko vulgo kikko et kirukao Kämpf. Amoen. p. S22. - Fortune plant. exsicc. chin. n. 149.

\section{Wahlenbergia Schrad.}

605. W. marginata Alph. De Cand. Monoyr. Campan. p. 144. Prodr. VII. p. 433. Campan. marginata Thunb. Flor. jap. p. 89. Decades plant. jap. 3. c. ic. - Camp. gracilis var. Spreng. Syst. Veget. I. $p .736$.

Radix perennis. Caules plures herbacei vel basi lignescentes decumbentes ramosi, ramis gracilibus erectis sulcatis glabris. Folia sessilia, linearia vel inferiora lineari-lanceolata utrinque attenuata acuta, margine albida, undulata et remote subserrulata, parce pilosa vel glabra, vix pollicaria. Pedunculi ex apice ramuloruin elongati, 2- $\check{5}^{\prime \prime}$ longi, nudi, nuiftori. Calycis glabri laciniae lanceolatae acutae dimidium corollae campanulatae coeruleae aequantes. 


\section{CampanulaL.}

609. C. Trachelium L. Thunb. Fl. jap. p. 88. A. De Cand. Prodr. VII. p. 469. A planta europaea nullo modo diversa.

610. C. remotiflora $\boldsymbol{S}$. et $\boldsymbol{Z}$. C. radice perenni, caulibus herbaceis teretibus erectis uti tota planta glabris, foliis inferioribus petiolatis e basi cordata vel rotundata ovatis vel ovato-lanceolatis, superioribus sessilibus, utrinque attenuatis lanceolatis vel lineari-lanceolatis, omnibus acuminatis inaeqnaliter argute serratis, floribus in racemum terminalem panci- $(6-8)$ florum dispositis a se invicem remotis pedunculatis, calycis tubo brevissimo, laciniis linearibus vel lineari-lanceolatis glabris vel ciliato-hispidis, corolla glabra, stylo subexserto stigmate trilobo.

Folia caulina remota panca, summa sessilia linearia. Flores distantes bractea lineari suffulti pedunculati, pedunculo bracteam (soepe plus quam duplo) superante. Calyeis laciniae patentes dimidium corollae tubum aequantes, lineares glabrae, vel lineari-lanceolatae et margine pilis longis albidis ciliato-hispidae.

344. Adenophora Fisch.

611. A. verticilla:a Fisch. A. De Cand. Prodr. VII. p. 492.Campan. tetraphylla T'hunb. Flor. jap. p. 87. et Auct.

Var. foliis verticillatis et oppositis oblongis vel lineari-lanceolatis, ramis paniculae vel verticillatis brachiatis vel oppositis alternisve adscendentibus.

345. Isolobus De Cand.

612. J. radicans D. C. Prodr. VII. p. 353. - Lobelia Erinus Thunb. Fl. jap. p. 325. L. radicans Thunb. Act. Linn. II. p. 330 .

613. J. campanuloides De Cand. Prodr. VII. p. 35̃3. - Lobelia erinoides Thunb. Fl. jap. p. 326. L. japonica Dietrich.

Occurrunt praeterea Lobeliaceae tres nondum determinatae. 


\section{6. (120 Endl.) COMPOSITAE Inss.}

346. Adenostemma Forst.

614. A. viscosum Torst. - Verbesina Lavenia Thunb. Flor. jap. p. 321. - A. erectum D. C. vel vera Verb. Lavenia $L$. recedit a planta nostra akeniis laevibus.

347. Nardosmia Cass.

615. N. juponica S.etZ. An Tussilugo Pefasites Thunb. Fl.jap. p. 314? Folia radicalia desunt. Squamae scapi oblongae vel inferiores ovatae acutiusculae, involucri Janceolatae acutae vel obtusae discum subaequantes. Capitula in thyrsum fastigiatum disposita, pedunculi bracteis $2-3$ linearibus muniti uti scapus subvillosi.

348. Eupatorium Tourn.

616. E. Finlaysonianum Wall. De Cand. Prodr. V. p. 179 et ex ejusdem sententia Eup. album Thunb. Fl. jap. p. 308.

617. E. chinense L. Thunb. l. c. Dubitat clar, De Cand. num planta japonica eadem sit ac chinensis.

618. E. japonicum Thunb. l. c. Quaerit cl. Willdenow an ab E. cannabino sit satis diversum.

Quid E. hyssopifolinn Thunb. I. c., a planta Limneana certe diversum.

349. Aster Nees.

619. A. japonicus Less. De Cand. Prodr. V. p. 228. - Inula dubia Thunb. Flor. jap. p. 318.

620. A. tataricus L. fil. De Cand. Prodr. I. p. 230.

Folia in specc. nostris lanceolata utrinque attenuata medio serrata, summa linearia integerrima, uírinque sed praesertim margine et subtus setulis decumbentibus aspera. Flores in corymbum fastigiatum dispositi, ramis bracteis linearibus brevibus obsitis, pedunculis subundis. Involucri squamae lanceolatae acutae apicem versus subserrulatae. Pappus rufescens. Specimina sibirica herbarii Ledebouriani optime cum nostris conveniunt. 
350. Tripolium Nees.

621. Tr. vulgare Nees. De Cand. Prodr. V. p. 253. Aster

\section{Tripolium L.}

35̃. Calinieris $\mathbf{N}$ ees.

622. C. amplexifolia S. et Z. C. caule flexuoso nti tota planta pubescenti-scabriusculo, foliis sessilibus, inferioribus basi rotundata subamplexicanlibus oblongis acuminatis grosse serratis serraturis mucronatis, summis lanceolatis integerrimis subpetiolatis, corymbis fastigiatis, invol. squamis biseriatis lineari-lanceolatis obtusis vel acutiusculis pubescentibus, pappo scabro (rufo), in floribus disci corollis breviore.

Caulis flexuosus subangulatus nti tota planta setulis decumbentibus pubescens et subcanescens. Folia sessilia basi subattenuata rotundata et subamplexicaulia, oblonga vel oblongo-lanceolata, longe acuminata, grosse et remote serrata serraturis mucrouatis, $2-3 \frac{1}{2}$ longa, 10-18" lata; folia summa soepius brevissime petiolata, lanceolata basi rotundata integerrima. Corymbus terminalis multiflorus. Involucri foliola biseriata, exteriora breviora, lineari lanceolata, obtusa vel acuituscula, apicem versus pubescenti-hirta. Flores radii circiter 15, coerulescentes. Achenia compressa, pilis albis hirta. Pappus uniserialis setis numerosis inaequalibus scabris rufis.

352. Döllingeria Nees.

623. D. scabra Nees. De Cand. Prodr. V. p. 263. - Aster scaber Thunb. Fl. jap. p. 316.

Specimina nostra incompleta.

353. Callistephus Cass.

624. C. sinensis Cass. -- Aster chinensis Thunb. l. c. p. 316. et Auct.

35̆4. Heteropappus Less.

625. H. incisus S. et Z. H. hispidus Lessing Synops. p. 189. De Cand. Prodr. V. p. 297. Aster hispidus Thunb. Flor. jap. p. 315 et Banks Icones Kämpfer. tab. 29. - Keitsjo vulgo Jomega Fagi Kämpfer Anoen. p. 876. Caliuneris hispida Nees Aster p. 227. 
Planta sibirica et dautrica, a japonica nullo modo diversa, est simul: Calimeris incisa De Cund. l. c. p. 258. Aster incisus Fisch. Mem. soc. mosq. III. p. 76 et Lessing Synops. p. 163. Grindelia incisa Spreng. Syst. UIL. p. 575. Kulimeris platycephala Cassin. dict. 24. $p .325$.

Nomen mutavimus quum nec japonica nee sibirica planta hispida diei possit. Caulis et folia setulis adpressis brevissimis scabriuscula. Folia inferiora oblonga vel rarius obovata subsessilia utrinque attenuata, grosse inciso-serrata, summa lineari-lanceolata integerrima. Involucri squamae lanceolatae acufae sursum iciliatae et pnbescentes vel glabrae. Radius pallide coeruleus. Achenia compresso-plana marginata hirta. Pappus in floribus radii brevissime setosus setis basi in coronulam subcomnatis, in floribus disei longior attamen akenium non aequans, uniserialis, rufescens, vel soepius abbreviatus ut in radio setulis nonnullis longioribus intermixtis.

Es ist sonderbar, dass man bei Bestimmung dieser wie vieler anderer japanischer Pflanzen die südöstliche Flora von Sibirien ganz ausser Acht liess und gleichsam a priori immer die vorkommenden Pflanzen als different amnahm. Daraus erklärt sich zum Theil, dass Lessing, welcher in seiner Synopsis nach der japanischen Pflanze die Gattung Heteropappus aufstellt, von der sibirischen, dem Aster incisus Fisch, ebendaselbst p. 163 sagt, es sei kein Grund, sie von Aster zu trenuen!

626. H. subserratus $\boldsymbol{S}$. et $\boldsymbol{Z}$.

H. caule tereti scabriusculo, foliis (caulinis) sessilibus linearibus acutiusculis, inferioribus apicem versus remote serratis superioribos integerrimis omnibus utrinque scabris, involueri sqnamis biseriatis linearibus acuminatis hirtis, acheniis compressis marginatis hispidis, radii pappo abbreviato setoso setis basi connatis albis coronaeformi, disei setoso scabro rufo.

Folia inferiora in spece. nostris desunt. Caulina media lineraria utrinque altenuata acutiuscula sesqui - bipollicaria, medio remote serru- 
lata, superiora sensim breviora integerrima. Corymbus laxus ramis fastigiatis paucifloris foliosis. Radii flores coerulei.

\section{H. rigens $\mathbf{S}$. et $\mathbf{Z}$.}

H. caule tereti scabro, foliis sessilibns basi attenuatis linearisuhspathulatis obtusis vel acutiusculis integerrimis utrinque scabris firmis rigidiusculis, corymbo laxo fastigiato, ramis nni-vel paucifloris foliosis, involucri squamis biseriatis linearibus acutis vel acuminatis scabris subciliatis, pappo radii coronaeformi abbreviato albo, disci setoso setis scabris ferrugineis.

Habitu cum majoribus Cal. altaicae varietatibus bene convenit, sed pappi structura facillime distinguenda. Folia pollicaria vel sesquipollicaria $2-4^{\prime \prime \prime}$ lata acutiuscula vel obtusa et brevissime mucronata, utrinque scabra, ramea superiora multo minora ad capitula usque producta approximata. Rami uni-vel pauciflori. Radius multi(25-30-) florus, albus?

\section{Conyza Less.}

628. Conyza japonica Less. De Cand. Prodr. V. p. 382. Erigeron japonicum Thunb. Fl. jap. p. 312.

356. Asteromaea Blume.

629. A. indica Blume. De Cand. Prodr. V. p. 302. - Aster indicus Thunb. Flor. jap. p. 316.

357. Inula Gaertn.

630. J. Helenium L. Thunb. Flor. jap. p. 317.

Planta ab europaea praeter capitula plerumque parum minora nullo modo diversa.

631. J. japonica Thunb.

J. caule herbaceo erecto subvilloso ramoso, foliis sessilibus subamplexicanlibus, oblongo-lanceolatis vel lanceolatis, acuminatis, remote denticulatis, superne glabris subtus plus minus sericeo-pubescentibus, ramis uni-vel paucifloris longis in corymbum laxum dispositis, capitulis basi plerumque nno alterove foliolo suffulis, involucri squamis 
linearibus acuminatis, exterioribus sericeo-pubescentibus, interioribus ciliato-serrulatis, pappi setis subulatis scabris albidis.

J. japonica Thunb. Fl. jap. p. 318. De Cand. Prod. V. p. 471. - Banks Icon. Kaempfer. tab. 30. Sen fuku vulgo Oburuma Kämpf: Amoen. p. 877.

Descriptio Thunbergiana optime in plantam nostram quadrat, icon Kämpf, foliis latioribus et ramis magis foliosis parum recedit. 358. Eclipta L.

632. E. prostrata L. Thunb. Fl. jap. p. 321. De Cand. Prodr. V. p. 490.

359. Siegesbeckia Linn.

633. S. orientalis L. Thunb. Fl. jap. p. 321. De Cand. Prodr. V. $p .495$.

360. Xanthium Tourn.

634. X. Strumarium L. De Cand. Prodr. V. p. 523. 361. Helianthus L.

635. H. annus $\beta$. pumilus Pers. De Cand. Prodr. V. p. 585. In hortis cultus.

362. Por op hyllum Vaill.

636. P. japonicum De Cand. Prodr. V. p. 650. Sieb. et Zuccar. Fl. jap. p. 161. tab. 84. - Senecio japonicus Thunb. Flor. jap. p. 315. - Kleinia japonica Lessing in Linnaea 1831. p. 134.

363. Bidens Linn.

637. B. chinensis Willd. Specc. plant. III. p. 1719. B. leucantha De Cand. Prodr. V. p. 598. - B. pilosa Thunb. Fl. jap. p. $30 \%$.

364. Ptarmica Tonrn.

638. Pt. sibirica Ledeb! Flor. ross. II. p. 528. (Ind. sem. hort. dorpat. 1811). Pt. mongolica De Cand. Prodr. VI. p. 22. Achillea mongolica Fischer in litteris.

Specimina japonica a dauuricis in herb. Ledebonriano aliisque a cl. Turczaninof communicatis nullo modo differunt. Abhandlungen d. II. Cl. d. k. Ak. d. Wiss. IV. Bd. III. Abth. 
Hasskarl (Catal. hort. Bogor. p. 101) führt Achillea squarrosa Ait. als aus Japan in den Garten zu Bujtenzorg übersiedelt auf. Ohne Zweifel ist auch dieses unsre Pflanze, vou welcher aber die Willdenow sche Definition durch pinnas verticales abweicht. 365. Pyrethrum Gaertn.

639. P. sinense Sabine. De Cand. Prodr. VI. p. 62. Chrysanth. indicum Thunb. Flor. jop. p. 320. - Kik, Kikf vel kikku Kämpfer Amoen. p. 875. et varietates p. 876, 877.

640. Species nondum determinata.

366. Chrysanthemum D. C.

641. Chr. coronarium L. Thunb. Flor. jap. p. 320.

Adnotatio. Chrysanth. japonicum Thunb. l. c. fide clar. Lessing (Linnaea 1831. p. 218.) delendum, nam specimen in herbario Thunberg. sub hoc nomine asservatum est ramulus folia tantum gerens Artemisiae japonicae.

367. Artemisia Linn.

642. A. borealis Pall. De Cand. Prodr. VI. p. 98.

Folia radicalia longe petiolata sericeo-cana pinnatifida laciniis linearibus soepe elongatis planis simplicibns bifidis vel incisis; canlina superiora linearia; racemus paniculatus, capitula nutantia.

643. A. japonica Thunb. Fl. jap. p. 310. De Cand. l.c.p. 100.

Varietatibus procerioribus A. desertorum Spreng. similis, sed jam capitulis multo minoribus diversa. Folia inferiora cuneata obovata apice rotundata inciso-trifida, laciniis lineari-oblongis argute serratis, superiora e basi cuneata lineari-oblonga apice tridentata, summa linearia, omnia rigida glabra. Capitula parva, globosa, squamis rotundatis glabris.

644. A. vulgaris L. Thby. Fl. jap. p. 310.

Specimina nobis obvia ad varietatem integrifoliam $(A$. integrifoliam L.) pertinent.

645. A. indica Willd. De Cand. Prodr. VI. p. 114.

646. A. annua L. De Cand. Prodr. VI. p. 119. 
647. 648. Species duae e specc. incompletis nondum determinatae.

Art. minimu Thunb. l. c. p. 311, est Myriogyne minuta Less. 368. Myriogyne Less.

649. M. minuta Less. Linn. 1831. p. 219. De Cand. Prodr. VI. $p .139$. - Artemisia minima Thunb. Flor. jap. p. 311. Cotula minuta Forst. Prodr.301. C. minuta et cuneifolia Willd. sp. plant. III. p. 2169. - Grangen sninuta et cuneifolia Poir. Suppl. II. $p .825$.

369. Gnaphalium D. Don.

650. Gn. confusum D. C. Prodr. VI. p. 222. Gn. arenarium Thunb. Fl. jap. p. 312. Gn. martabanicum Wall.

Folia canlina inferiora late linearia vel subspathulata obtusa, superiora acuta mucronata mucrone calvo.

65̆1. Gn. japonicum Thunb. Fl. jap. p. 311?

Dem einzigen vorliegenden Exemplar zu Folge scheint die Pflanze eher zu Helichrysum zu gehören. Stengel und Blätter stimmen mit der Tlıunbergschen Beschreibung überein, aber die Blüthenköpfchen sind nicht röthlich, sonderu rein weiss.

370. Carpesium Linn.

652. C. divaricatum S. et $\mathbf{Z}$.

C. pubescenti-hirtnm, ramis divaricatis, foliis breviter petiolatis ovato-oblongis oblongis lanceolatisve ntrinque attenuatis acutis remote dentieulatis utrinque sed praesertim subtus pubescentibus, capitulis cernuis, bracteis foliaceis petiolatis spathulatis suffultis, invol. squamis exterioribus foliaceis patulis, interioribus obtusis vel acutinsculis apice irregulariter denticulatis, corollae tubo cylindrico. Carp. cernuun Thunb. Flor. jap. p. 312.

C. cernuo affine differt foliis minutim denticulatis, capitnlis duplo minoribus, involucri squamis interioribus acutiusculis nec rotundatis.

653. C. Thunbergianum S. et Z. C. villoso-pubescens, foliis caulinis inferioribus breviter petiolatis ovato-ellipticis utrinque atte$24 *$ 
nuatis acutis denticulatis, superioribus subsessilibus lanceolatis, capitulis inferioribus axillaribus solitariis vel spicatis, summis aphyllis sessilibus in spicam laxam dispositis, omnibns erectis, squamis exterioribus parcis foliaceis patentibus, interioribus erectis obtusis ciliato-fimbriatis, corolla fauce campanulata. C. abrotanoides Thunb. Flor. jap. p. 312.

Canlis stricte erectus. Capitula inferiora axillaria plerumque plura in spicam brevem disposita, superiora solitaria sessilia absque folio fulcrante indeque in spicam laxam erectam nudam congesta. Squamae exteriores foliaceae breves villosae, interiores erectae ovatooblongae rotundatae margine fimbriato-ciliatae, ceterum glabrae, stramineae. Corollae tubus basi cylindriens, superne campanulato-ampliatos. Achenia infra areolam glauduloso-scabra.

371. Ligularia Cass.

654. L. Kämpferi S. et Z. Fl. jap. I. p. 77 tab. 35. - Senecio Kämpferi De Cand. Prodr. VI. p. 363. - Tussilago japonica Thunb. Fl. jap. p. 313. - Tswa Kämpfer Amoen. p. 827. Banks Icones Kämpfer. tab. 27. 28.

655. L. gigantea S. et Z. Flor. jap. I. p. 79. tab. 36.

Lessing und De Candolle stellen die erstere Art zu Senecio. Aber die Narbenschenkel sind doch anch unter dẹr Spitze kurz gebartet, der fast borstige nach oben gezähnelte Pappus ist bleibend und der Habitus ist dem der sibirischen Ligularien so ähnlich, dass wir beide Arten letzterer Gattung zuzuzählen uns berechtiget glaubten. 372. Erythrochaete S. et $\mathbf{Z}$.

Capitulum multiflorum radiatum, fl. radii uniseriatis $12-20$ ligulatis foemineis, disci tubulosis 5 dentatis hermaphroditis. Involucrum uniseriale, 8-12-phyllum, foliolis margine membranaceis. Receptaculum nudum, plannm. Stylus disei ramis linearibus obtusis vel acntiusculis superne calvis subtus in apicem usque pubescentibus. Achenia erostria, glabra. Pappus pluriserialis, simplex, pilosus, inaequalis, scaber, rubens. 
Herba foliis alternis caulinis palmatifidis petiolatis, petiolis basi vaginantibus, capitulis terminalibus subcorymbosis.

6556. E. palmatifida \$. et $\boldsymbol{Z}$. E. caule tereti, foliis inferioribus petiolatis, petiolo basi late vaginante sursum canaliculato, lamina circumseriptione semiorbiculari tripartita, segmentis lateralibus bi-, intermedio trifidis, laciniis profunde et inaequaliter inciso-serratis vel subpinnatifidis lobis dentibusque acnminatis, racemo terminali fastigiato pancifloro, pedunculis brevibus patentibus tomentoso-fuscescentibus. Arnica japonica Thunb. Fl. jup. p. 319. Icones plant. jap. dec. 4.Ligularia japonica dec. 4. Lessing Synops. p. 319 et ejusdem fide. De Cand. Prodr. VI. p. 316.

Canlis herbaceus crassitie pennae anserinae, teres glaber, apice aeque ac pedonculi lanugine floccosa derasili tomentoso-fuscescens. Folia canlina inferiora petiolata, petiolo $3-4^{\prime \prime}$ longo, ab insertione ad $\frac{1}{3}$ longitudinis late vaginante inde apicem versus semitereti canaliculato; lamina semiorbicularis basi subtruncata profunde tripartita, segmentis lateralibus bifidis, intermedio trifido, laciniis iterum apice $\mathrm{bi}$ - trifidis et grosse inciso-serratis lobis serraturisque acuminatis, subtus ad venas pubescens ceterum glabra, 6 -9 pollices longa et lata; folia superiora sensim minora petiolo multo breviore toto vaginante. Capitnla 5-10 in apice caulis in racemum brevem fastigiatum basi subramosum dispositi; pedunculi breves subdivaricati lanuginosi. Involucri squamae uniseriatae ovato-lanceolatae acutae margine plos minus membranaceae dorso subvillosae, numero inter 8 et 12 variantes. Flores radii radiantes ligulati foeminei (e Thunbergio rubri), lignla longa apice tridentata tripla longitudine pappi; corollae disci longe tubulosae vel subclavatae, 5 fidae, glabrae, dupla fere longitudine pappi. Antherae corollae longitudine acutae basi muticae. Stylus exsertus cruribus linearibus obtusiusculis superue subcanalicnJatis calvis, subtus in apicem usque papillis cylindricis barbatis nec in conum terminatis. Achenium glabrum, sessile, erostre, teretinseuJum? Pappus sessilis pluriseriatas simplex pilosus ruber; pili validi 
inaequales scabri vel ad lentem denticulati dentibus diametrum pili aequantibus.

Arnica ciliata Thunb. ist nach Lessing eine Cichoracea, A. palmata Ejusd. wahrscheinlich unsere Cacalia delphiniifolia.

373. Cacalia De Cand.

657. C. delphiniifolia S. et Z. C. caule erecto uti tota planta glabro, foliis inferioribus petiolatis e basi cordata suborbicularibus 5-9-partitis, laciniis lanceolatis grosse et inaequaliter inciso-serratis acuminatis, superioribus subsessilibus $3-5$-lobis lobis subintegerrimis acuminatis, panicula terminali multiflora, capitnlis cylindricis subquinquefloris, involucris pentaphyllis, corollae laciniis lineari-lanceolatis apice penicillato-barbatis. - Arnica palmata Thunb. Fl. jap. p. 319 ? et inde Senecio palmatus Lessing Synops. p. 392. - De Cand. Prodr. VI. p. 433.

Canlis herbacens bipedalis basi subflexuosus, sulcatus, erectus. Folia inferiora petiolata petiolo 2-3-pollicari basi non vaginante, lamina e basi cordata suborbiculari palmatifida, 5 -9-nervia totidemque lobata, lobis lanceolatis vel oblongo-lanceolatis acuminatis grosse et inaequaliter sinuato-serratis vel incisis, extimis multo brevioribus, $4-5^{\prime \prime}$ longa, $5-6^{\prime \prime}$ lata; folia superiora in petiolis vix lineam longis semipollicaria, minora, $3-5$-loba lobis deltoideis acuminatis integerrimis. Panicnla erecta multiflora; rami erecto-patentes, racemosi. Capitula gracilia cylindrica quinqueflora. Involucrum 5-phyllum, squamis linearibus acutiusculis glabris, basi squamulis minutis auctum. Corollae laciniae lineari-lanceolatae acutae et in ipso apice penicillo e pilis albis brevibus barbatae. Styli crures longi lineares tenniter pubescentes, apice truncati penicillato-barbati. Pappus candidus.

658. C. farfaraefolia $\mathbf{S}$. et $\mathbf{Z}$. C. caule erecto herbaceo inferne flexuoso apicem versus villoso, foliis petiolatis e basi cordata hastato-subdeltoideis acutis sinuato-dentatis dentibus brevibus mucronatis, ad venas pubescentibus vel totis glabris, panicula terminali mul- 
tiflora, ramis racemosis, capitulis cylindricis quinquefloris, involucris pentaphyllis, corollae laciniis lanceolatis apice nudis.

Caviles bipedales, teretes, basi flexuosi sursum recti et lanugine derasili villosi. Folia inferiora longe petiolata petiolo 2 -3-pollicari; lamina hasi profunde cordata et lobis angulato-patentibus hastata, late deltoidea acuta, margine remote et sinnato-dentata dentibus brevibus dilatatis, in mucronem subulatum terminatis, $3-4$ "longa et lata; folia superiora multo minora, brevins petiolata et in petiolum attenuata, inciso-dentata. Panicula erecta multiflora; rami racemosi capitulis breviter pedunculatis subsecundis cylindricis; involucri squamae lineari-oblongae obtusiusculae. Corollae glabrae. Pappus candidus.

659. Tertiae speciei antecedentibus affinis specimina hand suppetunt.

374. Senecio Less.

660. S. subensiformis D. C. Prodr. VI. p. 363. Senecio Lessing Synops. p. 392. Cineraria japonica Thunb. Fl. jap. p. 317.? Unsre nnvollständigen Exemplare gestatten nicht die Identität mit der Thunbergschen Pflanze mit voller Sicherheit zu ermittelv. Die Blătter stimmen allerdings überein, aber die Blüthenköpfehen sind ziemlich zahlreich in einem einfachen Doldenstransse, die vielblättrigen Hüllen glatt, die Blättchen linealisch, spitzig, die Randblüthen strahlig, die Achenien glatt.

375. Calendula Neck.

661. Species a C. officinali certe diversa.

376. Saussurea De Cand.

662. S. japonica De Cand. Prodr. VI. p. 536. Serratula japonicu Thunb. Flor, jap. p. 305.

Involucri squamae arachnoideo-villosae praeter extimas omnes appendiculatae; appendices suborbiculares aridae violaceae. 
377. Carthamus Tonrn.

663. C. tinctorius Linn. Thunb. Fl. jap. p. 307.

Nullo modo a planta europaea diversus.

378. Spanioptilon Lessing.

664. Sp. lineare Less. Synops. p. 10. D. Cand. Prodr. VI. p. 621. - Carduus linearis Thunb. Fl. jap. p. 305.

Caulis herbaceus erectus sulcatus ramosus, novellus arachnoideolanatus, adultior glaber. Folia caulina sessilia subapproximata linearia pungenti-acuminata, basi spinoso-dentata sursum spinulis subulatis adpressis ciliato-serrulata, superne glabra subtus magis minusve arachnoidea indeque virentia vel alhida, inferiora $3-4^{\prime \prime}$ longa, $3-4^{\prime \prime \prime}$ lata, superiora sensim minora. Capitula solitaria terminalia erecta (non cernua), hemisphaerica. Involueri squamae multiseriatae dense imbricatae, lineares pungenti-mucronatae dorso arachnoideo-floccosae, intimae apice aride subdilatatae glabrae. Flores homogami, tubulosi. Achenia glabra. Pappus uniserialis plumosns, cinerascens.

Variat foliis subtus viridibus vel albicantibns.

De Candolle nennt den pappus uniserialis setis paleaceo-setaceis. Lessing spricht dagegen schon im Namen der Gattung (блc̀vtos rarus und $\pi \tau i \hat{\lambda}_{0 \nu}$ pluma) aus, dass er gefiedert sey, wie auch unsere Exemplare zeigen. Im Habitus hat die Pflanze Aehnlichkeit mit Aucathia igniaria De Cand. (Cirsium igniarium Spreng.)

379. Cirsium Tourn.

665. C. japonicum De Cand. Prodr. VI. p. 640. - Carduus eriophorus Thunb. Flor. jup. p. 305.

666. Species C. kamtschatico Ledeb. De Cand. Prodr. VI. p. 644. affinis, sed specimina nostra nimis manca.

Cardus acaulis Thunb. l. c. an Cirsium acaule $\gamma$. ? Gmelini C. A. Meyer? 
3S0. Lappa Gaertn.

667. L. major. Gaertn. Arctium Lappa Thunb. Flor. jap. p. 304 .

381. Atractylodes D. C.

668. A. lyrata $\mathbf{S}$. et $\mathbf{Z}$. A. caule herbaceo erecto superne ramoso, follis in petiolum brevem decurrentibus inferioribus lyrato-pinnatifidis, lobis lateralibus 2 vel 4 lineari-oblongis terminali maximo obovato, superioribus simplicibns ovato-ellipticis, omnibus acutis mucronatis setulis spinescentibus dense ciliato-serratis, involucri exterioris squamis setaceo-pinnatifidis, interioribus ovatis arachnoideis imbricatis.

Caulis herbaceus erectus inferne teres sursum angulatus, ramosus, glaher vel apicem versus arachnoideus, ad apicem usque foliosus. Folia alterna; inferiora in petiolum decurrentia lyrato-tri-quinqueloba lobo terminali maximo obovato, superiora subséssilia integra ovata vel ovato-oblonga, omnia acuta mucronata, margine setnlis adscendentibus spinescentibus dense ciliato-serrata; utrinque glabra, $2-3 \frac{1}{2}^{\prime \prime}$ longa, $1-1 \frac{1}{2}^{\prime \prime}$ lata. Capitula terminalia solitaria erecta, foliis seu bracteis numerosis setaceo-pinnatifidis cincta. Capitula ipsa globosa involucri squamis ovatis imbricatis arachnoideis.

Wir bezeichnen die Pflanze vorlänfig als eigne Art, da keine der kurzen Beschreibungen Thunbergs von Atractylis lancea und ovata genau auf dieselbe passt. Wahrscheinlich beschrieb indessen der Verf. der Flora japon. seine A. ovata wach einem eimblüthigen Aste mit oberen ungetheilten Blättern unserer Pflanze. Leider sind übrigens an den uns vorliegeuden Exemplaren die Blüthen noch za wenig entwickelt, um darnach den Gattungscharacter genaner feststellen zu können.

Acarna chinensis Bunge Enum. pl. chin. p. 36 scheint nach der Beschreibung ähnlich, weicht aber durch lederartige dornig doppeltsägezähnige Blätter ab.

Abhandlungen d. Il. Cl. d. k. Ak. d. Wiss. IV. Bd, Abthl. 111. 
382. Anandria Siegesb.

669. Anandria Lessing in Linnaea 1830. p. 346 et ejusdem fide Perdicium tomentosum Thunb. Fl. jup. p. 319.

De Candolle Prodr. VII. p. 40. zieht A. radiata und discoidea als Spielarten von A. Bellidiastrum zusammen, citirt aber aus Versehen Thunberg bei A. discoidea statt bei radiata. Hieher gehört auch Chaptalia lyrata Bunge Enum. plant. Chin. p. 3 S.

383. Cichorium Linn.

670. C. Intybus L. Thunb. Fl. jap. p. 304.

Thunberg führt auch C. Endivia als wildwachsend bei Yedo auf. Ist sie wirklich identisch mit C. Cosnia Ham. welche De Candolle als die wilde indische Form von Endivia betrachtet? 384. Picris Iuss.

671. P. japonica Thunb. Fl. jap. p. 299. P. kamtschatica Ledeb. P. duhurica Fisch. et De Cand. Prodr. VII. p. 129.

Specimina japonica a kamtschaticis et dahnricis praeter flores parum minores nullo modo differunt.

Quid Picris flexuosa Thunb. Act. Linn. II. p. 340.? 38ว̃. Youngia Cass.

672. Y. Thunbergiana De Cand. Prodr. VII. p. 192. Prenanthes lyrata Thunb. Flor. jap. p. 303.

673. $\boldsymbol{Y}$. pygmaea Ledeb. Hl. ross. II. - Prenanthes debilis Thunb. Flor jap. p. 300. Icon. plant. jap. dec. 4. - Youngia? debilis De Cand. Prodr.VII. p. 194 et simul Barkhausia nana De Cand. l. c. p. 156. - Prenanthes pygmaea Ledeb. Act. Petrop. $V$. p. 553. P. polymorpha $\mathrm{Fl}$. Ejusd. Flor. alt. IV. p. 144. var. $\alpha$.

Diese Art scheint durch den ganzen Nordosten von Asien verbreitet zu seyn. Exemplare aus der Gegend von Ochozk und ans dem östlichen Sibirien waren mit den japanischen vollkommen übereinstimmend.

Die übrigen von De Candolle wohl mit Recht grösstentheils zu Youngia gezogenen Thunberg'schen Prenanthes-Arten unterliegen noch genauerer Untersuchung. 
386. Tara xacum Hall.

674. T. Dens Leonis Desf.-Leontodon Taraxacum Lim. Thbg. Flor jap. p. 304. Scapus infra capitulum lannginosus.

Quid Sonchus oleraceus, Serratula tinctoria, Carduns acaulis, Eupatorium hyssopifolium, Artemisia capillacea, Abrotanum, Erigeron scandens, Solidago Virgaurea, Arnica ciliata Thunb.?

\section{7. (119 Endl.) DIPSACEAE. Vaill.}

387. Scabios a Linn.

675. 676. Species duae nondum accuratius examinatae. Ex his Sc. maritima Thunb. Fl. jap. p. 58 non Lim. nec Thunb. Fl. cap. 1. 531. An Knatia?

\section{8. (118 Endl.) VALERIANEAE $D e$ Cand.}

388. Patrinia Iuss.

677. P. villosa Sieb. in Flora 1828. P. 759. Valeriana villosa Thunb. Fl. jap. p. 32.

Caulis hérbaceus stricte erectus villoso-scahriusculus. Folia caulina subsessilia lyrato-pinnatifida, laciniis lateralibus $2-3$ linearibus vel oblongis acutis integerrimis vel subserratis terminali maxima e basi cuneata ovata grosse serrata; superiora lineari-oblonga integerrima, omnia utrinque pilosa. Corymbus brachiatus patens multiflorus; rami dense bifariam hispidi. Flores sessiles; calyces glabri.

678. P. parviftora $\boldsymbol{S}$. et $\boldsymbol{Z}$.

P. tota glabra, foliis caulinis pinnatifidis, laciniis lateralibus biquinquejugis lineari-oblongis vel lanceolatis grosse serratis vel subintegerrimis, terminali ovali, lanceolata vel lineari acuminata soepius elongata, corymbo terminali brachiato multifloro, ramis bifariam hispidnlis, bracteis ciliatis.

Folia variant lobo terminali laterales aequante vel iisdem duplo longiore, ovato-oblongo, lanceolato vel lineari et ve grosse serrato vel subintegerrimo. Flores congenerum minimi. 
Occurrunt praeterea Valerianae species duae (ex his Val officinalis Thunb. Fl. jap. p. 31 non Linn.) et Valerianella.

\section{9. (117. Endl.) PLumbagineae $R$. $B r$.}

389. Statice Willd.

679. St. japonica S. et Z. St. foliis radicalibus obovato-oblongis obtusis mucronatis in petiolo decurrentibus glabris, scapis pluribus paniculatis basi simplicibns acute tetragonis sursum angulatis, panicula pyramidali ramis elongatis subsecundis, spicis tandem distichis subsecundis multifloris, floribus singulis binisve tribracteatis, bracteis duabus inferioribus abbreviatis ovatis mucronatis tertia late ovata obtusa vel cuspidata calycem subaequante, omnibus coriaceis glabris, calycis dentibus subulatis membranaceo-marginatis, tubo quinquenervio nervis basin versus piloso-barbatis, - Statice Limonium Thunb. Fl. jap. p. 129.

Folia radicalia roselata, 4" (cum petiolo) circiter longa, 1" lata. Scapi pedales vel sesquipedales foliorum loco squamulis $\mathrm{s}$. bracteis nonnullis lanceolatis acutis muniti. Rami stricte adscendentes basi undi apicem versus floriferi.

Statice Fortunei Lindl. (Fortune pl. exsicc. chin. n. 130) quamvis toto habitn affinis recedit floribus in quovis paniculae ramo in spicam densam fastigiato-glomeratam congestis, bracteis et calycis laciniis late membranaceis rotundatis irregulariter crenulatis. Flores in utraque aurei.

\section{0. (116 End].) PLANTAgINEAE Iuss.}

390. Plantago $\mathrm{L}$.

680. Species 4 nondum determinatae.

\section{1. (114 Endl.) ARISTOLOCHIEAE Ins.s.}

391. Heterotropa Mor'r. et De Caisne.

681. H. asaroides Mors. et De C'aisne. Nouv. Annales des Sciences natur. II. p. 314. tab. 10. - Asarum virginicum Thunb. Flor. jap. p. 190.

Quid Asarum canadense Thunb. l. c.? 
392. A ristolochia Tourn.

682. Ar. Kaempferi Willd. A. caule fruticoso volubili, folïs petiolatis e basi cordata late ovatis vel hastato-trilobis, lobis lateralibus rotundatis abbreviatis, terminali ovato-oblongo acuto, omnibus superne glabris subtus canescenti-hirtis, pedunculis nudis unifloris hirtis, perigonio aeque ac ovario extus dense tomentoso, tubo infracto, limbo bilabiato labio superiore breviore rotundato, inferiore late ovato obtuso. A. Kämpferi Willd. Specc. pl. IV. p. 15ॅ2. - Sın kakso Kämpfer Amoen. p. 884. et Banks Icones Kämpfer. tab. 19.

Immensum scandens ac repens (Kämpfer). Folia longe petiolata, petiolo 1-2" longo; lamina folii basi cordata et inter cordaturae lobos rotundatos cuneatim in petiolum descendens, late ovata vel hastato-triloba lolis lateralibus brevibus rotundatis terminali oblongo acuto, $2 \frac{1}{2}-3^{\prime \prime}$ longa, $2-2 \frac{1}{2}$ lata. Pedunculi nudi ebracteatl longitudine circiter petioli, villosi. Ovarium cylindricum dense tomentosum. Perigoninm infractum circiter pollicare, extus dense tomentosum, fide Kämpferi striatum et variegatum, tubi parte inferiore elliptico-subinflata superiore coarctata cylindrica; limbus bilabiatus labio inferiore majore ovato obtuso.

683. A. debilis S. et Z. A. canle herbaceo volubili uti tota planta glabro, foliis petiolatis e basi cordata deltoideo-oblongis obtusis glabris quinquenerviis, stipulis nullis, floribus pedunculatis solitariis ebracteatis, perianthii glabri tubo basi globoso superne constricto cylindrico subarcuato, limbi labio oblique descendente lanceolato acuminato.

A. longa Thunb. Flor. jap. p. 144.

Caulis debilis prostratus vel scandens. Folia breviter petiolata petiolo 4-6 $6^{\text {iI }}$ longo; lamina basi profunde cordata cordaturae angulo lobisque rotundatis, deltoideo-oblonga rotandato-obtusa utrinque glabra, quinquenervia nervis 3 mediis parallelis, exterioribus divergentibus, 2" longa, unum lata. Pedunculi solitarii ebracteati nudi pollicares. Perianthium vix pollicare, glabrum; tubus basi globoso-infla- 
tus sursum constrictus cylindricus, labium oblique descendens ovatolanceolatum acuminatum tubum subaequans.

\section{2. (113 Endl.) PRoteaceae $\boldsymbol{R}$. Br.}

393. Helicia Lour.

\section{H. lancifolia S. et Z $\mathbf{Z}$.}

H. ramis angulatis foliis alternis oblongo-lanceolatis oblongisve utrinque attenuatis acuminatis integerrimis vel a medio apicem versus remote et argute serratis utrinque glabris, racemis axillaribns folia subaequantibus cylindricis, pedunculis bifloris parce pilosis, ovario cylindrico glabro, squamis hypogynis rotundatis semiconnatis glabris.

Rami glabri, novelli angulati. Folia alterna breviter petiolata petiolo vix $6^{\prime \prime \prime}$ longo semitereti; lamina oblongo-lanceolata vel anguste oblonga, utrinque attenuata acuminata integerrima vel a medio apicem versus remote et argute serrata serraturis subspinescentibus, utrinque glabra, $3-4 \frac{1}{2}$ " longa, $12-15^{\prime \prime \prime}$ lata. Racemi axillares solitarii folia subaequantes erecti cylindrici, fere a basi floriferi; rachis glabra; pedunculi breves $1-2^{\prime \prime \prime}$ longi, bracteam lanceolatam acutam superantes, parce pilosi apice bracteolis 2 linearibus minimis ancti; pedicelli uniflori lineam longi. Perianthium basi globosum sursum tenuiter cylindricum vel subfiliforme utrinque glabrum; limbus quadrifidus laciniis anguste oblongo-spathulatis obtusis. Stamina fanci affixa, filamentis brevibus; antherae lineares connectivo adnatae ejusque apice ultra locula producto obtuse mucronatae, quadriloculares loculis duobus interioribus brevioribus. Ovarium cylindricum, glabrum. Stylus cylindricus stigmate clavato, stamina subaequans. Squamae hypogynae dimidium ovarium aequantes basi connatae rotundatae glabrae.

\section{3. (111 Endl.) ELAEAGNEAE $\boldsymbol{R}$. $B r$.}

394. El a eagnus L, 
685̄-690. L. crispa, multiflora, umbellata, glabra, macrophylla, pungens Thunb. Fl. jap. p. 66-68.

\section{4. (109 Endl.) DAPHNOIDEAE Vent.}

395. Daphne L.

691. D. odora Thbg. jap. p. 159 et Auct.

692. D. japonica hort. Lugd. D. foliis subsessilibus e basi longe attenuata oblongis vel oblongo-lanceolatis obtusis vel acntiusculis coriaceis utrinque glabris superne nitidis, floribus e gemmis propriis lateralibus axillaribus, capitatis, capitulis breviter pedunculatis multi-( $8+12-)$ floris, pedunculis basi perulis involucratis praesertim apicem versus villosis, perianthiis glabris, stigmate capitato subsessili.

Rami teretes glabri innovando-subverticillati. Folia alterna subsessilia e basi longe attenuata oblonga vel oblongo-lanceolata, obtusa

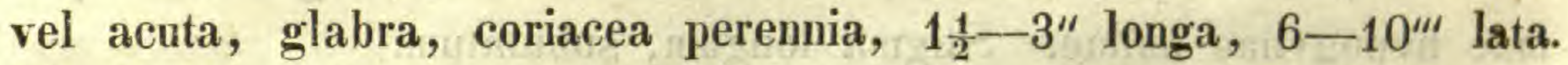
Flores in ramis anni praecedentis axillares et terminales e gemmis propriis, in capitulum 8-12-florum pedunculatum dispositi; pedunculi basi perulis interioribus involucrati, bracteati bracteis ovato-lanceolatis acutis membranaceis ciliatis, primum nutantes demum erecti apice incrassati et tomentoso-hirti, 3-4" $4^{\prime \prime \prime}$ longi. Perianthii tubus cylindricus glaber, limbo 4 partito laciniis ovatis acutiusculis. Antherae lineari-oblongae. Ovarium ovatum glabrum. Stigma capitatum, papillosum.

Habitu et floribus viridibus $D$. Laureolam refert.

Einer japanischen Abbildung zufolge findet sich eine Spielart mit fast stiellosen, nur 3-4 blüthigen Köpfchen. Gehört hieher D. triflora Lour. Cochinch. p. 291?

693. D. Genkwa Sieb. et Zuccar. Flor. jap. 137. tab. 75. 396. Edgeworthia Meisn.

694. E. papyrifera S. et $\boldsymbol{Z}$. E. capitulis multifloris breviter pedanculatis subnutantibus primum involncrati's demum nudis, floribus praecocibus extus dense serice-tomentosis, foliis petiolatis lanceo- 
latis utrinque attenuatis acutis pubescentibus et subtus canescentibus deciduis. Daphe papyrifera Sieb. in Act. Batav. XII. 24. Hasskarl Catal. hort. Bogor. p. 92.

Rami stricti teretes glabri, innovando-subverticillati vel furcati. Folia annua, alterna, in superiore ramorum parte approximata et inde

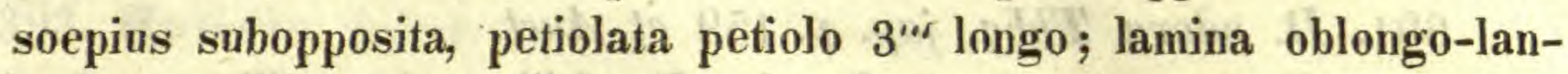
ceolata vel lanceolata utrinque attenuata acuta superne pilis adpressis pubescens, subtus canescens. Alabrastra capitulorum ex axillis foliorum summorum jam auctumno anni praecedentis, pednnculata, bracteis 5-6 ellipticis acutis involncrata, una cum pedunculo subnutante tota sericeo-tomentosa, perhyemantia, primo vere tandem evoluta et tum bractearum lapsu nuda. Capitula ipsa hemisphaerica 30-50-flora, floribus densissime coarctatis sessilibus. Perianthium extus totum dense sericeo-tomentosum basi subglobosum demum cylindricum, limbo quadrifido laciniis ovatis obtusis intus glabris. Squamae hypogynae nullae. Stigma longum, subulatum.

397. Passerina L.

695. P. japonica S. et $\boldsymbol{Z}$. P. frutescens ramis gracilibus, foliis oppositis breviter petiolatis e basi rotundata ovatis vel ovato-ellipticis acutiusculis vel obtusis utrinque glabris, racemis terminalibus simplicibus vel basi trifidis fastigiatis paucifloris, pedunculo communi stricto filiformi, pedicellis brevissimis, stigmate capitato muricato. Stellera japonica Siebold in Act. Batav. XII. $p .22$.

Rami annui gracillimi divaricato-patentes. Folia semper opposita, magnitudine varia, semi-sesquipollicaria, petiolo $1-2^{i \prime \prime}$ longo affixa, basi rotundata, ovata vel ovato-elliptica, breviter acutiuseula vel obtusa, utrinque glabra. Racemi terminales in rachi gracillima stricta, trifidi vel simplices, 8-12 flori, fasciculato-fastigiati; flores decussati, brevissime pedicellati pedicellis apice articulatis. Perianthinm gracile glabrum, album, tubo cylindrico sursum clavato, limbi laciniis oblongis obtusis. Ovarium ellipticum basi attenuatum substipitatum apice pilosum. Stylus brevissimus sublateralis, stigmate capitato dense muricato. Nux sicca, elliptica, perigonio inclusa. 
Die Pflanze hat ịm ganzen Habitus, vorzüglich aber im Blüthenstande viele Aehnlichkeit mit Daphne virgata Wall., doch haben wir keine squamas hypogynas wahrnehmen können, wie C. A. Meyer Bullet. de T Acad. de St. Petersb. 1343. p. 356 für die Gattung Diplomorpha angibt.

\section{P. Ganpi S. et Z $\mathbf{Z}$.}

G. suffruticosa, ramis virgatis simplicibus veI superne ramosis et canescenti-hirtis, foliis alternis subsessilibus ellipticis, oblongoellipticis vel superioribus lanceolatis, utrinque attenuatis acutis vel obtusis, subtus ad venas pilosis vel novellis canescenti-hirtis, florum capitulis axillaribus pedunculatis 10-12-floris tandem racemosis, perianthii tubo extus canescenti-hirto, stigmate-depresso-capitato papilloso. - Stellera japonica Sieboldt $l$. $c$.

Rami recti virgati crassitie pennae corvinae, inferne glabri apicem versus canescenti-hirti. Folia anuua, alterna approximata brevissime petiolata, e basi attenuata elliptica, oblongo-elliptica vel lanceolata, acuta vel obtusa et mucronata, superne glabra vel parce et subtus ad venas densius pilosa vel novella canescenti-hirta, $10-15^{\prime \prime \prime}$ longa, 4-6"' lata. Pedunculi versus apicem ramorum axillares, folio breviores canescentes; flores primum fasciculato-capitati demum brevissime racemosi vel potius ob pedicellos brevissimos subspicati. Perianthii tubns tenuis, cylindricus, canescenti-hirtus, 5-6"it longus; limbus breviter quadrifidus lobis obtusis. Ovarium hirtum. Stylus. brevissimus; stigma incrassatnm depresso-capitatum.

\section{5. (108 Endl.) SANTALACEAE $\boldsymbol{R}$. $\boldsymbol{B}$.}

398. Thesium L.

697. Species. Specimen unicum nimis maneum. Folia anguste linearia uninervia, nervo subtus valde prominente carinata et subdecurrentia. Perianthii tabus cylindricus. 


\section{6. (106 Endl.) LAURINEAE Vent.}

399. Cinnamomum Burm.

698. C. dulce Nees Syst. Laurin. p. 62. - C. chinense Blume Bijdr. p. 569. - C. Cassia Siebold Synops. in Act. Batav. XII. p. 23. - Nikkei Japon.

699. C. Loureirii Nees Syst. Laurin. p. 65.

Ramos foliiferos tantum examinare licuit.

700. C. pedunculatum Nees Syst. Laur. p. 79. C. japonictem Siebold Synops. l. c. p. 23. - Laurus pedunculata Thunb. Flor. jap. p. 174.

701. C. daphnoides S. et Z. C. ramis compresso-tetragonis sericeo-tomentosis, foliis plerumque oppositis petiolatis obovato-ellipticis vel subspathulatis rotundatis coriaceis superne glabris glancescentibus subtus dense albido-sericeis, trinerviis, pedunculis dichotome 3 -5 floris quam folia longioribus vel brevioribus.

702. C. species. In insulis Peel et Boninsima legit beatus Mertens.

400. Camphora Bauhin.

703. C. officinarum Bauhin. Nees Syst. Laur. p. 88. Laurus Camphora Thunb. Fl. jap. p. 172. et Auct. - Cinnanomun Camphora Siebold Synops. l. c.

401. Machilus Rumph.

704. M. Thunbergii S. et Z. Laurus indica Thunb. Fl. jap. p. 173. - Persen japonica Siebold in litt.

705. M. japonica S. et Z. - Laurus aokari herb. Sieb.

402. Benzoin Nees.

706. B. trilobum S. et $\mathbf{Z}$. B. foliis deciduis triplinervïs superne glabris subtus molliter pubescentibus, e basi late coneata ellipticis vel apicem versus dilatatis trilobis, lobis acuminatis subaequilongis, intermedio basi constricto sinubus rotundatis, umbellis breviter pedunculatis panci- $(2-5$-) floris, pednnenlo glabro pedicellis seri- 
ceo-hirtis, fructiferis clavato-inerassatis et pedunculum plus quam duplo superantibus, perianthii laciniis deciduis.

Sassafras officinalis Siebold Synops. in Act. Batav. l. c. p. 23. (excl. Symon.).

Arbor frequens in montibus insulae Nippon. Rami teretes subflexuosi cortice sordide cinerascente. Foliorum cicatrices anguste lunatae. Gemmae oblongae, acntae, perulatae, glabrae. Folia alterna petiolata, petiolo $8-12^{\prime \prime \prime}$ longo semitereti canaliculato; lamina e basi late cuneata vel elliptica acuta integerrima, vel sursnm dilatata et fere ad medium usque triloba lobis subaequilongis acuminatis, lateralibus lanceolatis, intermedio basi utrinque constricto elliptico; omnia triplinervia, supra glabra, subtus ad venas molliter pilosa, glandulis tenuibus pellucide punctata, $2-3 \frac{1}{2}$ "longa, inter lobos $1 \frac{1}{2}-3^{\prime \prime}$ lata. Umbellae ex inferiore innovationum parte et perula decidua suffultae, pauciflorae; pedunculus glaber, vix $2^{\text {i“ }}$ superans, serins non excrescens; involucrum e squamis 5 parvis coriaceis glabris longe ante anthesin deciduum; pedicelli 2-6 uniflori, sub anthesi $3^{\prime \prime \prime}$ longi, sericeo-hirti, fructiferi elongati. Floribus $\delta$ perianthium profunde sexpartitum laciniis ellipticis obtusis extus glabris intus sericeo-pubescentibus. Stamina 9 fertilia tripliei serie; filamenta basi latiora hirsuta sursum glabra, intima basi utrinque glandula breviter stipitata, adscendente reniformi carnosa ancta; antherae omnes introrsum dehiscentes biloculares valvulis sursum dehiscentibus, dense pellncide glandulosae. Ovarii rudimentum ovato-globosum glabrum. Floribus $q$ perianthium ut in mare, deciduum. Staminum rudimenta novem exterioribus sex linearibus glabris, intimis tribus glandula stipitata carnosa utrinque anctis. Ovarinm ovatum, glabrum, uniovulatum. Stylus? Pedunculi fructiferi plerumque solitarii fere pollicares, praesertim apicem versus valde incrassati indeque clavati, sub frnctu truncati sine ridimeuto perianthii. Bacea globosa, magnitudine globi selopetarii minoris; semen peudnlum, globosum, testa crnstacea. 
707. B. T'hunbergii S. et Z. B. foliis annuis e basi longe attennata anguste oblongis vel oblongo-ellipticis obtuse acuminatis, junioribus subtus aeque ac petioli et rami novelli sericeo-hirtis, umbellis coëtaneis pedunculatis multi- $(10-15-)$ floris, pedicellis sericeohirtis pedunculum aequantibus, perianthii laciniis deciduis.

Sassafras Thunbergii Siebold Symops.. l. c. p. 23. - Lindera umbellata Thunb. Flor. jap. p. 9. et 145. tab. 21 et Auct.

Folia basi longe in petiolum attennata et cum hoc $3-4_{2}^{1 / 2}$ longa, 8-12“" lata, penninervia, superne glabra subtus ad venas pilosa vel novella sericeo-hirta. Umbellae ex axillis perularum solitariae hemisphaericae, multiflorae; pedunculus glaber aeque ac pedicelli sericei 3-4" longus. Perianthii laciniae ntrinque basi sericeo-pubescentes. Bacca pedunculo incrassato clavato insideus globosa, magnitudine pisi minoris.

Dass Thunberg bei Beschreibung seiner Lindera unsere Pflanze vor sich gehabt habe, ergibt sich ans seiner Abbildung auf das dent-1 lichste. Abweichend erscheint in Gattungscharakter vorzuglich die Angabe einer sechsmännigen $\mathbf{Z w i t t e r b l u ̈ t h e ~ u n d ~ e i n e r ~ z w e i f a ̈ c h r i g e n ~}$ Kapselfrucht. Aber daraus, dass weiter gesagt wird: Stamina corolla multoties breviora und antherae minutae, lässt sich mit Groud vermuthen, dass Thunberg nur weibliche Blüthen untersucht und die kleinen fadenförmigen sterilen Staubfaden übersehen, die sechs gèstielten nierenförmigen Staminodien dagegen für fruchtbare Stamina gehalten habe. Die zweifächrige Kapselfrucht hat er wohl nur aus der Zahl der Narben vermuthet, weil er in der Beschreibung nichts Näheres darüber erwähnt, oder vielleicht auch eine andre Frucht unit der unsrer. Pflanze verwechselt.

708. B. sericeum S. et $\boldsymbol{Z}$, B. foliis annuis petiolatis e basi cuneata ohovato-oblongis acutis pennirerviis supra pnbescentibus subtus melliter villosis vel novellis albido-sericeis, floribus coëtaneis, umbellis subsessilibus multi- $(10-15-)$ floris, pedicellis gemmisque sericeis, fructibus globosis. 
Rami graciles cortice atro-fusco vel nigricante glabro. Folia alterna, petiolata; petiolus $3-4^{\prime \prime \prime}$. longus, semiteres, sericeo-pubescens; lamina e basi late cuneata obovata vel obovato-oblonga, acuta, penninervia, superne ad nervum medium pilosa ceterum pubescens, subtus pilis longis ad venas densius positis tota molliter villosa vel novella albido-sericea, $3-4^{\prime \prime}$ longa, $16-20$ " lata. Unbellae ex axillis perularum solitariae, breviter pedunculatae, pedunculo vix lineam longo uti pedicelli multoties longiores sericeo-hirto. Perianthium medio dorso pubescens, uti antherae dense glandnloso-punctatum. Bacea magnitudine pisi minoris, globosa, mucronulata; pedunculi fructiferi $6-8^{\prime \prime \prime}$ longi, quam in praecedentibus minus incrassati.

Eine Abart oder verwandte Art, welche wir nur in fruchttragenden Exemplaren vor uns haben, unterscheidet sich durch schmälere beiderseits fast völlig kahle auf der Rückseite graugrüne Blätter und längere nach oben fast gar nicht verdickte Fruchtstiele.

709. B. praecox S. et $\boldsymbol{Z}$. B. foliis annuis petiolatis ovatoellipticis ntrinque attenuatis acuminatis glabris subtus glancescentibus, umbellis praecocibus breviter pedunculatis involucratis panci- $(3-5-)$ floris, pedunculis involucris gemmisque glabris, pedicellis abbreviatis hirtis, fructiferis longioribus incrassatis calvis.

Rami tennes subfiexuosi cortice cinereo. Gemmae oblongae perulis glabris. Umbellae praecoces breviter pedunculatae, squamis plerumque quatuor coriaceis castaneis glabris involucratae, pauciflorae; pedicelli iuvolucro breviores vix lineam longi, hirti. Folia petiolata, petiolo $3^{\prime \prime \prime}$ longo tenui; lamina $1 \frac{1}{2}-2^{\prime \prime}$ longa, $8-12^{a \prime \prime}$ lata, ntrinque glabra, peuninervia, subtus glaucescens. Fructus e quavis umbella abortu reliquorum florum solitarii, pedicello insidentes sursum incrassato robusto semipollicari. Bacea magna, globosa.

710. B. glaucum S. et Z. B. foliis amnis breviter petiolatis e basi atteunata vel subrotundata oblongo-ellipticis acntis, junioribus subtus aeque ac ramuli sericeo-hirtis, adultis soperne glabris subtus magis minusve pilosis et glaucescentibus, umbellis praecocibus sub- 
sessilibus paucifloris, pedicellis fructiferis incrassatis pilosis, fructibus globosis parvis, gemmis glabris.

Rami subflexuosi eortice cinereo-fuscescente glabro. Gemmae oblongae acutae perulatae castaneae glabrae. Folia annua in petiolo 1-2"“ longo oblongo-elliptica, basi breviter attenuata vel subrotundata, acrita, penninervia, novella subtus sericeo-hirta, adulta superne glabra, subtus pilis longis decumbentibus praesertim ad venas magis minusve hirta vel tandem calva, glancescentia, $1 \frac{1}{2}-3^{\prime \prime}$ longa, 10-15" lata. Umbellae praecoces subsessiles $3-5$ florae, pedicellis sericeis. Hlores masculi non visi. In foemineis stamina sterilia 9 minima, lineari-subulata. Glandulae sex carnosae stipitatae, per paria staminibus interioribus apposita. Ovarium ovatum glabrum; stylus brevis; stigma bilobum lobis ovatis patentibus.

Die bisher beschriebenen Arten weichen von dem Charakter der Gattung Benzoin, wie Nees solchen anfgestellt hat, darin ab, dass das Perianthium der weiblichen Blüthen wenigstens his anf eine schmale ganzrandige Scheibe um den Rand des verdickten Fruchtstieles her abfällt; aber anch bei dem nordamerikanischen B. odoriferum gliedern sich die Lappen des Perianthiums dicht über der Basis nnd die stehenbleihenden Zälnnchen werden so klein, dass wir auf deu Mangel derselben an unsern Arten keinen Werth legen können. Solten ferner, abgesehen davon, die so genau mit einander verwandten Gattungen Benzoin und Sassafras nicht wieder vereiniget werden?

711. B.? citriodorum S. et $\mathbf{Z}$. B. foliis annuis petiolatis obovato-oblongis longissime et argute acuminatis penninerviis utrinque glabris subtus glancescentibus, umbellis glabris pedunculatis involncratis panci-(3-5-) floris, pedicellis fructiferis glabris subinerassatis perianthio persistente sexfido explanato coronatis, bacca globosa.

Rami teretes, cortice nigricante vestiti, novelli angulati glabri. Folia annua, petiolata, petiolis $6-9^{\prime \prime \prime}$ longis semiteretibus superne planis glabris; lamina basi breviter, apicem versus longe attennata et 
in acumen pollicare subfalcatum argutum terminata, penninervia nervis lateralibus utrinque $7-8$ intra marginem combinatis, utrinque glabra et subtus praesertim in foliis novellis glaucescens, $4-6^{\prime \prime}$ longa, $1-2$ " lata. Umbellae pedunculatae ex axillis perularum decidnarum gemmae foliferae anni sequentis jam auctumno provenientes, peduneulo glabro $3-5^{\prime \prime \prime}$ longo insidentes et involucro coriaceo inclusae pauciflorae; florentes non observatae. Pedicelli fructiferi $2-3$ in quavis umbella, glabri, $3^{\prime \prime \prime}$ longi, subincrassati; perianthio explanato vix aucto coronati. Bacca globosa, magnitudine pisi.

Zu der Gattung gehört wahrscheinlich auch Laurus Sassafras Lour. Flor. Cochinch. p. 312 und Nees Syst. p. 657.

403. Tetranthera Jacq.

712. T. japonica Spreng. Syst. Veget. II. p. 266. Nees Syst. Laurin. p. 524. Sieb. et Zuccar. Flor. jap. I. p. 166 tab. $87.100 .-$ Tomex japonica Iuss. Ann. du Mus. VI. p. 210. et Auct. - Litsaea Thunbergii Siebold Synops. in Act. Batav. l. c. p. 24.

404. Actinodaphne Nees.

713. 714. Species duae a beato Merteus in insulis Peel et Boninsima lectae et nondum descriptae, sed propter defectum florum adhuc reponendae.

405. Da phnidium Nees.

715. D. Myrrha Nees Syst. Laur. p. 612. Siebold in Annuaire de la Soc. hortic. des Pays-bas 1844 p. 28.

716. D. strychnifolium S. et $\mathbf{Z}$.

717. D. lancifolium S. et Z.

406. Litsa éa Iuss.

715. L. ylanca Siebold Synops. l. c. p. 24. Nees Syst. Laur. p. 633. Laurus glauca Thunb. Fl. jap. p. 173. et Auct.

719. L. foliosa Nees Syst. Laurin. $p$. 622. Tetrudenia foliosa Nees in Wallich plant. As, rar. II. p. 64.

Specimina japonica ab indicis Wallichianis nullo modo recedunt. 


\section{7. (104 Endl.) NYCTAGINEAE Iuss.}

407. Mirabilis L.

720. M. Jalapa L. T'hunb. Fl. jap. p. 91.

Wir haben die Pflanze nicht selbst gesehen, aber Thunberg sagt, dass die Japaner ans dem Samienmehl dieser Art eine weisse Schminke bereiten. Da nun dieselbe Art nach Hooker (Beechey p. 207) auch in China, nach Loureiro in Cochinchina und nach andern Angaben in Ostindien vorkommt, so zweifeln wir nicht an der Richtigkeit der Thunbergischen Bestimmung.

118. (103 Endl.) POLYGONEAE Iuss.

408. Rheum L.

721. Rh. palmatum L. Siebold Synops. plant. oecon.

In hortis enltum.

722. Rh. tataricum L. Siebold pl. l. c. p. 19.l.c.

409. Polygonum L.

723. P. chinense L. Thunb. Fl. jap. p. 166. Siebold l. c. p. 18.

724. P. orientale L. Thunb. l. c. Siebold l. c.

725. P. aviculare L. Thunb. 1. c.

726. P. barbatum L. Thunb. l. c. p. 165. Siebold l. c. p. 18.

727. P. perfoliatum L. Thunb. l. c. p. 168.

728. P. Fagopyrum L. Thunb. l, c. p. 169. Siebold l. c. p. 19.

729. P. Thunbergii S. et Z. P. arifolium Thunb. I. c. p. 168. non Linn.

Die japanische Pflanze ist von dem amerikanischen $P$. arifolium wesentlich verschieden, aber die uns vorliegenden Exemplare genügen nicht zu ausführlicher Beschreibung.

730. P. multiflorum Thunb. l. c. p. 169. Meisner Polygon. p. 64.

731. P. cuspidatum S. et Z. P. caule erecto flexuoso glabro tereti, foliis petiolatis e basi rectilinea vel rotundata late ovatis repente cuspidatis utrinque glabris subtus ad venas seabriusculis, ochreis glabris margine nudis paucinerviis oblique truncatis, paniculis axillaribus divaricatis, rachi flexuosa, ramis tenuibus furfuraceo-villo- 
sis, bracteis ochreaeformibus cupularibus oblique truncatis cnspidatis, floribus geminis ternisve, pedicellis filiformibus infra medium articnlatis glabris perianthio duplo longioribus, staminibus octo, ovario triquetro, stylis tribus divaricatis.

Caulis erectos, flexuosus, herbaceus. Petioli $6-8^{\prime \prime} /$ longi, lamina folii basi rectilineo-truncata vel rotundata late ovata apicem versus rotundata et repente in cuspidem producta vel rarius subattenuata, ntrinque glabra, subtus in venis prominalis denticulis vix conspicuis subscabra, 3-4" longa, 2-2 $\frac{1}{2}$ " laia. Paniculae axillares patentes graciles ramis divaricatis solitariis geminisve filiformibus furfurace0-villosis. Flores laxe racemosi, pedicellis filiformibus $1 \frac{1}{2}-2^{m i}$ longis glabris. Perianthium exignum vix $\frac{3}{4}$ lm longum, patens, laciniis ellipticis obtusis. Ovarium ellipticum trigonum. Stylus brevissimus, stigmata tria divaricata.

Polygoni species ultra viginti in Japonia occurrum,, quae vero accuratiori examini adbuc remanent.

410. Rumex L.

732. R. crispus L.? Thunb. Fl. jap. p. 149.

Die vorliegenden leider sehr unvollständigen Exemplare sind von den europäischen durch kleinere Blüthen etwas verschieden.

\section{9. (102 Endl.) AMARANTACEAE $\boldsymbol{R}$. $\boldsymbol{B r}$.}

411. Gomphrena L.

733. G. globosa L. Thunb. Fl. jap. p. 114.

412. Celosia L.

734. C. margaritacea L. C. argentea L. Thumb. l. c. p. 106.

735. C. cristata L. Thunb. l. c.

413. Achyranthes L.

736. A. aspera L. Thunb. l. c. p. 105.

414. A marantus L.

Abhandlungen d. II: Cl. d. k, Ak. d. Wiss. IV. Bd. III. Abtb. 
737. A. Blitum L. Thunb. l. c. p. 57.

Die japanischen Amarantus-Arten, 6-7 an der Zahl, unterliegen noch genauerer Untersuchung. In der Synopsis Plant. oecon. p. 21 erwähnt v. Siebold A. tricolor L. (A. bicolor Nocca), inamoenus Willd. (japonicus Houtt.), oleracens $\mathbf{L}$ und eaudatus $\mathbf{L}$., welche sämmtlich anch als Gemüse verspeist werden.

\section{0. (101 Endl.) CHENOPODEAE Bartl.}

415. Spinacia Tourn.

738. Sp. oleracea L. Siebold Synops. pl. oecon. p. 20.

416. Beta Tourn.

739. B. vulgaris L. Thunb. Flor. jap. p. 113. Siebold l. c. 417. Kochia Roth.

740. K. Scoparia Schrad. - Chenop. Scoparia Thunb. Flor. jap. p. 113.

418. Chenopodium L.

741. Ch. album L. Thunb. Fl. jap. p. 112. Siebold l. c. p. 19.

742. Ch. ambrosioides L. Thunb. Fl. jap. p. 113. Siebold l. c. p. 20.

Vermuthlich eingeführt.

743. Ch. virgatum Thunb. Act. Upsal. VII. p. 143. Siebold l. c. p. 20.

419. Basella L.

744. B. rubra L. Thunb. Fl. jap. p. 127. Siebold l. c. p. 20. 420. Schoberia C. A. Meyer.

745. Sch. maritima C. A. M. - Chenop. maritimum L. Siebold l. c. p. 20.

421. Salsola L.

746. Salsola Soda L.? Siebold l. c. p. 30.

Fast alle Chenopodiaceen werden in Japan als Gemüse verspeist. Es ist aber ebendesshalb auffallend, dass die Gattung Atri- 
plex daselbst sich nicht zu finden scheint, während doch in China einige Arten wild und kultivirt vorkommen.

\section{1. (99 Endl.) SALICINEAE L. C. Rich.}

422. Salix L.

747. S. japonica Thunb. Fl. jap. p. 24. Icones plant. jap. dec.

4. Blume Bijdr. p. 516.

Folia ea $\boldsymbol{S}$. daphnoidis referunt.

748. S. Sieboldiana Blume Bijdr. p. 517.

749. S. integra Thunb. Fl. jøp. p. 24.

Amenta coëtanea subsessilia e gemmis basi folifferis. Foeminea cylindrica obtusa vix pollicaria. Squamae ovatae acutiusculae basi et dorso sericeo-hirtae, fuscae. Ovarium sessile, ovato-globosum, rotundatum, dense albo-lanatum. Stylus longitudine fere ovarii, cylindricus, glaber. Stigmata oblonga, emarginata. Glandula ovata obtusa vel emarginata, vix $\frac{1}{4}$ ovarii aequans. Folia (novella) linearioblonga vel lanceolata, obtusa, cuspidata vel breviter acuta, plerumque argute serrulata rarius integerrima, superne glabra, subtus ad nervnim medium pilosa et utrinque (sicea) punctis minimis fuscescentibus densissime obsita, pollicaria, 3-4" lata.

Habitu S. purpuream L. refert.

Praeter has tres adhuc in Japonia occurrunt Salicis species, e specc. mancis nondum rite determinandae.

423. Populus L.

750. 751. Species duae accuratins adhac examinandae.

\section{2. (98 Endl.) BALSAMIFLUAE Blume.}

424. Liquidambar L.

752. Species fide Catal. herb. Siebold. An L. Altingia Blume? 


\section{3. (96 EndI.) ANTIDESMEAE Sweet.}

425. Antidesma L.

753. A. japonicum S. et Z. A foliis oblongo-lanceolatis vel oblongis utrinque attenuatis acuminatis glabris vel subtus ad nervos parce pubescentibus, stipulis caducis linearibus membranaceis, spicis foemineis terminalibus solitariis, calycibus quadrifidis, fructiferis pedunculatis pedunculo filiformi drupae ellipticae dimidium superante, stigmatibus tribus.

Rami teretes nudi vel pilis parcis scabriusculi. Folia alterna breviter petiolata petiolo $2-3^{m}$ longo pubescente; lamina oblongolanceolata vel oblonga utrinque attenuata acuminata et nervo medio ultra telam producto mncronata, penninervia, membranacea, utrinque glabra vel subtus praesertim basin versus in nervis primarïs parce pubescens, 2-5" Jonga, $8-18^{\prime \prime \prime}$ lata. Stipulae caducae, membranaceae, lineares, acutae. Flores masculi et foeminei non observati. Raceni fructiferi terminales solitarii simplices vel rarius basi subramosi, laxi, bipollicares; rachis angulata tenuissime strigoso-pubescens; pedicelli uniflori horizontaliter patentes filiformes, bractea minnta lancéolata acuta nembranacea suffulti. Calyx sub fructu persistens parvus, quadripartitus laciniis ovatis acutis glabris. Discus carnosus anuularis. Drupa elliptica, stigmatibus tribus subulatis reflexis coronata, magnitudine nuculae cannabinae, (sicca) compressiuscula margine acuto faciebus convexis rugosis. Patamen tenue, carnosum. Pyrenum uniloculare, monospermum, durum, ellipticum utrinque acutiusculum, compressum, margine acute carinatum, faciebus convexis lacunoso-rugosis. Semen pendulum, pyreno conforme, rugosum. Testa tenuis membranacea. Albumen carnosun, putaminis processubus scrohiculatum. Embryo axilis, cotyledonibus ellipticis plane sibi incumbentibus, radicula cylindrica recta. 


\section{4. (95 Endl.) CANNABINAE Endl.}

426. Cannabis $\mathbf{L}$.

754. C. sativa L. Thunb. IFl. jap.p. 113. Siebold Synops. p. 29. 427. Humulas L.

755. H. Lupulus L. non Thunb.

Culta.

756. H. japonicus $\mathbf{S}$. et $\mathbf{Z}$. H. caule volubili retrorsum aculeato, foliis e basi cordata suborbicularibus palmato-5-7-lobis, lobis ovato-oblongis vel oblongis acutis acuminatisve dense et acute serratis scaberrimis, petiolis Jaminam folii superantibus, paniculis masculis terminalibus elongatis subaphyllis, perianthii laciniis acutis hispidis, capitulis foemineis axillaribus et terminalibus pedunculatis solitariis vel subpaniculatis, bracteis floralibus late ovato-deltoideis acutis margine aculeato-ciliatis hispidissimis foliaceis, quam nucula lenticularis vix dimidio longioribus, eglandulosis. H. Lupulus Thunb. Fl. jap. p. 113.

A. H. Lupulo plurimis notis recedit. Petioli quam lamina folii semper longiores $3-4$ pollicares; lamina folii densius serrata ejusque lobi in planta foeminea angustiores oblongi, praesertim subtus aculeolis antice versis hispidissimi. Paniculae masculae terminales pedales erectae, axi recta nec ut in Lapulo flexuosa. Flores quam in hoc duplo minores, perianthii laciniis acutis dorso hispidis. Capitula foeminea pedunculata, axillaria solitaria ant racemosa, vel termiualia panicnlata. Bracteae late ovato-deltoideae, margine aculeis longis albidis dense ciliatae dorso hispidae, acuminatae eglandulosae. Nuculae duas tertias squamae aequantes lenticulares marginatae utrinque convexae eglandolosae.

\section{5. (94 Endl.) URTICACEAE $D e$ Cand.}

428. Splitgerberia Miquel.

757. Spl. japonica Miq. Comment. bot. 134. tab. 14. ap. Endlicher gen. plant. Suppl. II. n. 1884. - Urtica? bifida Hasskarl 
hort. Bogor. p. 79. - Urt. biloba Siebold Annuaire de la Soc.hortic. des Pays-bas p. 38. et hort. europ.

429. Urtica Linn.

758. U. Thunbergiana S. et Z. H. canle herbaceo nti tota planta dense pubescente et stimulis longis hispido, foliis oppositis e basi cordata ovatis acuminatis acumine lineari subfalcato, grosse inciso-serratis serraturis subfalcatis integerrimis vel hine unidentatis, spicis masculis axillaribus plerumque geminis simplicibus vel parce ramosis secundis elongatis laxis, floribus glomeratis tetrandris.

Urtica dioica Thunb. Fl. jap. p. 69.

Perennis, herbacea; caules simplices subtetragoni pilis decumbentibus retrorsis aeque ae petioli dense obsiti et stimulis rectis lineam longis hispidi. Folia opposita petiolata petiolo 1-2" longo hispido; lamina $2 \frac{1}{2}-4^{\prime \prime}$ longa, $1 \frac{1}{2}-2 \frac{1}{2}$ " lata e basi cordata late ovata grosse incise-serrata et inter serraturas summas repente in acumen lineare subfalcatum $6-10^{\prime \prime \prime}$ longum excurrens; serraturae subfalcatae acutae integerrimae vel hinc unidentatae. Stipulae late lanceolatae acutae foliaceae. Spicae masculae axillares plerumque geminae filiformes laxae $2-4$ " longae, simplices vel inferne ramosae, interruptae, floribus glomeratis tetrandris.

759. U. nivea Thumb. Fl. jup. p. 71.

An a planta Linneana diversa?

760. U. (Laportea Gaud.) bulbifera s. et Z. U. eaule herbaceo glabro vel setulis parvis obsito, foliis alternis longe petiolatis e basi rotundata ovato-ellipticis acuminatis dentatis paree setosis, stipulis membranaceis aridis, floribus monoicis in panieulas cymosas dispositis, cymis masculis axillaribus, inferioribns plerumque bnlbil$\operatorname{los} 1-3$ in axilla foventibus divaricatis, floribus pentandris, perianthiis quinquefidis laciniis acutis, cyma foeminea subterminali solitaria, perianthiis diphyllis foliolis obovato-spathulatis, achenio substipitato oblique obovato compresso, stylo basi demum uncinato-deflexo filiformi persistente. 
Bulbilli ad basin cymarum mascularum inferiorum solitarii vel 2-3 glomerati ovato-globosi magnitudine nuculae cannabinae vel grani papaveris minoris.

761. U. petiolaris $\boldsymbol{S}$. et $\mathbf{Z}$. U. caule herbaceo glabro, foliis alternis longe petiolatis e basi rotundata oblongis vel oblongo-ellipticis acuminatis grosse crenatis trinerviis parce setulosis utrinque viridibus, stipulis lanceolatis obtusis membranaceo-subhyalinis, floribus dioicis, cymis masculis axillaribus dichotomis divaricatis petiolo pluries brevioribus, perianthii quadrifidi laciniis ovatis acutis, staminibus quatuor.

Petioli longitudine inter $1-3$ pollices variantes in foliis superioribus sensim breviores; lamina folii $2 \frac{1}{2}-5^{\prime \prime}$ longa, 15-24" lata. Flores foeminei nobis non obvii.

430. Boehmeria Jacq.

762. B. macrophylla S. et Z. B. caule herbaceo vel sublignoso? obsolete tetragono pubescente, foliis oppositis petiolatis, e basi rotundata integerrima suborbicularibus, repente in cuspiden longam linearem falcatam basi bidentatam terminatis, ceterum grosse incisoserratis, serraturis subfalcatis hine soepe unidentatis inferioribus sensim decrescentibus, trinerviis, superne scabris subtus subvillosis, stipulis lineari-lanceolatis acuminatis membranaceis fuscis, spicis foemineis axillaribus simplicibos vel ramosis elongatis anguste cylindricis strictis, florum glomerulis distinetis bractea solitaria suffultis, peri-. anthio tubuloso-ventricoso apice bidentato hirto.

Urtica macrophylla Thunb. Fl. jap. p. 69. et Auct. Urt. japonica Linn. Suppl. 418? Urt. spicata Blume Bijdr. p. 492?-Acalypha japonica Houtt. Pflanzensyst. X. tab. 72. f. 2. - Fortune plant. chinens. exsiccatae. A. 85.

Caulis stricte erectus atrorubens. Folia opposita petiolata petiolis $1 \frac{1}{2}-2$ pollicaribus adpresse pubescentibus; lamina folii basi rotundata vel cuneato-truncata integerrima suborbicularis sursum inciso-serrata, serraturis superioribus multo majoribus deltoideo-subfal- 
eatis acuminatis $6-8^{\prime \prime}$ longis, in margine deorsum spectante soepe unidentatis, apice repente terminata in acumen lineare falcatum basi bidentatum pollicare, trinervis, 4-5" longa, $3-4^{\prime \prime}$ lata. Spicae foemineae axillares solitariae vel geminae, simplices vel basi ramosae elongatae et soepe $6-8^{\prime \prime}$ longae, anguste cylindricae. Florum glomeruli distincti, bractea parva arida acnta suffulti, nultiflori. Perianthium tnbuloso-ventricosum bidentatum hirtum. Stigma elongatum filiforme hirtum.

Thunbergs Beschreibung seiner Urtica macrophylla passt vollkommen auf grosse Exemplare unsrer Planze mit ästigen Aehren, dagegen die Honttuynsche Abbildung anf schmächtigere mit einfachen Aehren, wie sie Thunberg vielleicht nicht zur Hand hatte, und deshalb Houttuyn unrichtig bei seiner Boehmeria spicata citirt.

763. B. spicata Thunb. B. caule herbaceo vel sublignoso tereti glabro, foliis oppositis e basi cuneata ovato-rhombeis acuminatis acumine lineari falcato, grosse et profunde serratis trinerviis glabris, stipulis lineari-lanceolatis acuminatis membranaceis fuscis, spicis foemineis axillaribus solitariis geminisve simplicibus filiformibus erectis strictis, florum glomerulis distinctis, braetea solitaria lanceolata acuta suffultis multifloris, perianthio tubuloso subcylindrieo apice bidentata hirto.

Boehm. spicata Thunb. Act. Linn. II. p. 330. et Auct. Irtica spicata Id. Fl. jap. p. 69.

Cạnlis herbaceus teres crassitie pennae corvinae, inferne ramosus, atrorubens, glaber. Folia opposita petiolata petiolo 1-2" longo, lamina folii e basi cuneata ovato-rhombea acumine lineari subfalcato $9-15^{\prime \prime \prime}$ longo terminata, profunde serrata serraturis grossis deltoideis subfalcatis acutis, utrinque glabra vel subtus ad nervos setulis parcis adpressis obsita, rugulosa, trinervis nervis per venas transversas inter se combinatis. Spicae axillares solitariae vel geminae simplices, 2-3-pollicares, erectae, gracillimae, filiformes; rachis inferne vel nuda vel bracteolis alternis lanceolatis acutis membranaceis 
superioribus floriferis conformibus obsita. Florum glomernli distincti alterni multiflori. Perianthium minimum tubuloso-cylindricum apice bidentatum. Stigma filiforme, hirtnm, vix lineam longum.

Bei dieser wie bei der vorhergehenden Art werden die Aehren hänfig durch Insectenstiche in rundé ans dachziegelig gedrängten zottigen Deckblättchen bestehende Köpfchen verändert.

Die Synonymie beider Species lässt sich schwer mit Sicherheit ermitteln. Willdenow's Definition von Boehm. spicata in Spece. plant. IV. p. 341 ist offenbar mehr auf die Houttnynsclie Abbildung als anf die Thubergsche Beschreibung begründet und passt daher zum Theil anf B. macrophylla. Dahin düften anch $\mathbf{U}$. japonica L. und spicata Blume gehören.

Boehmeria frutescens so wie Urtica japonica und villosa Thunb. haben wir noch nicht vergleichen können.

\section{Proeris Commers.}

763. Pr. umbellata $\boldsymbol{S}$. et $\boldsymbol{Z}$. Pr. caule herbaceo subflexuoso, foliis alternis sessilibus inaequilateris e basi semicordata oblongis repente acuminatis apicem versus grosse serratis superne parce setosis subtus glahris, stipulis linearibus membranaceis, floribus masculis umbellato-fasciculatis, pedunculo axillari solitario quam folium multo breviore, umbella bracteis lanceolatis $8-10$ involucrata $10-15$-flora, pedicellis unifloris apice articulatis, perianthiis pentaphyllis [foliolis ovatis acutis, staminibus quinque. Herb. Göring. n. 173.

Herbacea canle debili ramoso sursum subflexuoso-glabro. Folia alterna subsessilia dimidiato-inaequilatera, hinc basi in lobum rotundatum extensa indeque semicordata oblonga, apice repente in acnmen lineare $6-8$ lineas longum producta, et a dimidio sursum grosse serrata serraturis utrinque $3-4$ deltoideis acutis, penninervia superne

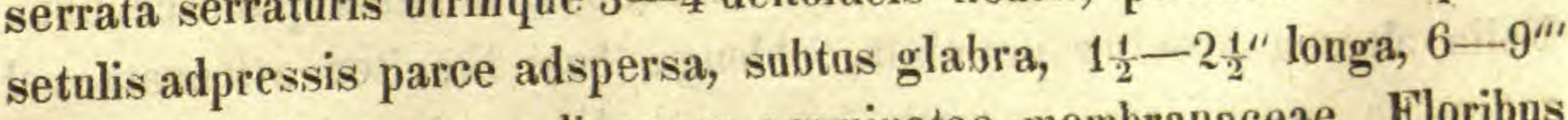
lata. Stipulae parvae lineares acuminatae membranaceae. Floribus masculis: Pedunculi axillares solitarii $6-10$ lineas longi umbelliferi. Umbella s. fascieulns simplex, 10-15-florus, bracteis lineari-lanceo-

Abhandlungen d. II. Cl. d. k. Ak. d. Wiss. IV. Bd. III. Abthl. 28 
latis acuminatis membranaceis pubescentibus basi in receptaculi speciem connatis cinctus; pedicelli uniflori $2^{\prime \prime \prime}$ longi teretes apice articulati. Perianthium pentaphyllum foliolis ovatis acutis membranaceis glabris. Flores foem. nobis non obvii.

764. Pr. radicans $\mathbf{S}$. et $\mathbf{Z}$. Pr. caule herbaceo prostrato radicante, foliis alternis breviter petiolatis inaequilateris basi semicordatis ovatis vel ellipticis acutis remote serratis; capitulis foemineis axillaribus subsessilibus geminis ternisve hemisphaericis involucratis.

Caules debiles prostrati radicantes. Petioli $1-2^{\prime \prime \prime}$ longi; lamina folii basi inaequilatera et in latere latiore semicordata lobo rotundato, ovata vel ovato-ellictica, acuta, remote serrata, serraturis ntrinque $4-5,8-12^{\prime \prime \prime}$ longa, 4-6" lata.

432. Morocarpus $\mathbf{S}$. et $\mathbf{Z}$.

Dioica. Masculis: Perianthium triphyllum, aestivatione valvata. Stamina tria; filamenta primum induplicata, elastice desilientia; antherae antice quadriloculares. Ovarii rudimentum parvum villosum. Foemineis: Perianthium urceolatum ovatum brevissime tridentątum persistens, demum carnosum. Ovarium perianthio inclusum. Stigma sessile penicillatum. Fructus perianthio carnoso baccati, dense in capitula globosa congesti, minuti, pyriformes. Achenium ... - Frutex foliis alternis serratis, stipulis geminis membranaceis, floribus masculis breviter spicatis bracteatis, foemineis in capitula globosa congestis flavis, capitulis subsessilibus fasciculatis vel pedicellatis cymoso-subdichotomis.

765. M. edulis S. et Z. - Boehmeria Janagi-itsigo Siebold Synopsis in Act. Batav. l. c. p. 70. Herb. Göring n. 108. Specimen foemin. n. 176. Spec. masculum.

Arbor vel frutex ramis alternis teretibus, novellis pubescentibus Folia alterna breviter petiolata, oblonga, basi breviter attenuata vel rotundata, acuminata, serrata, superne pubescentia subtus hirta, rugosa, penninervia. Stipulae intrapetiolares inter se liberae lanceolatae acuminatae, carinato-uninerviae et in nervo pubescentes, mem- 
branaceae, fuscae. Flores coëtanei, dioici, e gemmis propriis perulatis. Masculi in spicas breves subcapitatas congesti, perulis involucrati, bracteati. Perianthium triphyllum, foliolis late ovatis cuspidatis concavis apicem versus barbatis. Stamina tria primum inflexa. Ovarii rudimentum villosum. Flores fọeminei in capitula parva congesti. Capitula in pedunculo conmuni $4-6$ subdichotome disposita, subsessilia bracteata. Perianthium urceolatum apice constrictom tridentatum dentibus acutis barbatis. Ovarium perianthio adhaerens et superne tantum liberum?, uniloculare, uniovulatum. Stigma sessile penicillatum. Capitula fructifera distincte pedunculata magnitudine pisi; baccae parvae pyriformes vel clavatae apice depressae et perigonii rudimento notatae, flavae, edules.

Die vorliegenden Exemplare sind zu unvollständig und übelgehalten, um namentlich die weiblichen Blüthen mit Sicherheit untersuchen zu können und auch die in Japan gefertigte Abbildung gibt nur die Ansicht, nicht aber die Details der weiblichen Bluthe und der reifen Frucht. Doch glaubten wir die Gattung nicht übergehen zu dürfen.

\section{0. (92 Endl.) MOREAE.}

\section{Morus Tourn.}

766. M. alba L. Thunb. Fl. jap. p. 71. (exclus. Synon. Kämpferi). Siebold Symops. l. c. p. 27.

767. M. indica L. Thunb. p. 76. Siebold Synops. p. 27.

768. M. japonica Sieb. Synops. p. 27.

434. Fatoua Gaud.

769. F. aspera Gaudich. ap. Freycinet Botan. p. 510.

770. F. pilosa Gaudich. l. c. p. 509.

Zn diesen beiden Arten zieht Gaudichand fragweise Urtica japonica Thunb. 1. c. p. 70 nach Exemplaren des Pariser Museums. Wir haben die Pflanze noch nicht gesehen. 


\section{Maclura Nutt.}

771. M. gerontogaea S. et Z. M. foliis oblongo-ellipticis utrinque attenuatis acutis integerrimis glabris subcoriaceis, fructibus subsessilibus geminis.

Rami teretes glabri fuscị. Folia alterna, petiolata, oblongo-elliptica utrinque attenuata acuta integerrima penninervia glabra subcoriacea; petioli $3-4^{\prime \prime \prime}$ longi, lamina $2-3^{\prime \prime \prime}$ longa, $10-15^{\prime \prime \prime}$ lata. Flores nobis non obvii. Fructuun capitula axillaria plerumque gemina, brevissime pedunculata, globosa, magnitudine nucis juglandis vel pomi minoris, globosa, aurantiaca. Receptaculum seu pedunculus irregulariter globoso-incrassatus, perianthiis fructiferis densissime obsitus. Perianthia sessilia, tetra-rarins pentaphylla; foliola opposita cuneato-oblonga truncata cucullato-concava, fructifera praesertim apicem versus valde carnoso-incrassata et préssione-vario sed plerumque eo modo sibi imposita ut exteriora duo interioribus plane incumbant, hae vero quasi equitantia altero margine se invicem amplectantur et achenium plane includant. Achenium ovato-orbiculare lenticulare lateribus convexis, epidermide carnosa derasili tectum, crustaceo-durum, uniloculare monospermum. Stylus persistens unicruris filiformis superne parum incrassatus, rudimento alterius cruris brevissimo. Semen hine ad basin pericarpii affixum erectum; testa membranacea albumini tenui arcte adhaerens. Embryo curvatus radicula longa cylindrica micropylen spectante, cotyledonibus magnis plane sibi incumbentibus sed simul inflexis et circa radiculam convolutis.

Mit M. aurantiaca am nächsten verwandt liefert diese Pflanze einen neuen Beweis für die nahe Beziehung, in welcher die japanische Flora zu der des atlantischen Nordamerika's sich befindet. 436. Broussonetia Vent.

772. Br. papyrifera Vent. Morus papyrifera Thunb. Fl. jap. p. 72 et Auct. Siebold Synops. l. c. p. 27. Kaadsi Kämpfer Amoen. p. 471 cum fig. in $p .472$. 
Folia in specc. japonicis plerumque indivisa rarius subtriloba, quam in planta culta brevius petiolata, ceterum figura varia, basi rotundata vel oblique cordata, acuta, acuminata vel cuspidata.

773. Br. Kämpferi Sieb. Br. fruticosa ramis ex parte longissimis volubilibus vel scandentibus, novellis pubescentibus, foliis e basi breviter cordata et şoepe obliqua oblongis acuminatis serratis utrinque pubescentibus scabris penninerviis, capitulis foemineis axillaribus solitariis globosis pedunculatis, pedunculis petiolos aequantibus. Br. Kämpferi Siebold Synops. l.c. p. 28. Kaadsj Kalsira, it. Kago Kadsira. Papyrus spuria Kämpf. Amoen. p. 474. cum icone in $p$. 472 et Kaadi Kadsura p. 895. Morus nigra Thunb. Fl. jap.,p. 71.?

Frutex ramis longis simplicibus nudis flexibilibus longe serpens scandensque (Kümpfer). In specc. siccis rami alii elongati simplices volubiles, alii stricti subflexuosi ramulosị, cortice badio glabro vestiti. Ramuli novelli pubescenti-hirti. Folia alterna, petiolata petiolo 3-4"' longo; lamina basi cordata vel oblique rotundata, oblonga, acuminata, subaequaliter serrata, superne scabra subtus hirta penninervia, magnitudine valde varians, $1 \frac{1}{2}-4^{\prime \prime}$ longa, $7-15^{\prime \prime \prime}$ lata. Stipulae laiceolatae acuminatae, membranaceae, uninerviae, hirtae, fuscae, deciduae. Flores masculi nobis non adsunt. Capitula foeminex axillaria solitaria pedunculata globosa magnitudine pisi; pedunculi petiolos aequantes hirti. Perianthium urceolatum apice breviter 3-4-dentatum hirtum. Stylus sublateralis longus filiformis brevissime barbatus.

Thunberg eitirt irrig Kämpfers Papyrus spuria zu seiner Morus alba, gewiss der ächten Linneischen Pflanze, zu welcher dagegen vermuthlich Soo valgo Kuwa Kämpfer p. 788. gehört, was Thunberg bei seinem Morus nigra anführt. Ob letzterer aber mit unisrer Broussonetia zusammenfalle, wage ich nicht zu entscheiden.

774. Br. Kasinoki Sieb. Br. foliis e basi oblique rotandata late ovatis serratis longe acuminato-cuspidatis utrinque scabris. Siebold Synops. l. c. p. 28. 
Rami teretes badii. Folia petiolata petiolis semipollicaribus, lamina basi oblique rotundata vel rarius subcordata late ovata, repente in acumen longum lineare terminata, serrata serraturis approximatis, penninervia vel nervis lateralibus infimis ultra dimidinm folii productis subtrinervia, papilloso-scabra, 4-5" longa, 2-3" lata. Flores. nobis non obvii.

437. Ficus L.

775. F. stipulata Thunb. Siebold Synops. I. c. p. 29.!

776. F. pumila Thunb. Fl. jap. p. 33. var. ce

777. F. erecta Thunb. Act. Linn. II. p. 327. H. pumila Flor. jap. l. c. var. $\beta$. Siebold Synops. p. 29. Inu Itabu. Kämpfer Amoen. p. 803 c. icon. p. 802.

778. F. japonica Blume Bijdr. p. 440.

779. F. pyrifolia Burm. Spreng. Syst. Veget. III. p. 780.

780. F. Kirta Vahl. Siebold Synops. l. c. p. 29. - E. China introducta.

781. F. Carica L. Thunb. Fl. jap. p. 32.

Thunberg sagt, diese Art sei von den Portugiesen eingeführt und werde um Nangasaki kultivirt, v. Siebold dagegen erwähnt ihrer nicht, sondern sagt, dass $\mathrm{F}$. hirta aus China übersiedelt der Früchte wegen angepflanzt werde. Sollte Thunbergs F. Carica zu dieser gehören?

Ausser den angeführten kommen in Japan noch wenigstens vier Arten von Ficus vor, dessen spätere Beschreibung, so wie die Ausscheidung der Gattung Plagiostigma (Zuccar. in Act. Acad. Monac. Mathèm. Phys. IV. 1. p. 154), wir uns vorbehalten.

\section{7. (91 Endl.) CELTIDEAE Endl.}

438. Celtis Tournef.

782. C. Willdenowiana Roem. et Schultes Syst. veget. VI. p. 306. Loudon Arboretum brittan. p. 729. fig. 1410. C. orientalis Thbg. Flor. jap. p. 114. Siebold Synops. p. 28. 
Nach v. Siebold ein grosser Baum, der in Japan zur Bezeichnung der Wegstunden an die Strassen gepflanzt wird, und schon durch diese Grösse hiureichend von C. sinensis Pers. verschieden. Die ausgewachsenen Blätter der blühenden $\mathbf{Z}$ wैeige sind völlig kahl und häufig ganzrandig, die der raschwüchsigen Lohden sägezähuig, rauh und behaart.

783. C. muku Siebold Synops. l. c. p. 28. Prunus aspera Thunb. Flor. jap. p. 201. Muknoki Kämpfer Amoen. p. 799. An Celtis politoria Wallich Catal.?

Folia breviter petiolata basi subaequilatera et rotundata, ovatoelliptica, longe attenuata et argnte acuminata, serrata serraturis mucronatis, penninervia nervis lateralibus parallelis utrinque $6-8$, setis adpressis utrinque aspera, $2-5^{\prime \prime}$ longa, 12-20" lata. Flores subsessiles, masculi plerumque $2-3$ glomerati infra folia ex axillis perularum, hermaphroditi vel foeminei ex axillis foliorum subsolitarii. Perianthium plerumque sexpartitum laciniis ovatis basi cohaerentibus. Filamenta brevissima, antherae ad lentem minutissime pubescentes. Stigmata linearia, revoluta.

439. Sponia Commers.

784. Sp. nudiflora $\boldsymbol{S}$. et $\boldsymbol{Z}$. Sp. foliis basi inaequilateris rotundatis vel subcuneatis ovato-ellipticis acuminatis argute mucronatoserratis penninerviis utrinque pubescenti-scabris subtus canescentibus, floribus subserotinis, masculis infra folia ex axillis perularum in cymas laxas paucifloras dispositis, perianthii quinquepartiti laciniis oblongis obtusis cucullatis, floribus foemineis ex axillis foliorum superiorum solitariis sessilibus, perianthii laciniis lanceolatis acuminatis, stigmatibus lineari-oblongis divaricatis.

An genus proprium? - Folia adulta nobis non obvia, novella sesqui-bipollicaria, setulis adpressis utrinque scabriuscula et subtns canescentia, penninervia nervis lateralibus parallelis utrinque $5-6$. Cymae masculae infra folia, rarius axillares pedunculo pedicellisque laxis filiformibus. Perianthium ad basin usque 5-partitum, rotatum, 
laciniis oblongis obtusis cucullato-concavis. Stamina 5, filamenta filiformia. Ovarii rudimentum villosum. Flores foeminei solitarii sessiles ex axillis foliorum superiorum. Perianthii laciniae lanceolatae acuminatae.

\section{8. (90 Endl.) ULMACEAE:}

440. Euptelea Sieb. et Zucc.

785. E. polyandra S. et Z. Flor. jap. I. p. 134. tab. 72.

441. Ulmus L.

786. Species $3-4$ nondum accuratins examinatae.

442. Micr optelea Spach.

787. M. parvifolia Spach. Annales des Sc. natur. 1841. p. 359. Ulmus parvifolia Jacq. hort. Schoenbr, III. tab. 262. Ulmus chinensis Persoon Synops. I. p. 291.

Loudon im Arboretum britt. $p .717$ zieht Ulinus chinensis Pers. als Varietät zu Ulmus campestris. Vermuthlich kannte er, wie auch aus der Abbildnng zu erhellen scheint, die ächte Pflanze nicht.

\section{9. (89 Endl.) CUPULIFERAE Richard.}

443. Castanea Tournef.

788. C. vesca Gaern. B. pubinervis Hasskarl hort. Bogor. p. 73. Fagus Castanea Thunb. Flor. jap. p. 195. - Riitz vulgo Kuri fructu majore Kämpfer Amoen. p. 816.

789. C. crenata $\boldsymbol{S}$. et $\boldsymbol{Z}$. C. foliis e basi rotundata vel subcordata oblongis acuminatis crenatis crenis rotundatis vel setaceomucronatis, subtus ad venas pubescenti-hirtis ceterum glabris, minutim glanduloso-punctatis, junioribus pilis simul minutissimis stellatis obsitis et novellis canescentibus, amentis elongatis gracilibus laxis, stylis 7-8. Castanea chinensis Hasskarl hort. Bogor. p. 73.?

Rami quam in C. vesca tenuiores. Folia brevius petiolata et ipsa minora, 3-5" longa, $15-24^{\prime \prime \prime}$ lata; crenae in margine brevissimae repandae rotundatae et seta tantum mucronatae nec ipsae in 
acumen extensae; pili in petiolis et nervis paginae inferioris simplices, in venulis dense reticulatis minutissimi stellati et glandulis globosis flavescentibus mixti. Spicae $4-6^{\prime \prime}$ longae quam in C. vesea multo graciliores.

Castanea chinensis Spreng. (Fagus Castanea Loureiro) ist durch scharf sägezähnige Blätter von unserer Art verschieden. Bunge vêrmuthet Enum. plant. chin. p. 63, dass die Loureiro'sche Pflanze, welcher eine capsula bivalvis monosperma zugeschrieben wird, mit seiner Quercus chinensis zusammenfalle. Aber bei dieser sind die Blätter auf der Rückseite feinwollig und Loureiro beschreibt sie glatt. Desshalb dürte seine Pllanze doch wohl eine andre Art, aber allerdings eher eir Quercus als eine Castanea seyn.

790. C. stricta S. et Z. C. ramis ranulisque strictis, foliis breviter petiolatis e basi rotundata oblongis vel oblongo-lanceolatis acuminatis crenatis, crenis repando-rotundatis setaceo-mueronatis, superne glabris subtus pilis minutis stellatis canis et dense glandulosopunctatis, adultis calvescentibus coriaceis, amentis strictis cylindricis. Castanea pumila Catal. hort. Bogor. p. 73.

Rami cortice badio lenticellis albis verrucoso vestiti, novelli villosi. Petioli $3^{\prime \prime \prime}$ longi; lamina folii $2-3^{\prime \prime}$ longa, $8-12^{\prime \prime \prime}$ lata, coriacea. Spicae masculae $2-4^{\prime \prime}$ longae strictae.

C. pumila Mich. unterscheidet sich durch grössere und breitere, kürzergestielte oder fast stiellose Blätter und spitzig vorgezogene Sägezähne am Rande derselben.

\section{Fagus Tourn.}

791. Species. F. ferruginea Siebold Sinnops. p. 25, sed a planta americana certe diversa.

445. Quercus Linn.

793. Qu. glabra Thunb. Flor. jap. p. 175. Siebold et Zuccur. Flor. jap. I. p. 170. tab. 89.

794. Qu. acuta Thunb. Fl. l. c.

Abhandlungen d, II. Cl. d. k. Ak. d. Wiss. IV. Bd. III. Abth. 
Folia novella subtus aeque ac rami ferrugineo-tomentosa, superne molliter hirsuta, adulta utrinque glabra, coriacea et non semper integra sed apicem versus plerumque crenulata, petioli pollicares.

794. Qu. glauca Thunb. l. c.

Folia novella subtus dense sericeo-hirta, argentea, adulta calva glauca.

795. Qu. cuspidata Thunb. l. c. p. 176. Siebold et Zuccar. Fl. jap. I. p. 8. tab. 2.

796. Qu. serrata Thunb. l. c.

Amenta mascula gracillima filiformia. Flores pentandri filamentis basi monadelphis, antherae imberbes. Folia novella anguste lanceolata longissime acuminata dense costata, superne hirsuta subtns tomentosa; adulta elongato-oblonga acuminata mucronato-serrata utrinque calva vel subtus parce pubescentia.

Ausser dieser kommen in Japan noch mindestens 12 Arten von Eichen vor, welche später beschrieben werden sollen.

446. Corylus L.

797. C. heterophylla Fisch. Trautvetter Icones plant. russic. p. 10. tab. 4. et ejusdem fide Cor. Avellana var. davurica Pallus f. ross. Edit. min. I. 2. p. 36. - C. Avellana Thunb. Flor. jap. p. 160. - Cor. americana Siebold Synops. l. c. p. 26. Cor. Hasibami Sieb. Annuaire l. c. p. 27.

Die japanischen Exemplare stimmen in allen Dingen mit denen vom Argun und mit der Trantvetterschen Abbildung überein.

447. Distegocarpus S. et Z. Tab. III. 3 .

Flores monoici. Masc. Amenta cylindrica laxa e gemmis propriis. Squamae s. bracteae simplices stipitatae, laxe imbricatae. Peri gonium uullum. Stamina 12-15 squamae stipiti inserta; antherae barbatae. Foem. Amenta cylindrica laxa e gemmis simul foliiferis. Bracteae lanceolatae acuminatae biflorae. Involucrum cujusvis floris diphyllum foliolis oppositis, exteriore multo majore. Perigonium adnatum limbo supero brevissịmo annulari. Ovarium biloculare. Stylus 
brevissimus, stigmatibus duobus elongatis filiformibus. Racemi fructiferi strobilacei imbricati ex involucris diphyllis geminis monospermis ; foliola simplicia nervosa grosse serrata, exteriore multoties majore interius oppositum basi amplectante. Glans s. nucula ovata compressa laevis, perigonii margine brevissimo coronata, monosperma, semine pendulo.

Arbores omnino Carpini habitu, gemmis perulatis, foliis alternis petiolatis argute inaequaliter serratis acuminatis costato-multinerviis, novellis transversim plicatis adultis lineatis, strobilis ovato-cylindricis crassis, involucri squamis ovatis grosse serratis serraturis mucronatis, palmati-nerviis, reticulatim venosis.

Recedit a Carpino amenti masculi squamis stipitatis et fructus involucro diphyllo foliolis oppositis.

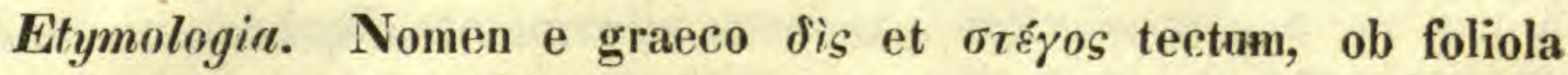
involucri duo opposita fructum obtegentia.

Endlicher sagt bei Carpinus von den weiblichen Blüthen: involucri biflori foliolis geminis petiolan̂s trilobis; besser dürfte es heissen squamae amenti biflorae, singulo flore squama triloba involucrato. Dieses erhellt deutlich aus unsrer vorliegender Gattung, wo für jedes Blüthchen die zweite innere Involucral-Schuppe hinzukömmt nud das Nüsschen auch von der Innenseite bedeckt.

799. D. Carpinus S. et $\boldsymbol{Z}$. D. foliis e basi cordata vel rotundata subobliqua oblongo-ellipticis acuminatis dense inaequaliter serratis serraturis macronatis, costatis nervis parallelis rectis superne impressis, junioribus sericeis, amentis masculis laxis, squamis stipitatis ovatis acutis ciliatis multinervio-striatis, foemineis eylindricis erectis, strobilis pedunculatis ovato-cylindricis, involueri foliolis palmatinerviis reticulatis, majori ovato acuto grosse serrato, minori rotundato 4-5-dentato nuculam ovatam compressam glabram aequante.

Rami subtortuosi, cortice glabro badio lenticellis oblongis albidis notato, novelli jubescentes. Gemmae perulatae ovato-oblongae perulis oblongis obtnsis dorso sericeis. Folia petiolata petiolo $4-6^{\prime \prime \prime}$ 


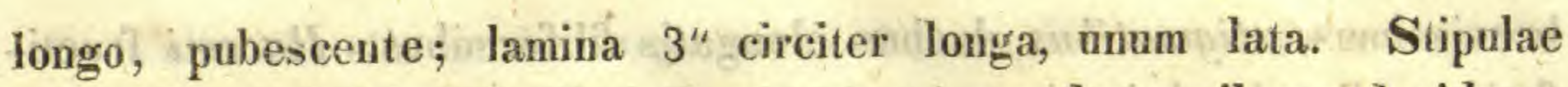
lineari-lanceolatae longe acuminatae nervosae, dorso pilosae deciduae. Amenta mascula pollicaria, laxa, squamis disjunctis patentibus distincte stipitatis dense nervoso-striatis, sericeo-ciliatis castaneis. Strobili pedunculati, pedunculo bi-tribracteato sursum tomentoso, ovatocylindrici, 2" circiter longi, imbricati; bracteae ovato-lanceolatae acutae aridae biflorae; involucri foliolum exterius $6^{m}$ longum, $4^{\prime \prime}$ latum, interius nuculam aequans ovatam convexo-compressam, glabram, nervis 10 lineatam.

\section{D. laxiflora $\mathbf{S}$. et $\mathbf{Z}$.}

Amenta florentia foeminea filiformia laxa bracteis remotis vix nltra 12 lanceolatis longe acuminatis. Folia novella ovato-elliptica acuminata, dense serrata, costata et in nervis sericea.

\section{0. (88 Endl.) BETULACEAE Rich.}

\section{Betula Tournef.}

800. B. grossa S. et Z. B. ramulis novellis resinoso-punctatis angulatis glabris, foliis e basi rotundata vel subcordata ovato-ellipticis acutis vel acuminatis inaequaliter argute serratis subtus punctulatis et ad nervos pilosis, strobilis solitariis breviter pedunculatis vel subsessilibus erectis, foliis $1-2$ suffultis, grossis oblongo-ellipticis, squamis trispermís extus hirtis late cuneatis breviter trilobis, lobis subaequalibus vel medio parum longiore, rotundatis, alis loculamento oblongo angnstioribus, sursum latioribus.

Folia $1 \frac{1}{2}-2^{\prime \prime}$ longa, $10-15^{\prime \prime \prime}$ lata, subtus nervis parallelis costata resinoso-punctata, nec reticulata, floralia 1-2; pétioli semipollieares. Strobili pollicares, grossi, pedunculo quam petioli breviore vel subnullo. Squamae firmae, extos canescenti-hirtae.

801. B. carpinifolia S. et $\boldsymbol{Z}$. B. ramulis novellis glabris teretibus, foliis inferioribus e basi cordata ovatis, superioribus basi rotundatis vel cuneatis oblongis, summis lanceolatis, onnibus longe aenminatis argute et inaequaliter serratis superue glabri subtus ad ner- 
vos costatos pilosis glanduloso-punctatis, strobilis solitariis subsessilibns ovato-ellipticis, squamis trispermis late cuneatis glabris breviter trilobis, lobis lateralibus subdivaricatis rotundatis, terminali parum productiori oblongo recto, alis loculo oblongo angustioribus et parum longioribus. - B. alba Thunb. Fl. jap. p. 76.

Folia $2 \frac{1}{2}-3 \frac{1}{2}$ " longa, $12-20^{\prime \prime \prime}$ lata summis sensim minoribus et angustioribus; subtus inter nervos parallelos tenuiter reticulata; petioli 10-12 "' longi. Amenta mascula in apice ramorum et ex axillis foliorum summorum $4-6$ subracemosa, cylindrica, nuda. Gemmae foliiferae ovato-oblongae perulatae glabrae. Strobili subsessiles semipollicares.

802. B. ulmifolia S. et Z. B. ramulis novellis angulatis? pubescentibus, foliis e basi inaequaliter cordata ovatis acominatis inaequalicer et subduplicato-serratis serraturis falcatis, aeque ac petioli utrinque ad venas pilosis subtus tenuiter reticulatis, strobilis solitariis foliis $1-2$ suffultis cylindricis breviter pedunculatis pedunculo (quam petioli triplo breviore) hirto, squamis trispermis profunde trilobis, lobis rectis lineari-oblongis obtusis ciliatis, medio dimidio longiore.

Folia $2 \frac{1}{2}-3^{\prime \prime}$ longa, $1 \frac{1}{2}{ }^{\prime \prime}$ lata, utrinque ad venas pilis longis adpressis aeque ac petioli semipollicares molliter pilosa. Strobili erecti vix pollicaris squamae extus pubescentes intus glabrae.

803. B. japonica Sieb. Synops. l. c. p. 25.

Die uns vorliegenden blühenden Exemplare genügen nicht $\mathbf{z u}$ vollständiger Diagnose.

449. Alnus Tournef.

804. A. firma S. et Z. A. ramulis novellis angulatis verracosis, ceterum glabris, foliis e basi rotundata ovatis acutis inaequaliter serratis serraturis rectis cuspidatis, superne glabris subtus ad nervos costatos parce pilosis imberbibus dense glanduloso-punctatis firmis, amentis masculis terminalibus plerumque geminis sessilibns cylindricis, foemineis (hyeme gemma inclusis) solitariis - ternis, pedunculatis, stro- 
bilis ovatis, squamis lignosis breviter quinquefidis truneatis, samarae obcordatae alis sursum ampliatis.

Gemmae substipitatae glabrae. Folia $2-3^{\prime \prime}$ longa, $10-15^{\prime \prime \prime}$ lata, coriacea, firma; petioli semipollicares. Amenta mascula pollicaria. Strobili maturi ovati utrinque rotundati grossi semipollicares.

805. A. japonica $\$$. et $\boldsymbol{Z}$. A. ramulis novellis angulatis glabris, foliis longe petiolatis, e basi cuneato-attenuata rarius rotandata ovatis, ovato-lanceolatis vel summis lanceolatis, acuminatis inaequaliter et argute serrulatis, utrinque glabris, subtus in axillis venarum barbulatis reticulatis impunctatis, amentis foemineis (hyeme nudis) terminalibus racemosis $3--6$, strobilis maturis ovatis obtusis, squamis lignosis truncatis breviter quinquefidis resinofis, samaris orbicularibus ala brevissima marginatis.

Betula Alnus Thumb. Flor. jap. p. 76. Alnus harinoki Siebold Synops. p. 25.

Folia $2-4$ " longa, $1-2 \frac{1}{2}$ "lata, summa valde angustata vix $6^{\prime \prime \prime}$ lata, venis quam in reliquis speciebus remotioribus costata, praeter barbulas in axillis venarum tota glabra; petioli 9-15" longi. Strobili racemosi, pedicellati, ovati, obtusi; squamae cuneato-flabellatae truncatae, quinquefidae laciniis arcte sibi imbricatis, superne glandulis resiniferis dense punctatae.

\section{1. (87 EndI.) MYRICEAE L. C. Richard.}

\section{Myrica L.}

806. M. rubra $S$. et $\boldsymbol{Z}$. M. foliis perennibus e basi longe attenuata oblongo-lanceolatis acutiusculis integerrimis vel raro apicem versus remote serratis, utrinque glabris coriaceis, amentis axillaribus fasciculatis vel solitariis cylindricis, drupis globosis dense papillosis.

Rami teretes cortice cinereo vel fuscescente verruculoso tecti. Folia alterna in petiolum brevem longe attenuata, oblongo-lanceolata vel oblonga, acutiuscula vel obtusa, plerumque integerrima, rarius apicem versus remote serrata, ntrinque glabra peminervia, nervis intra mar- 
ginem arcuation combinatis reticulatim venosa firma coriacea, $2-4^{\prime \prime}$ longa, 6-12"' lata. Amenta axillaria sessilia solitaria vel fasciculata cylindrica pollicaria. Fructus globosi Arbuti in modum papillosi, coccinei.

\section{2. (84 Endl.) CALLITRICHINAE Leveille.}

451. Callitriche L.

807. C. verna Thunb. Fl. jap. p. 16.

\section{3. (83 Endl.) CERATOPHYLLEAE Gay.}

452. Ceratophyllum L.

808. C. demersum Thunb. Fl. jap. p. 190.

Wir führen diese so wie die vorangehende Gattung auf Thunbergs Autorität an, ohne selbst japanische Exemplare gesehen zu haben. Da beide auch im nördlichen Asien, so wie in Ostindien vorkonmen, so ist ihre Anwesenheit in Japan wahrscheinlich, obgleich die Species von, den europäischen verschieden seyn mögen.

\section{4. (82 Endl.) SAURUREAE $L$. C. Rich.}

453. Houttuynia Thunb.

S09. H. cordata Thunb. Fl. jap. p. 234. tab. 26.

454. Saururus L.

810. S. Loureiri De Caisne in Annales des Sc. natur. 1845. p. 102. S. cernuus Thunb. Fl. jap. p. 154. An S. chinensis hort.?

135. (\$1 Endl.) PIPERACEAE $L$. C. Rich. 455. Piper L.

811. P. futokadsura Sieb. - An P.? chinense Miquel Animadvers. in Piperaceas (Bullet. de l. Acad. Bruxelles 1845)? 


\section{6. (80 Endl.) CHLORANTHACEAE R. Brovn.}

456. Chloranthus Swartz.

taoll 812. Chl. inconspicuts Swartz. Nigrina spicata Thunb. Fl. jap. p. 5 et 65 .

813. Chl. serratus Roem. et Schult. Syst. Veget. III. p. 461.Nigrina serrata Thunb. Act. Upsal. VII. p. 142. tab.'V. f. 1.Chlor. inconspicuss $\beta$. var. japonica Siebold Annuaire de la Soc. lortic. des Pays-bas 1844: p. 26.

\section{7. (78 Endl.) TAXINEAE L. C. Rich.}

\section{Taxus Tourn.}

814. T. cuspidata S. et Z. Flor. ja, II. tab. 128.-T. baccata Thunb. Fl. jap. p. 275.

458. Torreya Arnott.

815. T. nucifera S. et Z. IHT. jap. II. tab. 129. (Caryotaxus Zuccar. mscpt.) Taxus nucifera Thunb. l. c. et Auct. -Ti vulgo kaja Kämpfer Amoen. p. 814 c. ic. in p. 815.

459. Cephalotaxus $\mathbf{S}$. et $\mathbf{Z}$.

816. C. drupacea S. et Z. Flor. jap. II. tab. 130. 131.

817. C. pedunculata \$. et Z. Fl. jaj. H. tab. 132. 460. Podocarpus LHerit.

818. P. macrophylla Wall. Sieb. et Zaccar. Hl. jap. I. tab. 133. 134. - Taxus macrophylla Thunb. Fl. jap. p. 276. to Sin vulyo Maki Kämpfer Amoen. p. 780.

ß. P. Maki S. et Z:-Ken Sin it. Sen Bakv vulgo Inu Maki Kämpfer l. c.

Kultivirte Zwergspielart und als solche zu den Garienkünsteleien der Japaner sehr beliebt. Das angeführte Citat ans Kämpfer wird von Thunberg mit Uureclit zui seinem Taxus verticillata (Sciadopitys) gezogen.

819. P. coraiana Sieb. Annuaire de la Société hortic. des Pays-bas. 1844.,p. 35 . 
820. P. Nageia R. Br. Mém. du Museum XIII. p. 75. 76. S. et Z. Fl. jap. II. tab. 135. - Myrica Nagi Thunb. Fl. jap. p. 76. - Nageia japonica Gaert. Carpol. I. p. 491. tab. 39. fig. 8. Na vulgo Nagi Kämpfer Amoen. p. 773. et fig. in p. 874. 468. Salisburia Smith.

821. S. adianthifolin S. et Z. l. c. tab. 136. Ginkgo biloba Thunb. Fl. jap. p. 358. - Ginkgo vel Ginan vulgo Itsgò. Kämpfer Amoen. p. 811. c. ic. in p. 813.

469. Iuniperus L.

822. I. rigida S. et Z. Fl. jap. II. tab. 125. Iun. communis Thbg. Flor. jap. p. 264. (excl. Synon. et nom. japonicis). - Moro, aliis Sonoro maatz. Iuniperus arborescens, baccis Sabinae, Kämpfer Amoen. V. p. 883.

823. I. taxifolia Hook. ap. Beechey Botan. p. 272.

Vidimus specimina a beato Mertens in insulis Bonin lecta.

824. I. chinensis L. - I. barbadensis et I. virginica Thunb. l. c. p. 264. - Quai et Ibuki, Tatsj bjakusj, Ssugi bjakkusj Kämpfer Amoen. V. 884.

Erscheint sowohl wildwachseud als kultivirt in den mannigfachsten Spielarten bald als $15-30^{\prime}$ hoher aufrechter Baum mit schlanker pyramidaler Krone, bald als niedriger Straneh mit niedergebogenen Aesten. In der Grösse, Gestalt und Richtung der Nadeln variirt er in ähnlicher Weise, wie J. lycia, virginiana u. a. Diese verschiedenen Formen scheint Thunberg unter seinen I. barbadensis und virginica zu meinen, verwechselt dabei aber zugleich in seinen Citaten die in Japan für diese sowohl als für I. rigida üblichen Landesnamen. Hooker (ap. Beechey l. c.) citirt dagegen die Thunberg'schen I. virginica und barbadensis zu seinen I. taxifolia und Thunbergii ans den Bonin-Inseln. Wir besitzen nur von I. taxifolia Exemplare, ebendaselbst von Mertens gesammelt, aber diese sind voin allen uns vorliegenden Iuniperusformen aus Japan selbst weAblandlungen d. II. Cl, d. k. Ak. d. Wiss. IV. Bd, III Abth. 30 
sentlich verschieden, und die Thunbergischen Citate möchten deshalb bei den Hookerschen Arten zu tilgen seyn.

825. I. procumbens Sieb. in Annuaire de lu Société hortic. des Pays-bas. 1844. p. 31. 470. Thuja Tournef.

826. Th. orientalis L. Sieb. et Zuccar. Fl. jap. II. p. 31. tab. 118. Thunb. Fl. jap. p. 266. - Finoki altera Kämpf. Amoen. $\dot{V}$. p. 884 .

827. Th. excelsa Bongard Mémoires de l'Acad. de St. Petersbourg. Sciences mathem. phys. et natur. II. 1833.

828. Th. pendula Lamb. Sieb. et Zuccar. l. c. p. 30. tab. 117. Cupressus pendula Thunb. Fl. jap. p. 265. - Fi moro Kämpfer Amoen. V. p. 883.

471. Thujopsis S. et $\boldsymbol{Z}$.

829. Th. dolabrata S. et Z. Fl. jap. II. p. 32. tab. 119. 120. - Thuja dolabrata Thunb. Fl. jap. p. 266. (excl. Synon. Kämpferi) 472. Retinis pora Sieb. et Zucc.

830. R. obtusa S. et Z. Fl. jap. II. p. 38. tab. 121.

831. R. pisifera S. et Z. l. c. p. 39. tab. 122.

832. R. squarrosa S. et Z. l. c. p. 40. tab. 123.

473. Cryptomeria Don.

833. Cr. japonica Don Linn. Transact. XVIII. 2.p. 166. Sieb. et Zuccar. Fl. jap. II. p. 43. tab. 124. et 124. b. - Cupressus japonica Linn. fil. suppl. p. 421. Thunb. Fl. jap. p. 265. - San vulgo Sugi Kämpfer Amoen. V. p. 883. et Banks Ic. Kämpfer. tab. 48.

\section{9. (77 Endl.) ABIETINAE L. C. Rich.}

\section{Abies L. C. Rich.}

a. Abietinae verae.

834. A. (Larix) leptolepis S. et Z. Fl. jap. II. p. 12. tab. 105. - Pinus Larix Thunb. Fl. jap. $p$. 275. 
835. A. Tsuga S. et Z. Fl. jap. l. c. p. 14. tab. 106.

836. A. (Picea) firma S. et Z. Fl. jap. l. c. p. 15. tab. 107. 837. A. homolepis S. et Z. Fl. jap. l. c. p. 17. tab. 108.

838. A. (Picea) bifida S. et Z. Fl. jap. l. c. p. 18. tab. 109. 839. A. jezoënsis S. et Z. l. c. p. 19. tab. 110.

840. A. polita S. et Z. l. c. p. 20. tab. 111. - Pinus Abies Thuib. Fl. jap. p. 275.

475. Pinus L. C. Rich.

841. P. densiflora S. et Z. l. c. p. 22. tab. 112.

842. P. Massoniana Lamb. Sieb. et Zucc. l. c. p. 24. tab. 112. 114. P. sylvestris Thunb. Fl. jap. p. 247. Pinus rubra Siebold Synops. in Act. Batav. l. c. p. 12. - \$jo vulgo Maats Kämpf. Amoen. p. 883.

Nach Hooker (Beechey p. 271.) auch auf den Liu-Kin Inseln. Am Kap der guten Hoffnung kultivirt.

843. P. parvifora S. et Z. l. c. p. 27. tab. 115. - P.Cembra Thunb. Fl. jap. p. 274. (excl. synon.)

844. P. koraiensis S. et Z. l. c. p. 28. tab. 116. - P. Strobus Thunb. l. c. p. 275.

b. Cunninghamieae Zuccar.

476. Cunninghamia R. Br.

845. C. sinensis R. Br. S. et Z. l. c. p. 7. tab. 103. 104. Pinus lanceolata Lamb. Pin. tab. 34. - Belis jaculifolia Salisbury Act. Linn. VIII. $p$. 315.

Wir haben schon früher (Fl. jap. l. c. p. 9) die Ansicht ausgesprochen, dass die Gattung Arthrotaxis, welche Don nach zwei in Tasmanien gefundenen Arten aufstellte, wohl mit Cunninghamia zu vereinigen seyn dürfte, weil der einzige Unterschied zwischen beiden in die Zahl der Antherenfächer beruht, deren bei Cunninghamia gewöhnlich 3, bei Arthrotaxis nur 2 anf jeder Blüthenschuppe stehen. Seitdem hat Sir W. Hooker im 6. Bande seiner Icones tab. 560 und 573 noch zwei Arthrotaxis-Arten, A. tetragona und taxifolia 
aus demselben Vaterlande hekannt gemacht, welche aber ebenfalls keine weiter abweichenden Gattungsmerkmale zeigen und uns deshalb noch mehr für die Vereinigung beider Gattungen zo sprechen scheineu.

477. Sciadopitys Sieb. et Zuccar.

846. Sc. verticillata S. et Z. Fl. jap. II. p. 1. tab. 101. 102. Taxus verticillata Thunb. jap. p. 276. (excl. synon. Kämpfer.)

\section{0. (38 Findl.) CYCADEACEAE $\boldsymbol{R} . \boldsymbol{B} \boldsymbol{r}$.}

478. Cycas L.

847. C. revoluta L. Thunb, Fl. jap. p. 229. - Tessio, vulgo Sotits et Sodetz Kämpfer Amoen. p. 897. - Arbor Calappoides sinensis Rumph herb. Amboin. I. p. 92. tab. 24.

B. prolifera $\boldsymbol{S}$. et $\boldsymbol{Z}$. trunco abbreviato elliptico undique prolifero, frondihus abbreviatis circumscriptione oblongis.

Thunberg und Kämpfer beschreiben zwar den Stamm der gewöhnlichen Form von C. revoluta ebenfalls als ästig, so wie er demu auch in nusern Gärten Sprossen treibt. Aber bei unsrer angegebenen Spielart ist der keineswegs cylindrische, sondern wie bei manchen Encephalartus-Arten elliptische Hauptstanm rings umher mit ähnlichen Sprossen besezt, die Wedel sind nur 1-1 $1 \frac{11}{2}$ lang, fast gleich von der Basis dicht mit Fiederblättchen besetzt und dic weiblichen Spadices zur Zeit der Blüthe ebenfalls sehr verkürzt (ungefähr 6" lang). Von einer zweiten Spielart besitzen wir nur einen sehr jungen Wedel, dessen sehr schmale an den Rändern zurückgerollte anf der Rückseite rostbraunwollige Fiederblättchen um mehr als ihre doppelte Breite von einander abstehen. Es ist möglich, dass diese beiden Formen nur Kultur-Spielarten sind, doch glanbten wir sie nicht übergehen zu dürfen.

Anmerkung. Die Aufzählung der monocotyledonären Familien müssen wir wegen Mangel an Raum dem nächsten Bande der Denks chriften vorbelialten. 
Unter den Leguminosen ist einzuschalten:

$5 / 2$. Pach yrrhizus Rich.

$7 / 2$. P. Thunbergianus S. et Z. - P. radice tuberosa, caule volubili frutescente canescente, foliis ternato-pinnatis, foliolis lateralibus brevius, terminali longe pedicellatis, ommibus stipellis setaceis bistipellatis, late ovato-suborbicularibus cuspidatis soepe angulatosubbilobis vel terminali trilobo, subtus sericeo-canescentibus, racemis elongatis densifloris, leguminibus linearibus compressis subtorulosis ferrugineo-hirsutissimis polyspermis. - Dolichos hirsutus Thunb. Linn. Transact. II. p. 339. De Cand. Prodr. II. p. 397 et Auct. Katz vulgo Kudsu, Kudsu Kadsura et Kadsune Kämpfer Amoen. p. 840. Banks Icones Kämpfer tab. 41.

Radix carnosa cubitalis, brachii crassitie, e qua farina edulis molitur (Kämpfer l. c.). Caules volubiles, lignosi in specim. nostris crassitie pennae anserinae, teretes, pilis adpressis sericeo-canescentes. Folia longe petiolata petiolo $4-5$-pollicari tereti superne canaliculato; foliola lateralia brevius pedicellata pedicellis $3^{m}$ longis, lamina e basi inaequilatera, rotundata vel late obovata cuspidata vel angulato-subbiloba, terminali aequali late rhombeo vel trilobo lobis lateralibus brevioribus rotundatis; omnia pilis adpressis subtus sericeo-cana, $3-5^{\prime \prime}$ longa, $2 \frac{1}{2}-4^{\prime \prime}$ lata; stipulae et stipellae subulatae. Racemi axillares, simplices, eylindrici, densiflori, soepe elongati, 3-9" longi; rachis serìceo-cana; pedicelli $2-3^{\prime \prime \prime}$ longi patentes ad ealycis basin bracteolis duabus linearibus aucti. Calyx 4-partitus, canescenti-hirtus, lacinia infima longiori lineari subfalcata, reliquis lanceolatis acutis summa quam laterales parum latiore apice integra. Vexillum obovato-emarginatum, earina parum brevius, incumbens, basi ad unguem linearem callosum et utrinque plica parva auriculatum; alae longitudine vexilli oblongae obtusae auricula descendente falcata; carina recta apice adscendente truncata; petala omnia inter se libera. Stamina inclusa; filamenta diadelpha, 9 infer. ultra dimidium connatis rectis apicem versus liberis subulatis adscendentibus, alternis parum brevioribus; antherae omnium aequales oblongae. Ovarium sub- 
stipitatum basi vaginula cucullata oblique cinctum, lineare, $8-12$-ovulatum, hirtum. Stylus uncinatus, filiformis, stigmate capitato papilloso, stamina parum superans. Legumen lineare $2-3^{\prime \prime}$ longum, compressum, stylo coronatum, subtorulosum, 8-10-spermum, pilis longis patentibus ferrugineis dense hirsutum.

Endlich erwähnen wir am Schlusse der Dikotyledonen noch einer merkwürdigen, leider nur in unreifen Fruchtexemplaren uns vorliegenden Gattung, deren Stellung im natürlichen System wir für jetzt noch nicht näher zu bestimmen wagen.

\section{Cercidiphyllum S. et $\mathbf{Z}$.}

Calyx tetraphyllus, foliolis quatuor coriaceis, deciduis. Corolla? Stamina? Capsulae quatuor vel abortu $3-2$, substipitatae, cylindricae, primum erectae demum divergentes et subarenatae, in latere exteriore sutura longitudinali percursae ibique dehiscentes, bivalves; - placentae in marginibus valvularam decurrentes lineares, seminibus uniseriatis imbricatis pendulis subrhombeis, in alam membranaceam terminatis. Stylus in quavis capsula terminalis, longus, subulatus, in latere exteriore sulco decurrente exaratus, stigmate obtuso, primum persistens, tandem ad $\frac{1}{3}$ longitudinis usque delabens.

Frutex ramis teretibus erectis strictis cortice cinereo glabro vestitis. Folia decussatim opposita vel rarius subalternantia, annua, petiolata, e basi cordata suborbicularia obtusa crenata crenis glandnla pellucida mucrouulatis, utrinque glabra subtus glancescentia, palmatoquinque-vel septemnervia, nervis tenuibus venoso-ramosis, $1 \frac{1}{2}-2 \frac{1}{2}$. longa totidemque lata; petioli pollicares vel sesqui-pollicares ima basi articulati. Stipulae intrafoliaceae tenuiter membranaceae, ultra medium connatae caducae. Gemmae oppositae perulatae; perula unica cucullata in dorso (ramo adverso) binervis et sulco profundo exarata, ventre (petiolum spectante) longitudinaliter fissa. Ramuli laterales floriferi abbreviati, vix $3^{\prime \prime \prime}$ longi, incrassati, foliorum et perularum cicatricibus dense annulati, in gemmam terminati quae quotan- 
nis folium unicum et pednnculam profert oppositifolium uniflorum nudum, 3-6"' longum.

Die dünne Rinde schmeckt gewürzhaft. Die Blätter haben im Umriss und Gefüge Aehnlichkeit mit denen von Cercis Siliquastrum. Die blüthentragenden verkürzten Seitenzweige wachsen sehr langsam, so dass sie in einem Alter von 5-6 Jahren kaum 3-4" lang sind. Die blänlichbereiften $6-8$ Linien langen Kapseln springen nach aussen der Länge nach anf und sind durch die bleibende Basis des Griffels geschnabelt.

sis des Griffels geschnabelt.

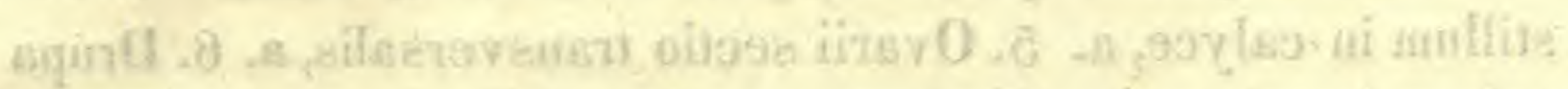

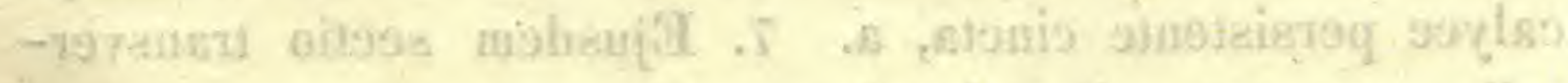

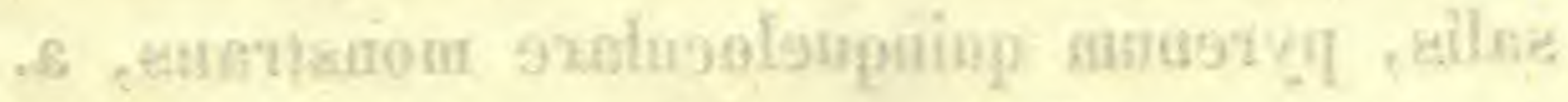

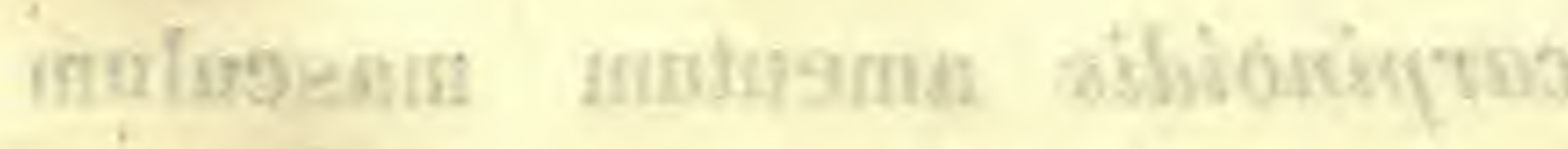

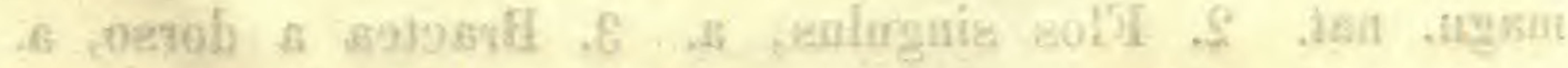

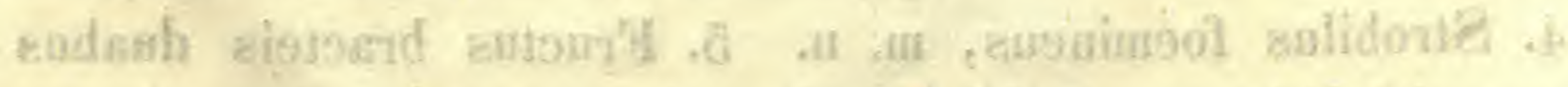

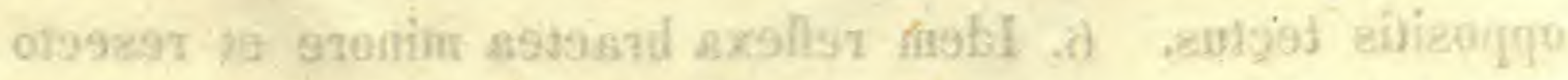

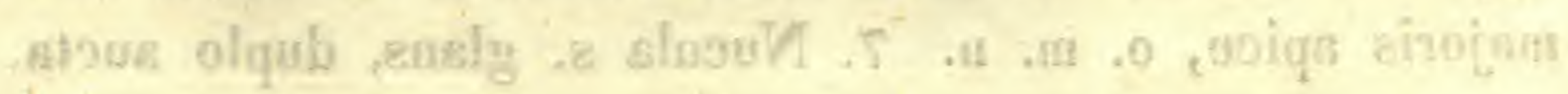




\section{Explicatio Tabularum.}

Tab. III. Fig. 1. Meisteriae cernuae racemus floriferus, magn. nat. 2. Flos singulus. 3. Corolla dissecta et expansa. 4. Calyx. Omnia auct. 5., Genitalia in calyce. 6. Stamen a facie et a dorso. 7. Pistillum, o. a. - 8. Racemus fructiferus magn. nat. 9. Capsula aperta resectis valvulis anterioribus et ademtis seminibus, a. 10. Valvula a facie, a. 11. Columna centralis cum placentis et stylo persistente, a. 12. Semen valde auctum.

Tab. III. 2. Fig. 1. Flos Pentacoelii bontioides magn. nat. 2. Ejusdem corolla longitudinaliter dissecta et expansa m. $n$. 3. Staminis pars superior a facie et a dorso, ancta. 4. Pistillum in calyce, a. 5. Ovarii sectio transversalis, a. 6. Drupa calyce persistente cincta, a. 7. Ejusdem sectio transversalis, pyrenum quinqueloculare monstrans, a.

Tab. III. 3. Fig. 1. Distegocarpi carpinoidis amentum masculum magn. nat. 2. Flos singulus, a. 3. Bractea a dorso, a. 4. Strobilus foemineus, m. n. 5. Fructus bracteis duabus oppositis tectus. 6. Idem reflexa bractea minore et resecto majoris apice, o. m. n. 7. Nucula s. glans, duplo aucta. 

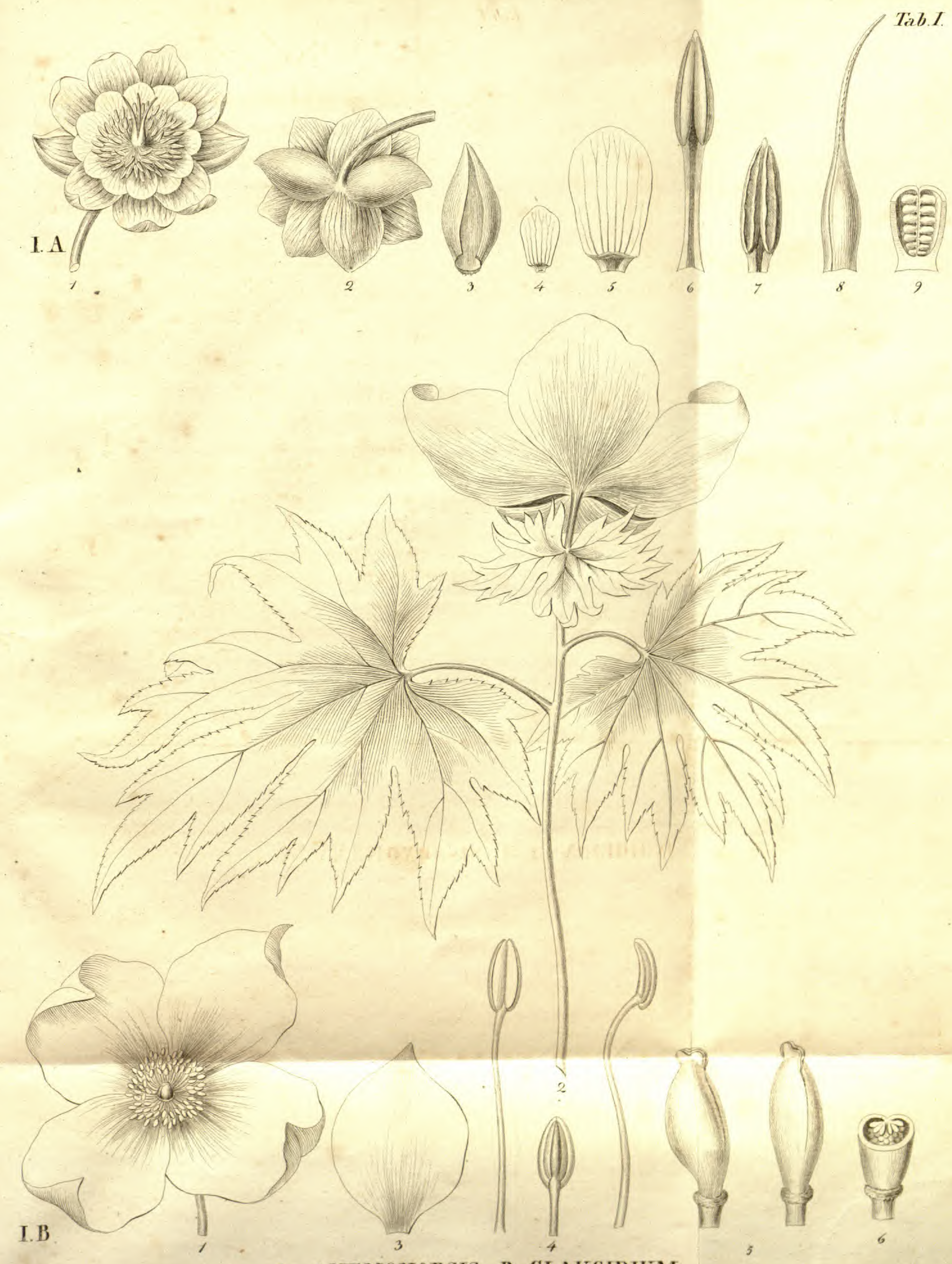


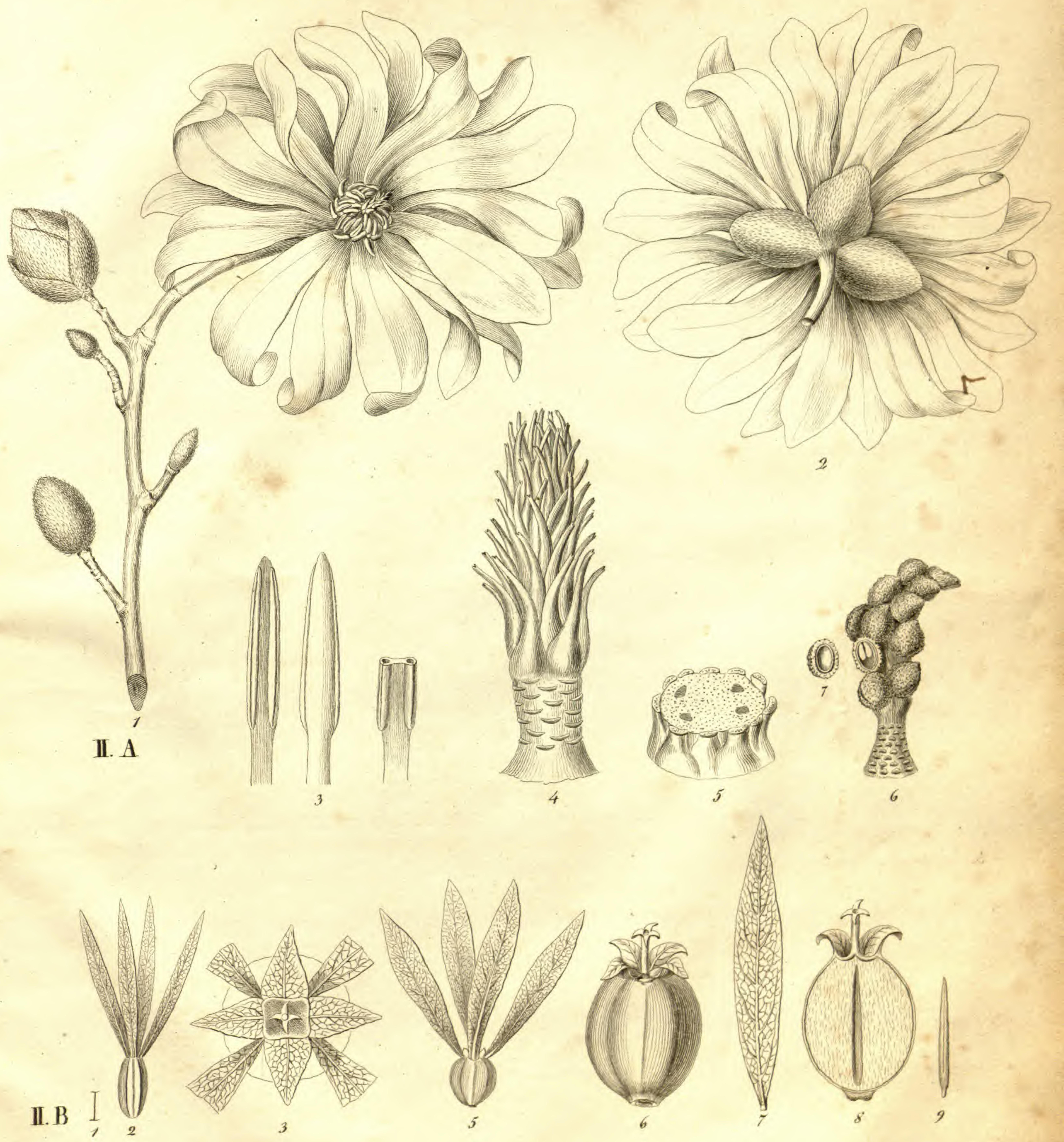

\section{A. BÜRGERLA. B. QUTADRTALA.}

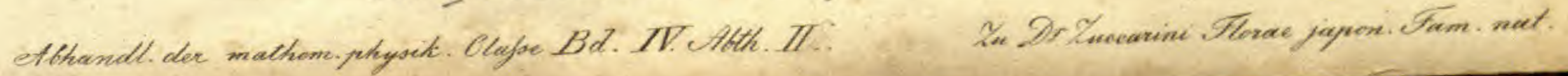




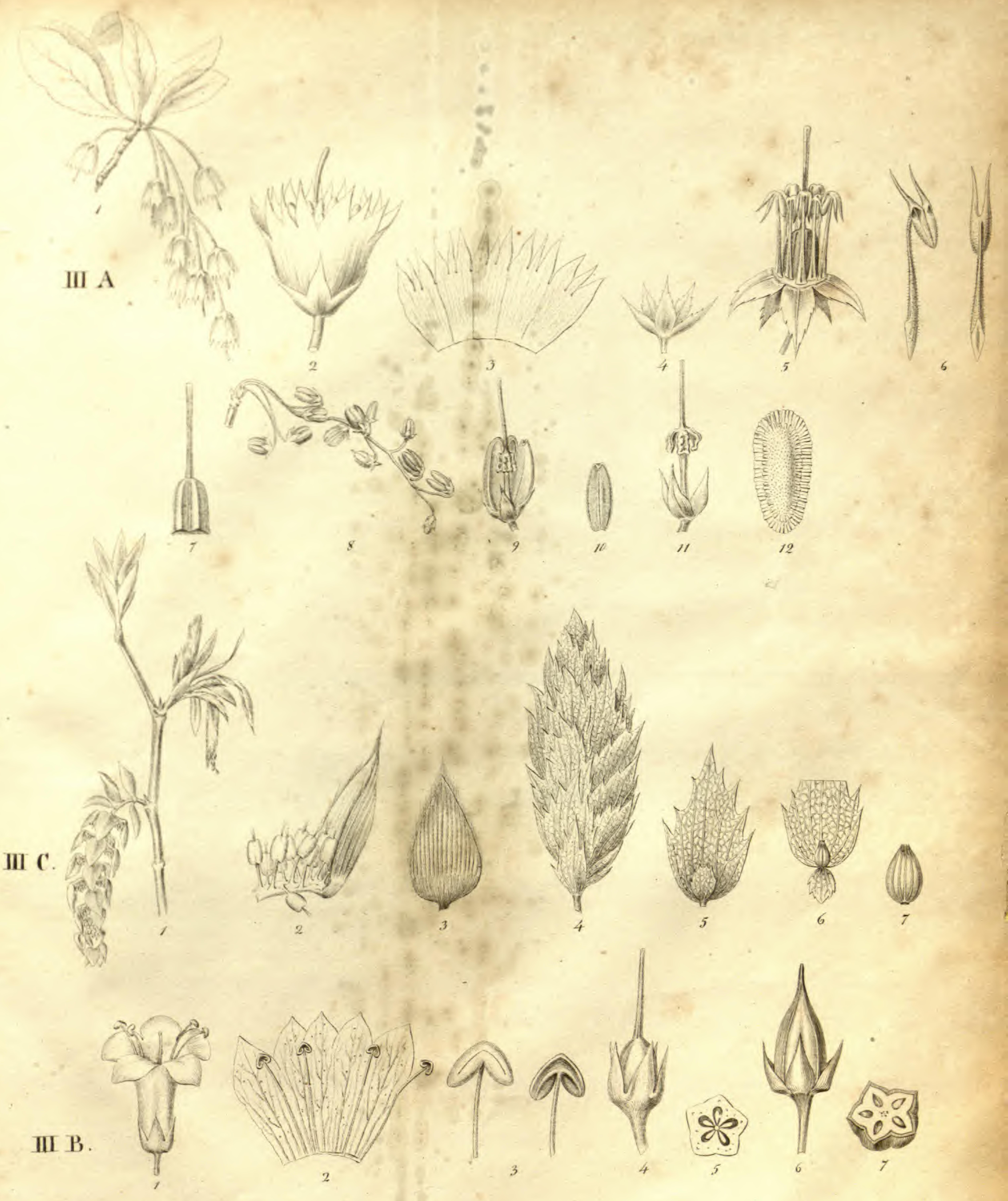

A. MEISTERIA. B PENTACOELIUM. C. DISTEGOCARPUS.

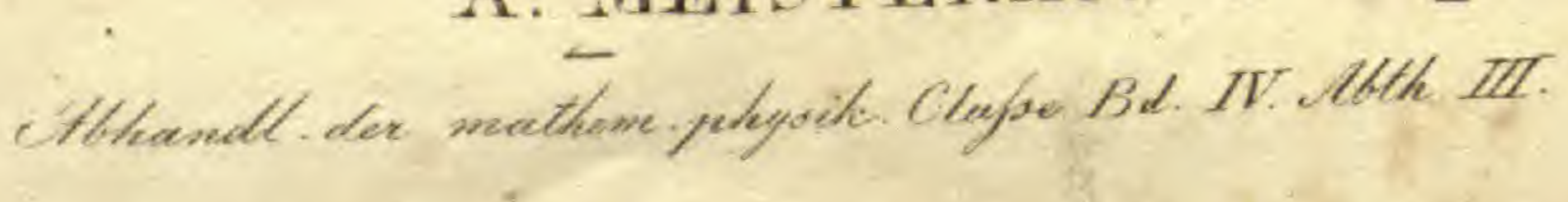

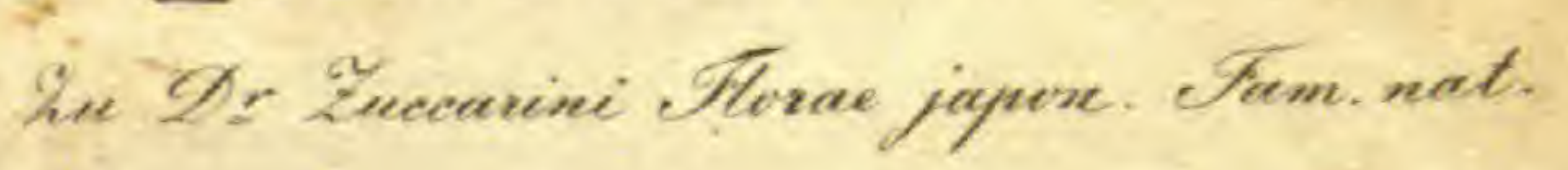

